\section{UCDNN}

LIBRARY
University of Connecticut OpenCommons@UConn

4-14-2016

\title{
The Impact of Social Class in the Hiring Process
}

Nicole CJ Young

University of Connecticut - Storrs, nicole.jones@business.uconn.edu

Follow this and additional works at: https://opencommons.uconn.edu/dissertations

\section{Recommended Citation}

Young, Nicole CJ, "The Impact of Social Class in the Hiring Process" (2016). Doctoral Dissertations. 1045.

https://opencommons.uconn.edu/dissertations/1045 
The Impact of Social Class in the Hiring Process

Nicole Carrie Jones Young, PhD

University of Connecticut, 2016

\begin{abstract}
Social class describes individuals' possession of economic, social, and cultural capital, and their subjective social rankings relative to others (Bourdieu, 1984). As social class can be easily detected, it is quite likely that it plays a significant role in many workplace processes, such as selection. By considering the context of the hiring process, my dissertation explores the impact of social class from the perspective of hiring managers. First, I conducted a construct clarity study to clarify the multidimensional nature of the construct of social class. Second, using the factors found from my construct clarity study, I developed applicant stimulus materials (e.g., referral email, resume, video interviews) representative of three stages of the hiring process (e.g., acquiring, screening, and interviewing). Stimulus materials were presented to 78 participants in the acquiring stage, 105 participants in the screening stage, and 220 participants in the interviewing stage. Results of this dissertation find that hiring managers' perceptions of applicant P-O fit are influenced by applicants' social class. These effects are found during the acquiring stage and decrease in significance and prevalence as the hiring process progresses. Implications to research and practice as well as future directions for continued research on social class in the management literature are presented.
\end{abstract}


The Impact of Social Class in the Hiring Process

\author{
Nicole Carrie Jones Young
}

B.A., Towson University, 2003

M.B.A., Fairleigh Dickinson University, 2007

\author{
A Dissertation \\ Submitted in Partial Fulfillment of the \\ Requirements for the Degree of \\ Doctorate of Philosophy \\ at the \\ University of Connecticut
}

2016 
Copyright by

Nicole Carrie Jones Young

2016 


\section{APPROVAL PAGE \\ Doctor of Philosophy Dissertation}

The Impact of Social Class in the Hiring Process

Presented by

Nicole Carrie Jones Young, B.A., M.B.A.

Major Advisor

Dr. Greg Reilly

Associate Advisor

Dr. John Mathieu

Associate Advisor

Dr. Travis Grosser

External Reader

Dr. Stacy Blake-Beard

University of Connecticut

2016 


\section{Acknowledgements}

Although my name is the only name to appear on the title page, this dissertation was a result of the support received from a variety of individuals.

First and foremost, I have to thank my family. My husband Eugene has been a true supporter throughout this entire experience, and our daughter Madison has served as my inspiration and drive. My parents, Reginald and Beverly Jones, encouraged me to persist. From listening to my ideas to reading my work, they were extremely instrumental in my success. My brother, Bryan Jones, is wise beyond his years. He provided me with numerous key pieces of advice that proved quite useful during my PhD experience. To my other family members and friends who really took the time to understand my process and my research interests, thank you. My dissertation chair, Dr. Greg Reilly, was immensely helpful. He took a chance on me, and for that I am forever grateful. I also appreciate my other dissertation committee members, Dr. John Mathieu, Dr. Travis Grosser, and Dr. Stacy Blake-Beard. My committee made time to provide me with feedback and have discussions, but most importantly, they made time to understand me and made me a better scholar. I would also like to thank the remainder of the faculty, staff, and PhD students at the University of Connecticut who made time to get to know me and always had their doors open despite their busy schedules.

Lastly, I extend a huge thank you to my fellow members of the Management Doctoral Students Association and the $\mathrm{PhD}$ Project. This organization truly made a difference for me, and without this level of support, I may not have completed this dissertation. I appreciate all of the opportunities to engage in meaningful exchanges and to serve in a leadership capacity, which significantly broadened my network and perspectives. 


\section{Table of Contents}

\section{Chapter 1: Introduction}
a. Background \& Overview
i. Social class
ii. Person-Organization Fit

\section{Chapter 2: Construct Development}
a. Social class perspectives
b. Social class defined
c. Categorizations of social class
d. Social class in the workplace
e. Social class differentiated
f. Results of construct clarity

\section{Chapter 3: Hypothesis Development}
a. Social class and perceptions of P-O fit
b. Emergence of the forms of social class during the selection stages
c. Hiring manager and applicant social class similarity
d. Applicant social class consistency

\section{Chapter 4: Methods}
a. Study design
b. Sample
c. Power analysis
d. Survey development
e. Survey testing
f. Survey deployment
g. Measures

\section{Chapter 5: Analysis \& Results}
a. Analysis overview
b. Sample
c. Measures
d. Design
e. Hypothesis testing overview
f. Results

\section{Chapter 6: Discussion, Implications, \& Conclusion}
a. Discussion
b. Research \& practical implications
c. Future directions
d. Limitations
e. Conclusion 


\section{References}

\section{Tables}

a. Table 1 - Various measures of social class

b. Table 2 - Total combination of applicants

c. Table 3 - Amazon Mechanical Turk (MTurk) screening process

d. Table 4 - Organizational culture profile - Values (40 items)

e. Table 5-Demographic overview - All stages

f. Table 6 - Counterbalancing - All stages

g. Table 7 - Percentage of variance for each hiring stage

h. Table 8 - Means, SD, correlations - Acquiring stage

i. Table 9 - Means, SD, correlations - Screening stage

j. Table 10 - Means, SD, correlations - Interviewing stage

k. Tables $11 \mathrm{a}-\mathrm{c}-$ Results of three-level analysis - Acquiring stage

1. Tables $12 \mathrm{a}-\mathrm{c}-$ Results of three-level analysis - Screening stage

m. Tables 13a-c - Results of three-level analysis - Interviewing stage

n. Table 14 - Hypothesis summary - Overview

o. Table 15 - Hypothesis summary - Detailed

p. Table 16 - Manager's summary

\section{Figures}

a. Figure 1 - Model depicting the impact of applicant social class and hiring managers' perception of P-O fit

b. Figure $2-$ Forms of capital in current literature

c. Figure 3 - Forms of capital based on construct clarity study

d. Figure 4 - Power Analysis from Optimal Design - Stage One: Referral Email

e. Figure 5 - Power Analysis from Optimal Design - Stage Two: Applicant Resume

f. Figure 6 - Power Analysis from Optimal Design - Stage Three: Applicant Interview

g. Figure 7 - Interaction graph (Hypothesis five - Acquiring stage)

h. Figure 8 - Interaction graph (Hypothesis six - Acquiring stage)

i. Figure 9 - Interaction graph (Hypothesis five - Screening stage)

j. Figure 10 - Interaction graph (Hypothesis six - Screening stage)

k. Figure 11 - Interaction graph (Hypothesis five - Interviewing stage)

1. Figure 12 - Interaction graph (Hypothesis six - Interviewing stage)

\section{Examples}

m. Example 1 - Sample Referral Email

n. Example 2 - Sample Applicant Resume

o. Example 3 - Sample Applicant Interview Script

p. Example 4 - Overview of directions for each stage

\section{Appendix A: Construct Clarity Study}

a. Table 17 - Economic capital item by sample type

b. Table 18 - Social capital item loadings by sample type

c. Table 19 - Cultural capital item loadings by sample type 


\section{Appendix B: Resume Pilot Study}

d. Example 4 - Working class sample resume

e. Example 5-Middle class sample resume

\section{Appendix C: Development of stimulus material}

a. Table 20 - Most popular boys and girls' names in New York in 2009

b. Table 21 - Most popular boys and girls' names in New York in 2010

c. Table 22 - Most popular boys and girls' names in Maryland in 2011

d. Example 6 - Actor recruitment email

e. Example 7 - Video setting 


\section{CHAPTER 1: INTRODUCTION}

The divide between those with and without resources in the United States is growing. Although income was virtually similar through the 1960's, beginning in the 1970's income differentials began to create separation, resulting in a divide between the top $5 \%$ and the bottom $20 \%$. By 2010 income gains for the top $1 \%$ were $200 \%$, while income gains for the bottom $20 \%$ were only 40\% (Stone, Trisi, Sherman, \& DeBot, 2014). According to the U.S. Census (2014) only $28.8 \%$ of adults aged 25 or older completed a Bachelor's degree or above. While this is a substantial increase since the first collection by the U.S. Census in 1940, college attainment for low-income individuals has remained virtually stable (Rampell, 2013). Occupational changes have also occurred, shifting from manufacturing and agriculture to professional and service industries over the $20^{\text {th }}$ century (Wyatt \& Hecker, 2006). Despite this shift, the majority of the ten largest professions continue to be of low occupational prestige (e.g., waitresses, administrative assistants) (Bureau of Labor Statistics, 2014b). These aforementioned factors often have far reaching effects, such as impacting our perceptions and categorizations of class. Therefore, understanding the differences between the classes and the implications of those differences is of critical importance.

The U.S. tends to separate rich from poor and lump everyone else in the middle. However, as Tirado (2014) explains the lives of those living "hand to mouth", various classes exist between these extremes. She categorizes classes by those who are impoverished, poor, working class, middle class, and rich. Some researchers have attempted to separate the large "middle class" into the "middle" and "working" classes (Zweig, 2004). Despite the different terms, one thing we can agree on is that individuals often categorized in this large "middle" class are not similar. While some individuals such as Tirado (2014), have first hand experience in a 
class above impoverished but below middle, some individuals may have to consciously explore different classes to broaden their perspectives. In an effort to explore the lives of "working" class individuals, author Barbara Ehrenreich (2001) assumed various low wage jobs and found that many of her new working class colleagues had additional differences besides their lower income, educational levels, and occupational prestige. She realized that who was in their social network and how or why they relied those individuals differed. Furthermore, she often experienced difficulty trying to understand the divergent perspectives or values of some of her new colleagues, which differed from those held by her middle class colleagues. Thus, social class differences may not only result in separation, but also a lack of understanding, which may subsequently impact our perceptions.

Social class is defined as the possession of resources related to economic, social, and cultural capital, and their subjective social rankings relative to others (Bourdieu, 1984). Economic capital is "immediately and directly convertible into money" (Bourdieu, 1986, p. 242). Social capital describes actual or potential relationships (Bourdieu, 1986) and the differential amount of resources possessed by these individuals (Lin, Vaughn \& Ensel, 1981). Cultural capital describes tastes, knowledge, and practices that are displayed through an individual's behaviors, beliefs, and values (Bourdieu, 1984; Holt, 1998). Within the workplace, social class can manifest and influence organizations in a variety of ways. As suggested by Scully and BlakeBeard (2006), class can operate as a structure, style, and process. Thus, it can impact various factors such as how reward structures are developed or even the type of clothing individuals decide to wear.

Although social class has been considered to be quite relevant and has been explored within the disciplines of psychology (e.g., Kraus, Piff, Mendoza-Denton, Rheinschmidt, \& 
Keltner, 2012; Stephens, Markus, \& Townsend, 2007), sociology (e.g., Centers, 1953; Zweig, 2004, 2000), and economics (e.g., Ludwig, Duncan, Gennetian, Katz, Kessler, Kling, \& Sanbonmatsu, 2013; Smith, 1998), social class has received scant attention in the management literature (e.g., Audretsch, Bönte, \& Tamvada, 2013; Gray, \& Kish-Gephart, 2013). However, because the professional workplace tends to be more aligned with middle or upper class values and norms (Ridgeway \& Fiske, 2012), consideration of social class within management literature may actually help to explain many of the inequities that persist within organizations (Acker, 2006). From a research perspective, it may also help to clarify many of the assumptions we hold about how individuals interact within the workplace. Consequently, it is critical to understand how social class impacts workplace processes to increase our relevance and inclusivity within an increasingly diverse workforce.

The hiring process is believed to be "the primary way an organization influences its diversity and human capital" (Ployhart, 2006, p. 868). Thus, selecting applicants who contribute and align with an organization is an important process. Person-organizational fit (P-O fit), which is defined as "the congruence between the norms and values of organizations and the values of persons" (Chatman, 1991, p. 476), provides a commonly used theory to explore how hiring managers interpret applicants. Although social class has been shown to be quite relevant to both interactions within the workplace (Gray \& Kish-Gephart, 2013) and hiring decisions (Rivera, 2012), much of the diversity research related to the selection process has focused on the impact of demographic characteristics such as race (e.g., McKay \& Avery, 2006; Thomas \& Wise, 1999), gender (e.g., Goldberg, 2005; Graves \& Powell, 1995), and age (e.g., Goldberg, 2003). While consideration of these aforementioned demographic characteristics has provided a strong foundation, because the majority of management samples continue to rely on middle class 
participants (e.g., college students, managers) (Liu, 2001), failure to consider social class may have limited prior research and theoretical frameworks. Therefore, consideration of social class within the realm of selection deserves further attention.

Considering the above rationale, the contribution of this dissertation is two-fold. First, I intend to clarify the construct of social class. Social class is a multidimensional construct, thus it is imperative that the factors selected within this dissertation adequately represent the construct I seek to observe (MacKenzie, 2003). A variety of factors (e.g., education, level of qualifications) have been used to highlight the different forms of capital that comprise social class. However, many of these factors are representative of multiple forms of capital (e.g., education), which limits our ability to clearly explore the various factors of capital and make assertions about their implications. In short, while our current assessments of social class and its associated forms of capital provide a foundation, some of the relationships may be muddled. Therefore, I conduct and present a construct clarity study that relies on three different sample types to confirm the factors that adequately represent the three forms of capital (e.g., economic, social, cultural) of the social class construct. This study also helps to confirm what factors are considered representative of upper and lower class individuals. To incorporate the social class indicators identified during my construct clarity study, I develop applicant stimulus materials (i.e., referral email, resume, and video interviews) representative of items hiring managers would expect during the hiring process. Next, I examine how applicants' social class impacts hiring managers' perceptions of person-organization fit. Research has shown that individuals are able to accurately perceive individuals' social class (Kraus \& Keltner, 2009). Thus, while hiring managers are expected to make unbiased assessments about applicants, they frequently make judgments using jobirrelevant employment characteristics or stereotypes (Perry, Davis-Blake, \& Kulik, 1994). 
Therefore, I examine the impact of applicant social class as related to hiring managers' perceptions of applicant P-O fit during the hiring process. To explore these relationships I rely on a three-part scenario-based design, formatted to align with three hiring stages (i.e., acquiring, screening, interviewing), which will explore the construct of social class and its impact to applicants during the hiring process.

Before proceeding, it is important to note the context of focus for this dissertation. First, due to the differences in conceptions of social class throughout the world, this dissertation is limited to the U.S. context. Second, while the hiring process is relevant within a variety of workplace contexts, I am focused on the professional workplace and related occupations (e.g., computer and mathematical, legal, education, or community and social science occupations), in accordance with the Bureau of Labor Statistics (2014a). The professional workplace often emphasizes the importance of strategic human capital, which provides organizations with a competitive advantage (Ployhart, Nyberg, Reilly \& Maltarich, 2014). Conversely, employers within the support professions are concerned with generic work behavior, such as tracking attendance (Hunt, 1996). While a decision to focus exclusively on the professional workplace may in and of itself seem classist and align with an upper class bias, it is likely that the professional and support workplace environments and associated processes (i.e., hiring) are limited in comparability. Lastly, for purposes of this study, I assume that applicants meet the minimum qualifications, such that significant differences related to knowledge, skills, or abilities do not exist. 


\section{Overview \& Background}

\section{Social class}

Researchers have explored the impact of social class on a variety of topics such as work attitudes and interactions (e.g., Benjamin, Bernstein, \& Motzafi-Haller, 2011; Gray \& KishGephart, 2013; Judge \& Hurst, 2007), careers and career mobility (e.g., Audretsch et al., 2013; McLeod, O'Donohoe, \& Townley, 2009; Snipp, 1985), work life balance (e.g., Lautsch \& Scully, 2007), job performance (e.g., Johnson, Messe, \& Crano, 1984), and perceptions of risk (e.g., Cooper, 2008). This research often found distinctions between individuals of varying social class. However, rather than simply creating a laundry list of findings, it is important to understand why these distinctions may have occurred. Because social class is comprised of economic, social, and cultural capital, these forms of capital often influence our experiences and beliefs, creating subtle differences between those of varying social classes. Thus, despite our limited consideration of social class as a demographic characteristic within the management literature, we should expect that social class will influence the workplace.

Considering impression management as an example, we can illustrate how social class may impact the workplace and our associated assumptions. Impression management tactics allow individuals to maintain or create an image of themselves that they promote to another individual (Bozeman \& Kacmar, 1997). While use of impression management has been found to positively relate to interview outcomes (Bolino, Kacmar, Turnley, \& Gilstrap, 2008), engaging in these types of actions is often opposed by those of lower class (Williams, 2012). Lower classes may find that these actions display a "two-face" behavior (Lamont, 2000, p. 108). Therefore, while the value and propensity to engage in impression management may be an expected behavior for those of upper class, researchers may have not adequately considered the perspective of lower 
class individuals. As such, differences in workplace preferences, attitudes, and behaviors may be attributed to some of the underlying distinctions applicable to social class. Consequently, it is important to understand some of the most notable differences that have been found within the social class literature.

One of the biggest differences between upper and lower class individuals relates to their perspective on individualistic and communal behavior. Individualism refers to those who are more intently focused on their self-reliance and personal goals, whereas communal behavior refers to those who place greater emphasis on their relationships with others (Piff, Stancato, Martinez, Kraus, \& Keltner, 2012). These beliefs may be partially attributed to the difference in resources possessed by those of varying social class. As upper class individuals generally have more access to resources they are less likely to need to rely or understand the need to provide resources to others (Piff et al., 2012). In a study comparing individuals who earned below $\$ 25,000$ and above $\$ 100,000$, those earning less actually donated $4.2 \%$ of income as compared to only $2.7 \%$ of income donated by those earning more (Independent Sector, 2002). This statistic was examined further in a study on prosocial behavior using various samples of lower and upper class undergraduate participants. Despite using a variety of different scenarios, researchers found that the lower class participants were more likely to help their upper class counterparts, and upper class individuals were not likely to reciprocate these actions (Piff, Kraus, Côté, Cheng, Keltner, 2010). In society these differences often manifest into divergent perspectives regarding governmental programs or tax codes (Zweig, 2000). However, in the workplace these differences may result in uncomfortable interactions (Gray \& Kish-Gephart, 2013) or discrepant viewpoints about what successful behaviors in the workplace entail. 
Another critical difference between those of varying social class relates to choice. Choice is believed to be positive for individuals, resulting in happier and healthier lives (Deci \& Ryan, 1985). However, the assumption about the benefit of choice may be an upper class perspective. Choice — in and of itself — assumes that individuals have available resources (e.g., time, education, money) to seek out the best alternatives and make a decision. Upper class individuals often have access to knowledge and information (Stephens, Fryberg, \& Markus, 2012), which may explain their intense desire to select different options. However, as described by Markus and Conner (2013, p. 96), “because the people taking the bus can't be in the driver's seat, lower-class Americans master skills other than choosing and controlling..." As children, those of upper class are encouraged to be unique and select professions that are reflective of their personalities (Kusserow, 2012). Thus, they often adopt an "independent model of agency" (Stephens et al., 2012, p. 93), where they assume and prefer to make controllable personal decisions reflective of their own preferences (Markus \& Kitayama, 2003). Conversely, lower class children are encouraged to be disciplined and follow a particular structure (Kusserow, 2012). While they may be encouraged to explore and think critically, lower class children will simultaneously be taught to be "resourceful and aware" (Tirado, 2014, p. 129). As these children often grow up with choices already made on their behalf, the ability to choose often has a decreased importance even starting at an early age.

Using a sample of upper and lower class individuals (i.e., MBAs and firefighters), Stephens and colleagues (2007) were able to illustrate that even when choice is simple and without much meaning, upper and lower class participants will differ in their selections. When presented with a number of different colored pens, upper class individuals were more likely to select the pen color that was in lower quantity, signaling a unique choice, whereas lower class 
individuals were more likely to select the pen color that was in the majority. When exploring this finding with something of more value, such a car selection, upper class-particularly White upper class - individuals became frustrated when a friend selected the same car, whereas lower individuals were happy knowing that they had the same car as a friend. As aligned with the aforementioned beliefs about individualistic and communal behaviors, lower class individuals may use choice as a way to build and maintain connections whereas upper class individuals tend to use choice as a way to highlight their individuality and uniqueness.

Perceptions of control also often diverge between those of different social class. As noted, while upper class individuals often have access to more resources, lower class individuals are constantly reminded of their lesser quality educational resources, lower occupational prestige job roles, and increased health risks (Adler et al., 1994). Not surprisingly, lower class individuals tend to perceive a lack of control and associate external contextual conditions as determinant of their opportunities (Kraus, Piff, \& Keltner, 2009). Even in situations where individuals can exert control, such as parents in their child's education, lower class parents often opted not to intervene and adhered to the belief that the teacher was the expert and they had limited control to assist in the outcome (Lareau \& Calarco, 2012). This perspective stands in stark contrast to upper class individuals, who believe they exert control and that opportunities are attributed to individual effort (Kraus et al., 2009). Furthermore, upper class individuals tend to assert that injustice and negative ramifications are due to personal choice rather than circumstance (Kraus et al., 2012), which aligns with beliefs related to the just-world perspective (Lerner, 1980). As Lerner (1980, p. 11) asserted, "people 'get what they deserve." Consideration of these perspectives provides significant insight into the worldviews of upper class individuals and how they starkly differ from those of lower class individuals. 
Another underlying difference relates to perspectives of chaos. Chaos can be characterized by disorganization or unpredictable events that may interfere with daily life (Evans, Gonnella, Marcynyszyn, Gentile, \& Salpekar, 2005). In a study comparing upper class individuals from Manhattan's Upper East Side to lower class individuals from a lower class neighborhood in Queens, the upper class individuals described the world as "safe" and "welcoming", whereas the lower class individuals from Queens described the world as "filled with ups and downs" and "potentially dangerous" (Kusserow, 2012). In a separate study, individuals were asked about their future expectations of chaos by selecting a graph that was generally linear with few varying points versus a graph that highlighted significant variation. Although upper class individuals may encounter chaos, they often have enough resources to successfully navigate their obstacle, allowing them to perceive their lives as stable. Instead lower class individuals were more likely to select the tumultuous graph, perceiving their lives as more chaotic (Piff et al., 2012). In effect, chaotic situations such as unreliable transportation (Gurley \& Bruce, 2005) or childcare (Brooks \& Buckner, 1996; Gennetian, Crosby, Huston \& Lowe, 2004) are often difficult for lower class individuals with limited resources to navigate. Perspectives about chaos have been shown to impact work related factors such as career choice. In a qualitative study that explored creative career choices, many upper or elite class parents were supportive of their child exploring creative careers, whereas those of lower class often encouraged their children to seek more stable careers (McLeod et al., 2009). As lower class parents were likely hoping their children would be able to navigate chaotic situations, selection of a stable career often takes precedence for lower class individuals.

It should be noted that the previous description of resources are not purely economic, as such, differences in perspectives regarding who to trust or how trust is developed also underlie 
upper and lower class differences. Upper class individuals are less likely to personally experience negative situations in their surrounding environment (Ross \& Jang, 2000). This limited exposure to negative life events and outcomes helps to substantiate the belief that the world is generally a positive place, resulting in a generalized feeling of trust (Fiske, Moya Russell, \& Bearns, 2012). In effect, upper class individuals tend to have a more positive outlook on life and are more likely to extend trust to others.

In contrast, lower class individuals generally have a lower overall sense of positivity. First, individuals with access to fewer material resources have been shown to have higher levels of cynicism and mistrust (Gallo \& Matthews, 2003). Furthermore, lower class individuals are more likely to have a higher level of exposure to negative situations (e.g., crime, noise, violence), resulting in a desire to seek comfort from close-knit social capital networks (Ross \& Jang, 2000). Therefore, lower class individuals may have a high level of trust for those closest to them (e.g. family, friends), but a much lower level of trust for those outside of their immediate close social capital networks (Tyler, Rasinski, \& McGraw, 1985). As such, mistrust toward those outside of their immediate networks is quite common for those of lower social class and may be unlikely to dissipate in institutionalized settings (i.e., the workplace), which are primarily comprised of higher social class individuals (Stephens et al., 2007).

Although the aforementioned differences prompted by social class are not representative of an all-inclusive list, these differences highlight why we may expect divergent perspectives in the workplace that have not previously been considered within the current management literature. As shown in Figure 1, it is important to consider how applicant social class and other related factors may impact hiring managers as they assess the P-O fit of applicants. Thus, in addition to applicants' social class I also consider the importance of each form of capital (i.e., 
economic, social, cultural) to perceptions of P-O fit, as well as whether these relationships are altered due to the hiring process stage. Next, diversity research has suggested that demographic similarity or dissimilarity impacts hiring managers' perceptions of applicants. Therefore, I explore how perceptions of applicant P-O fit may shift depending on the hiring managers' own social class. Lastly, although individuals are expected to detect social class accurately (Kraus \& Keltner, 2009), this finding may assume that alignment exists between all three forms of capital. As such, I draw attention to how hiring managers interpret P-O fit for applicants with conflicting forms of capital.

\section{Person-Organizational Fit}

Kristof (1996, p. 4) asserts that P-O fit is "the compatibility between people and organizations that occurs when: (a) at least one entity provides what the other needs, or (b) they share similar fundamental characteristics, or (c) both." As P-O congruence is synonymous with congruence between a person and an organizational culture, the term of "person-culture fit" (O'Reilly, Chatman, \& Caldwell, 1991), is often used interchangeably. Person-organization fit is a part of the larger person-environment (P-E) fit literature. Other types of fit such as personvocation (P-V), person-group (P-G), person-job (P-J), and person-supervisor (P-S) fit have all been investigated and shown to have some overlap with P-O fit. In a meta-analysis that investigated pre- and post-entry factors related to different types of fit, each type was associated with different variables (Kristof-Brown, Zimmerman, \& Johnson, 2005). Organizational commitment is most influenced by P-O fit, job satisfaction by P-J fit, satisfaction with coworkers by P-G fit, and satisfaction with supervisor by P-S fit. Despite these various forms of fit and their associated consequences, P-O and P-J fit are the most commonly investigated (Lauver \& Kristof, 
2001), and have been quite influential during various phases and perspectives of the selection process (e.g., Cable \& Judge, 1996; Goldberg, 2003).

As related to pre-entry factors, P-O and P-J fit had similar correlations to the organization's intent to hire, and P-O fit had a moderate correlation with job offers (KristofBrown et al., 2005). In sum, perceived fit has a positive relationship to hiring recommendations (Higgins \& Judge, 2004), and determinations of fit during the employee hiring process have been shown to be an antecedent to subsequent positive perceptions of P-O fit (Chatman, 1991). As such, this is dissertation is focused solely on the perception of P-O fit. It should be acknowledged that a significant amount of research exists related to the applicant's perception fit and its implications during the hiring process (e.g., Cable \& Judge, 1996; Dineen, Ash, \& Noe 2002; Ruiz-Palomino, Martínez-Cañas, \& Fontrodona, 2013). However, as my focus is on the hiring managers' perceived fit of applicants I do not consider the applicant's perceptions of fit.

Beginning with an early study conducted by Rynes and Gerhart (1990), these researchers confirmed that assessing fit is different than assessing general employability. In effect, firmspecific information (e.g., culture, expectations) will influence hiring manager perceptions of fit over and above general applicant qualifications. This research was furthered as Adkins, Russell, and Werbel (1994) investigated the importance of the actual hiring manager. Using a sample of corporate recruiters, they completed surveys about their personal and organization's work value as well as pre- and post-surveys after conducting candidate interviews. While recruiters' congruence with work values did not influence their initial perceptions of applicant employability, they did influence their perceptions of organizational-fit during later stages of the selection process. In a subsequent study using professional recruiters, researchers were able to identify a latent model related to the subjective impressions of interviews (Wade \& Kinicki, 
1997). These interpretations of applicants' qualifications mediated the relationship between applicant experiences and hiring decisions, highlighting that hiring managers may be accounting for other factors such as applicant fit, in addition to simply assessing objective criteria.

Another area of interest related to hiring manager perceptions of $\mathrm{P}-\mathrm{O}$ fit is focused on the role of applicant characteristics and behaviors. Hiring managers have been shown to rely on a variety of indicators to assess applicant fit, and reliance on subjective applicant factors may be considered just as relevant as objective applicant factors during the selection process (Wade \& Kinicki, 1997). Parsons and Liden (1984) suggested that hiring managers considered applicant non-verbal cues within their overall perception of qualifications. Personality factors have also been shown to provide hiring managers with indicators of applicant P-O fit (Kristof, 2000). Applicant race (King, Mendoza, Madera, Hebl, \& Knight, 2006) and gender (Fernandez \& Mors, 2008) have been shown to relate to hiring managers' decisions of applicant suitability. Even factors such as applicant attractiveness impact recruiter perceptions of applicant fit (Rynes \& Gerhart, 1990). Despite the relevance of demographic characteristics in fit perceptions, many of these effects have been inconsistent. For instance, perceived demographic similarity was shown to impact applicant liking and performance expectations, but not fit perceptions (García, Posthuma, \& Colella, 2008). Sex similarity has also resulted in conflicting findings, as female hiring managers found male applicants to be more similar and in turn, extended more positive ratings to applicants of the opposite sex (Graves \& Powell, 1995). Clearly, significant variation is expected as related to demographic characteristics and perceptions of fit (Bowen, Ledford, \& Nathan, 1991).

Hiring managers have also been shown to compare their values to those of applicants. Although information asymmetry may prevent full access to accurate information between hiring 
managers and applicants (Spence, 1973), hiring managers are able to detect value congruence relatively accurately between applicants and organizations (Cable \& Judge, 1997). Once detected, value congruence between applicants and recruiters was a determinant of fit perceptions and employability (Adkins et al., 1994). Upon further exploration of this aforementioned relationship, Cable and Judge (1997) determined that perceived value congruence between hiring managers and applicants directly related to hiring managers' perceptions of organizational fit. Rivera (2012) lent additional support to these findings with her study on hiring and cultural matching. Specifically, she suggested that hiring managers seek applicants who are culturally similar to themselves and the larger organization. Taken together, we can assert that hiring managers' perception of applicant P-O fit is impacted by applicant characteristics.

Conceptualizations of fit. Various conceptualizations of $\mathrm{P}-\mathrm{O}$ fit have emerged within the literature, with the five most common as supplementary, complementary, demands-abilities, needs-supplies, and supplies-values fit (Cable \& DeRue, 2002; Morley, 2007).

Supplementary and complementary fit. Applicants who possess similar characteristics as compared to current employees may be considered to provide supplementary fit to that organizational environment, which has been shown to result in higher performance and more stable employment (Muchinsky \& Monahan, 1987). Individuals have a desire to participate in organizations with similar individuals in accordance with theories such as similarity attraction (Byrne, 1971), social categorization (Turner, 1985), or the attraction-selection-attrition (ASA) framework (Schneider, 1987). However, the process of determining supplementary fit can be challenging, as it requires both applicants and organizations to have detailed information to ensure similarity is achieved (Muchinsky \& Monahan, 1987). As attrition provides a way for 
employees to exit the organization when compatibility is determined not to exist, ASA may be the theoretical framework most associated as an antecedent to achieving supplementary P-O fit, (Ruiz-Palomino, Martínez-Cañas, \& Fontrodona, 2013).

Complementary fit emphasizes when "weaknesses or needs of the environment are offset by the strength of the individual, and vice-versa" (Muchinsky \& Monahan, 1987, p. 271). In short, complementary fit allows organizations to fill areas of deficiency (Muchinsky \& Monahan, 1987). As such, organizations identify their needs and seek individuals with abilities to match those needs. Research on psychological need fulfillment (Edwards, 1991), which examines how fit influences work attitudes and outcomes (Cable \& Edwards, 2004), provides the basis for complementary fit.

Although complementary and supplementary fits have generally developed separately (Cable \& Edwards, 2004), research has found these types of fit to be highly correlated (KristofBrown, 2000). For instance, team members' perceptions of supplementary and complementary fit were found to closely relate to person-group fit (Seong, Kristof-Brown, Park, Huong, \& Shin, 2012). However, some perspectives suggest that one type of fit is better suited for certain activities than another. Werbel and Johnson (2001) posited that supplementary fit influences group cohesiveness whereas complementary fit may be most relevant for group task orientation or boundary spanning activities. Subsequent research has shown complementary fit can be beneficial in situations where homogeneity can be harmful. For instance, in a study of extraversion, Kristof-Brown, Barrick, and Stevens (2005) found that team members had higher levels of attraction to their teams when the level of extraversion was dissimilar. In sum, consideration of these types of fit in tandem may provide the most clarity. 
Demand-abilities, need-supplies, and supplies-values fit. Demands-abilities (D-A) fit is a “match between environmental demands and a person's abilities" (Edwards, 1996: 296). Thus, it emphasizes individuals' abilities and the demand for those abilities within an organization (Hoffman \& Woehr, 2006). In effect, D-A fit may be a version of complementary fit, only a bit more specific as D-A fit highlights the need for employees to not only fit the larger organization, but also the specific job role.

Needs-supplies fit results when “an organization satisfies individuals' needs, desires, or preferences" (Kristof, 1996, p. 3). Congruence between employees and organizations on the basis of basic needs (e.g., salary, benefits) is often critically important for employees. In fact, Cable and DeRue (2002) suggest that from an employee's perspective, needs-supplies fit may be the most important type of fit. Similar to demand-abilities fit, needs-supplies fit is also a form of complementary fit, as they allow both individuals and organizations to fill areas of deficiency (Muchinsky \& Monahan, 1987).

Although supplies-values (S-V) fit could be perceived as a form of needs-supplies fit, it is clear that employees conceptualize the three types of fit differently (Cable \& DeRue, 2002). S-V fit is focused on whether employees and organizations possess the same values (Cable \& Edwards, 2004). Congruence between individual and organizational values has been shown to result in increased positive behaviors, such as extra-role behavior (Lauver \& Kristof-Brown, 2001). As such, it is most closely related to supplementary fit (Muchinsky \& Monahan, 1987).

Comparisons between S-V and D-A fit are quite common. For instance, in a study about creativity only S-V fit was significantly related to job satisfaction, whereas high D-A fit was related to increased job commitment (Livingstone, Nelson, \& Barr, 1997). As highlighted by Edwards (1996), S-V fit is more closely aligned to job dissatisfaction, such that when a 
mismatch between values and supplies occurs employees are more likely to be dissatisfied, resulting in strain. Conversely, because D-A fit is more closely associated with knowledge, skills, and abilities (KSAs), a mismatch is more likely to result in outcomes related to increased tension and strain. Clearly, each type of fit may be relevant and alter perceptions of applicants throughout the hiring process.

Measures of PO fit. In addition to the different conceptualizations, P-O fit has also been measured quite differently in the literature, resulting in different outcomes. P-O fit has been assessed perceptively, subjectively, and objectively. As described by Verquer, Beehr, and Wagner (2003), perceived P-O fit captures individuals' description of themselves and their organization on similar dimensions allowing for a comparison. Subjective fit captures individuals' viewpoint on how well they think their characteristics align with their organizational characteristics. Lastly, objective fit requires feedback from two sources, such that the individuals describe their own characteristics and another individual describes the organizational characteristics on the same dimensions, allowing for a comparison. The determination of when to use each type of fit may be most dependent on the topic. For instance, subjective fit provides stronger relationships when assessing employee outcomes (Verquer et al., 2003), but perceived and objective measurements may be more useful when assessing employee attitudes (Hoffman \& Woehr, 2005). As this dissertation is focused on the attitudes hiring managers hold as related to applicants of varying social class, I consider the perceived fit hiring managers have toward applicants of varying social class. 


\section{CHAPTER 2: CONSTRUCT DEVELOPMENT}

Social class is a form of a stratification system, which describes how individuals interpret inequalities and arrange themselves and others into a social order. According to Grusky (1994, p. 3 ), the three important factors for the foundation of stratification systems are:

"(1) the institutional processes that define certain types of goods as valuable and desirable, (2) the rules of allocation that distribute these goods across various positions or occupations in the division of labor (e.g., doctor, farmer, or "housewife"), and (3) the mobility mechanisms that link individuals to occupations and thereby generate unequal control over valued resources."

Relying on the above, determinations about how to categorize or rank individuals within

societies can occur. Once stratification systems are established, they remain in tact due to a clear inequality of distribution among individuals, a rigid social standing over time, biological traits that allow for classification, and strong correlations between certain individuals and their levels of resources (Grusky, 1994). These factors have allowed societies to create and maintain various stratification systems to organize individuals since the beginning of time.

Early societies of hunter-gatherers relied on a meritocracy system. As men and women were often selected for positions they were naturally inclined to do (Schmitt, Realo, Voracek, Allik, 2008), positions were determined solely on your ability to achieve the needed goals. Fuedalism separated individuals into nobility, clergy, and commoners, and was readily adopted by those of the Roman Catholic empire. The basis for this distinction was based upon economic power, which created clear distinctions between individuals who owned property (e.g., lords) and those who did not (e.g., serfs). In fact, these beliefs were so strong that serfs had to remain in their physical locations because moving to a city was considered a form of property theft (Wright \& Wright, 1985). 
Systems of slavery were similarly dependent on economic power; however, they also encompassed the idea of natural selection, most popularly introduced by Darwin (1859). The timing of Darwin aligned with other race related theories of the $17^{\text {th }}$ and $18^{\text {th }}$ centuries, which purported the view that "God had ordained that Europe should rule" (Zuberi, 2001).

Consequently, slavery—particularly in the United States—reinforced beliefs about stratification due to biological characteristics present at birth and correlations between certain individuals and levels of resources. Slavery was similar to the caste system used in India, which was justified by the prominent ideology of Hinduism. This system is extremely rigid (Audretsch et al., 2013), even preventing marriage between those of differing castes. As suggested by Grusky (1994), rigidity and belief that you are born into a particular system, in this case a caste, is one of the main reasons why the caste system in India has remained the predominant stratification system over time.

The above examples are not exhaustive, as there were numerous types of stratification systems that have existed in various cultures, such as those imposed by societies in Egypt, Nazi Germany, or Rwanda. In each case, one group of individuals has claimed dominance or power over another group of individuals based on factors related to economic (e.g., possession of land; Marx \& Engels, 1848), social (e.g., powerful networks; Coleman, 1990), and cultural (e.g., consumption, lifestyle; Bourdieu, 1977; 1984) inequalities. Thus, each group is associated with higher or lower levels of these aforementioned factors. For instance, nobility owned property and had labor power over the serfs (Wright, 1980). In an attempt to understand these societal categorizations, researchers have adopted the term social class. Therefore, it is important to understand the various perspectives that have provided a foundation for this construct.

\section{Social class perspectives}


While social classes have been embedded in societies for centuries and scholars have sought to understand them, the most prominent perspectives that have explored social class, developed theories, and driven continued research may have been from Darwin (1859), Marx (1845), Wright (1980), Weber (1930), and Bourdieu (1977; 1984). While different, each perspective contributed significant value to our understanding of the social class concept. Therefore, researchers of varying disciplines continue to rely on these competing perspectives in current research on the topic of social class.

Charles Darwin perspective. Charles Darwin proposed a view of natural selection, but one that differed slightly from prior viewpoints of evolution (Darwin, 1859). Darwin suggested that over time individuals would not simply become "better", but instead, they become more diverse and develop adaptations applicable for their surroundings. Second, Darwin posited that species are different and may evolve into one another. Within the context of human progression, this significantly impacted previous beliefs about race. Specifically, Darwin suggested that individuals have biological differences that allow some races to emerge as superior over others.

Within countries such as the United States, this perspective was particularly influential in justifying the existence of slavery (Zuberi, 2001). Using Darwin as a foundation, Whites could argue that Africans were inferior beings and slavery improved their quality of life, as they would be unable to care for themselves otherwise. Despite these prevailing views and alignment between Darwinistic beliefs and later imposed structures such as Jim Crow (i.e., racial segregation laws), American social scientists eventually abandoned the theories of Darwin (Zuberi, 2001). However, the teachings of Darwin remain a highly influential viewpoint and may have subtle influences on other social class perspectives. 
Karl Marx perspective. In a similar timeframe as Darwin, Karl Marx emerged with a different perspective - the labor perspective. Unlike the theory of Darwin, Marx's perspective was more widely embraced and continues to be relied on significantly within social class research. Initial conceptions of Marx and Engel (1848) suggested the existence of two classes, the bourgeoisie and proletariat. The difference between these two classes was primarily related to capital distinctions (Marx, 1981). The bourgeoisie was representative of the ruling class, or those who possessed the resources and controlled the value, and thus the capital, to be earned by those in the proletariat class. Conversely, the proletariat class was described as the "modern working class" or the "class of laborers", who had limited access to resources and were subject to the rules determined by the bourgeoisie. This capitalist perspective suggested clear distinctions, such that individuals were divided into categories (e.g., capitalists, workers) as opposed to in relation to each other (e.g., upper, lower) (Wright, 1980). These distinctions were based primarily on economic capital or labor distinctions. Thus, Marx posited that it was an exchange of labor for capital that created the value of working men and constantly reproduced the capitalist class (Marx, 1968).

The differences in power and control over wages allowed Marx and Engel (1848) to suggest the rise of unions, which would be formed of proletariat class members against the bourgeoisie or ruling class. Although they acknowledged that any successes by the working class would be short-lived, the authors did acknowledge that the ruling power of the bourgeoisie would also be unsustainable. They suggested that the proletariat class will eventually be unable to maintain even their lower level of capital, relegating them to the status of a "pauper." As this lowest status is believed to be even more difficult to emerge from, the bourgeoisie will eventually find themselves taking care of the former proletariat class. In short, the Marx 
perspective was unsupportive of capitalism, suggesting that labor inequities will ultimately result in negative outcomes. Marx's perspective provided the foundation for "The Communist Manifesto," (1848) which promoted the disadvantages of the capitalist system and the eventual rise of the communist system to address differences in class. While all who rely on Marx's perspective are not communists, his perspective has remained prominent due to its central focus on the role of labor and capital within social class distinctions.

Numerous theoretical perspectives emerged subsequent to Marx's initial underpinnings. Interestingly, many of these theoretical perspectives seemed to align because of their inherent disapproval of Marx's conception of class. For instance, Ralf Dahrendorf (1959) agreed with Marx that industrial production serves as the root of change within the newly formed capitalist societies. As such, his conceptualization of class also focused on authority and capital, however, he disagreed with Marx about the differentiation of ownership and roles. Marx (1845) suggested that the difference between classes relates to the alienation of work, which is premised on the idea that work is not pleasurable, but is done to satisfy needs. This difference results in one man who can execute the labor (i.e., worker) and another who sets the value (i.e., authority figure with power and control). Dahrendorf suggested that this conception did not account for arrangements such as joint-stock ownership companies, where workers are now closer to ownership and owners are not simply concerned with the exploitation of workers.

Dahrendorf also suggested that other factors impacted social standing, resulting in a more complex social stratification. Specifically, he suggested a rise of the "new middle class" or bureaucrats, which resemble the previous bourgeoisie and engage in the interests and attitudes of supreme society members. Additionally, the remaining individuals, white-collar and industrial workers, may share more similarities than they do differences. Due to the difference in time 
when these perspectives were proposed, I will not suggest this was necessarily counter to what was proposed by Marx. Instead, I posit that Dahrendorf built on the initial foundation provided by Marx, likely fueled by prominent changes within the economy.

Erik Olin Wright perspective. Wright (1984) offered a slightly different perspective, which acknowledged a relational aspect between the classes. Therefore, while possession of capital was considered, Wright focused on inequality and the domination of one group over another. For instance, lords were dominant to serfs during feudalism and plantation owners were dominant to Blacks during slavery. It was suggested that many reasons exist for domination of one group over another (e.g., sex, race, nationality, economic), and social class is one of the many ways individuals can be dominated, and no one reason is more important than another.

Wright (1984) challenged the social class categories posited by Marx, by considering the idea of a "contradictory location," which accounted for more nuanced roles such as managers and supervisors, small employers, and semiautonomous employees. In all cases, Wright suggested that these categories of employees had a contradictory placement between two social class statuses due to their simultaneous ability to dominate over others while having others dominate over them. In short, Wright (1980) suggested that these categorizations force individuals to rely on a limited set of criteria (e.g., education, income) to assess someone's class without accounting for other relevant factors. For instance, categories of individuals such as managers are trapped between the working class and the capitalist class, such that they have control over their physical work, but no control over larger decisions related to how capital is allocated (e.g., merger or acquisition of a company) (Wright, 1976). As such, his conception of social class was more relational. 
Despite these differences, his overall viewpoint did consider differences in domination and authority, which aligned with Marx's perspective.

Max Weber perspective. Another prominent perspective was that of Weber (1946), who believed that power was the underpinning of the differentiator of class. His objection to Marx centered on the belief that economic power was just one type of power, and that class must also consider the importance of social order and social honor, which are the basis of authority (e.g., political, head of household, authority at work). Specifically, individuals acquire power based on market exchange, or the value of goods that they bring into the market (Wright, 1980). Therefore, those with a higher authority can command more power.

Weber also introduced the terms "status groups" and "status honor" as opposed to class, as he believed the term "class" to be primarily associated with economics. Instead, his focus was a "style of life" (Weber, 1946, p. 634), such that individuals who share the same status honor will have similar expectations and may associate with those of similar status. Thus, status honor perpetuates stratification by encouraging exclusivity and discouraging intermingling between those of varying status. Therefore, signals of status honor may become obvious through lifestyle preferences or privileges such as access to certain types of food or participation in activities (Weber, 1946).

Although Weber differed from Marx, he agreed that social order is dependent on economic order. However, Weber encouraged the consideration of additional factors besides economics to determine status, which was subsequently developed further by Bourdieu.

Pierre Bourdieu perspective. Building on some of Weber's conceptions, Bourdieu (1984) also emphasized the importance of the social position of individuals and their lifestyles (e.g., consumption patterns) as significantly related to individuals' development of social class. 
Bourdieu posited that individuals have two consumption patterns described as the tastes of luxury and tastes of necessity. Once individuals have necessities, the dominant classes have their spending separated into food, culture, and presentation, and each class spends differently in these areas. For instance, working classes place emphasis on the function rather than the form of their clothing. Thus spending on food is less expansive for teachers than professionals.

Bourdieu also relied heavily on the concept of habitus, which he defined as a "meaningful necessity internalized and converted into a disposition that generates meaningful practices and meaning-giving perceptions" (Bourdieu, 1994, p. 405). Habitus provides an organizing structure for practices and perceptions as well as allows comparisons of social statuses by individuals. This incorporation of lifestyle indicators provides the unique departure of Bourdieu from prior perspectives. Continuing in this realm, Bourdieu (1986) suggested there were three forms of capital: economic, social, and cultural, which inform individuals' class status. In a review of social class by Côté (2011), economic capital has been most frequently conceptualized using the categories of income, education, and occupation. Social capital has often been highlighted using differences in the power or status of individuals within a social capital network (e.g., Lin et al., 1981), how individuals develop trust (e.g., Fiske et al., 2012), and the purpose or expectations of their social capital network (e.g., Piff et al., 2012). As cultural capital itself has three dimensions—embodied, objectified, and institutionalized—research has relied on these dimensions to investigate the impact of values and understanding of customs (e.g., Dacin, Munir, \& Tracey, 2010), possession of goods (e.g., Holt, 1998), and comparisons of levels of achievement (e.g., Jaeger, 2011). Although he asserted that all forms of capital stemmed from economic capital, he considered the importance and relevance of these additional forms of capital within social class distinctions. 
These competing perspectives have resulted in various outgrowths within the realm of social class. Mann (1973) suggested that individuals must understand and realize that they are members of a particular class by engaging in stages described as "class identity, class opposition, class totality, and the conception of an alternative society" (Wallace \& Junisbai, 2004, p. 388). While individuals may experience these revelations separately, Mann (1973) asserted that class consciousness must occur by all individuals of a particular class to ensure a class. Additionally, while various events may unify individuals (e.g. Occupy Wall Street), short-term movements are often not enough to ensure class consciousness will be sustained.

Using this premise, Liu (2001) developed the social class worldview model, which centered on the various factors needed to assess social class and the awareness of individuals to place themselves within a hierarchy. Some perspectives were more focused on outcomes, such as those found in health psychology, which considered the differential outcomes experienced by upper and lower class individuals (e.g., Kawachi, Kennedy, Lochner, \& Prothrow-Stith, 1997; Kessler, 1982; Sallume \& Notestein, 1932). Finally, some literatures sought to combine prior perspectives, such as the social cognitive perspective (Kraus et al., 2012), which integrated the labor and cultural perspectives and proposed that objective resources and the experiences surrounding them will determine subsequent thoughts and behaviors. In sum, the aforementioned perspectives have been critical in establishing a foundation for the continued research on social class.

\section{Social class defined}

Due to the varying perspectives related to social class, it is "one of the most frequently used and inconsistently defined concepts in the social sciences" (Evans \& Mills, 1998, p. 87). 
These varied definitions have also resulted in different measures of social class, as shown in Table 1. Although social class has been found to be one of the most relevant predictors of how individuals behave and interact in the workplace (Côté, 2011) consensus on a definition of social class is challenging. As noted by Scott and Leonhardt (2005, p. 2):

"one difficulty in talking about class is that the word means different things to different people. Class is rank, it is tribe, it is culture and taste. It is attitudes and assumptions, a source of identity, a system of exclusion. To some, it is just money. It is an accident of birth that can influence the outcome of a life. Some Americans barely notice it; others feel its weight in powerful ways."

Some definitions have primarily relied on objective factors. Piff and colleagues (2010, p. 772) relied on various scholars who described social class as "a multifaceted construct that is rooted in both objective features of material wealth and access to resources (income, education; Oakes \& Rossi, 2003) as well as in conceptions of socioeconomic status (SES) rank vis-a'-vis others in society" (subjective SES; Adler, Epel, Castellazzo, \& Ickovics, 2000). However, other researchers have acknowledged the importance and relevance of both objective and subjective factors. Côté (2011) suggested that social class is the possession of objective material resources and the associated subjective perceptions of those resources relative to others. Further adding to this definition, Côté, Piff, and Willer (2013, p. 491) considered the perceptions and comparisons between individuals, as noted in the following:

"Psychologists view social class as a relatively stable individual-level characteristic that is rooted in objective, socially valued resources (e.g., income, education, and occupational prestige) and corresponding subjective perceptions of rank vis-a'-vis others (Kraus et al., 2012; Snibbe \& Markus, 2005; Stephens et al., 2007)."

Despite the variation of definitions, Bourdieu's (1984) consideration of cultural capital may have provided the most robust addition. As cultural capital often drives our values and behaviors and is commonly shared by other members of the same class, it critical to consider. In 
a recent theoretical exploration of social class within the management literature, Gray \& KishGephart (2013) adopted the definition proposed by Bourdieu (1984). As such, I similarly define social class as the possession of resources related to economic, social, and cultural capital, and their subjective social rankings relative to others.

Forms of capital. Economic capital is "immediately and directly convertible into money" (Bourdieu, 1986, p. 242), allowing it to often be used interchangeably with socioeconomic status (SES). In accordance with the American Psychological Association (2014), SES accounts for the social standing comparisons between individuals as related to their income, education, and occupation. Lower class individuals often have lower levels of income, less prestigious occupations, and less prestigious educational experiences as compared to upper class individuals (Zweig, 2004). However, all three factors do not have to align to assess the economic capital and subsequent social class of individuals.

Social capital is an aspect of the social structure (Coleman, 1990), describing actual or potential relationships (Bourdieu, 2008). Within the context of social class, social resources theory provides the foundation. Thus, emphasis is on the value or quality of members within a social capital network (Lin, 2000). It also acknowledges the role of socioeconomic factors in creating the inequality of social capital networks (Lin, 2000). For instance, Scott (2005) described how three individuals of different social classes received different types of medical treatment, subsequent care, and support after suffering a heart attack due to the resources available through their social capital networks. Other prominent perspectives, such as weak tie theory (Granovetter, 1973), may be less applicable within the context of social class. Although a weak tie can provide significant benefit in a workplace context, allowing for the transference of non-redundant information, this belief may be most applicable for upper class individuals. As 
discussed, upper and lower class individuals establish trust and rely on their networks for different purposes. Therefore, despite the value of a weak tie, because it may take longer for a lower class individual to develop a trusting relationship, this value may not be similarly recognized or utilized by individuals of varying social class.

Lastly, cultural capital describes tastes, knowledge, and practices that are displayed by an individual's behaviors, beliefs, and values (Bourdieu, 1984; Holt, 1998), and can take three forms - embodied (i.e., acquired by a person through upbringing and interactions), objectified (i.e., observable in a tangible form), and institutionalized (i.e., established criteria allowing for comparisons between individuals). While different contexts may require or regard certain norms as acceptable, having the "right" form of cultural capital is often deeply embedded in social institutions and has become a status symbol of an elite population (Bourdieu, 1984). Thus, formal and institutionalized contexts may provide the ultimate setting for displays of cultural capital competence (Dacin et al., 2010).

As shown in Figure 2, different factors have been associated with each interrelated form of capital, allowing individuals to develop social class categorizations of others.

\section{Categorizations of social class}

Similar to the various perspectives and definitions of social class, reaching consensus regarding how to categorize social classes has been equally challenging. While social class distinctions may have been clearly delineated by possession of resources or status, previous relevant markers such as clothes, cars, political affiliations, or even race may no longer directly correlate to social class statuses (Scott \& Leonhardt, 2005). Additionally, due to the varying levels of value individuals attach to resources, social class categorizations can be quite complex. 
The complexity of social class categorization may be best highlighted in a study by Lenski (1952). Individuals in a community were asked to categorize neighboring families by social class levels. Despite the familiarity with the families in the sample, individual responses varied substantially both in the number of social class levels and the number of families categorized into those levels. In a subsequent study, Centers (1953) asked participants to categorize occupational titles into four social class categories: upper, middle, working, and lower. While consistency existed for the upper and lower class occupations, categorization of middle and working class occupational titles proved to be quite challenging.

Some more recent researchers have increased the number of classes to five, describing the categories as elite class (i.e., capitalist and institutional elite subgroups), professional or "upper" middle class, middle class, working class, and poor (Bullock, 2004). Conversely, some researchers simplified the classes to three, with upper, middle, and working classes (McLeod, et al., 2009), whereas Resnick and Wolff (2003) returned to four classes, upper, middle, working, and lower. These authors posited that the middle class exerts power and has power exerted over them, whereas the working class has less power and autonomy with limited or no input on their work conditions. However, as Wright suggested, contradictory locations are likely. As explained by Zweig (2004), a working class employee who earns a considerable amount through overtime may earn a similar wage as compared to a middle class employee, but may still have limited autonomy over their work. Not surprisingly class categorizations often result in social class misclassification of oneself and others (DiMaggio, 2012; Hout, 2008). Thus, individuals may be unable to be categorized into a finite grouping. As such, throughout this dissertation I rely on the terms "upper class" and "lower class" to allow for the continuous nature of class statuses. Before proceeding, it is important to confirm my population of focus within this dissertation. 
As suggested by Zweig (2004), individuals with occupations that require advanced education, exceedingly large responsibility, or are considered highly autonomous can be categorized as the capitalist class. Conversely, those with the lowest levels of income, education, and occupational prestige represent the underclass. Therefore, the capitalist class is included in the upper class and the underclass is included as the lower class. The images of these two classes are quite common in the media, ranging from CEOs to welfare recipients respectively; however these two classes represent a substantially smaller portion of the population as compared to the middle and working classes (Bureau of Labor Statistics, 2014b; Zweig, 2004). Due to the small proportion of the population associated with these classes and their likely unique situations when compared to the broader population, I consider these populations to be outliers, and thus, exclude them from my conception of upper and lower classes. Lastly, while I assert that upper social class individuals may experience treatment that is comparatively better or that they possess more resources as compared to those of lower class, it should be noted that the upper class is not better than the lower class. Instead, I intend to highlight they are simply different, which results in varying experiences in contexts such as the workplace.

\section{Social class in the workplace}

The workplace is one of the most consistent settings where individuals of different social classes can interact and experience cross-class encounters (e.g., Gray \& Kish-Gephart, 2013; Holvino, 2002). As Gray and Kish-Gephart (2013) describe, cross-class encounters are interactions between those of varying social class that allow social class to emerge as salient. Social class is likely to emerge as apparent in the workplace because institutionalized structures or processes (e.g., how work is organized or rewarded) often reinforce the differing experiences 
of those of varying social classes (Scully \& Blake-Beard, 2006). Not surprisingly, research has uncovered a variety of differences between those of varying social class.

Research has suggested that interactions between those of varying social classes are often strained. Individuals tend to rely a variety of strategies such as withdrawal or distancing to limit or avoid contact with those of different social classes (Gray \& Kish-Gephart, 2013). As Ehrenreich (2001) discussed when she assumed the role of a housemaid, the maids were encouraged to make themselves invisible and decline interaction in the presence of their upper class clients. In addition to strained interactions, work preferences may also differ. Using a sample of approximately 1,400 mid-level, retail employees, researchers explored the preference for a four-day, 10-hours per day workweek, as compared to the traditional five-day, 8-hours per day workweek (Dunham \& Hawk, 1977). They found that employees who prefer the former arrangement are generally younger, and of lower income, job status, and levels of satisfaction with their work and pay. In a qualitative case study Lautsch and Scully (2007) explored lower class workers at a plant production facility and found that their interpretation of work family balance differed from upper class workers. Lower class workers often relied on overtime as a way to gain additional income and support their families, suggesting that work life conflict is representative of "money for family" dilemma as opposed to the longstanding upper class view of the "money or family" dilemma. Another reason for these differences may be due to underlying differences, such as perceptions of chaos. If reliable transportation is only needed for four instead of five days, and overtime income provides additional resources to pay an outstanding bill, lower class individuals may be able to better navigate chaotic situations that are outside of the purview of upper class individuals. Because social class often results in varying perspectives, beliefs, and experiences, cross-class encounters in the workplace are often quite 
frustrating for both parties (Gray \& Kish-Gephart, 2013) and are further highlighted in the hypothesis development section.

\section{Social class differentiated}

Considering that social class is interrelated with a variety of factors it is important to distinguish between those that may have resulted in construct confusion (e.g., socioeconomic status and social status) as well as those that may have resulted in significant relationships with the construct of social class (e.g., race and sex). Therefore, I present explanations of these constructs and their connections to social class below.

Social class and socioeconomic status. In accordance with the definition from the American Psychological Association (2014), socioeconomic status (SES) is representative of "the social standing or class of an individual or group. It is often measured as a combination of education, income and occupation." Therefore, within the context of social class, SES is only representative of economic capital. Using these constructs interchangeably significantly limits our understanding of social class, as this variable does not consider other important factors such as how an individual obtained this status or why a particular status is important. Additionally, reliance on SES to determine social class may assume that alignment occurs between all forms of capital. Considering this, SES should be used as a portion of social class, but not as representative of the entire construct.

Social class and status. Status is defined as "the extent to which an individual or group is respected or admired by others" (Magee \& Galinsky, 2008, p. 359). While alignment may exist between social class and status, it is not inherently the case. As Côté (2011) suggested, an employee may be admired and respected by others, which gives him or her a higher status. However, the reasons for this admiration or respect may have nothing to do with this individual's 
level of capital. Another use of the term status relates to social status, which refers to a statistical index that is used to assess the social standing of individuals within a given society. Hollingshead developed a four-factor social status index in the 1970's, which quickly became one of the most highly cited social science articles (Adams \& Weakliem, 2011). Similar to the construct of social class, this social status index assumes a multidimensional construct, and thus, may be easily confused with social class. However, social status is based on the actual measurement of four factors related to education, occupation, sex, and marital status (Hollingshead, 1975). Accordingly, while these concepts are similar they are not the same.

Social class and race. Race is a complex term that "has been defined statistically, genetically, and demographically" (Zuberi, 2001). As Coates (2015) suggests, the idea of race as less about biology is a classic and old belief and instead race is more about creating a hierarchy or organization within a culture. Thus, similar to social class the definitions of race are also quite varied. I adopt a viewpoint similar to Zuberi, such that I view race as a biological component surrounded by deeply rooted beliefs. Therefore, to grasp the concept of race, it must be viewed from a historical and social perspective. However, because history and social influences differ dramatically by culture, examining race from a worldview perspective will introduce a variety of considerations beyond the scope of this dissertation. Consequently, my focus on race will be contained to the categories I am exploring within this dissertation, which are Blacks and Whites in the United States.

During times of slavery, Blacks were treated as property to Whites, and thus, represented the lowest class in society. In fact, "justifying racial stratification was essential for the system of enslavement to exist in the Americas" (Zuberi, 2001, p. 18). During the time period of the Civil War through World War II, many Blacks were unable to increase their social position due to the 
continued enslavement of thousands of Black men in mining companies in southern states (Blackmon, 2009). Also coinciding with this timeframe through the 1960's was the introduction of Jim Crow and segregation, which perpetuated inequities and allowed Blacks to remain with the lowest economic resources (Oliver \& Shapiro, 2006).

As posited by Grusky (1994), rigid structures and strong correlations between individuals and their level of resources often allow stratification systems to be maintained. Although slavery, Jim Crow, and segregation have been eliminated, these historical events have allowed negative stereotypes of Blacks and lower economic income to persist among many Blacks (Shapiro, 2004). The result is that Blacks continue to be perceived as a low social class group (Brannon \& Markus, 2013) and Whites are often regarded as one of the highest social class groups. Considering race from this historical perspective makes it easy to see why individuals associate race with social class.

Despite the influence of race on social class there are important distinctions to acknowledge about these two concepts. The first is that race does not determine social class. Instead, as asserted by the definition, the three aforementioned forms of capital determine social class. Therefore, individuals of any race can be of any social class. Second, and particularly relevant from an employment perspective, is that race is considered a protected category whereas social class is not. As described by the U.S. Equal Employment Opportunity Commission (EEOC) (2014), various categories such as age, disabilities, national origin, race, religion, and sex are considered protected from discrimination in the workplace. While workplace discrimination of any kind is discouraged, employees or applicants who experience discrimination due to race can seek a remedy, but this same protection does not exist for social class. Therefore, while race and social class share some similarities, they are distinct constructs. 
Social class and sex. Sex refers to the biological differences that separate men from women (Powell, 2011). ${ }^{1}$ While it is likely that social class will not be confused with the construct of sex, sex also has significant overlap with social class. From an economic capital perspective, differences continue to exist between the earnings of men and women. According to the Bureau of Labor Statistics (2014a), women earn $82.2 \%$ of the median weekly earnings of men.

Differences in the formation of social capital networks between men and women also exist. In part due to differences in socialization between men and women, it is believed that women often possess less access and opportunities to social capital networks for employment and career mobility (Timberlake, 2005). Lastly, the formation or transference of cultural capital has also been shown to have gendered effects, as Bourdieu emphasized the central role of family—and specifically mothers - in the transference of cultural capital between individuals (Reay, 2004).

While these aforementioned examples highlight the relatedness of social class and sex, these relationships may be quite complicated. For instance, despite the lower wages that women typically earn, women are more likely than men to graduate from college (Bidwell, 2014). Additionally, different forms of capital may also be obtained through unions such as marriage. One of the most prominent reasons women marry is for security, frequently referring to security in financial terms (Einarsdóttir, 2013). Taken together, sex may have a similar relationship to social class as does race, such that both are important factors to consider, but not enough to make a social class determination.

\section{Results of construct clarity}

\footnotetext{
${ }^{1}$ I intentionally consider sex as opposed to gender because I focus on the biological rather than socially constructed or role based differences between men and women. Gender refers to the "psychological implications of being male or female, such as beliefs and expectations about what kinds of attitudes, behaviors, skills, values, and interests are more appropriate for or typical of one sex than another" (Powell, 2011, p. 4). While understanding the connection between social class and gender is important, as gender identity may vary within sex connections between social class and gender may be less consistent.
} 
Social class is a multidimensional construct, which is described as a construct that "consists of a number of interrelated attributes or dimensions and exists in multidimensional domains" (Law, Wong, \& Mobley, 1998, p. 741). Further complication exists because social class is a relational form construct, such that the higher-order construct exists and is observable at the same level as its dimensions (Law et al., 1998). This is relevant because each form of capital is observable, individuals may rely on one form to drive perceptions of social class. Considering this it should not be surprising that the construct of social class is consistently misinterpreted (Evans \& Mills, 1998). Therefore, prior to engaging in my study it was necessary to clarify the construct of social class and to identify the representative factors of the three forms of capital that underlie social class (i.e., economic, social, and cultural capital), as asserted by Bourdieu (1986).

To ensure that my conception of social class was consistent with what individuals interpret as their perception of social class I conducted three studies on construct validity with three different sample types: academic, professional, and Amazon Mechanical Turk (MTurk). The academic sample was comprised of graduate students and professors. The professional sample was comprised of human resource professionals and hiring managers. Finally, the Amazon MTurk sample was comprised of professionals ranging in a variety of industries. It should be noted that the Amazon MTurk participants received minimal compensation for their completion of this survey (e.g., one dollar), whereas the other participant samples did not. As previously noted, a variety of perspectives exist related to social class, therefore, I do not consider my variables to be exhaustive. Instead, I suggest that my selection of factors have been considered relevant within the scope of most perspectives and social class research. While the 
detailed results of this construct clarity study are presented in Appendix A, I have presented an overview of the main findings below.

Economic capital. The economic capital dimension has generally been considered the most straightforward, highlighting objective information such as income, occupation, education, and that of parents, to explain an individual's economic capital. While income and parent's income were related to economic capital, occupation and parent's occupation were related to both economic and social capital. Interestingly, education was representative of all three forms of capital (i.e., economic, social, cultural). In sum, survey participants seemed to acknowledge the interrelatedness of these items and accounted for the underlying factors related to how or why individuals may be able to obtain a certain level of resources. For instance, social class scholars have viewed education as a pathway to achieving a particular occupation or income. However, it seemed the samples also considered education as a way to influence an individual's social connections (e.g., alumni association) or their exposure to various beliefs and experiences. Therefore, economic capital items may not be as straightforward as once assumed.

Social capital. Within the social class literature social capital has primarily focused on the power and prestige of one's network, the development of a trust in the formation of a social capital network, and the purpose or reason why individuals rely on their social capital network. Although the power and prestige element squarely fit within the social capital form of social class, the development of trust and the purpose of the network (e.g., why you depend on those around you) were shown to overlap with cultural capital. Similar to economic capital, participants seemed to attach a deeper meaning to these concepts. Specifically, sample participants seemed to infer that cultural capital differences such as beliefs or experiences may impact how or why someone relies on or develops a social capital network. 
Cultural capital. Lastly, the items associated with cultural capital also resulted in deviation. While the embodied form, represented by beliefs and behaviors was found to be strongly related to cultural capital, the other two forms of cultural capital, objectified and institutionalized, were shown to be representative of multiple forms of capital. Objectified cultural capital, which was represented by possession of sophisticated goods, was split between cultural and economic capital. Institutionalized cultural capital, which was represented by a high level of qualifications, was related to both economic and social capital. As with the prior items, participants may have again considered how individuals would acquire sophisticated goods or who would validate the higher levels of qualifications.

As shown in Figure 3, the results from my construct clarity study highlight that the factors associated with each form of capital slightly differ from the current factors used to highlight each form of capital in the social class literature.

It should be noted that I do not suggest that prior literature was incorrect or haphazard in relying on these factors. In fact, the results of my construct clarity study help to support the interrelatedness of these forms of capital as suggested by prior literature (Bourdieu, 1984; Côté, 2011; Gray \& Kish-Gephart, 2013). However, for purposes of this dissertation I will rely on the results obtained from my construct clarity study to explore the impact of social class within the hiring process and its associated relationships.

\section{CHAPTER 3: HYPOTHESIS DEVELOPMENT}

\section{Social class and perceptions of P-O fit}


Surface-level demographic characteristics (e.g. race, age, sex) are readily detectable and visibly determined by overt physical features (Harrison, Price, \& Bell, 1998; Milliken \& Martins, 1996). Visibility of these characteristics allows individuals to easily categorize others. However, categorizations of surface-level characteristics are often "likely to evoke responses that are due directly to biases, prejudices, or stereotypes" (Milliken \& Martins, 1996, p.404). Various theoretical perspectives such as social categorization theory (Tajfel, 1972; Turner, 1985, 1987) and similarity attraction paradigm (Byrne, 1971) emphasize the innate preference and subsequent behavior individuals have toward similar others. This innate preference and associated behaviors have proven quite relevant during the hiring process.

Research has shown that hiring managers have been influenced by applicants' surfacelevel characteristics (e.g., García et al., 2008; Graves \& Powell, 1995). In a meta-analysis of Black and Hispanic applicants and interview ratings, both minority groups were shown to receive lower average interview ratings as compared to White applicants (Huffcutt \& Roth, 1998). Panel interviews comprised of a majority of black raters (e.g., two Black and one White) were shown to rate black interviewees more favorably, however, these results were not found when the racial proportion on the panel was reversed (McFarland, Ryan, Sacco, \& Kriska, 2004). When comparing identical male and female applicants for a lab manager position, both male and female science faculty members were more likely to prefer male applicants, perceiving them as more competent and offering them a higher starting salary with more mentoring opportunities (Moss-Racusin, Dovidio, Brescoll, Graham, \& Handelsman, 2012). Clearly surface-level characteristics are relevant within the selection process. However, deep-level characteristics are also believed to be influential—even emerging as more influential over time (Harrison et al., 1998). 
Deep-level demographic characteristics are underlying attitudes, values, and beliefs (Harrison et al., 1998; Milliken \& Martins, 1996). Personality and educational background are examples of such characteristics. Although initially less detectable than surface-level characteristics, deep-level characteristics often emerge as more influential during workplace interactions (Harrison et al., 1998). Specifically, as team members interact and collaborate, deeplevel characteristics become more salient and relevant to team outcomes such as task performance (Harrison, Price, Gavin, \& Florey, 2002). Furthermore, deep-level dissimilarity in personality or values often results in negative processes and outcomes. For instance, in a study by Tepper, Moss, and Duffy (2011), perceived deep-level dissimilarity was found to correlate positively with relationship conflict and abusive supervision, and negatively with subordinate performance evaluations. Additionally, perceived deep-level dissimilarity has been found to have a subsequent negative effect on overall job attitudes, resulting in lower attitudes toward helping behaviors and increased job withdrawal (Liao, Chung, \& Joshi, 2008). Taken together, knowledge of deep-level characteristics may provide further insight into hiring manager responses during the hiring process.

Deep-level characteristics, such as personality factors, significantly relate to organizational culture preferences and applicant organizational attraction (Judge \& Cable, 1997). In fact, in a study of recruiting decisions, personality was determined to be the second most important factor in hiring decisions (Kwok, Adams, \& Price, 2011). Rivera (2012) suggested that hiring managers prefer to engage in an exercise of "cultural matching" whereby they seek applicants who share similarity related to leisure activities, experiences, and self-presentation styles. As such, use of assessments, such as personality testing, are often suggested as a way for organizations to more effectively select candidates (Highhouse, 2008). Taken together, hiring 
managers are likely to rely on a combination of surface- and deep-level characteristics to evaluate applicants and their potential fit with organizations.

As previously discussed, the theory of person-organization (P-O) fit focuses on the congruence between organizations and individuals (Chatman, 1991). This theory helps to explain how hiring managers quickly evaluate applicants for supplementary characteristics within an organization (Kristof, 1996; Muchinsky \& Monahan, 1987). Determinations of applicant fit have been shown to be increasingly important in a variety of professional contexts such as law, investment banks, and consulting (Holt, 1998), likely due to their positive relationship to employee work performance (Hoffman \& Woehr, 2006). Hiring managers' perceptions of applicant P-O fit have been found to be positively related to hiring recommendations (Higgins \& Judge, 2004) and employers' intention to hire (e.g., Kristof-Brown et al., 2005), which positively relate to providing actual job offers (Vivian Chen, Lee, \& Yeh, 2008).

Despite the usefulness of $\mathrm{P}-\mathrm{O}$ fit, hiring manager perceptions of applicant $\mathrm{P}-\mathrm{O}$ fit often include non-job related factors. In fact, once job applicants meet minimal job requirements, nonjob related factors have been found to be increasingly relevant (Ricklefs, 1979). Visible demographic characteristics (Huffcutt \& Roth, 1998), personal values, personality, and even hobbies have all been shown to influence hiring manager perceptions of applicant P-O fit (Rynes \& Gerhart, 1990). Hiring managers have also relied on perceptions of value similarity between themselves and applicants to assess applicant P-O fit (Kristof, 2000). Clearly, hiring managers use a variety of characteristics to assess applicant P-O fit. Although some research has considered the simultaneous interactive effects of surface- and deep-level characteristics (e.g., Phillips \& Loyd, 2006), much research has considered the impact of these characteristics separately. As such, additional research is needed to further understand the impact of 
characteristics that invoke both surface- and deep-level factors. I intend to explore this intersection by focusing on social class, which is a multi-dimensional characteristic with visible and invisible cues that drive our values and behaviors (Bourdieu, 1984). Therefore, inclusion of social class may explain how the intersection of applicant surface- and deep-level characteristics contributes to hiring manager perceptions of applicant $\mathrm{P}-\mathrm{O}$ fit, as well as to the overall selection and diversity literatures.

Social class is comprised of economic, social, and cultural capital, and is believed to be a relatively stable characteristic (Côté et al., 2013). First, social class allows for a quick assessment and categorization, similar to other surface-level characteristics. Secondly, individuals of the same social class are more likely to hold similar deep-level values and beliefs (Bourdieu, 1984) as compared to other surface-level distinctions. Additionally, these deep-level values are often quickly detectable and reinforced through social interactions (Markus \& Fiske, 2012). Due to the multi-stage hiring process, which involves various social interactions (e.g., Barber, 1998; Cappelli, 2001), different factors may emerge as relevant throughout the hiring process (LopezKidwell, Grosser, Dineen, \& Borgatti, 2013). Therefore, perceptions of surface- and deep-level characteristics obtained during the hiring process may result in perceptions of applicant social class.

Although social class is believed to be invisible (Acker, 2006), I posit that social class is visible and allows for categorizations similar to other surface-level characteristics. Social class is visibly indicated by individuals' mannerisms, clothing, speech, and accents (Scully \& BlakeBeard, 2006), making it apparent and able to be determined quickly (Kraus, Côté, \& Keltner, 2010). As described by Bullock (2004, p. 32) "I could not help but to contrast the classic, dark, wool suit, and silk blouse of this well-dressed managerial woman with the pants and casual 
sweaters of the agents working in the other building." In a study comparing mannerisms between upper and lower class individuals, those of upper class were more likely to display disengaged non-verbal behavior (e.g., checking a cell phone) as compared to those of lower class (Kraus \& Keltner, 2009), which aligns with social class preferences of communal interactions for lower class individuals and individualistic interactions for those of upper class. Differences in speech as related to vocabulary, style (Bourdieu, 1991; Miller \& Sperry, 2012), and complexity (Bernstein, 1962) are also easily detectable, allowing hiring managers to assess applicant social class by visual and auditory means. Therefore, various social class cues can allow social class to be assessed as a surface- and deep-level demographic characteristic. Thus, it can be categorized and used by hiring managers to determine P-O fit during the selection process.

The current professional workplace tends to promote and encourage behaviors such as empowerment, autonomy, and impression management. In a review by Maynard, Gilson, and Mathieu (2012), empowerment, which describes the authority employees have over their work, has been shown to enhance a variety of employee outcomes such as values, performance, wellbeing, and attitudes, and thus, has been implemented by approximately $70 \%$ of organizations. Autonomy, a related concept, has been defined as the ability employees have to make decisions related to the completion of their work (Hackman \& Oldham, 1975). Job autonomy has been shown to relate to positive outcomes such as increased employee engagement (Nahrgang, Morgeson, \& Hormann, 2011) and role breadth, which is related to job performance (Morgeson, Delaney-Klinger, \& Hemingway, 2005). Impression management describes efforts undertaken to maintain a particular image by others (Bozeman \& Kacmar, 1997). These behaviors have been shown to result in positive workplace outcomes such as favorable interview ratings (Levashina \& Campion, 2007) and an increased likelihood of 
managers' ability to obtain board appointments (Westphal \& Stern, 2007). However, these aforementioned these behaviors also align with the belief that individuals control their outcomes, which aligns most with the values and norms of upper class individuals (Ridgeway \& Fisk, 2012).

As discussed, upper class individuals are taught to think creatively, seek autonomy (Kusserow, 2012), value the ability to choose (Stephens, Fryberg, \& Markus, 2011), and believe individuals have personal control over their own situations (Kraus et al., 2009). They often believe that people are empowered and negative ramifications are due to personal choice rather than circumstance (Kraus et al., 2012). Upper class individuals are aware that impression management tactics such as conflict avoidance and savvy promotion increases success in the professional workplace (Williams, 2010). They are also more individualistic (Piff et al., 2012), making them more concerned with their own as opposed to others' success. Accordingly, they are more adept at using these aforementioned behaviors in the workplace.

Conversely, lower class individuals are taught to have structure and discipline (Kusserow, 2012). They are generally more communal (Kraus et al., 2012), making them more likely to show compassion and concern for their colleagues as opposed to just themselves (Piff et al., 2010). In contrast to upper class, those of lower class perceive a lack of control and associate external contextual factors as influential to their opportunities (Kraus et al., 2009). These stark value differences often result in discomfort, particularly when lower class individuals interact with upper class organizational representatives (Stephens et al., 2007). As the values of lower class individuals are less aligned to those of a professional workplace, these deep-level characteristics may negatively impact hiring manager perceptions of P-O fit of lower class applicants. 
The visibility of social class combined with the deep-level value differences between upper class and lower class applicants, allows hiring managers to not only make an assessment of social class status, but also of P-O fit. Therefore, applicants perceived to be of upper class may be believed to align more with a professional workplace, as compared to lower class applicants, resulting in higher perceptions of person-organization fit.

Hypothesis 1: Controlling for other demographic differences, upper class job applicants are more likely to be perceived by hiring managers to have higher P-O fit than lower class applicants.

\section{Emergence of the forms of social class during the selection stages}

As described by Rynes (1989), research on the selection process can focus on pre-hire (e.g., attraction, selection, job acceptance) and post-hire (e.g., employee performance, turnover, job satisfaction) events. Hence, prior research has conceptualized the selection stages in a variety of ways. In a study using a sample of undergraduates, the selection process was separated into five stages consisting of the campus interview, post-campus stage, site visit stage, job offer stage, and job offer decision (Taylor \& Bergman, 1987). Barber (1998) also suggested three discrete stages including acquiring job candidates, maintaining job applicants, and influencing the job selection decision. Within the online hiring process, Cappelli (2001) described the selection stages as attracting, sorting, and contacting contacts. While disagreement exists regarding the exact names or number of stages, research has shown that hiring managers will engage in a sequential process to evaluate applicants. As this dissertation is focused on pre-hire activities from the hiring manager perspective, I rely on these aforementioned models to focus on three temporal stages involving the acquiring, screening, and interviewing of job applicants.

The acquiring stage relies on organizational recruitment practices (e.g., Breaugh \& 
Starke, 2000; Taylor \& Bergman, 1987) with the goal of generating a large pool of applicants at minimal expense (Gatewood \& Feild, 1994). Screening describes actions related to narrowing the pool of applicants (Cappelli, 2001; Schneider, 1987), which is often accomplished through a more detailed review of applicant qualifications. Lastly, the interviewing stage provides hiring managers with a direct opportunity—either in person or virtually— to learn more about applicants and determine if congruence exists between the applicant and the organization (Barber, 1998; Dineen et al., 2002; Taylor \& Bergman, 1987). In each stage hiring managers will interpret applicant cues, which will provide a signal of employability (Spence, 1973). However, hiring managers may also rely on these cues to form impressions of applicants' social class (Himmelfarb \& Senn, 1969). As individuals often attach stereotypes to each social class (Berger, Cohen, \& Zelditch, 1966), once impressions are formed, hiring managers may rely on these impressions to determine P-O fit, ultimately preferring upper class applicants as suggested in hypothesis one. Because each stage may allow different factors to emerge as relevant to assessments of social class, it is important to understand what factors are relevant when (LopezKidwell et al., 2013). Prior research has found applicant demographic factors influence hiring managers' perceptions of applicants. Thus, it is important to understand what forms of capital within social class may be driving hiring managers' perceptions of applicant P-O fit.

Despite the differences between each hiring stage, demographic characteristics have been shown to impact each stage. Employee referrals are one of the most common ways applicants learn of job vacancies (Marsden, 1994). However, race and gender often impact the use or effectiveness of employee referrals (Taber \& Hendricks, 2003). During the screening stage, applicants with ethnic names, such that they are discernable on their resumes, are less likely to be selected to continue in the hiring process (King et al., 2006). When interviewing, perceived 
demographic similarity between hiring managers and applicants was shown to increase perceptions of applicant liking (García et al., 2008) and hiring manager ratings (McCarthy, Van Iddekinge, \& Campion, 2010). Taken together, applicant demographic characteristics and the demographic similarity between applicants and hiring managers are extremely relevant throughout all stages of the hiring process.

Considering the above, I expect social class to exert similar influences within the selection process stages. However, I assert that its effects may be more complex than previously researched demographic characteristics. As discussed, social class can assume a variety of forms such as economic, social, and cultural capital (Bourdieu, 1986). Because each form of capital embodies different characteristics and each stage of the hiring process requires hiring managers to engage in different tasks (e.g., job posting, phone screens) (Society for Human Resource Management, 2014a), each stage may allow different forms of applicant social class to emerge as more or less salient. While all forms of capital may combine to result in an overall perception of social class (Bourdieu, 1986), the form of capital that is most salient during a particular stage may influence how hiring managers perceive applicant social class, thereby impacting their perception of P-O fit.

Acquiring stage $\&$ social capital. The acquiring stage includes processes necessary to obtain applicants for available positions (Barber, 1998). Thus, during this stage individuals are considered potential applicants, such that they are determining whether or not to apply for a particular position within an organization (Ryan, Horvath, \& Kriska, 2005). Research has shown organizational recruitment practices to be quite relevant during the applicant acquiring stage (e.g., Breaugh \& Starke, 2000; Taylor \& Bergman, 1987), with the goal of generating a pool of applicants at minimal expense (Gatewood \& Feild, 1994). For instance, in a document provided 
to Society for Human Resource Management (SHRM) volunteers, an employer's purpose at recruitment events, such as a job fair, is to "meet and greet" and have the "opportunity to talk to more than one candidate at a time" (2014b). Thus, while hiring managers may acquire a large number of applicants, they may possess only limited information during this stage. However, one way employers may be able to detect more information about an applicant is through the use of employee referrals.

While organizations rely on a variety of methods to recruit applicants, many employers rely on employee referrals, which encourage employees to recommend individuals within their social capital network (e.g., friends, family, colleagues) to apply for available positions within their organization (Shinnar, Young, \& Meana, 2004). Employee referrals have been shown to be one of the most effective ways to ensure high quality applicants (Society for Human Resource Management, 2001) and minimize costs (Morehart, 2001). Research has shown that job applicants who have been referred are more likely to get hired and less likely to turnover (Brown, Setren, \& Topa, 2012). As such, hiring managers are likely to rely on employee referrals as a way to acquire applicants.

Social capital, which is defined as a collection of contacts into a socially structured network that creates value and facilitates change (Coleman, 1990), has been shown to be more influential in the assessment of applicants than human capital (Nguyen, Allen, Lynn Godkin, 2006). Employees are assumed to view referrals as impacting their own reputation (Ullman, 1966), thus employees may be most likely to refer those with whom they have an established relationship. Theories such as similarity attraction (Byrne, 1971) suggest that individuals are most likely to associate with those who are most similar. Friendship ties between applicants and organizational contacts allow transmission of additional information about an applicant that may 
not be otherwise available (Nguyen et al., 2006). Additionally, connections with socially acceptable figures often serve as a way to highlight legitimacy to third parties (Baum \& Oliver, 1992). However, because inequality exists regarding the power and prestige in individuals' social capital networks (Lin, 2000), it is likely that social class may impact who refers an applicant for a position. Therefore, hiring managers may make assumptions about the social capital of the applicant based on who provided the employee referral, allowing them to form impressions about an applicant's social class and assess P-O fit.

Asch (1946) suggested that impressions of characteristics are dependent on the context in which they are observed. Therefore, it is likely that hiring manager impressions of applicants' social capital may depend on who provided the employee referral during the hiring process. Both the social class literature and the results of my construct clarity research confirmed that upper class individuals are viewed as having social capital networks that are more influential, powerful, and job relevant as compared to lower class individuals (Williams, 2012). Furthermore, social resources theory (Lin et al., 1981) suggests that different individuals have access to different resources through their social capital networks. Using racial minorities—particularly Blacks—as an example, these individuals often have access to the "wrong networks" (Fernandez \& Fernandez-Mateo, 2006), which can impact their ability to become aware of various job openings. Not surprisingly, social networks are believed to be one of the most powerful ways that inequalities are maintained in organizations (Acker, 2006). Thus, hiring managers may rely on the power or prestige of the referral to determine fit within an organization.

Other factors such as salary, which indicate economic capital, may be difficult to interpret during the acquiring stage due to the various elements that can impact salary rates (e.g., geographic location, industry; Bureau of Labor Statistics, 2010). Thus, reliance on economic 
capital indicators during this stage may be limited. Secondly, while some cultural capital information may be known during this stage, such as applicant involvement in activities, due to the limited richness of the information during this stage, hiring managers may be unable to assess the meaning of these activities (i.e., applicant beliefs). As the presence of social ties is a way to evaluate the quality of another party (Podolny, 2001) and social capital has been shown to be an indicator of applicant fit within an organization (Dindoff, 2000), social capital may emerge as the most salient form of capital during the acquiring stage, influencing hiring manager perceptions of applicant social class.

Taken together, hiring managers' interpretation of applicants' social capital connections may drive their perceptions of applicant social class during the acquiring stage.

Hypothesis 2a-c: Economic capital (2a), social capital (2b), and cultural capital (2c), positively relate to hiring managers' perception of perceived applicant $P$-O fit during the acquiring stage. Hypothesis $2 d$ and 2e: During the acquiring phase, applicant social capital will have a stronger relationship with hiring managers' perception of applicant $P$-O fit than economic capital (2d) and cultural capital (2e).

Screening stage \& social, economic, and cultural capital. As hiring managers often must "infer the type of person required" (Bowen et al., 1991, p. 37) for their organization, this second stage involves the organizational screening of candidate skills (Bowen et al., 1991). In effect, hiring managers are encouraged to narrow down the pool of available applicants so that a small number can continue in the process (Society of Human Resource Management, 2014b). Therefore, hiring managers commonly rely on actions such as resume screening and selection tools such as personality and cognitive testing. These tools not only provide insight into an applicant's values and abilities, but can also provide organizations with a way to standardize 
their hiring process and objectively assess applicants (e.g., Bowen et al., 1991; Highhouse, 2008). As such, the screening stage provides hiring managers with access to applicant materials (i.e., resume) that may emphasize information representative of all forms of capital.

Resumes can vary substantially regarding the information applicants choose to include and exclude. Using a sample of human resources professionals, Fritzsche and Brannick (2002) found that applicants should include the following elements in their resumes: targeted career objective, relevant education and training, relevant work experience, interests, activities and special skills, references, and format, visual appeal and spelling. These sections are representative of all forms of capital, and have been shown to assist hiring managers as they make inferences about applicants regarding their ability, motivation, or even personality (Cole, Rubin, Feild, \& Giles, 2007). However, because the priority of the aforementioned information may vary over time or even by hiring manager (e.g., Hutchinson, 1984; 1997), resume screening may be a more complex and interactive process. Furthermore, some elements within the resume may result in interactive effects. In a study by Knouse (1994), education and experience were shown to interact, such that hiring managers were more likely to hire applicants with irrelevant education and relevant experience, but less likely to hire applicants with the reverse. In short, hiring managers have been shown to rely on combination of factors to determine the employability of an applicant (Cole et al., 2007). Considering the numerous factors that can be included on a resume and hiring managers' priorities, all forms of capital may be perceived as equally important during this stage.

While powerful social capital network connections have been shown to assist job applicants both gain access and remain in the hiring process (Lin, Ensel, \& Vaughn, 1981), this information may continue to be apparent during the screening stage. Resumes often list 
information pertaining to recommendations or referrals. Within the context of college students, providing recommendation information from a former employer was of similar importance to providing a listing of students' grades (Hutchinson \& Brefka, 1997). As such, applicants may continue to provide social capital during the screening stage of the hiring process, allowing this information to remain salient for hiring managers.

Within the social class literature, economic capital has been conceptualized as income, occupation, and education (Bourdieu, 1986). Within the selection process literature, these factors - particularly education and occupation—have been considered to be extremely relevant to hiring managers' screening of applicants. In fact, applicants are often excluded or discontinued from the hiring process due to a lack of education or experience (Behrenz, 2001). However, as discussed during the construct clarity section, education and occupation were not solely representative of economic capital. As such, my conception of economic capital focuses solely on the impact of applicant income.

While many organizations remain secretive about communicating employee salary information (Colella, Paetzold, Zardkoohi, \& Wesson, 2007), applicants are frequently asked to disclose their salary history or salary requirements when applying for available positions. In fact, according to a survey of HR professionals, neglecting to provide salary history or salary requirements on a resume when asked to do so is considered a mistake (SHRM, 2005). Salary is often a signal for income, possession of material resources, and position within a social hierarchy (Adler et al., 2000), frequently indicating other factors such as residential location or homebuyer status (Shapiro, 2004). Not surprisingly, disclosure of salary related information on a resume has increased in importance over time. In an initial study conducted in 1984, disclosure of salary history on a resume was found to be of moderate importance, viewed as less important than other 
information such as military experience (Hutchinson, 1984). However, when this study was replicated in 1997, inclusion of salary history on a resume was viewed as significantly more important, while military experience decreased in importance (Hutchinson \& Brefka, 1997). Additionally, because various web resources (e.g., Salary.com, Indeed.com, Glassdoor.com) provide detailed salary information by industry and job role, individuals can make valid applicant comparisons using salary information. Therefore, economic capital may be easily highlighted and referred to as hiring managers screen applicant resumes during this stage.

Lastly, while determinations of P-O fit may be based on a match between applicants and organizational needs (Kristof, 1996), recruiters have been shown to account for perceptions of personality and values as additional important factors (Nguyen, Allen, \& Godkin, 2006), which are representative of cultural capital. Value similarity has been shown to be relevant to hiring manager assessments of applicant P-O fit (Kristof, 2000). As applicants may likely include information pertaining to their interests and activities (Fritzsche and Brannick (2002), hiring managers may become aware of applicant information pertaining to hobbies or group affiliations (Fallow \& Kantrowitz, 2013). As these factors may serve as signals (Spence, 1973) for applicant values, hiring managers may also consider cultural capital during the screening stage.

Clearly, hiring managers may rely on all forms of capital to assess applicants’ P-O fit. However, because each form of capital may still be apparent during the screening stage, hiring managers may be unable to differentiate between the forms that are more or less salient to their assessment during stage. As such, hiring managers may similarly consider all forms of capital during the screening stage. Hypothesis 3a-c: Economic capital (3a), social capital (3b), and cultural capital (3c), positively relate to hiring managers' perception of perceived applicant $P$-O fit during the screening stage. 
Interviewing process stage $\boldsymbol{\&}$ cultural capital. This final stage involves the actual interview (Lopez-Kidwell et al., 2013). Hiring managers have the opportunity to analyze and assess applicants more in depth (Bowen et al., 1991), allowing hiring managers to develop subjective interpretations of job applicants (Rivera, 2012). Although the interviewing stage typically occurs at the end of the hiring process, it is the most common tool used by organizations to assess applicants (McCarthy et al., 2010) and is often considered the most relevant to the actual hiring decision (Graves \& Powell, 1995). While the information obtained during this stage will have likely remained unchanged from the prior stages, it is the richness of the information that is different and may substantially impact the hiring manager. Interviews may occur in-person or via an online tool (e.g., Skype, videoconferencing), allowing the job applicant to be visibly seen and heard. Because of the increased level of interaction that occurs during the interviewing stage, determinations of the most salient form of social class may again shift, impacting the perception of applicant P-O fit.

Unlike the prior two stages, interviews often allow the style of social class (Scully \& Blake-Beard, 2006) or visible factors such as behaviors, speech, and dress to be observed. The richness of these cultural capital indicators may overshadow other forms of capital. Hiring managers initially relied on applicant social capital networks to inform them of applicant social class. However, hiring managers may find this information to be incomplete when compared to the rich information obtained by cultural capital. As such, use of social capital to determine applicant social class is less likely during this stage. Secondly, while applicant income information may be requested and used by hiring managers for various purposes (e.g., salary offers, negotiation, assess qualifications), reliance on economic capital during this stage may be decreased, particularly when compared to the rich information gained through cultural capital. 
Due to the desire that hiring managers have to engage in cultural matching with applicants (Rivera, 2012) and the frustration experienced when individuals engage in cross-class interactions (Gray \& Kish-Gephart, 2013), cultural capital—which relates to norms and behaviors - may emerge as most salient during this stage.

Although the cultural capital of upper and lower class individuals often differs, it is an upper class form or "habitus" (Bourdieu, 1984) that is typically regarded as most acceptable in the workplace. Habitus describes dispositions and norms, which are adopted by different classes making their attitudes or values appear normal. Therefore, upper and lower class applicants frequently have different experiences during a job interview simply due to their ability or inability to engage in small talk conversation with a hiring manager (Ridgeway \& Fisk, 2012).

As cultural capital can encompass a variety of factors, it is important to understand its sub-dimensions. Embodied cultural capital, which focuses on dispositions of the mind and body (Bourdieu, 1986), may highlight divergence in values between applicants of varying classes (Piff et al., 2012). As confirmed during my construct clarity research, upper class individuals attribute economic disparities to differences in the hard work of individuals, whereas lower class individuals attribute this to available opportunities. These findings also align with previous social class research (e.g., Kraus et al., 2009), which asserts that lower class individuals tend to attribute external forces, such as prejudice, to their outcomes whereas upper class individuals believe outcomes are affected by individual behaviors, such as effort. Behaviors, such as participation in activities such as sailing or basketball were also reflective of upper and lower class individuals, respectively. Congruence between interviewer and applicant behaviors is often used as criteria when selecting new applicants (Rivera, 2012). 
Objectified cultural capital describes the possession of tangible cultural goods (Bourdieu, 1986). During the interview, this dimension may be exposed as applicants discuss a new car or house purchase. Possession of cultural goods can also be in the form of items such as books, as was highlighted during my construct clarity research. As suggested by Holt (1998), what and how individuals consume goods is often reflective of their cultural capital. Therefore, individuals of low and high levels of cultural capital will often own different types of items or have differing priorities on their purchases, making cultural capital easy to detect.

Lastly, the institutionalized dimension of cultural capital relates to a designated standard, such as standardized testing (Bourdieu, 1986), allowing different individuals to be evaluated along similar criteria (e.g., scores on an SAT exam). Another example of this is organizational membership, which also often signals a certain standard. Weber (1946) suggested that certain "lifestyle markers" indicate group membership, and thus inclusion and exclusion from different opportunities. As shown in a study of college applicants, admissions personnel were able to detect social class differences due to organizational membership, associating some as more consistent with a lower class status (e.g., ROTC, 4H) (Espenshade \& Radford, 2010). Similar to the prior forms of capital, because my construct clarity research only indicated beliefs and behaviors as solely representative of cultural capital, my focus is solely on these factors.

During an interview, applicants' beliefs and behaviors emerge quite quickly, providing hiring managers with the opportunity to assess applicant social class. While surface-level observations such as dress may be difficult to miss, value similarity-a deep-level characteristic — has been shown to be much more relevant in workplace interactions (Kristof, 2000). DiMaggio (1992, p. 127) emphasized the importance of "cultural matching", or a similarity between employers and applicants, as critical within the hiring process. As such, 
factors such as experiences or even leisure pursuits are considered relevant ways hiring managers may assess applicants (Rivera, 2012). In a study of hiring in elite firms, one hiring manager stated, "I'd have to pick Blake and Sarah. With his lacrosse and her squash, they'd really get along...” (Rivera, 2012, p. 1009). Although participation in sports was unrelated to the job, this behavior allowed hiring managers to associate a higher level of cultural capital, and thus social class, to these applicants. As such, it is quite likely that hiring managers may use applicant beliefs and behaviors to assess applicants' P-O fit.

Because hiring managers and applicants will engage in conversations and interactions during the interviewing stage, aspects of cultural capital may become increasingly apparent (DiMaggio, 2012). Additionally, because many of the differences attributed to cultural capital are involuntary and innate, and frequently obtained through childhood (Bourdieu, 1984), applicants may be unable to engage in faking, which is common during other parts of the hiring process (e.g., personality assessments; Morgeson, Campion, Dipboye, Hollenbeck, Murphy, \& Schmidt, 2007). Therefore, cultural capital may emerge as the most salient form of capital during the interviewing stage, allowing hiring managers to use it in their assessment of applicant $\mathrm{P}-\mathrm{O}$ fit.

Hypothesis 4a-c: Economic capital (4a), social capital (4b), and cultural capital (4c), positively relate to hiring managers' perception of perceived applicant $P$-O fit during the interviewing stage.

Hypothesis 4d and 4e: During the interviewing phase, applicant cultural capital will have a stronger positive relationship with hiring managers' perception of applicant $P$-O fit than social capital (4d) and economic capital (4e).

\section{Hiring manager and applicant social class similarity}


Relational demography describes the similarity or dissimilarity of demographic characteristics of dyads or groups of individuals who are likely to interact (Tsui \& O'Reilly, 1989). Various theories such as the similarity attraction paradigm (Byrne, 1971) or social identity theory (Turner, 1985), support the preference individuals have toward similar others. Moreover, theories such as stigma (Goffman, 1963) emphasize the exclusion or negative reactions individuals often display toward those who are dissimilar or possess "an attribute that is deeply discrediting” (p. 3). As such, demographic similarity has been considered one of the most relevant factors to explain employee interactions and outcomes (e.g., Tsui \& O'Reilly, 1989).

Within the selection literature, demographic similarity between hiring managers and applicants on the basis of race and ethnicity (e.g., Avery, McKay, \& Wilson, 2008; Cunningham \& Sagas, 2004; McCarthy et al., 2010; McFarland et al., 2004), gender (e.g., García et al., 2008; Goldberg, 2003, 2005; Huffcutt, 2011), and age (e.g., García et al., 2008; Goldberg, 2003, 2005; Macan, 2009) have been considered relevant to perceptions of applicant fit. However, research has yielded mixed findings. For instance, while perceived demographic similarity between applicants and hiring managers influenced fit perceptions with the organization and applicant liking, it failed to increase positive hiring decisions (García et al., 2008). Graves and Powell (1995) found that female hiring managers were more likely to view male applicants as similar to themselves, and thereby assigned higher ratings to male applicants. When using structured interviews, effects of demographic similarity as related to race and gender were not found, which may suggest that the use of structured interviews can eliminate instances of bias due to demographic characteristics (McCarthy et al., 2010). Within the context of panel interviews, racial proportions were shown to be relevant, as a higher proportion of Black hiring managers were found to provide more positive ratings to Black applicants, but these effects were not found 
between White hiring managers and applicants (McFarland et al., 2004). This finding may be partially attributable to the initial lower ratings Black raters assigned to White applicants, which did not occur with White raters toward Black applicants. Clearly, demographic similarity is relevant during the selection process, but "analyses of demographic effects must consider the full impact of an individual's demographic profile rather than only one or two demographic characteristics" (Tsui \& O’Reilly, 1989, p. 404).

As prior theories have suggested (e.g., similarity attraction, Byrne, 1971; social categorization, Turner, 1985, 1987), individuals often seek comfort in those most similar to themselves. This desire for similarity is not excluded from the hiring practice, but because individuals consider themselves to be members of an infinite number of groups (Goldberg, 2003), perceived similarity between a hiring manager and applicant may be based on multiple dimensions. Interestingly, some of the most powerful criteria that hiring managers use to determine fit is often linked to factors of social class. Rivera (2012) found that hiring managers actively engage in cultural matching to ensure similarities between themselves and applicants exist. Specifically, matching as related to experiences, leisure activities, self-presentation styles - all of which are related to aspects of cultural capital—were noted as particularly important. As individuals of the same social class are more likely to share the same norms and rituals (Dacin et al., 2010), social class similarity between hiring managers and applicants may best satisfy hiring managers' desire to engage in cultural matching and provide hiring managers with more accuracy when determining similarity.

Despite the possible preference for social class similarity, due to the increasing diversity within the workplace (e.g., Cox \& Blake, 1991; Roberson, 2006), we can expect that instances of social class dissimilarity between hiring managers and applicants will also occur. Cross-class 
interactions, which are described as interactions between individuals of differing social class (Ridgeway \& Fiske, 2012), have been found to be frustrating (Benjamin et al., 2011; Gray \& Kish-Gephart, 2013) as these interactions frequently highlight a lack of shared experiences. Within the hiring process this is particularly detrimental, as hiring managers often assess applicant fit during the first few minutes of an interview through small talk conversation (Rivera, 2012); and lack of similarity frequently results in poorer interview performance (Ridgeway \& Fisk, 2012). Additionally, attempts to adopt the style of another individual's class may not mitigate these uncomfortable encounters, as "style acquired consciously may not come across quite right" (Scully \& Blake-Beard, 2006, p. 441). In short, social class dissimilarity may be apparent and uncomfortable, negatively impacting hiring manager perceptions of applicant fit. Considering this, we must understand how hiring managers' social class influences the relationship between perceived applicant social class and perceived P-O fit.

Upper class hiring managers may strengthen the relationship between applicant social class and perceived P-O fit—regardless of the applicant's social class. As suggested in hypothesis one, upper class applicants will be perceived by hiring managers with higher levels of P-O fit. This relationship may become even more pronounced when hiring managers are also upper class. These individuals may be more likely to relate due to similar education, income, occupational prestige (Markus \& Conner, 2013), or social networks (Scott, 2005). Additionally, beliefs about topics such as the reasons for inequality or how much trust to extend to individuals are likely also similar (Fiske et al., 2012; Kraus et al., 2009). As previously stated, because the professional workplace tends to adhere to upper class norms and values (Ridgeway \& Fisk, 2012), upper class similarity between a hiring manager and an applicant may only serve to strengthen hiring manager perceptions of applicant $\mathrm{P}-\mathrm{O}$ fit. 
However, upper class hiring managers and lower class applicants are less likely to find similarities, allowing them to rely on strategies such as distancing to limit interactions (Gray \& Kish-Gephart, 2013). Gray and Kish-Gephart (2013, p. 679) describe distancing as the creation of "barriers that prevent or minimize the incidence of anxiety associated with cross-class encounters." Thus, it can span from avoidance to minimal engagement with an individual of a differing class. In a study of interviews with lower class employees, Lubrano (2004, p. 148) described the context as one where "nobody is being rude, but nobody is connecting either." This lack of cultural matching may result in hiring managers who are less likely to understand a lower class applicant's qualifications or consider their selections valid (Rivera, 2012). For instance, lower class individuals often emphasize the value of family over work (Lautsch \& Scully, 2007) and perceive work as a job — not a career (Holt, 1998), which is contrary to upper class beliefs. Additionally, because hiring managers of upper class status likely have access to greater material resources than lower class applicants, hiring managers may be less empathetic toward chaotic situations (Piff et al., 2012), such as lateness to an interview due to unexpected car trouble or lack of childcare needs. Due to their lack of common ground, upper class hiring managers may be more likely to develop stronger perceptions pertaining to the lack of fit between lower class applicants and their organization.

In contrast to upper class hiring managers, lower class hiring managers may weaken the previously established relationship between perceived applicant social class and perceived P-O fit. As professional organizations are likely to be dominated by upper class individuals, lower class hiring managers may experience a lack of belonging and increased social rejection within their organization (Stephens et al., 2007). Therefore, hiring managers may take solace in an applicant who shares their lower social class status. Similar to upper class individuals, lower 
class individuals are also likely to share experiences, values, and perspectives, which will make their interactions during the hiring process more positive. Lower class individuals are more likely to be empathetic toward others (Kraus et al., 2012) and attribute disparities to contextual factors (Kraus et al., 2009). Additionally, because lower class individuals are more communal and display more prosocial behavior without a need for reciprocating behavior (Piff et al., 2010), hiring managers may display higher levels of helping behavior. In fact, cultural matching similarities increase the likelihood that hiring managers will become energized about applicants and fight for them during deliberations (Rivera, 2012). Thus, lower class hiring managers may be more likely to fight for lower class applicants who may otherwise be perceived with lower levels of P-O fit. Consequently, social class similarity on the basis of lower class status may weaken the initial relationship that upper class applicants are perceived with higher P-O fit.

Lower class hiring managers and upper class applicants may also result in an uncomfortable situation. For instance, the hiring manager and applicant may have difficulty communicating due to differences in speech patterns (Argyle, 1994). Most importantly, because of the varying experiences and beliefs, lower class hiring managers may be overly critical of upper class applicants. Lower class individuals tend to believe that upper class employees are book smart and unable to get actual work done (Howell, 1972). Thus, lower class individuals may attribute characteristics such as "lucky" or "clueless" to upper class individuals (Skeggs, 2010, p. 682). Views such as these often stem from prior negative or humiliating interactions with individuals of a higher class (Williams, 2012). However, this strategy allows lower class individuals to establish and maintain a positive identity about their social class, while simultaneously decreasing positive perceptions of upper class individuals. Therefore, lower class 
hiring managers may perceive interactions with upper class applicants negatively, resulting in a weaker relationship between perceived applicant social class and perceived applicant $\mathrm{P}-\mathrm{O}$ fit.

Taken together, hiring managers' social class will influence the relationship between perceived applicant social class and perceived applicant P-O fit, with upper class hiring managers strengthening this relationship and lower class hiring managers weakening it. Hypothesis 5: The relationship between applicants' social class and perceived P-O fit is moderated by the hiring managers' social class, such that the relationship is strengthened when hiring managers are of upper class and attenuated when hiring managers are of lower class.

\section{Applicants' forms of capital alignment}

As previously discussed, hiring managers will rely on three forms of capital (e.g., economic, social, cultural) to assess whether an applicant is of upper or lower class. These perceptions of social class subsequently impact perceptions of applicant P-O fit. Despite the interrelatedness of these forms of capital (Bourdieu, 1984), these forms of capital do not necessarily have to align. Therefore, while individuals may be able to accurately detect the social class of others when presented with forms of capital that align (Kraus \& Keltner, 2009), hiring managers may experience difficulty when presented with applicants who possess conflicting forms of capital. In short, when applicants simultaneously display forms of capital representative of both upper and lower class, hiring managers may develop conflicting perceptions about social class, which impact perception of P-O fit.

Conflicting perceptions are not new to the management literature, and are actually quite likely within the context of social class. For instance, lower class individuals may have high levels of income, but significantly differ from upper class individuals regarding their beliefs about how to earn that income (Williams, 2012). Despite the likelihood of conflicting forms of 
capital, limited research exists regarding the interactions or consequences after mixed impressions of social class are perceived (Côté, 2011). In one of the few studies about mixed impressions of social class, Himmelfarb and Senn (1969) relied on components of socioeconomic status (SES) (i.e., income, occupation, education) to assess how managers perceived conflicting information. These authors found that individuals were able to assess those who were consistently high or low in the aforementioned components, but tended to rely on an average of SES components to develop an impression when conflicting information was presented (e.g., high income, high occupation, low education). Therefore, perceptions of individuals may differ depending on whether their forms of capital are aligned or conflicting.

"Nature does not create discrete categories of human traits or identities" (Reynolds \& Pope, 1991, p. 175), instead, humans categorize individuals to simplify information (Turner, 1985). Within the hiring process, the ability to categorize provides hiring managers with a clear way to assess and evaluate applicants. Thus, when hiring managers are unable to categorize applicants due to conflicting forms of capital, they may experience discomfort. Cognitive dissonance describes the discomfort experienced when individuals' attitudes are incompatible with their behaviors (Festinger, 1962). It can be experienced as a bodily or psychological discomfort (Festinger, 1957), however, it is "the psychological discomfort that motivates or 'drives' the attitude or change process" (Fazio \& Cooper, 1983, p. 132). Dissonance can become increasingly uncomfortable when occurrences impact individuals' self-concept (Pugh, Groth, \& Hennig-Thurau, 2011). Therefore, when hiring managers are presented with applicant social class cues that conflict with their beliefs about what constitutes a particular social class, hiring managers may rely on the motivational state of cognitive dissonance to change behavior and mitigate the discomfort. 
As asserted by Vandenberg and Lance (1992, p. 155), "the stronger the cognitive dissonance the greater the need to reduce it." Thus, assuming motivation exists to resolve the tension, Festinger (1957) suggested three dissonance reduction strategies. One option is for individuals to change their attitudes, values, or behaviors. A second strategy is to seek new information to reduce the inconsistency. Lastly, individuals may decrease or trivialize the importance of the conflicting element. It may be difficult for hiring managers to change their long-standing attitudes, values, or behaviors, particularly because these aspects are representative of their own cultural capital. Secondly, while it behooves hiring managers to seek additional information about applicants, many hiring managers may be unable to adequately do so. Between a combination of the limited time frame of the hiring process (Pager, Western, \& Sugie, 2009), the reliance on a "gut feeling" to assess applicants (Moss \& Tilly, 2001, p. 209), and the general lack of assessments during the hiring process (Highhouse, 2008), this solution may be out of reach for many hiring managers. Unlike the prior two strategies, trivializing a conflicting form of capital may relieve hiring managers of their discomfort without requiring a significant investment. Additionally, determining what form of capital to trivialize may also not require a significant investment. As asserted by Asch (1946, p. 285), "the content and functional value of a trait changes with the given context." Therefore, hiring managers may decide to trivialize the forms of capital that they perceive as least salient within the hiring process context.

Trivializing different factors during the hiring process, which in turn emphasizes other factors, is quite common. For instance, some organizations gain a substantial number of applicants from an applicant's social capital network or contacts established directly by the organization (e.g., internship contacts, university intermediaries) (Obukhova \& Lan, 2013). Other organizations and hiring managers emphasize prestigious credentials rather than informal 
networks (Rivera, 2012). Finally, some hiring managers evaluate applicants based on their cultural match with the organization or themselves (Rivera, 2012). Considering this, it is likely that hiring managers may trivialize the forms of capital they perceive to be less salient, which may help them reconcile an applicant's social class, and ultimately the applicant's P-O fit.

However, because trivializing means minimizing as opposed to disregarding, it is likely that the less salient forms of capital may still have some influence on the perception of applicant P-O fit. Although Rivera (2012) suggested that grades, course work, and even work experience were trivialized during the interview process, these factors were still considered in the overall evaluation of an applicant. Accordingly, conflicting perceptions have been shown to result in a slightly lower or higher assessment of social class (Himmelfarb \& Senn, 1969). While trivializing one or more forms of conflicting capital may reduce hiring managers' discomfort, applicants with conflicting forms of capital may be perceived with a different applicant P-O fit as compared to those with aligned forms of capital.

Considering the above, it is likely that the presence of conflicting forms of capital will weaken the previously established relationships between applicant social class and perceived applicant P-O fit.

Hypothesis 6: The relationship between applicant social class and perceived P-O fit is moderated by alignment between the forms of capital, such that the relationship is weakened when applicants' forms of capital are perceived to conflict. 


\section{CHAPTER 4: METHODS}

\section{Study Design}

To investigate my hypotheses related to the impact of social class within the hiring process, it was important to capture the various aspects of the hiring process within my study. Therefore, I relied on an experimental vignette methodology, which has been described as a way to enhance "realism and also allows researchers to manipulate and control independent variables, thereby simultaneously enhancing both internal and external validity (Atzmüller \& Steiner, 2010; Hox, Kreft, \& Hermkens, 1991)"(Aguinis \& Bradley, 2014, p. 352). Specifically, I used a modified policy capturing format, which assessed the implicit decision making process of hiring managers when presented with applicant information in a variety of forms.

Policy capturing allows researchers to understand the decision making process of individuals (i.e., within subjects design) rather than formulating an average based on various individuals (i.e., between subjects design) (York, 1989). Thus, individuals were presented with multiple scenarios where one more factors were manipulated and their decisions were captured (Webster \& Trevino, 1985). Various management studies have relied on policy capturing approaches as related to promotion decisions (Stumpf \& London, 1981), job evaluation (GomezMejia, Page, \& Tornow, 1982), acquisition integration (Pablo, 1994), and performance ratings (Rotundo \& Sackett, 2002). As policy capturing allows for in-depth exploration about individuals' decision making, it provides greater insight into perceptions of social class within the hiring process.

Participants responded to one portion of an online scenario based survey divided into the three stages of the hiring process (i.e., acquiring, screening, interviewing). Stimulus materials applicable to each stage were developed and presented to survey participants. Therefore, 
participants completing the survey for the acquiring stage were presented with email referrals (see Example 1), those completing the survey for the screening stage were presented with resumes (see Example 2), and those completing the survey for the interviewing stage were presented with video interviews (see Example 3). In each stage I manipulated the following factors: economic capital (upper or lower), social capital (upper or lower), cultural capital (upper or lower), applicant race (Black or White), and applicant sex (male or female). Therefore, my study relied on a $2 \times 2 \times 2 \times 2 \times 2$, matrix design with 32 possible combinations in each stage (see Table 2). While not manipulated, I also tested for social class similarity between the hiring manager and applicant. Lastly, while neither hiring manager race nor gender were hypothesized or manipulated in my matrix design, both were included in the analysis to test for any significant effects of race and gender of the hiring manager and applicant.

\section{Sample}

I tested my proposed hypotheses using a two-part sample comprised of individuals involved in the hiring process (e.g., human resource professionals, hiring managers) and registered Amazon Mechanical Turk (MTurk) users who are currently or have previously been involved in the hiring process. Amazon MTurk is an online resource that allows for a simple data collection process of a large number of participants for minimal compensation (Amazon Mechanical Turk, 2014). Amazon has its own screening process for individuals to become members of the Mechanical Turk site, thus I have included pertinent information regarding the selection criteria and process in Table 3.

Although education is often a differentiator of social class, individuals with less education tend to respond less frequently to surveys (Porter, 2004). However, because Amazon MTurk samples have been found to be more diverse and as reliable as the typical samples used in 
management research (Buhrmester, Kwang, \& Gosling, 2011), inclusion of participants from Amazon MTurk provided greater access to individuals of varying educational backgrounds. As an example, when conducting my pilot studies $97 \%$ of the academic sample and $90 \%$ of the professional sample indicated their highest educational level was a Bachelor's degree or above. However, almost 50\% (16 out of 33) of MTurk participants indicated that their highest educational level was less than a Bachelor's degree. The higher levels of diversity and similar reliability of Amazon MTurk samples may also explain its increased use in recent publications in prestigious academic journals (e.g., Academy of Management Journal, Journal of Applied Psychology) (e.g., Bendersky \& Shah, 2013; Chua, 2013; Lee, Gino, \& Staats, 2014).

Regarding the field sample participants, described herein as the professional sample, these individuals were identified through a variety of sources such as the MBA and undergraduate career center contacts of a large Northeastern university and professional organizational members (e.g., Society of Human Resource Management, Human Resources Leadership Council) located in the Northeast and Mid-Atlantic regions of the United States. To increase participation and diversity of the sample, participants were able to forward the survey link onto other hiring professionals, thereby invoking snowball sampling. Snowball sampling, which is quite common and supported in qualitative research, is often used to gain more in-depth knowledge about a particular population or context (Merriam, 2009). In this context, use of snowball sampling provided greater access to HR professionals and hiring managers who met this study's criteria.

\section{Power Analysis}

As my study used a three-stage format, I conducted a power analysis for each stage. Using Optimal Design (Spybrook, Bloom, Congdon, Hill, Martinez, \& Raudenbush, 2011) I 
conducted a power analysis using the two-level cluster randomized trial analysis. I used a moderate effect size, similar to what has been found in the diversity and selection literature. Therefore, I used an effect size of $.20, \alpha=.05$, power $=.80$, and covariate $=.30$. As previously noted, 32 total applicant combinations exist within my study; however, participants were only presented with a subset of applicants. Specifically, 16 were presented in the acquiring stage, 10 in the screening stage, and four in the interviewing stage. Thus, each stage required a different minimum number of participants, as depicted by the power analysis graphs shown in Figures 4 through 6. Seventy-eight participants were included in the acquiring stage, 105 participants were included in the screening stage, and 220 participants were included in the interviewing stage, which met the required power of .80 .

\section{Survey Development}

As discussed, because participants reviewed multiple stimulus materials in their assigned stage, all participants were presented with directions applicable to their particular stage, as shown in Example 4. After reviewing the stimuli material (e.g., email, resume, video) participants responded to questions about their perceptions of applicant P-O fit and provided a hiring recommendation or recommendation to continue in the process (whichever is applicable depending on stage). This repeated until participants finished reviewing all stimuli within their applicable stage. At the conclusion of the survey, participants responded to background and demographic questions.

Economic, social, and cultural capital were manipulated in the stimulus materials using the following factors: current salary or salary history of applicant (income; economic capital), the title of the referrer (power and prestige; social capital), and participation in an elite (e.g., book club) or non-elite (e.g., basketball league) activities or discussion of beliefs (behaviors and 
beliefs; cultural capital). Race and gender were indicated by applicant name, and during the interviewing stage these characteristics were apparent in the applicant videos. Applicant social class was aligned (e.g., same social class status for all forms of capital) or conflicting (e.g., varying social class status for all forms of capital) throughout the prompt. Additional detail related to the development of the stimulus materials is provided in Appendix C.

\section{Survey testing}

Various portions of the survey have been tested with a professional, academic, and MTurk sample, as detailed in Appendix A and B. After the full survey was developed each version was tested to assess survey length, and each survey averaged less than 20 minutes for completion.

\section{Survey deployment}

Surveys to the non-MTurk sample were emailed from the email account of the student researcher identified in the IRB. Surveys allowed multiple responders to use the same link, which enabled participants to forward survey links onto other professionals. However, it prevented individuals from responding to the survey multiple times from the same IP address. Surveys to the MTurk sample were posted directly on the Amazon MTurk website, in accordance with the Amazon Mechanical Turk policies. These surveys were unable to be forwarded.

Prior to beginning the survey, each participant reviewed the consent form, provided their electronic consent, confirmed that they previously or currently were involved in the hiring process, and confirmed that they previously or currently worked in the United States. Participants who declined consent or asserted that they have had no involvement in the hiring 
process or work background in the United States were exited from the survey. Prior to beginning the survey, participants were presented with instructions applicable to the hiring stage.

As previously noted, survey participants were only be presented with a subset of the 32 applicant combinations. Subsets were used due to the length of time it would take participants to review all stimulus materials of multiple applicants and to avoid survey fatigue (e.g., Porter, Whitcomb, \& Weitzer, 2004). Therefore, subsets presented to participants were randomized through Qualtrics. However, it was important to ensure that this random order did not introduce additional bias. As described by Brooks (2012), this is particularly important with repeated measures or within subject designs, where participants are presented with multiple conditions. Specifically, it was important to confirm that some applicants were or were not consistently presented prior to presenting another applicant or that some applicants were presented in a disproportionate frequency as compared to others. Random and counterbalancing effects were set up by me within Qualtics and were reviewable as surveys were completed. It should be noted that a slightly different randomization procedure was used for the video interview stage. To maintain realism, participants were presented with each applicant type once (e.g., Black female, White male). However, variation still occurred related to the order that applicants of a particular demographic combination (i.e., race, sex, social class) were presented. race or sex are presented and the applicant's social class.

Responses were anonymous, with only IP addresses and the date of completion recorded. Although questions were not mandatory, participants were prompted to respond to each question prior to proceeding to the next page. Participants were also prevented from going backward in the survey. 


\section{Measures}

Each form of social class as well as the upper and lower social class factors have already been tested and shown to result in accurate perceptions of individuals' social class status. Therefore, participants were not presented with additional information related to the identification of applicant social class and this variable was dummy coded (lower class $=0$; upper class=1).

Perceived person-organization fit. P-O fit has been assessed perceptively, subjectively, and objectively. As described by Verquer and colleagues (2003), perceived P-O fit captures individuals' description of themselves and their organization on similar dimensions allowing for a comparison. Subjective fit captures individuals' viewpoint on how well they think their characteristics align with their organizational characteristics. Lastly, objective fit requires feedback from two sources, such that the individuals describe their own characteristics and another individual describes the organizational characteristics on the same dimensions, allowing for a comparison.

In accordance with Chen and Lin (2014) who measured perceived P-O fit, I relied on four measures of P-O fit established by Kristof-Brown (2000). These items included: "I think this applicant is very suitable for our company", "I think this applicant is highly similar to our other company employees", "My colleagues will likely agree with me that this applicant is very suitable for our company", and "I am convinced that this applicant is suitable for our company". All items relied on a scale ranging from $1=$ strongly disagree to $5=$ strongly agree.

Hiring recommendations. Collecting information on the final hiring decision is preferable. However, questions relating to the final hiring decision would be premature and unrealistic to participants who were presented with email referrals and resumes. Therefore, 
participants who completed surveys representative of the acquiring and screening stages of the hiring process were asked for their recommendation to allow an applicant to continue in the process, whereas those who complete the interviewing stage of the hiring process were asked for their recommendation to hire.

Recommendation to allow applicant to continue in the process. As suggested by Cable and Judge (1997), decisions to offer applicants a second interview are directly reflective of hiring intentions. Therefore, participants were asked, "How likely are you to allow this applicant to continue in the hiring process?" This item was rated on a scale ranging from $1=$ strongly disagree to $5=$ strongly agree, which allowed me to combine the responses from this question to the responses of the recommendation to hire question.

Recommendation to hire. Following a variation of Cable \& Judge (1997), Higgins and Judge (2004) relied on a two-item measure, which includes the following: "I would recommend extending a job offer to this applicant", "overall, I would evaluate this applicant positively". To ensure a minimum of three-item measure, I also included an additional measure from Sekiguchi and Huber (2011) "I want to hire this candidate". All items relied on a scale ranging from $1=$ strongly disagree to $5=$ strongly agree.

Hiring manager demographic and background information. In addition to collecting information on participant ratings, all participants were asked to provide the following demographic and background information.

Age. Participants were asked to provide their age.

Sex. Participants were asked to designate whether they are a male or female. Sex was dummy coded (female $=0$; male $=1$ ). 
Race and ethnicity. Participants were asked to provide their race and/or ethnicity using the following categories: "Asian / Pacific Islander," "Black / African American, West Indian," "Hispanic / Latino," "Native American / American Indian," "White / Caucasian," "Other," and "Prefer not to respond."

Highest level of education. Participants were asked to provide their highest level of education within the following categories: "Some high school," "High school graduate, diploma, or equivalent (ex. GED)," "Some college credit, no degree," "Trade / Technical / Vocational Training," “Associate's Degree," "Bachelor's Degree," "Master's or Professional Degree," and "Doctorate Degree."

Income. Participants were asked to provide their current household income within the following categories: “Under $\$ 25,000$, , “\$25,001 - \$50,000,” “\$50,001 - \$75,000,” “75,001 $\$ 100,000, ”$ “\$100,001 - \$125,000,” “Above \$125,000,” and “Prefer not to respond.”

Subjective social class scale. I used a combination of subjective social class scales that have been used in various social class studies. First, participants were asked to evaluate their own social standing. Participants were presented with a sliding scale with 10 places and the following description as adapted from Adler and colleagues (2000):

"You have been presented with a sliding scale with 10 rungs. Think of the ladder as representing where people stand in our society. The top of the ladder are the people who are the best off, those who have the most money, most education, and best jobs, and at the bottom are the people who are the worst off, those who have the least money, least education, and worst jobs or no job. Move the slider to the position that best represents where you think you stand on the ladder."

Second, participants were asked questions about their childhood and current or future social class. Using two, three-item scales from Griskevicius, Tybur, Delton, \& Robertson (2011), the first is focused on childhood social class, which includes the following items: "My family usually had enough money for things when I was growing up," "I grew up 
in a relatively wealthy neighborhood," "I felt relatively wealthy compared to the other kids in my school." The second scale is focused on current or future social class: "I have enough money to buy things I want," "I don't need to worry too much about paying my bills," "I don't think I'll have to worry about money too much in the future." All items relied on a scale ranging from $1=$ strongly disagree to $5=$ strongly agree.

Job Title. Participants were asked to select their job title from a drop down listing. The listing was developed using the most frequently occurring occupational titles provided in my previous pilot studies, as these titles may be most applicable to the sample type of participants in this study. An option for "other" with an open-ended response will also be provided.

Industry. Participants were asked to select their industry from a drop down listing. Listing will be developed using the 2012 North American Industry Classification System (NAICS) listing from the U.S. Census (2012). The industries are as follows: "Administrative and Support and Waste Management and Remediation Services," "Agriculture, Forestry, Fishing, and Hunting," "Accommodation and Food Services," "Arts, Entertainment, and Recreation," "Construction," "Finance and Insurance," "Health Care and Social Assistance," "Educational Services," "Information," "Management of Companies and Enterprises," "Manufacturing," "Mining, Quarrying, and Oil and Gas Extraction," "Other Services (except Public Administration)," "Professional, Scientific, and Technical Services," "Public Administration" "Real Estate and Rental and Leasing," "Transportation and Warehousing," "Utilities," "Wholesale Trade, Retail Trade." An option for "other" with an open-ended response was also provided.

Organizational values. Using the Organizational Culture Profile (OCP) developed by O’Reilly, Chatman, and Caldwell (1991), participants will be asked to assess various 
organizational value terms as related to their own organization's values. The initial OCP comprised 54 values and required participants to sort these terms into nine categories ranging from "most characteristic of this organization" to "least characteristic of this organization." As shown in Table 4, Cable and Judge (1997) were able to decrease the number of terms to 40 by eliminating similar terms. Using this reduced list, participants were asked to rate these terms in the same nine categories.

\section{Control variables}

The following variables were used as control variables.

Applicant demographic characteristics. To fully examine the effects of applicant social class, it was important to confirm that these effects were not confounded with other demographic characteristics such as an applicant's race or sex. However, it was also important to consider the effects of intersectionality. Intersectionality considers the relevance and reinforcing nature of characteristics, such as race, sex, and class, and their inability to be separated (Nash, 2008). In effect, exploring these characteristics separately neglects to fully consider their deeper implications and the experiences related to these characteristics (Crenshaw, 1989). Therefore, I examined each hypothesis by controlling and not controlling for the race and sex of each applicant.

Importance of social capital network. As discussed, perceptions of the value or purpose of a social capital network may be influenced by individuals' own social class. Therefore, after reviewing the applicant emails in the acquiring stage, participants were asked about their own perceptions of the value of a social capital network. Using a five-item scale adapted from Tucker, Kennedy, Ryan, Wenzel, Golinelli, Zazzali, and McCarty (2009), which emphasizes frequency, closeness, and types of support received from individuals. The scale ranged from $1=$ 
strongly disagree to $5=$ strongly agree, and the items were: "I believe that personal referrals provide access to job opportunities," "Knowing powerful individuals provides more access to resources," "Relying on others helps with career advancement," "I have no where to turn for job assistance," "It is important to remain in touch with individuals if you want help."

\section{CHAPTER 5: ANALYSIS \& RESULTS}

\section{Analysis overview}

This study is based on evaluations of applicants' P-O fit by hiring managers within a particular hiring process stage. Due to the nested nature of this data, a multi-level analysis was warranted (Raudenbush \& Bryk, 2002) and hypothesis testing was completed using HLM. Specifically, because of the cross-classified nature of this data, I relied on a two-level crossclassified analysis using the software program HLM (HCM2). HCM2 analysis allows for two level-2 files, and my model included the ratings of each applicant (level-1), cross-classified by two level-2 groupings, 1) hiring manager characteristics and 2) applicant characteristics. Because each hiring manager rated several applicants and each applicant received multiple ratings, using HLM allowed me to control for issues of non-independence, similar to other research with comparable designs (e.g., McCarthy et al., 2010).

\section{Sample}

Source. Although some participants were sourced through Amazon Mechanical Turk (MTurk) and some using a traditional field based sample, all participants had current or previous involvement in the hiring process (e.g., human resources professionals, hiring managers) with organizations located in the United States. To ensure adequate qualification for the survey all participants had to respond "yes" that they had previous or current involvement in the hiring 
process and that have previously or currently worked in the United States. Participants who responded "no" were removed from the survey.

Second, because M-Turk participants were incentivized to complete the survey in order to receive payment, surveys completed by M-Turk participants received additional review. Suspicious data — such as survey completions in short time frame - from the M-Turk sample were removed. Because each participant's survey was linked by a unique response code I could identify suspicious surveys and decline payment of participants without relying on any personally identifying information. However, prior to declining payment and deeming a survey suspicious, M-Turk participants were contacted via email. Some participants understood their error and responded to me with responses such as this "The error was on my end... so I'm OK with your rejecting it. No worries." Others provided a legitimate explanation such as "Thank you for bringing this to my attention - actually, I am a manager at a real estate office here in downtown Jacksonville, FL, and am called upon several times per. year to evaluate prospective candidates..." In these situations the discrepancy was clarified (i.e., adequate explanation provided) and survey response included as applicable. Participants from Amazon M-Turk who adequately completed the survey were paid $\$ 2.00$.

This recruitment resulted in 79 participants for the acquiring stage, 105 participants for the screening stage, and 220 participants for the interviewing stage. Therefore, sufficient power exists in each stage to conduct analysis.

Demographics. Table 5 provides the sample demographics for each stage (e.g., acquiring, screening, interviewing) separated by the M-Turk and professional sample. However, because I combined the M-Turk and professional samples to conduct the analysis, an overview of the demographic information is presented below. 
Seventy-eight participants completed the survey for the acquiring stage. The average age was $37.19(\mathrm{SD}=11.82)$, with males comprising $53.8 \%$ of the sample. The race and ethnicity of the sample was Asian (6.5\%), Black (5.2\%), Latino (7.8\%), Native American (1.3\%), and White (79.2\%). The majority of the sample (63.3\%) had a Bachelor's degree or above. For the screening stage, data was based on 108 participants. The average age was $39.58(\mathrm{SD}=10.17)$, with females comprising $51.4 \%$ of the sample. The race and ethnicity of the sample was Asian (6.5\%), Black (14.8\%), Latino (6.5\%), Native American (1.9\%), and White (70.4\%). The majority of the sample (72\%) had a Bachelor's degree or above. Lastly for the interviewing stage, data was based on 200 participants. The average age was $39.35(\mathrm{SD}=12.12)$, with males comprising $53.0 \%$ of the sample. The race and ethnicity of the sample was Asian (4.0\%), Black (24.6\%), Latino (6.0\%), White (62.3\%), other (1.0\%), and those who preferred not to respond $(2.0 \%)$. The majority of the sample $(65.5 \%)$ had a Bachelor's degree or above.

\section{Measures}

Scales. In addition to viewing the applicable applicant stimulus materials in each stage, participants were asked to respond to various questions. Below outlined the various scales, items, alphas, and CFAs (as applicable) for each set of questions.

Perceived P-O fit. In accordance with Chen and Lin (2014) who measured perceived P-O fit, I relied on four measures of P-O fit established by Kristof-Brown (2000). These items included: "I think this applicant is very suitable for our company", "I think this applicant is highly similar to our other company employees", "My colleagues will likely agree with me that this applicant is very suitable for our company", and "I am convinced that this applicant is suitable for our company" (ranging from $1=$ strongly disagree to $5=$ strongly agree). The 
Cronbach's alpha was .93 in the acquiring stage, .93 in the screening stage, and .90 in the interviewing stage. Therefore, the scale was considered reliable.

Hiring recommendations. Asking for hiring recommendations during the acquiring and screening stages was premature and unrealistic to participants who were only presented with email referrals and resumes. Therefore, hiring recommendations were only asked of participants who completed surveys in the interviewing stage. To ensure a minimum of three-item measure, I included a two-item measure, which followed a variation of Cable and Judge (1997) and Higgins and Judge (2004), which included the following: "I would recommend extending a job offer to this applicant" and "overall, I would evaluate this applicant positively". The final item was from Sekiguchi and Huber (2011) "I want to hire this candidate". All items will rely on a scale ranging from $1=$ strongly disagree to $5=$ strongly agree. The Cronbach's alpha was .95 .

As noted, four items or indicators were representative of perceived P-O fit and three items or indicators were representative of hiring recommendations. As these variables were collected at the same time, I conducted a confirmatory factor analysis (CFA) using AMOS 17.0 to test for discriminant validity between these two variables. Results showed that all models provided an excellent fit to the data. In the acquiring stage the model fit was $\left[\chi^{2}(2)=1.871, p=\right.$ $.392 ; \mathrm{CFI}=1.00 ; \mathrm{RMSEA}=.00]$, and all indictors loaded significantly $(\mathrm{p}<.01)$ on the hypothesized latent variable. In the screening stage the model fit was $\left[\chi^{2}(2)=4.662, p=.097\right.$; $\mathrm{CFI}=.999 ; \mathrm{RMSEA}=.017]$, and all indictors loaded significantly $(\mathrm{p}<.01)$ on the hypothesized latent variable. In the interviewing stage the two factor model of P-O fit and hiring recommendations were included. The model fit was $\left[\chi^{2}(13)=86.050, p<.001 ; C F I=.973\right.$ RMSEA $=.081]$, and all indicators loaded significantly on the hypothesized latent variables. 
Importance of social capital network. In the acquiring stage participants were asked about the importance they place on a social capital network, in short, the value they assign to social capital. I used a five-item scale adapted from Tucker, Kennedy, Ryan, Wenzel, Golinelli, Zazzali, and McCarty (2009), which included the following "I believe that personal referrals provide access to job opportunities," "Knowing powerful individuals provides more access to resources," "Relying on others helps with career advancement," "I have no where to turn for job assistance," "It is important to remain in touch with individuals if you want help" (items ranged from $1=$ strongly disagree to $5=$ strongly agree). The Cronbach's alpha was .66. However, because one item was reverse coded (e.g., item four), the reliability analysis was conducted with this item removed. Once removed, the Cronbach's alpha increased to .77. Therefore, analysis was conducted without this item and this scale was considered reliable.

Social class scale. To complement the subjective social class scale, social class was also measured using two, three-item scales from Griskevicius, Tybur, Delton, \& Robertson (2011), where participants were asked about their childhood and current or future social class. This scale included the following items: “My family usually had enough money for things when I was growing up," "I grew up in a relatively wealthy neighborhood," "I felt relatively wealthy compared to the other kids in my school." The second scale is focused on current or future social class: "I have enough money to buy things I want," "II don't need to worry too much about paying my bills," "I don't think I'll have to worry about money too much in the future' $(1=$ strongly disagree to $5=$ strongly agree). The Cronbach's alpha was . 78 in the acquiring stage, .67 in the screening stage, and .75 in the interviewing stage. Therefore, this scale was considered reliable. 


\section{Design}

I relied on an experimental vignette methodology, where I created applicant stimulus materials representative of those you would expect to review during the hiring process (e.g., referral email, resume, video interviews). Therefore, participants responded to one portion of a three-part survey, which was divided into the three stages of the hiring process (i.e., acquiring, screening, interviewing). In each stage, economic capital (upper or lower), social capital (upper or lower), cultural capital (upper or lower), applicant race (Black or White), and applicant sex (male or female) were manipulated. Thus, my study relied on a $2 \times 2 \times 2 \times 2 \times 2$, matrix design with 32 possible combinations in each stage.

To ensure that the ratings related to applicant stimulus materials were not simply due to the order or frequency in which they were presented, applicant stimulus materials were randomly presented to survey participants. This resulted in a minimal, but different, number of times each applicant was presented to survey participants, as shown in Table 6. After review and analysis of the presentation of applicants in each stage, I concluded that there were no counterbalancing effects and the random presentation of stimuli was maintained. An additional factor that contributed to the number of ratings per applicant related to the number of participants who started the survey and were presented with applicants to evaluate, but declined to complete the survey.

Levels. My study involved the P-O fit ratings of each applicant, which were dependent on hiring manager and applicant characteristics. Thus, my study relied on a cross-classified model. Applicant P-O fit ratings were level-1, and they are cross-classified by two level-2 groupings, 1) hiring manager characteristics and 2) applicant characteristics. To justify the use of a 3-level model, I calculated the percentage of variance that existed at each level. As shown in Table 7, 
enough variance was found in each stage and at each level to justify analysis as a three level model.

\section{Hypothesis Testing Overview}

Although some hypotheses were applicable to the overall hiring process (i.e., hypotheses 1, 5, and 6), while others pertained to a particular stage of the hiring process (i.e., hypotheses $2 \mathrm{a}-$ e, 3a-e, and 4a-e are specific to the acquiring, screening, and interviewing phases, respectively), I used three datasets with three files, hiring managers' ratings of applicants (level-1), hiring manager characteristics (level-2), and applicant characteristics (level-2) for each stage (e.g., acquiring stage only, screening stage only, interviewing stage only). The three files listed above contained the same information, respective of each stage. There was no overlap between samples, thus each stage of the hiring process represented a different sample. There was one level-1 file, which contained all information related to the applicant ratings. This file included my dependent variable, hiring managers' rating of applicant $\mathrm{P}-\mathrm{O}$ fit. This file also contained the supplemental dependent variable, decision to continue in the hiring process. My first level-2 file is the hiring managers' characteristics file, which contained the hiring manager's race, sex, and social class. Lastly, the second level-2 file was the applicants' characteristics file, which contained the applicant's race, sex, social class, and a dummy code for applicants' forms of capital alignment. For each sample file (i.e., the three stages), I fit a baseline or null model with no predictors to determine the percentage of outcome variance that resides at each level. Then I tested the level-1 variables (step 1), followed by the level-2 applicant variables (step 2), next the level-2 hiring manager variables (step 3), and last the cross-level interactions (step 4).

Handling missing data. All participants had the opportunity to exit or decline to complete questions while completing any of the three hiring process surveys. While missing data 
was present for all surveys, incomplete or missing demographic data was particularly

problematic in the interviewing stage. Additionally, because contact information was not collected I was unable to contact participants to request survey completion. Furthermore, the majority of participants who declined to respond to the demographic questions did so by declining to respond to questions within the entire section. As such, I could not reasonably assign a value for a participant's sex or race based on other provided information. Therefore, I was unable to use techniques such as data imputation, which describes the process where data are “simulated" based on other available information (Fichman \& Cummings, 2003, p. 283). As such, additional steps were performed to ensure retention of as many surveys as possible for analysis.

First, I determined why the data were missing. I conducted a supplemental analysis in SPSS to determine if there was a relationship between the applicants evaluated by participants and their demographic characteristics (e.g., sex, race, social class). No relationship was determined to exist. Thus, I determined the missing data to be missing at random (MAR). MAR data are defined as "unrelated to the underlying values of missing data but can be related to the outcomes as long as there are other observed variables that capture or control for the cause of missingness" (Jelicic, Phelps, \& Lerner, 2009, p. 1196).

Second, I confirmed if the missing data were relevant in hypothesis testing. I uploaded the data files with the hiring manager demographic information, which resulted in 189 rows of data. After testing the baseline model, I added in all control variables including hiring manager race and sex. Hiring manager race and sex were not significant. I then tested all hypotheses and the hiring managers' race and sex were not significant in any of the hypotheses. Additionally, in comparing the datasets, both were quite similar regarding the percentage of variance. In the 
dataset with 189 hiring managers, $73 \%$ percent variance was found at level-3, 23\% at level-2, and 5\% at level-1 was found. Considering the above I thereby concluded that the hiring managers' race and sex did not significantly contribute to the evaluation of the applicants presented in the interviewing stage. Because the social class of the hiring manager was the only demographic characteristic directly considered in a hypothesis (i.e., hypothesis five), I relied on the "complete" dataset, which contained data from 189 hiring managers, including their demographic data, for hypothesis five. For the remaining hypotheses pertaining to the interviewing stage (e.g., hypotheses one, four, and six), I relied on data from the "majority" dataset, which contained data from 220 hiring managers, but without their demographic characteristics. I found this to be adequate treatment of the data because imputing the data would have meant I would be making assumptions about the sex, race, or social class of hiring managers solely based on their P-O fit evaluations of applicants. Particularly because hiring managers' demographic characteristics were found to be not significant, simulating data in this fashion may have impacted my results.

Lastly, I considered why missing demographic data may have occurred more in the interviewing stage as compared to the prior two stages. I suggest that the placement of the demographic questions and overall length of the survey contributed to the decreased response. Questions related to demographic characteristics occurred at the end of the survey. Because responses were not mandatory, it is likely that some participants determined the main purpose of the survey to have concluded and left the remainder of the survey incomplete. Second, while the applicant stimulus materials in the acquiring and screening stages resembled commonly formatted documents, the applicant stimulus material in the interviewing stage (i.e., interview video) may have required additional attention and time from the survey participant. While the 
average time hiring managers spend reviewing a resume is 6.25 seconds (The Ladders, 2012) the videos embedded in the survey ranged from two to five minutes. Therefore, despite reviewing only four videos as compared to ten resumes or 16 emails in the prior two stages, the interviewing stage survey may have been markedly longer for survey participants to complete. Considering these obstacles, having missing demographic data during this stage was expected.

\section{Results}

Correlations. Means, standard deviations, and correlations for each stage are presented in Tables 8 through 10 .

Acquiring stage. In the acquiring stage (Table 8), internal reliabilities are presented in parenthesis, and ranged from .77 to .93 .

The dependent variable perceived P-O fit was collected using a four-item measure and decision to continue in the hiring process was collected using a one-item measure. As predicted these variables were highly correlated $(\mathrm{r}=.760, \mathrm{p}<.01)$. As such, and accordance with the hypotheses, I rely on perceived P-O fit as my dependent variable throughout the remainder of the analysis for the acquiring stage.

Other significant correlations to the dependent variable perceived P-O fit included, economic capital $(\mathrm{r}=.118, \mathrm{p}<.01)$, social capital $(\mathrm{r}=.111, \mathrm{p}<.01)$, hiring managers' social class - scale $(\mathrm{r}=.082, \mathrm{p}<.01)$, hiring managers' value of social capital $(\mathrm{r}=-.085, \mathrm{p}<.01)$, and hiring managers' sex $(r=.062, \mathrm{p}<.05)$. Lastly, hiring managers' race was significantly correlated with applicants' social capital $(r=-.073, \mathrm{p}<.05)$.

Screening stage. In the screening stage (Table 9), internal reliabilities are presented in parenthesis, and ranged from .67 to .93 . 
The dependent variable perceived P-O fit was collected using a four-item measure and decision to continue in the hiring process was collected using a one-item measure. As predicted these variables were highly correlated $(\mathrm{r}=.805, \mathrm{p}<.01)$. As such, and accordance with the hypotheses, I relied on perceived P-O fit as my dependent variable throughout the remainder of the analysis for the screening stage.

Other significant correlations to the dependent variable, perceived P-O fit, included economic capital $(\mathrm{r}=-.153, \mathrm{p}<.01)$, cultural capital $(\mathrm{r}=.122, \mathrm{p}<.01)$, hiring managers' social class - ruler $(\mathrm{r}=.062, \mathrm{p}<.05)$, hiring managers' social class - scale $(\mathrm{r}=.118, \mathrm{p}<.01)$, hiring managers' race $(\mathrm{r}=.073, \mathrm{p}<.05)$. Additional significant correlations related to hiring manager demographic characteristics. Hiring managers' social class - scale was significantly correlated with hiring managers' social class - ruler $(\mathrm{r}=.451, \mathrm{p}<.01)$. Hiring managers' race was significantly correlated with hiring managers' social class - ruler $(r=.073, p<.05)$ and hiring managers' social class - scale $(\mathrm{r}=.149, \mathrm{p}<.01)$. Hiring managers' sex was significantly correlated with hiring managers' social class $-\operatorname{ruler}(r=-.096, \mathrm{p}<.01)$ and hiring managers' social class - scale $(\mathrm{r}=-.110, \mathrm{p}<.01)$.

Interviewing stage. In the interviewing stage (Table 10), internal reliabilities are presented in parenthesis, and ranged from .75 to .95 .

The dependent variable, perceived P-O fit, was collected using a four-item measure. Decision to continue in the hiring process was collected using a one-item measure and hiring recommendations were collected using a three-item measure. As predicted perceived P-O fit was highly correlated with the decision to continue in the hiring process $(\mathrm{r}=.858, \mathrm{p}<.01)$ and hiring recommendations $(\mathrm{r}=.891, \mathrm{p}<.01)$. As such, and accordance with the hypotheses, I relied on 
perceived P-O fit as my dependent variable throughout the remainder of the analysis for the screening stage.

Other significant correlations to the dependent variable perceived P-O fit included, economic capital $(\mathrm{r}=-.732, \mathrm{p}<.01)$, cultural capital $(\mathrm{r}=.072, \mathrm{p}<.05)$, applicants' race $(\mathrm{r}=$ $.078, \mathrm{p}<.01)$, applicants' sex $(\mathrm{r}=.113, \mathrm{p}<.01)$, hiring managers' social class - ruler $(\mathrm{r}=.095, \mathrm{p}$ $<.05)$, and hiring managers' social class - scale $(\mathrm{r}=.094, \mathrm{p}<.01)$. Additional significant correlations related to hiring manager demographic characteristics. Hiring managers' social class - scale was significantly correlated with hiring managers' social class - ruler $(r=.788, p<.01)$. Hiring managers' sex was significantly correlated with hiring managers' social class - scale $(r=$ $.084, \mathrm{p}<.05)$.

Hypothesis tests. Because of the study format, analysis was conducted separately for each hiring stage (e.g., acquiring, screening, interviewing). As such, the same steps and were repeated in each hiring stage and the same model equations were used in each stage. Therefore, I present the results by hiring stage and present the model equations once. I rely on a $p<.05$ significance level throughout the analysis.

Acquiring stage. Models for the acquiring stage are presented in Tables 11a-c. First, I fit a baseline null model to determine the percentage of variance that existed at each level.

Level-1: $\quad$ PO_PERC $C_{i j k}=\pi_{0 j k}+e_{i j k}$ where:

\section{PO_PERC $=$ Perceptions of applicant P-O fit}

Thirty-eight percent variance was found at level-3, 58\% at level-2, and $4 \%$ at level-1, which was enough variance was found to justify the use of a 3-level model. 
Next, hiring manager and applicant control variables (e.g., race, sex, value of social capital) were added to the model.

Level-1: $\quad$ PO_PERC $C_{i j k}=\pi_{0 j k}+e_{i j k}$

Level-2: $\quad \pi_{0 j k}=\theta_{0}+b_{00 j}+c_{00 k}$

$+\left(\gamma_{01}\right) * S E X_{j}$

$+\left(\gamma_{02}\right) * R A C E_{j}$

$+\left(\gamma_{03}\right) * S C A P V A L_{j}$

$+\left(\beta_{01}\right) * A P P_{-} R A C E_{k}$

$+\left(\beta_{02}\right) * A P P \_S E X_{k}$

where:

$$
\begin{aligned}
& \text { SEX = Hiring managers' sex } \\
& \text { RACE = Hiring managers' race } \\
& \text { SCAPVAL = Hiring managers' value of social capital } \\
& \text { APP_RACE = Applicants' race } \\
& \text { APP_SEX = Applicants' sex }
\end{aligned}
$$

As shown in Model 1, none of the control variables were significant. These variables contributed $18 \%$ of the variance and were left in the model throughout the remaining hypothesis tests.

To test hypothesis one, the applicant average capital variable was entered into the model.

Level-1: $\quad P O \_P E R C_{i j k}=\pi_{0 j k}+e_{i j k}$

Level-2: $\quad \pi_{0 j k}=\theta_{0}+b_{00 j}+c_{00 k}$

$$
+\left(\gamma_{01}\right) * S E X_{j}
$$

$+\left(\gamma_{02}\right) * R A C E_{j}$ 


$$
\begin{aligned}
& +\left(\gamma_{03}\right)^{*} S C A P V A L_{j} \\
& +\left(\beta_{01}\right)^{*} A V G C A P_{k} \\
& +\left(\beta_{02}\right) * A P P_{-} R A C E_{k} \\
& +\left(\beta_{03}\right) * A P P \_S E X_{k}
\end{aligned}
$$

where:

$$
\text { AVGCAP }=\text { Applicants' average forms of capital }
$$

As shown in Model 2, this was significant $(\gamma=.49$, S.E. $=.05, \mathrm{p}<.001)$, which accounted for $21 \%$ of the variance, and provided support for hypothesis one. These results are consistent with an interpretation that hiring managers are more likely to perceive upper class applicants with a higher P-O fit as compared to their lower class counterparts.

To test hypothesis two a through e, all three forms of capital (e.g., economic, social, cultural) were added into the model.

Level-1: $\quad$ PO_PERC $C_{i j k}=\pi_{0 j k}+e_{i j k}$

Level-2: $\quad \pi_{0 j k}=\theta_{0}+b_{00 j}+c_{00 k}$

$$
\begin{aligned}
& +\left(\gamma_{01}\right) * S E X_{j} \\
& +\left(\gamma_{02}\right) * R A C E_{j} \\
& +\left(\gamma_{03}\right)^{*} S C A P V A L_{j} \\
& +\left(\beta_{01}\right)^{*} E C_{k} \\
& +\left(\beta_{02}\right)^{*} S C_{k} \\
& +\left(\beta_{03}\right)^{*} C C_{k} \\
& +\left(\beta_{04}\right)^{*} A P P_{-} R A C E_{k}
\end{aligned}
$$




$$
+\left(\beta_{05}\right) * A P P \_S E X_{k}
$$

where:

$$
\begin{aligned}
& \mathrm{EC}=\text { Applicants' economic capital } \\
& \mathrm{SC}=\text { Applicants' social capital } \\
& \mathrm{CC}=\text { Applicants' cultural capital }
\end{aligned}
$$

As shown in Model 3, introducing each form of capital into the model did not result in a change to $\mathrm{R}^{2}\left(\sim \Delta \mathrm{R}^{2}=.00\right)$. Each form of capital, economic $(\gamma=.16$, S.E. $=.03, \mathrm{p}<.001)$, social $(\gamma=.22$,

S.E. $=.03, \mathrm{p}<.001)$, and cultural $(\gamma=.11$, S.E. $=.03, \mathrm{p}<.001)$ was significant, providing support for hypothesis two a through c. These results are consistent with an interpretation that each form of capital contributes to hiring managers' perceptions of applicant P-O fit.

Next, additional hypothesis testing was performed to confirm that each form of capital was distinct from each other. The model deviance (1982.955) and number of parameters (10) were entered, and each form of capital was constrained to one. Chi-square was found to be greater than $3.84\left(\Delta \chi^{2}=98.467, \mathrm{df}=1, \mathrm{p}<.001\right)$, signaling that each form of capital was distinct from one another. Additional analysis constrained two forms of capital at a time to specifically compare to social capital and economic capital $\left(\Delta \chi^{2}=90.332, \mathrm{df}=1, \mathrm{p}<.001\right)$ and social capital and cultural capital $\left(\Delta \chi^{2}=66.904, \mathrm{df}=1, \mathrm{p}<.001\right)$. As chi-square remained significant for each, these three forms of capital were determined to be distinct from each other. Therefore, social capital had the strongest positive relationship in the acquiring stage, offering further support for hypothesis $2 \mathrm{~d}$ and $2 \mathrm{e}$.

To test hypothesis five, applicants and hiring managers' social class were entered into the model (Model 4a), and then an interaction between the two variables (Model 4b) was entered. First, applicants' social class was dichotomized into an upper and lower class designation 
represented by ULCODE. Next, hiring managers' social class was entered using the social class scale, SCLASS. Last, the interaction between ULCODE x SCLASS was entered into the model.

Level-1: $\quad$ PO_PERC $C_{i j k}=\pi_{0 j k}+e_{i j k}$

Level-2: $\quad \pi_{0 j k}=\theta_{0}+b_{00 j}+c_{00 k}+\left(\gamma_{01}\right)^{*} S E X_{j}$

$+\left(\gamma_{01}\right) * S E X_{j}$

$+\left(\gamma_{02}\right) * R A C E_{j}$

$+\left(\gamma_{03}\right) * S C A P V A L_{j}$

$+\left(\gamma_{04}\right) * S C L A S S_{j}$

$+\left(\beta_{01}\right) * A P P_{-} R A C E_{k}$

$+\left(\beta_{02}\right) * A P P \_S E X_{k}$

$+\left(\beta_{03}\right) * U L C O D E_{k}$

$+\operatorname{SCLASS}_{j}^{*} U L C O D E_{k}^{*} \gamma_{05}$

where:

$$
\begin{aligned}
& \text { SCLASS }=\text { Hiring managers' social class } \\
& \text { ULCODE }=\text { Applicants' social class designation }
\end{aligned}
$$

As shown in Model $4 \mathrm{~b}$ and graphically in Figure 7, introducing these variables into the model did not result in a change to $\mathrm{R}^{2}\left(\sim \Delta \mathrm{R}^{2}=.00\right)$. However, the interaction between applicants and hiring managers' social class was significant $(\gamma=.07$, S.E. $=.04, \mathrm{p}<.05)$. Therefore, hypothesis five was supported. These results are consistent with an interpretation that hiring managers' social class may significantly impact perceptions of applicants' P-O fit during the acquiring stage. 
To test hypothesis six, the applicants' social class designation (ULCODE) and the dummy code for whether the forms of capital conflict (CONFLICT) were entered into the model, as shown in Model 5a. Next, an interaction term (INT) between these two variables was entered into the model, as shown in Model 5b.

Level-1: $\quad$ PO_PERC $C_{i j k}=\pi_{0 j k}+e_{i j k}$

Level-2: $\quad \pi_{0 j k}=\theta_{0}+b_{00 j}+c_{00 k}$

$$
\begin{aligned}
& +\left(\gamma_{01}\right) * S E X_{j} \\
& +\left(\gamma_{02}\right) * R A C E_{j} \\
& +\left(\gamma_{03}\right)^{*} S C A P V A L_{j} \\
& +\left(\beta_{01}\right)^{*} A P P_{-} R A C E_{k} \\
& +\left(\beta_{02}\right)^{*} A P P \_S E X_{k} \\
& +\left(\beta_{03}\right)^{*} U L C O D E_{k} \\
& +\left(\beta_{04}\right)^{*} C O N F L I C T_{k} \\
& +\left(\beta_{05}\right)^{*} I N T_{k}
\end{aligned}
$$

where:

CONFLICT $=$ Presence or absence of applicant conflicting forms of capital INT = Interaction term between applicants' social class designation and the presence or absence of conflicting forms of capital

As shown in Model 5b and graphically in Figure 8, introducing these variables into the model did not result in a change to $\mathrm{R}^{2}\left(\sim \Delta \mathrm{R}^{2}=.00\right)$. However, the interaction term was significant and negative $(\gamma=-.32$, S.E. $=.07, p<.001)$, thereby supporting hypothesis six. These results are 
consistent with an interpretation that the presence of conflicting forms of capital will weaken hiring managers' perceptions of applicants' P-O fit.

Exploratory analysis. Additional analysis was conducted on hypothesis six to determine how receipt of conflicting social class information may differ depending on the form of capital. As such, an interaction term was computed with each form of capital and then each form of capital and its respective interaction term was tested separately, as shown in Model X.

Level-1: $\quad$ PO_PERC $C_{i j k}=\pi_{0 j k}+e_{i j k}$

Level-2: $\quad \pi_{0 j k}=\theta_{0}+b_{00 j}+c_{00 k}$

$$
\begin{aligned}
& +\left(\gamma_{01}\right) * S E X_{j} \\
& +\left(\gamma_{02}\right) * R A C E_{j} \\
& +\left(\gamma_{03}\right) * S C A P V A L_{j} \\
& +\left(\beta_{01}\right) * E C_{k} \\
& +\left(\beta_{02}\right) * A P P \_R A C E_{k} \\
& +\left(\beta_{03}\right) * A P P \_S E X_{k} \\
& +\left(\beta_{04}\right) * C O N F L I C T_{k} \\
& +\left(\beta_{05}\right) * E C I N T_{k}
\end{aligned}
$$

where:

ECINT $=$ Interaction term between economic capital and conflict This model equation was repeated with social and cultural capital, thus:

SCINT $=$ Interaction term between social capital and conflict

CCINT $=$ Interaction term between cultural capital and conflict 
As shown in Models 5c through 5e, the interaction term was significant and negative for all three forms of capital, economic $(\gamma=-.44$, S.E. $=.09, \mathrm{p}<.001)$, social $(\gamma=-.35$, S.E. $=.08, \mathrm{p}<.001)$, and cultural $(\gamma=-.51$, S.E. $=.09, \mathrm{p}<.001)$. Introducing these variables into the model resulted in a slight decrease to $R^{2}\left(\sim \Delta R^{2}=-.01\right)$, explaining $20 \%$ of the variance, as compared to when all forms of capital are considered in total. These results are consistent with an interpretation that conflicting forms of capital may attenuate perceptions of applicant P-O fit, with conflicting cultural capital information resulting in the most pronounced negative effect.

Screening stage. Models for the screening stage are presented in Tables 12a-c. First, I fit a baseline null model to determine the percentage of variance that existed at each level.

Sixty-six percent variance was found at level-3, 29\% at level-2, and 4\% at level-1, which was enough variance was found to justify the use of a 3-level model.

Next, hiring manager control variables (e.g., race, sex) were added to the model and applicant control variables (e.g., race, sex) were added to the model. As shown in Model 6, none of the control variables were significant. These variables contributed $31 \%$ of the variance and were left in the model throughout the remaining hypothesis tests.

To test hypothesis one, the applicant average capital variable was entered into the model. As shown in Model 7, this was not significant $(\gamma=-.10$, S.E. $=.11, n s)$. These results are consistent with an interpretation that during the screening stage, upper class applicants are not viewed with a higher P-O fit as compared to their lower class counterparts. Hypothesis one was not supported in the screening stage.

To test hypothesis three a through c, all three forms of capital (e.g., economic, social, cultural) were added into the model. As shown in Model 8, introducing these variables into the model resulted in a change to $\mathrm{R}^{2}\left(\sim \Delta \mathrm{R}^{2}=.03\right)$, explaining $35 \%$ of the variance. Economic capital 
was significant, but in the opposite direction that was hypothesized $(\gamma=-.26$, S.E. $=.04, p<$ $.001)$. Therefore, hypothesis 3 a was not supported. Social capital was not significant $(\gamma=-.01$, S.E. $=.04, n s)$, Therefore, hypothesis $3 \mathrm{~b}$ was not supported. Cultural capital was significant and in the direction as hypothesized $(\gamma=.17$, S.E. $=.04, \mathrm{p}<.001)$, therefore, hypothesis $3 \mathrm{c}$ was supported. These results are consistent with an interpretation that cultural and economic capital may operate differently in the interviewing stage. Specifically, while cultural capital positively relates to hiring managers' perceptions of applicants' $\mathrm{P}-\mathrm{O}$ fit, economic capital perceived to deviate from the average expected salary may negatively impact perceptions of fit.

Supplemental analysis was conducted to confirm that each form of capital was distinct from each other. The model deviance (1986.888) and number of parameters (9) were entered, and each form of capital was constrained to one. Chi-square was found to be less than 3.84 ( $\Delta \chi^{2}$ $=2.28, \mathrm{df}=1, n s)$, signaling that each form of capital was not distinct from one another. Additional analysis constrained two forms of capital at a time. Social and cultural capital $\left(\Delta \chi^{2}=\right.$ 9.335, $\mathrm{df}=1, \mathrm{p}<.05)$ were significant, however, economic capital and social capital $\left(\Delta \chi^{2}=\right.$ 27.112, $\mathrm{df}=1, \mathrm{p}<.001)$ and economic capital and cultural capital $\left(\Delta \chi^{2}=2.419, \mathrm{df}=1, n s\right)$ were not significant.

To test hypothesis five, applicants and hiring managers' social class were entered into the model (Model 9a), and then an interaction between the two variables (Model 9b) was entered. First, applicants' social class was dichotomized into an upper and lower class designation represented by ULCODE. Next, hiring managers' social class was entered using the social class scale, SCLASS. Last, the interaction between ULCODE x SCLASS was entered into the model. As shown in Model 9b and graphically in Figure 9, the interaction between applicants and hiring managers' social class was not significant $(\gamma=.02$, S.E. $=.06, n s)$. These results are consistent 
with an interpretation that hiring managers' social class may not significantly impact perceptions of applicants' P-O fit during the screening stage. Hypothesis five was not supported.

To test hypothesis six, the applicants' social class designation (ULCODE) and the dummy code for whether the forms of capital conflict (CONFLICT) were entered into the model, as shown in Model 10a. Next, an interaction term (INT) between these two variables was entered into the model. As shown in Model 10b and graphically in Figure 10, the interaction term was not significant $(\gamma=-.02$, S.E. $=.23, n s)$, thus hypothesis six was not supported. These results suggest that during the screening stage the presence of conflicting forms of capital may not significantly influence hiring managers' perceptions of applicants' P-O fit.

Exploratory analysis. Additional analysis was conducted on hypothesis six to determine whether the conflicts related to the different forms of capital may impact hiring managers' perceptions. As such, an interaction term was computed with each form of capital and then each form of capital and its respective interaction term was tested separately. As shown in Models 10c through 10e, the interaction term was significant and negative for economic capital $(\gamma=-.22$, S.E. $=.09, \mathrm{p}<.05)$. The interaction term was significant and positive for cultural capital $(\gamma=.36$, S.E. $=.11, \mathrm{p}<.01)$. The interaction term was not significant for social capital $(\gamma=.11$, S.E. $=$ $.15, n s)$. Introducing economic and cultural capital into the model resulted in a change to $\mathrm{R}^{2}$ $\left(\sim \Delta \mathrm{R}^{2}=.02\right)$, respectively, explaining $34 \%$ of the variance. Therefore, the presence of conflicting economic and cultural capital information influences hiring managers' perceptions of applicant $\mathrm{P}-\mathrm{O}$ fit, resulting in a weakened or strengthened perception of $\mathrm{P}-\mathrm{O}$ fit, respectively.

Interviewing stage. Models for the interviewing stage are presented in Tables 13a-c. As previously discussed, analysis was conducted using data from 220 hiring managers (i.e., large dataset) with the exception of hypothesis five, which relied on data from 189 hiring managers 
(i.e., abbreviated dataset). It should be noted that both datasets were used to fit baseline models and determine the significance of control variables.

First, I fit a baseline null model to determine the percentage of variance that existed at each level.

Seventy-two percent variance was found at level-3, 23\% at level-2, and 5\% at level-1, which was enough variance was found to justify the use of a 3-level model.

Next, using the abbreviated dataset hiring manager control variables (e.g., race, sex) and applicant control variables (e.g., race, sex) were added to the model. As shown in Model 11a, applicant sex was significant $(\gamma=.22$, S.E. $=.08, \mathrm{p}<.05)$ and resulted explaining $5 \%$ of the variance. As hiring manager race and sex were not significant they were removed from the model, which allowed use of the large dataset for remaining hypothesis tests. All applicant control variables were left in the model throughout the remaining hypothesis tests.

To test hypothesis one, the applicant average capital variable was entered into the model. As shown in Model 12, this was not significant $(\gamma=.01$, S.E. $=.15, n s)$ and did not result in a change to $\mathrm{R}^{2}\left(\sim \Delta \mathrm{R}^{2}=.00\right)$. These results are consistent with an interpretation that upper class applicants are not viewed with a higher P-O fit as compared to their lower class counterparts during the interviewing stage. Therefore, hypothesis one was not supported in this stage.

To test hypothesis four a through e, all three forms of capital (e.g., economic, social, cultural) were added into the model. As shown in Model 13, introducing these variables into the model resulted in a change to $\mathrm{R}^{2}\left(\sim \Delta \mathrm{R}^{2}=.02\right)$, accounting for $7 \%$ of the variance. Economic capital was significant, but in the opposite direction that was hypothesized $(\gamma=-.20$, S.E. $=.07, \mathrm{p}$ $<.05)$. Social capital $(\gamma=.07$, S.E. $=.07, n s)$ and cultural capital $(\gamma=.13$, S.E. $=.07, n s)$ were not significant. These results suggest that economic capital that is representative of upper class 
may be perceived by hiring managers with a lower perception of P-O fit. Whereas, applicants' social and cultural capital does not contribute to hiring managers' perception of P-O fit. Therefore, hypothesis four a through $\mathrm{c}$ were not supported. Consequently, because cultural capital was not significant or positively related to perceptions of applicant P-O fit, hypotheses four $\mathrm{d}$ and e are also not supported.

Supplemental analysis was conducted to confirm that each form of capital was distinct from each other. The model deviance (2152.13) and number of parameters (9) were entered, and each form of capital was constrained to one. Chi-square was found to be less than $3.84\left(\Delta \chi^{2}=\right.$ $.005, \mathrm{df}=1, n s$ ), signaling that each form of capital was not distinct from one another. Additional analysis constrained two forms of capital at a time. Chi-square was significant for social and cultural capital $\left(\Delta \chi^{2}=4.53, \mathrm{df}=1, \mathrm{p}<.05\right)$. Comparisons between economic capital and cultural capital $\left(\Delta \chi^{2}=0.43, \mathrm{df}=1, n s\right)$ and economic capital and social capital $\left(\Delta \chi^{2}=1.57, \mathrm{df}=1, n s\right)$ were not significant.

To test hypothesis five, the abbreviated dataset was used and applicants and hiring managers' social class were entered into the model (Model 14a), and then an interaction between the two variables (Model 14b) was entered. First, applicants' social class was dichotomized into an upper and lower class designation represented by ULCODE. Next, hiring managers' social class was entered using the social class scale, SCLASS. Last, the interaction between ULCODE x SCLASS was entered into the model. As shown in Model 14b and graphically in Figure 11, the interaction between applicants and hiring managers' social class was not significant $(\gamma=-.14$, S.E. $=.08, n s)$ and a change to $\mathrm{R}^{2}\left(\sim \Delta \mathrm{R}^{2}=.07\right)$ accounting for $12 \%$ of the variance. However, as this effect was not significant, hiring managers' social class may not impact perceptions of applicants' P-O fit during the interviewing stage. Hypothesis five was not supported. 
To test hypothesis six, the applicants' social class designation (ULCODE) and the dummy code for whether the forms of capital conflict (CONFLICT) were entered into the model, as shown in Model 15a. Next, an interaction term (INT) between these two variables was entered into the model. As shown in Model 15b and graphically in Figure 12, the interaction term was not significant $(\gamma=.04$, S.E. $=.04, n s)$ and a change to $\mathrm{R}^{2}\left(\sim \Delta \mathrm{R}^{2}=.01\right)$ accounting for $12 \%$ of the variance, thus hypothesis six was not supported. Therefore, during the interviewing stage the presence of conflicting forms of capital may not significantly influence hiring managers' perceptions of applicants' P-O fit.

Exploratory analysis. Additional analysis was conducted on hypothesis six to determine whether the conflicts related to the different forms of capital may impact hiring managers' perceptions. As such, an interaction term was computed with each form of capital and then each form of capital and its respective interaction term was tested separately. The interaction terms for economic capital $(\gamma=-.18$, S.E. $=.16, n s)$ as shown in Model 15c, social capital $(\gamma=.19$, S.E. $=$ $.18, n s)$ as shown in Model 15d, and cultural capital $(\gamma=.27$, S.E. $=.17, n s)$ as shown in Model

$15 \mathrm{e}$, were not significant. Therefore, the presence of conflicting forms of capital information may not significantly influence hiring managers' perceptions of applicant P-O fit.

An overview of the supported and not supported hypotheses is presented in a condensed and detailed summary shown in Tables 15 and 16.

\section{CHAPTER 6: DISCUSSION, IMPLICATIONS, \& CONCLUSION}

Hiring managers consider a variety of non-job related factors as they evaluate applicants.

The findings of this dissertation suggest that social class is yet another demographic characteristic that may influence perceptions of fit. Although social class has been a relatively 
understudied demographic characteristic in the management literature, social class is relevant in the hiring process - particularly within the first stage. In the acquiring stage, hiring managers rated upper class applicants with higher levels of P-O fit as compared to their lower class counterparts. These effects occurred regardless of the race or sex of the applicant and hiring manager. This means that lower class applicants may be excluded from the selection process before the process even really gets started.

All forms of capital (e.g., economic, social, cultural) that comprise social class were detected and used by hiring managers to assess the P-O fit of applicants, and social capital emerged as the most salient. While hiring managers considered and relied on information pertaining to income and activities to be relevant when assessing fit, hiring managers considered the position of the individual who was referring the applicant to be more important than how the referred employee and applicant interacted or the applicant's salary requirement. Organizations should be satisfied to know that despite being presented with numerous pieces of information, hiring managers are able to parse out and prioritize information they deem to be most or least relevant. On the other hand, organizations should be aware that hiring managers may be parsing out and considering information that should be considered irrelevant. The impact to P-O fit ratings was even more pronounced when accounting for the social class of the hiring managers. Upper class hiring managers provided the most disparate ratings, such that upper class applicants were perceived with the highest $\mathrm{P}-\mathrm{O}$ fit and lower class applicants were perceived with the lowest P-O fit. Conversely, lower class hiring managers seemed to hedge a bit, providing more moderate ratings of all applicants. These results support the general more communal nature of lower class individuals, such that they may be foremost concerned with creating a collegial atmosphere rather than indicating an extreme preference in either direction. Finally, when 
applicants had conflicting forms of capital making applicants' social class difficult to assess, P-O fit ratings became less pronounced than when the applicant was clearly perceived to be upper or lower class. Taken together, hiring managers were aware and considered applicant social class during the acquiring stage as they made assessments of P-O fit.

During the screening stage, social class had a smaller influence in the selection process. Although upper class applicants were not rated with higher levels of P-O fit during the screening stage, cultural, and economic capital were still detected and used by hiring managers when assessing applicant $\mathrm{P}-\mathrm{O}$ fit. It is often suggested that providing personal interests and hobbies on a resume is optional. Applicants should know that if they opt to provide this information, hiring managers may use it when assessing applicant fit. While cultural capital was positive as hypothesized, economic capital had a significant but negative relationship. This may signal that hiring managers considered income information to be relevant, particularly when salary history and requirements are deviate from the average for the position. In accordance with my results from the construct clarity study, economic capital was solely represented by income. Therefore, inclusion of other factors such as education or occupation may have impacted these results. Lastly, contrary to the results found in the acquiring stage, the social class of the hiring manager and applicants' conflicting forms of capital did not result in significant effects. Although applicant resumes highlight information visually, they may not allow hiring managers to easily detect social class similarity or applicants' conflicting forms of capital.

The interviewing stage yielded the least significant results, with the exception of applicant sex, which was significant for the first time during this stage. Therefore, despite the use of gender specific names throughout the study, visually seeing the applicant resulted in females as the preferred candidate for a gender-neutral position. In this stage, $\mathrm{P}-\mathrm{O}$ fit ratings were not 
significantly different for upper or lower class applicants. Similar to the screening stage, economic capital was significant and in the opposite direction as hypothesized, however social and cultural capital were not significant. The cultural capital cues used in this study (e.g., beliefs and behaviors) did not impact hiring manager perceptions during the interviewing stage. As such, certain cultural capital cues may be more or less salient depending on the context. Additionally, and consistent with the results in the screening stage, the social class of the hiring manager and applicants' conflicting forms of capital did not result in significant effects. Overall, the richness of information provided in this stage (e.g., visual, audio) may have decreased the salience of many social class cues perceived and used by hiring managers to evaluate applicant P-O fit.

Another important aspect of this study was the significance—or lack thereof—of applicant race and sex. Previous studies (e.g., Bertrand \& Mullainathan, 2003; Fernandez \& Fernandez-Mateo, 2006; Taber, 2003) have found significant effects related to race and sex and hiring decisions. Because of these prior effects I manipulated applicant race and sex in my study design. In the acquiring and screening stages I highlighted both race and sex using names. In the interviewing stage both race and sex were visible. Similar to prior studies, I selected names that could easily be determined to be Black or White and male or female. However, unlike prior studies, I relied on the most popular baby names by race rather than stereotypical names to highlight race. As an example, "Jada" was included as a Black female name, but "Keisha" was not selected. Although "Keisha" is representative of a Black female, it may also be representative of a negative, stereotypical image of Black females. Stereotypical images of Black women that describe them as "Baby Mamas", unhealthy, or uneducated occur much more frequently in the media than positive images (Leger, 2013). The result was that race did not have an effect on 
perceptions of applicant P-O fit in any stage. Applicant sex was only found to be significant in the interviewing stage.

It should be noted that this study does not negate the impact of race or sex in selection decisions, but instead this study may help parse out subtle nuances. It may be that applicant race does not necessarily result in lower perceptions of applicant fit, but instead stereotypical racial names (e.g., Keisha), which were used in prior resume based studies (e.g., Bertrand \& Mullainathan, 2003) may trigger negative stereotypical perceptions that decrease perceptions of P-O fit. To combat sex stereotypes, I selected a gender-neutral position. Hiring managers only found sex to be significant when they could actually see the applicants, and females were preferred . Despite this significant finding, because it was only present during the interviewing stage, other factors (e.g., attractiveness; Marlowe, Schneider, \& Nelson, 1996; Tews, Stafford, \& Zhu, 2009) may have influenced the results.

In addition to the above, the generally non-significant findings related to race and sex also helps to highlight the importance of considering social class. As discussed, social class is a multi-dimensional construct, which is correlated with other demographic factors such as race and sex. However, without differentiating between social class and other demographic factors it is likely that some of our current findings within diversity research may be representative of a confounding between social class and other demographic characteristics. This may help to explain the numerous mixed results found within the diversity literature. For instance, individuals may associate race with a particular social class (Coates, 2016). Thus, it may be the combination of that information, rather than race or sex alone that drives perceptions and behaviors. Although in practice we may be unable to separate these factors, it is important for researchers to create distinction among variables to capture the effects of demographic factors. 
Similar to other studies related to diversity within the selection process, the results of this study were mixed. However, unlike other studies, the results emphasize that demographic characteristics may have disproportionate effects depending on the selection stage. The significance of applicant social class during the first selection stage means that applicants of lower social class may be exited from the hiring process prior to even having their qualifications reviewed for a position. This effect is concerning from an applicant, organizational, and larger societal perspective. Lower class applicants may find their job search process to be longer and more unsuccessful. Organizations may find they are less able to achieve social class diversity among their employees. Society may find a greater number of lower class individuals who are unemployed, underemployed, or in temporary positions. These implications may help to explain why lower class individuals remain lower class.

With this said, we should not assume that achieving social class diversity in hiring is something organizations aspire to do. In accordance with theories such as ASA (Schneider, 1987), organizations may actually desire homogeneity. In fact, some organizations may prefer to rely on social class cues to maintain a particular culture and limit disruption. As noted, social class influences values and behaviors, so utilizing social class information during the hiring process may provide hiring managers with additional insight into an applicant, over and above what is presented in their application materials. Secondly, social class is not a protected category (EEOC, 2014), nor a diversity characteristic reported on an organization's EEO-1 survey form ${ }^{2}$ (EEOC, 2015). Instead, it is a demographic characteristic that hiring managers could legally consider during the selection process. Thus, organizations may believe there is a high-risk, low reward by introducing individuals who substantially differ in values and networks. Instead, lower

\footnotetext{
${ }^{2}$ The EEO-1 Survey is a compliance survey employers are required to complete detailing their employees by race/ethnicity, sex, and job category.
} 
class individuals may be encouraged to adopt upper class perspectives, even those that are in conflict with their own, in an attempt to "fit in", similar to the facades of conformity effect described by Hewlin (2003). Those who fail to do so may continue to be overlooked during the hiring process without any recourse.

While the results of this study did not fully support all hypotheses, I would suggest that hiring managers rely on a combination of information to form perceptions of social class and P-

$\mathrm{O}$ fit. This may have been particularly true in the screening and interviewing stages, where more information about applicants was provided to hiring managers. The ability of hiring managers to go beyond demographic characteristics when assessing applicants signal tremendous progress as related to the issues of diversity and hiring. With that said, the significant results indicate that applicants should still remain cognizant of how their demographic characteristics, such as social class, may impact perceptions during the selection process. Considering the results of this study, applicant social class matters, but its influence may differ by stage. As such, additional research on the impact of social class within the hiring - and other organizational processes - is warranted.

\section{Research \& Practical Implications}

From a research and practical perspective these results of this dissertation leave us at a crossroad. With lower class applicants exiting from the selection process earlier, there will likely be fewer lower class employees in organizations. For organizational researchers, this may mean that our conceptions of the workplace may be biased towards an upper class perspective. For managers, this may mean that they are most familiar with and value upper class norms and practices. While this bias is likely unintentional, researchers and managers may wish to take these results into advisement as we design future studies and workplace processes. 
Research implications. As shown by the results of this dissertation, because the results differed by hiring stage, understanding how selection process mechanisms function or how associated perceptions shift during the selection process may provide us with more clarity related to diversity and hiring. Current diversity research suggests that demographic characteristics have an impact, but that these results are mixed (e.g., García et al., 2008; McCarthy et al., 2010). While understanding the impact of demographic characteristics in the selection process is useful, without exploring it in separate stages or from various perspectives (e.g., organization, hiring manager, applicant) we may be missing or overstating the effects of various demographic characteristics. For instance, because social class decreased in significance as the selection process continued it may be that some demographic characteristics become less relevant as the applicant pool decreases. Therefore, separating the selection process into stages and perspectives may result in greater clarity, allowing us to gain more precision related to the impact of different demographic characteristics throughout the selection process.

Second, this dissertation contributes to the management diversity literature by clarifying the social class construct. Prior management research may have been hesitant to explore social class due to the lack of clarity surrounding this multi-dimensional construct or the variety of perspectives associated with social class. One challenge with exploring multi-dimensional constructs is ensuring we are actually measuring what we set out to measure. By clarifying this construct and using representative factors to design stimulus materials, I highlighted one way to explore this multi-dimensional construct. It is important that subsequent research continue to build on this foundation as social class is explored within organizational research. Significant results related to the factors associated with social class highlight its relevance and suggest continued clarification may help parse out findings related to some of the factors found to reside 
within multiple forms of capital. Additionally, the multiple perspectives associated with social class may have provided us with a great foundation that researchers should now expand. Over time the meaning or determination of resources and other demographic characteristics may have shifted. It is important that scholars continue to build on the current social class literature and develop new conceptions that may consider more current factors (e.g., technology advances).

Third, it is important to acknowledge how social class may have impacted some of our assumptions, theories, or findings within management research. For instance, research on impression management has found that the level of self-monitoring impacts individuals' ability to appropriately utilize impression management tactics (Turnley \& Bolino, 2001). While true, this study may not have considered that individuals' differ in their desire to want to use impression management tactics. From social class research we know that lower class individuals find the use of impression management tactics to be distasteful (Bettie, 2003; Lamont, 2000; Williams, 2012). Therefore, lower class individuals may be less likely to use impression management tactics not because they are less self-aware, but rather because they are in disagreement with their use. Consideration of different social class perspectives may increase the generalizability of our management research and provide some additional boundary conditions for our management theories and findings.

Practical implications. We will likely be unable to fully account for all of the reasons why managers perceive some applicants more or less favorably than others. However, as highlighted in Table 16, the results of this study can provide managers with some insight how demographic characteristics such as social class can influence the evaluation of applicants. As an example, during the acquiring stage, accounting for the race and sex of the applicant and hiring manager explains $18 \%$ of the variation of how hiring managers' evaluated an applicant's fit. 
When we consider applicants' social class, we can now explain this impact by $21 \%$. As hiring managers sit around a conference room table to discuss the merits of one applicant over another, managers should know that over $20 \%$ of an applicant's evaluation is likely based upon non-job related, demographic characteristics. Considering this, managers and organizations should acknowledge the practical implications of social class within the hiring process.

First, organizations should review their policies and procedures to ensure they do not inadvertently bias individuals of a certain social class. Many organizations have and continue to develop diversity initiatives (e.g., leadership development training programs, mentoring programs) that consider various demographic characteristics and populations (Jayne \& Dipboye, 2004). However, prior to revising and implementing diversity initiatives, organizations may want to confirm they have considered the implications of social class. One program that may need to be revisited by organizations is the employee referral program. In accordance with the results of this study, hiring managers pay particular attention to the prestige of the referring employee when making assessments of applicant's P-O fit. Therefore, applicants referred by employees of higher levels of prestige may be more likely to be viewed with higher levels of P-O fit. While unintentional, programs such as these may reinforce social class distinctions and create divisions between employees of varying levels. In an effort to create a more inclusive environment, employee referral programs may actually do the opposite. However, because employee referral programs are often beneficial for organizations (Brown et al., 2012), organizations may wish to revise rather than eliminate them. For instance, employees could refer applicants using a unique identifying code, making this process anonymous and thereby eliminating access to information such as the prestige of the referral. Additionally, organizations may also wish to review other hiring related processes and programs (e.g., campus recruiting) and determine if there are ways 
to remove aspects that may highlight and reinforce social class distinctions-either from the referring employee or applicant.

Second, it is quite likely that well-intentioned managers are unaware of whether and how social class may be influencing their processes. Therefore, organizations may want to ensure their diversity or hiring related training includes social class. Incorporating the social class demographic into organizational training will emphasize its relevance to managers and allow them to consider it when designing and implementing future policies and processes. Creating and assessing training that incorporates social class may also provide an example of how academics and practitioners could collaborate. Researchers could assess the existence of bias prior to and after a training intervention and provide recommendations. Collaborations such as these could benefit HR professionals and hiring managers as they continue to recruit and evaluate applicants of all social classes.

From the opposite perspective, some organizations may use social class information as a way to eliminate applicants or employees from their organization. As found by Rivera (2012), hiring managers in elite firms commonly use cultural capital cues to evaluate applicants and determine whether a fit exists. Thus, further understanding of the social class construct may prompt some organizations to develop additional screening tools for use during the selection process. Rather than assessing information such as cognitive ability, some organizations may assess applicant beliefs and behaviors to determine whether alignment exists with their organizational culture. While these practices may eliminate potential issues related to fit, they will likely not contribute to a more inclusive and diverse culture.

Lastly, from a societal level organizations will want to remain actively involved in conversations involving diversity related legislation and protected categories. Larger societal 
events mean that legislation is constantly changing. According to SHRM there have been and are anticipated to be numerous changes to discrimination related legislation (Schuman, Lotito \& Chilco, 2014). Although businesses often strive to understand the impact of legislation to their bottom line, early involvement in the conversations may provide a more proactive response. Therefore, to avoid possible repercussions to changing legislation and ensure organizational perspectives are considered, HR professionals and hiring managers should enter and remain in conversations at the societal level.

\section{Future Directions}

This study provides numerous avenues for future research. First, it is quite likely that social class has an impact in various organizational processes and practices. As suggested by Scully and Blake Beard (2006), social class can permeate organizations in a variety of ways. Future research should explore how social class may impact various organizational processes. The dyadic nature of the performance management process (e.g., evaluations of one manager toward an employee) may result in the social class of the employee or manager impacting performance evaluations - either the rating or the response. Research may find that the social class of managers and employees is relevant to other organizational processes occurring over the employee life cycle such as promotion, compensation, and even turnover.

Second, future research on the selection process may benefit by exploring the selection process in stages as opposed to considering the selection process overall. As discussed throughout this dissertation, hiring managers consider different forms of applicant material depending on the stage of the process. Different results were found during each stage of the process. These results may have been partially attributed to the type of material hiring managers were asked to evaluate. Although selection research has previously considered the selection 
process over various stages (e.g., Barber, 1998; Cappelli, 2001), much of the more recent selection process research focuses on one stage in particular (e.g., interviewing). While this research is needed, researchers must then be careful to interpret these findings based solely on one stage of the process. Some researchers have returned to the exploration of the selection process over stages such as Lopez and colleagues (2013). The selection process literature may benefit from additional exploration of the selection process by stage.

Third, it is also important to consider the impact of social class from the applicant perspective. Applicants generally apply for positions where attraction exists and exclude those where this attraction does not exist. Diversity research has considered the relationship between different demographic characteristics and organizational attraction (e.g., Avery, 2003; McKay \& Avery, 2006). Although organizations themselves cannot be of a certain social class, organizations may exude values or behaviors consistent with a particular social class. Therefore, applicants may select or not select certain organizations because they perceive their social class does or does not align with the organization. Researchers could investigate this by presenting job descriptions or organizational recruitment processes to potential applicants and measuring their level of interest in different organizations.

In this study I presented participants with numerous versions of one type of applicant stimulus material (e.g., referral email) to capture their decision making process in one particular selection stage. Future research should consider presenting participants with all three of the applicant stimulus materials to simulate the decision making process over the course of an actual hiring process. In accordance with the findings from this dissertation, I would expect upper class applicants to be rated with higher levels of P-O fit during the initial stage, which would result in fewer lower class applicants in the subsequent stages. Moreover, future research should also 
consider the intersectionality between social class and other demographic characteristics (e.g., race, sex) during the hiring process. With less variation of applicant social class during the latter stages, hiring managers may concentrate on other demographic characteristics as they assess P-O fit.

Although this study largely did not find significant effects for race and sex, future research should continue to explore these demographic characteristics in a more nuanced way. Demographic comparisons within hiring often consider different characteristics (e.g., White and Black, Muslim and Christian). While research has highlighted a clear preference of one characteristic over the other (e.g., Bertrand \& Mullainathan, 2003; Wallace, Wright, \& Hyde, 2014), we have limited insight into the nuances. For instance, using less stereotypical racial names in this study yielded non-significance. As issues of diversity and inclusion increase in prominence, it is likely that perceptions have also shifted. Researchers may find value in considering demographic characteristics as a spectrum rather than a simple comparison of two items. In effect, we need more understanding about at what point do evaluators alter their perceptions.

Lastly, it is important that methods align with the stage of research. The nascent nature of social class research within the management literature makes it an ideal topic to explore qualitatively or with a mixed methods format (Edmondson \& McManus, 2007). Although this dissertation featured a creative approach and clarification of the construct aided in the design of the stimulus materials, continued research in this area may benefit from additional qualitative research. With that said, qualitative research encompasses a variety of methods and should not be solely limited to interviews. Case studies, focus groups, observation, and ethnographic research — to name a few—may prove quite useful in exploring social class within organizations. 
Additionally, combining quantitative and qualitative methods into a mixed methods study may provide deeper understanding into the experiences of applicants of varying social class as well as the perspectives of the hiring managers.

Taken together, considering social class within future management research may allow for numerous extensions into theoretical frameworks, methods, and findings over the entire employee life cycle.

\section{Limitations}

Although this dissertation offers a variety of noteworthy contributions, it is not without some limitations. First, despite the nascent nature of social class research in management literature, this dissertation is quantitative in nature. It should be noted that extensive pilot work was conducted to clarify the construct of social class. Additionally, the creative design (e.g., use of interview videos) may have mitigated the typical appearance associated with a purely quantitative survey data collection. However, future research could benefit by including a qualitative aspect, thereby creating a mixed methods study.

Second, although data was collected from a two-part sample including a traditional professional sample, a portion of my sample was from Amazon Mechanical Turk (M-Turk). While the use of M-Turk samples has become more common in research studies, some researchers remain skeptical of the workers accessed through M-Turk. Data obtained through MTurk samples has been found to be as reliable as that obtained through more traditional means (Buhrmester et al., 2011). Additionally, there are numerous options available to researchers to enhance their data collection such as blocking previous responders to surveys or setting specific criteria to ensure only qualified workers can access research materials (Chandler, Mueller, \& Paolacci 2012; Mason \& Suri, 2013). As numerous steps were taken to specify who could 
participate and data was reviewed prior to inclusion, use of M-Turk data provided additional diversity to the sample.

Third, while extensive pilot work was conducted to explore and clarify the construct of social class, the results may have limited the selection of social class cues. Social class cues such as education or clothing, which have both been shown to be relevant in assessment of social class (Markus \& Conner, 2013), were unable to be manipulated in this study. Although it was important to select constructs that were representative of only one form of capital or were distinguishable as either upper or lower class, I would encourage further construct clarity or innovative ways to confirm relevant social class factors. For instance, presenting participants with pictures or videos of applicants and asking them to select cues that are representative of the three forms of capital may be another approach to clarify social class cues. In sum, researchers should consider the construct clarity work in this study to be a contribution, not a constraint.

\section{Conclusion}

This dissertation contributes to our understanding of social class within the context of the selection process. Findings of this study show that applicant social class impacts hiring managers' perceptions of applicants' P-O fit during various stages of the selection process. Thus, the hiring process should be considered as one example of a context where social class is relevant. Similar to other well-researched demographic characteristics such as race and sex, it is likely that social class has played a role in many of our management assumptions, theoretical frameworks, and findings. Therefore, to ensure we adequately consider various perspectives, and that our research is generalizable to a variety of individuals, additional consideration of social class as a relevant demographic characteristic within organizational research is warranted. 


\section{REFERENCES}

Acker, J. 2006. Inequality regimes gender, class, and race in organizations. Gender \& Society, 20(4): 441-464.

Adams, J., \& Weakliem, D. L. 2011. August B. Hollingshead's "Four factor index of social status": From unpublished paper to citation classic. Yale Journal of Sociology: 8: 1-197.

Adkins, C. L., Russell, C. J., \& Werbel, J. D. 1994. Judgments of fit in the selection process: The role of work value congruence. Personnel Psychology, 47(3): 605-623.

Adler, N. E., Epel, E. S., Castellazzo, G., \& Ickovics, J. R. 2000. Relationship of subjective and objective social status with psychological and physiological functioning: Preliminary data in healthy, white women. Health Psychology, 19(6): 586-592.

Adler, N. E., Boyce, T., Chesney, M. A., Cohen, S., Folkman, S., Kahn, R. L., \& Syme, S. L. 1994. Socioeconomic status and health: The challenge of the gradient. American Psychologist, 49(1): 15.

Aguinis, H., \& Bradley, K. J. 2014. Best practice recommendations for designing and implementing experimental vignette methodology studies. Organizational Research Methods, 17(4): 351-371.

Amazon Mechanical Turk. 2014. Introduction. Retrieved on October 16, 2014 from https://www.mturk.com/mturk/welcome.

American Psychological Association. 2014 Socioeconomic status. Retrieved on December 11, 2014 from http://www.apa.org/topics/socioeconomic-status/.

Argyle, M. 1994. The psychology of social class. New York, NY: Psychology Press.

Asch, S. E. 1946. Forming impressions of personality. The Journal of Abnormal and Social Psychology, 41(3): 258-290.

Atzmüller, C., \& Steiner, P. M. 2010. Experimental vignette studies in survey research. Methodology: European Journal of Research Methods for the Behavioral and Social Sciences, 6(3): 128-138.

Audretsch, D. B., Bönte, W., \& Tamvada, J. P. 2013. Religion, social class, and entrepreneurial choice. Journal of Business Venturing, 28(6): 774-789.

Avery, D. R. 2003. Reactions to diversity in recruitment advertising--are differences black and white? Journal of Applied Psychology, 88(4), 672.

Avery, D. R., McKay, P. F., \& Wilson, D. C. 2008. What are the odds? How demographic similarity affects the prevalence of perceived employment discrimination. Journal of Applied Psychology, 93(2): 235. 
Barber, A. E. 1998. Recruiting employees: Individual and organizational perspectives. Thousand Oaks, CA: Sage Publications.

Baum, J. A., \& Oliver, C. 1992. Institutional embeddedness and the dynamics of organizational populations. American Sociological Review, 57(4): 540-559.

Behrenz, L. 2001. Who gets the job and why? An explorative study of Employers' Recruitment behavior Journal of Applied Economic, 4(2): 255-278.

Bendersky, C., \& Shah, N. P. 2013. The downfall of extraverts and rise of neurotics: The dynamic process of status allocation in task groups. Academy of Management Journal, 56(2): $387-406$.

Benjamin, O., Bernstein, D., \& Motzafi-Haller, P. 2011. Emotional politics in cleaning work: The case of Israel. Human relations, 64(3): 337-357.

Berger, J., Cohen, B. P., \& Zelditch, J., M. 1966. Status characteristics and expectation states. In Joseph Berger, Morris Zelditch, Jr., \& Bo Anderson (Ed.), Sociological theories in progress: 29-46. New York: Houghton Mifflin.

Bernstein, B. 1962. Social class, linguistic codes and grammatical elements. Language and speech, 5(4): 221-240.

Bertrand, M., \& Mullainathan, S. (2003). Are Emily and Greg more employable than Lakisha and Jamal? A field experiment on labor market discrimination (No. w9873). National Bureau of Economic Research.

Bettie, J. 2003. Women without class: Girls, race, and identity. Berkeley: University of California Press.

Bidwell, A. 2014. Women more likely to graduate college, but still earn less than men. Retrieved on November 2, 2014 from http://www.usnews.com/news/blogs/datamine/2014/10/31/women-more-likely-to-graduate-college-but-still-earn-less-than-men.

Blackmon, D. A. 2009. Slavery by another name: The re-enslavement of black Americans from the Civil War to World War II. New York, NY: Random House LLC.

Block, J. 1978. The Q-sort method. Palo Alto, CA: Counseling Psychologists Press.

Block, J. 1961. The Q-sort method in personality assessment and psychiatric research. Springfield, IL: Charles C Thomas Publisher.

Bolino, M. C., Kacmar, K. M., Turnley, W. H., \& Gilstrap, J. B. 2008. A multi-level review of impression management motives and behaviors. Journal of Management, 34(6): 10801109.

Bourdieu, P. 1994. Distinction: A social critique of the judgement of taste. In D.B. Grusky (Ed.), Social stratification: Class, race, \& gender in sociological perspective. Boulder, CO: 
Westview Press.

Bourdieu, P. 1991. Language and symbolic power. United States: Harvard University Press.

Bourdieu, P. 1986. The forms of capital. In J.E. Richardson (Ed.), Education: Culture, economy, and society: 241-258. New York: Greenwood Publishing Group.

Bourdieu, P. 1984. Distinction: A social critique of the judgement of taste. United States of America: Harvard University Press.

Bourdieu, P. 1977. Outline of a theory of practice. Cambridge, MA: Cambridge University Press.

Bowen, D. E., Ledford, G. E., \& Nathan, B. R. 1991. Hiring for the organization, not the job. The Executive, 5(4): 35-51.

Bowles, H. R., Babcock, L., \& Lai, L. 2007. Social incentives for gender differences in the propensity to initiate negotiations: Sometimes it does hurt to ask. Organizational behavior and human decision processes, 103(1): 84-103.

Bozeman, D. P., \& Kacmar, K. M. 1997. A cybernetic model of impression management processes in organizations. Organizational Behavior and Human Decision Processes, 69(1): 9-30.

Brannon, T. N., \& Markus, H. R. 2013. Social class and race: Burdens but also some benefits of chronic low rank. Psychological Inquiry, 24(2): 97-101.

Breaugh, J. A., \& Starke, M. 2000. Research on employee recruitment: So many studies, so many remaining questions. Journal of Management, 26(3): 405-434.

Brooks, J. L. 2012. Counterbalancing for serial order carryover effects in experimental condition orders. Psychological Methods, 17(4): 600-614.

Brooks, M. G., \& Buckner, J. C. 1996. Work and welfare: Job histories, barriers to employment, and predictors of work among low-income single mothers. American Journal of Orthopsychiatry, 66(4): 526-537.

Brown, M., Setren, E., \& Topa, G. 2012. Do informal referrals lead to better matches? Evidence from a firm's employee referral system. IZA Discussion Paper No. 8175. Available at SSRN: http://ssrn.com/abstract=2441471.

Buhrmester, M., Kwang, T., \& Gosling, S. D. 2011. Amazon's mechanical turk a new source of inexpensive, yet high-quality, data? Perspectives on Psychological Science, 6(1): 3-5.

Bullock, H. E. 2004. Class diversity in the workplace. In M. S. Stockdale \& F. J. Crosby (Ed.), The psychology and management of workplace diversity: 221-242. Malden, MA: Blackwell. 
Bureau of Labor Statistics. 2014a. Employed persons by occupation, sex, and age. Retrieved on February 25, 2014 from http://www.bls.gov/cps/cpsaat09.pdf.

Bureau of Labor Statistics. 2014b. Occupational employment and wages - May 2013. Retrieved on September 19, 2014 from http://www.bls.gov/news.release/pdf/ocwage.pdf.

Bureau of Labor Statistics. 2013. Employed persons by sex, occupation, class of worker, full- or part-time status, and race. Retrieved on December 12, 2014 http://www.bls.gov/opub/ee/2014/cps/annavg12_2013.pdf.

Bureau of Labor Statistics. 2010. Occupational pay comparisons among metropolitan areas, 2010. Retrieved on September 19, 2014 from http://www.bls.gov/news.release/pdf/ncspay.pdf.

Byrne, D. E. 1971. The attraction paradigm. Orlando, FL: Academic Press.

Cable, D. M., \& DeRue, D. S. 2002. The convergent and discriminant validity of subjective fit perceptions. Journal of Applied Psychology, 87(5): 875-884.

Cable, D. M., \& Edwards, J. R. 2004. Complementary and supplementary fit: A theoretical and empirical integration. Journal of Applied Psychology, 89(5): 822-834.

Cable, D. M., \& Judge, T. A. 1996. Person-organization fit, job choice decisions, and organizational entry. Organizational Behavior and Human Decision Processes, 67(3): 294-311.

Cable, D. M., \& Judge, T. A. 1997. Interviewers' perceptions of person-organization fit and organizational selection decisions. Journal of Applied Psychology, 82(4): 546-561.

Cappelli, P. 2001. Making the most of on-line recruiting. Harvard Business Review, 79(3): 139146.

Centers, R. 1953. Social class, occupation, and imputed belief. American Journal of Sociology, 58(6): 543-555.

Chandler, J., Mueller, P., \& Paolacci, G. (2014). Nonnaïveté among amazon mechanical turk workers: Consequences and solutions for behavioral researchers. Behavior Research Methods, 46(1): 112-130.

Chatman, J. A. 1991. Matching people and organizations: Selection and socialization in public accounting firms. Administrative Science Quarterly, 36(3): 459-484.

Chen, C., \& Lin, M. 2014. The effect of applicant impression management tactics on hiring recommendations: Cognitive and affective processes. Applied Psychology, 63(4): 698724.

Chua, R.,Y.J. 2013. The costs of ambient cultural disharmony: Indirect intercultural conflicts in social environment undermine creativity. Academy of Management Journal, 56(6): 
$1545-1577$.

Coates, T.N. 2016. The enduring solidarity of Whiteness. Retrieved on February 13, 2016 from http://readersupportednews.org/opinion2/277-75/35136-focus-the-enduring-solidarity-ofwhiteness

Coates, T.N. 2015. Between the world and me. New York, NY: Spiegel \& Grau.

Colella, A., Paetzold, R. L., Zardkoohi, A., \& Wesson, M. J. 2007. Exposing pay secrecy. Academy of Management Review, 32(1): 55-71.

Coleman, J. S. 1990. Foundations of social theory. Cambridge, MA: Harvard University Press.

Cooper, M. 2008. The inequality of security: Winners and losers in the risk society. Human relations, 61(9): 1229-1258.

Cortina, L. M., \& Wasti, S. A. 2005. Profiles in coping: Responses to sexual harassment across persons, organizations, and cultures. Journal of Applied Psychology, 90(1): 182-192.

Côté, S. 2011. How social class shapes thoughts and actions in organizations. Research in Organizational Behavior, 31: 43-71.

Côté, S., Piff, P. K., \& Willer, R. 2013. For whom do the ends justify the means? Social class and utilitarian moral judgment. Journal of Personality and Social Psychology, 104(3): 490-503.

Cox, T. H., \& Blake, S. 1991. Managing cultural diversity: Implications for organizational competitiveness. Academy of Management Executive, 5(3): 45-56.

Crenshaw, K. 1989. Demarginalizing the intersection of race and sex: A black feminist critique of antidiscrimination doctrine, feminist theory and antiracist politics. University of Chicago Legal Forum. 139-167.

Cunningham, G. B., \& Sagas, M. 2004. Examining the main and interactive effects of deep- and surface-level diversity on job satisfaction and organizational turnover intentions. Organizational Analysis, 12(3): 319-332.

Dacin, M. T., Munir, K., \& Tracey, P. 2010. Formal dining at Cambridge colleges: Linking ritual performance and institutional maintenance. Academy of Management Journal, 53(6): 1393-1418.

Dahrendorf, R. 1959. Class and class conflict in industrial society. Stanford, CA: Stanford University Press.

Darwin, C. 1859. On the origins of species by means of natural selection. London: Murray.

Deci, E. L., \& Ryan, R. M. 1985. Cognitive evaluation theory. In Intrinsic motivation and selfdetermination in human behavior: 43-85. New York: Springer. 
DiMaggio, P. 2012. Sociological perspectives on the face-to-face enactment of class distinction. In S.T. Fiske \& H.R. Markus (Ed.), Facing social class: How societal rank influences interaction. New York: Russell Sage Foundation.

DiMaggio, P. 1992. Nadel's Paradox Revisited: Relational and Cultural Aspects of Social Structure. In N. Nohria and R. Eccles (Ed.), Networks and Organizations: Structure, Form and Action, 118-42. Boston, MA: HBS Press.

Dindoff, K. M. 2000. Recruiter impressions of potential for job-specific and organizational fit in resume screening: Three field studies. Unpublished doctoral dissertation, University of Western Ontario Canada.

Dineen, B. R., Ash, S. R., \& Noe, R. A. 2002. A web of applicant attraction: Person-organization fit in the context of web-based recruitment. Journal of Applied Psychology, 87(4): 723734.

Dipboye, R. L., Arvey, R. D., \& Terpstra, D. E. 1977. Sex and physical attractiveness of raters and applicants as determinants of resumé evaluations. Journal of Applied Psychology, 62(3): 288-294.

Dunham, R. B., \& Hawk, D. L. 1977. The four-day/forty-hour week: Who wants it? Academy of Management Journal, 20(4): 644-655.

Eagly, A. H., \& Karau, S. J. 2002. Role congruity theory of prejudice toward female leaders. Psychological Review, 109(4): 573-598.

Edmondson, A. C., \& McManus, S. E. (2007). Methodological fit in management field research. Academy of Management Review, 32(4), 1155-1179.

Edwards, J. R. 1991. Person-job fit: A conceptual integration, literature review, and methodological critique. In C.L. Cooper \& I.T. Robertson (Ed.), International review of industrial and organizational psychology, vol. 6: 283-357. Oxford, England: John Wiley \& Sons.

Edwards, J. R. 1996. An examination of competing versions of the person-environment fit approach to stress. Academy of Management Journal, 39(2): 292-339.

Ehrenreich, B. 2001. Nickel and dimed: On (not) getting by in America. New York, NY: Picador.

Einarsdóttir, A. 2013. They married for love but keep it quiet: Same sex partners in Iceland. Sexualities, 16(7): 788-806.

Espenshade, T. J., \& Radford, A. W. 2010. No longer separate, not yet equal: Race and class in elite college admission and campus life. Princeton, NJ: Princeton University Press.

Evans, G., \& Mills, C. 1998. A latent class analysis of the criterion-related and construct validity of the goldthorpe class schema. European Sociological Review, 14(1): 87-106. 
Evans, G. W., Gonnella, C., Marcynyszyn, L. A., Gentile, L., \& Salpekar, N. 2005. The role of chaos in poverty and children's socioemotional adjustment. Psychological science, 16(7): $560-565$.

Fallow, S. S., \& Kantrowitz, T. M. 2013. Global assessment trends report. Retrieved on September 25, 2014 from http://www.shrm.org/india/hr-topics-and-strategy/talentdevelopment-engagement-and-retention/talent-career-and-leadership-development-andmentoring/documents/www.shl.com_assets/gatr_2013 us.pdf.

Fazio, R. H., \& Cooper, J. 1983. Arousal in the dissonance process. In J. T. Cacioppo, \& R. E. Petty (Ed.), Social psychophysiology: A sourcebook: 122-152. New York: Guilford Press.

Fernandez, R. M., \& Fernandez-Mateo, I. 2006. Networks, race, and hiring. American Sociological Review, 71(1): 42-71.

Fernandez, R. M., \& Mors, M. L. 2008. Competing for jobs: Labor queues and gender sorting in the hiring process. Social Science Research, 37(4): 1061-1080.

Festinger, L. 1962. Cognitive dissonance. Scientific American, 207(4): 93-107.

Festinger, L. 1957. A theory of cognitive dissonance. Stanford, CA: Stanford university press.

Fiske, S. T., Moya, M., Russell, A. M., \& Bearns, C. 2012. The secret handshake: Trust in crossclass encounters. In Facing social class: How societal rank influences interaction: 234252. New York, NY: Russell Sage Foundation.

Forsythe, S., Drake, M. F., \& Cox, C. E. 1985. Influence of applicant's dress on interviewer's selection decisions. Journal of Applied Psychology, 70(2): 374-378.

Gale, S. 2002. Three companies cut turnover with tests. Workforce, 81(4): 66.

Gallo, L. C., \& Matthews, K. A. 2003. Understanding the association between socioeconomic status and physical health: Do negative emotions play a role? Psychological bulletin, 129(1): 10-51.

García, M., Posthuma, R., \& Colella, A. 2008. Fit perceptions in the employment interview: The role of similarity, liking, and expectations. Journal of Occupational and Organizational Psychology, 81(2): 173-189.

Gatewood, R. D., \& Feild, H. S. 1994. Human resource selection. Fort Worth, TX: Dryden.

Gennetian, L. A., Crosby, D. A., Huston, A. C., \& Lowe, E. D. 2004. Can child care assistance in welfare and employment programs support the employment of low-income families? Journal of Policy Analysis and Management, 23(4): 723-743.

Goffman, E. 1963. Stigma: Notes on the management of spoiled identity. Englewood Cliffs, NJ: Prentice-Hall. 
Goldberg, C. B. 2005. Relational demography and similarity-attraction in interview assessments and subsequent offer decisions are we missing something? Group \& Organization Management, 30(6): 597-624.

Goldberg, C. B. 2003. Applicant reactions to the employment interview: A look at demographic similarity and social identity theory. Journal of Business Research, 56(8): 561-571.

Gomez-Mejia, L. R., Page, R. C., \& Tornow, W. R. 1982. A comparison of the practical utility of traditional, statistical, and hybrid job evaluation Approaches. Academy of Management Journal, 25(4): 790-809.

Granovetter, M. S. 1973. The strength of weak ties. American Journal of Sociology, 78(6): 1360-1380.

Graves, L.M., \& Powell, G.N. 1995. The effect of sex similarity on recruiters' evaluations of actual applicants: A test of the similarity-attraction paradigm. Personnel Psychology, 48(1): 85-98.

Gray, B., \& Kish-Gephart, J. J. 2013. Encountering social class differences at work: How "class work" perpetuates inequality. Academy of Management Review, 38(4): 670-699.

Griskevicius, V., Tybur, J. M., Delton, A. W., \& Robertson, T. E. 2011. The influence of mortality and socioeconomic status on risk and delayed rewards: A life history theory approach. Journal of personality and social psychology, 100(6): 1015-1026.

Grusky, D. B. 1994. Social stratification: Class, race, and gender in sociological perspective. Boulder, CO: Westview Press, Inc.

Gurley, T., \& Bruce, D. 2005. The effects of car access on employment outcomes for welfare participants. Journal of Urban Economics, 58(2): 250-272.

Hackman, J. R., \& Oldham, G. R. 1975. Development of the job diagnostic survey. Journal of Applied Psychology, 60(2): 159.

Harrison, D. A., Price, K. H., \& Bell, M. P. 1998. Beyond relational demography: Time and the effects of surface- and deep-level diversity on work group cohesion. Academy of Management Journal, 41: 96-107.

Harrison, D. A., Price, K. H., Gavin, J. H., \& Florey, A. T. 2002. Time, teams, and task performance: Changing effects of surface-and deep-level diversity on group functioning. Academy of Management Journal, 45(5): 1029-1045.

Hauser, R., \& Warren, J. 1996. Socioeconomic indexes for occupations: A review, update and critique (unpublished manual). University of Wisconsin-Madison: Center for Demography and Ecology.

Hewlin, P. F. 2003. And the award for best actor goes to...: Facades of conformity in organizational settings. Academy of Management Review, 28(4), 633-642. 
Higgins, C. A., \& Judge, T. A. 2004. The effect of applicant influence tactics on recruiter perceptions of fit and hiring recommendations: A field study. Journal of Applied Psychology, 89(4): 622-632.

Highhouse, S. 2008. Stubborn reliance on intuition and subjectivity in employee selection. Industrial and Organizational Psychology, 1(3): 333-342.

Himmelfarb, S., \& Senn, D. J. 1969. Forming impressions of social class: Two tests of an averaging model. Journal of Personality and Social Psychology, 12(1): 38-51.

Hoffman, B. J., \& Woehr, D. J. 2006. A quantitative review of the relationship between personorganization fit and behavioral outcomes. Journal of Vocational Behavior, 68(3): 389399.

Hollingshead, A.B. 1975. Four factor index of social status. New Haven, CT: Yale University.

Holt, D. B. 1998. Does cultural capital structure American consumption? Journal of Consumer Research, 25(1): 1-25.

Holvino, E. 2002. Class:" A difference that makes a difference" in organizations. Diversity Factor, 10(2): 28-34.

Hosoda, M., Stone, D. L., \& Stone-Romero, E. F. 2003. The interactive effects of race, gender, and job type on job suitability ratings and selection Decisions1. Journal of Applied Social Psychology, 33(1): 145-178.

Hout, M. 2008. How class works: Objective and subjective aspects of class since the 1970s. Social class: How does it work: 25-64.

Howell, J. T. 1972. Hard living on clay street: Portraits of blue-collar families. New York: Doubleday.

Hox, J. J., Kreft, I. G., \& Hermkens, P. L. 1991. The analysis of factorial surveys. Sociological Methods \& Research, 19(4): 493-510.

Huffcutt, A. I. 2011. An empirical review of the employment interview construct literature. International Journal of Selection and Assessment, 19(1): 62-81.

Huffcutt, A. I., \& Roth, P. L. 1998. Racial group differences in employment interview evaluations. Journal of Applied Psychology, 83(2): 179.

Huffington Post. 19-year-old black girl changes name from 'Keisha' to 'Kylie' to avoid bullying and stereotypes. Retrieved on September 5, 2014 from http://www.huffingtonpost.com/2013/11/05/keisha-austin_n_4220259.html .

Hunt, S. T. 1996. Generic work behavior: An investigation into the dimensions of entry-level, hourly job performance. Personnel Psychology, 49(1): 51-83. 
Hutchinson, K. L. 1984. Personnel administrators' preferences for resume content: A survey and review of empirically based conclusions. Journal of Business Communication, 21(4): 514.

Hutchinson, K. L., \& Brefka, D. S. 1997. Personnel administrators' preferences for resume content: Ten years after. Business Communication Quarterly, 60(2): 67-75.

Independent Sector. 2002. Giving and volunteering in the United States. Washington, DC: Independent Sector.

Jæger, M. M. 2011. Does cultural capital really affect academic achievement? New evidence from combined sibling and panel data. Sociology of Education, 84(4): 281-298.

Jayne, M. E. A., \& Dipboye, R. L. (2004). Leveraging diversity to improve business performance: Research findings and recommendations for organizations. Human Resource Management, 43(4): 409-424.

Johnson, C. D., Messe, L. A., \& Crano, W. D. 1984. Predicting job performance of low income workers: The work opinion questionnaire. Personnel Psychology, 37(2): 291-299.

Judge, T. A., \& Cable, D. M. 1997. Applicant personality, organizational culture, and organization attraction. Personnel Psychology, 50(2): 359-394.

Judge, T. A., \& Hurst, C. 2007. Capitalizing on one's advantages: Role of core self-evaluations. Journal of Applied Psychology, 92(5): 1212.

Kawachi, I., Kennedy, B. P., Lochner, K., \& Prothrow-Stith, D. 1997. Social capital, income inequality, and mortality. American Journal of Public Health, 87(9): 1491-1498.

Keister, L. A. 2004. Race, family structure, and wealth: The effect of childhood family on adult asset ownership. Sociological Perspectives, 47(2): 161-187.

Kessler, R. C. 1982. A disaggregation of the relationship between socioeconomic status and psychological distress. American Sociological Review, 47(6): 752-764.

King, E. B., Mendoza, S. A., Madera, J. M., Hebl, M. R., \& Knight, J. L. 2006. What's in a name? A multiracial investigation of the role of occupational stereotypes in selection decisions. Journal of Applied Social Psychology, 36(5): 1145-1159.

Kraus, M. W., Côté, S., \& Keltner, D. 2010. Social class, contextualism, and empathic accuracy. Psychological Science, 21(11): 1716-1723.

Kraus, M. W., \& Keltner, D. 2009. Signs of socioeconomic status a thin-slicing approach. Psychological Science, 20(1): 99-106.

Kraus, M. W., Piff, P. K., \& Keltner, D. 2009. Social class, sense of control, and social explanation. Journal of personality and social psychology, 97(6): 992-1004. 
Kraus, M. W., Piff, P. K., Mendoza-Denton, R., Rheinschmidt, M. L., \& Keltner, D. 2012. Social class, solipsism, and contextualism: How the rich are different from the poor.

Psychological review, 119(3): 546-572.

Kristof, A. L. 1996. Person-organization fit: An integrative review of its conceptualizations, measurement, and implications. Personnel Psychology, 49: 1-49.

Kristof-Brown, A. L. 2000. Perceived applicant fit: Distinguishing between recruiters' perceptions of person-job and personal-organization fit. Personnel Psychology, 53(3): 643-671.

Kristof-Brown, A. L., Zimmerman, R. D., \& Johnson, E. C. 2005. Consequences of individuals' fit at work: A meta-analysis of person-job, person-organization, person-group, and person-supervision fit. Personnel Psychology, 58(2): 281-342.

Kristof-Brown, A., Barrick, M.R., \& Stevens, C.K. 2005. When opposites attract: A multisample demonstration of complementary person-team fit on extraversion. Journal of Personality, 73(4): 935-958.

Kusserow, A. 2012. When hard and soft clash: Class-based individualism in Manhattan and Queens. In S.T. Fiske \& H.R. Markus (Ed.) Facing social class: How societal rank influences interaction: 195-215. New York: Russell Sage Foundation.

Kwok, L., Adams, C. R., \& Price, M. A. 2011. Factors influencing hospitality recruiters' hiring decisions in college recruiting. Journal of Human Resources in Hospitality \& Tourism, 10(4): 372-399.

Lamont, M. 2000. The dignity of working men: Morality and the boundaries of race, class, and immigration. New York: Russell Sage Foundation.

Lareau, A., \& Calarco, J. M. 2012. Class, cultural capital, and institutions: The case of families and schools. S.T. Fiske \& H.R. Markus (Ed.). Facing social class: How societal rank influences interaction: 61-86. New York: The Russell Sage Foundation.

Lautsch, B. A., \& Scully, M. A. 2007. Restructuring time: Implications of work-hours reductions for the working class. Human Relations, 60(5): 719-743.

Lauver, K. J., \& Kristof-Brown, A. 2001. Distinguishing between employees' perceptions of person-job and person-organization fit. Journal of vocational behavior, 59(3): 454-470.

Law, K. S., Wong, C., \& Mobley, W. M. 1998. Toward a taxonomy of multidimensional constructs. Academy of Management Review, 23(4): 741-755-755.

Lee, J., Gino, F., \& Staats, B. R. 2014. Rainmakers: Why bad weather means good productivity . Journal Of Applied Psychology, 99(3): 504-513.

Leger, D. 2013. Black women in the media: A 2013 reflection. Retrieved on January 19, 2016 from http://www.essence.com/2013/12/30/black-women-media-2013-reflection. 
Lenski, G. E. 1952. American social classes: Statistical strata or social groups. American Journal of Sociology, 58(2): 139-144.

Lerner, M. J. 1980. The belief in a just world. New York, NY: Springer.

Levashina, J., \& Campion, M. A. 2007. Measuring faking in the employment interview: Development and validation of an interview faking behavior scale. Journal of Applied Psychology, 92(6): 1638.

Liao, H., Chuang, A., \& Joshi, A. 2008. Perceived deep-level dissimilarity: Personality antecedents and impact on overall job attitude, helping, work withdrawal, and turnover. Organizational Behavior and Human Decision Processes, 106(2): 106-124.

Lin, N. 2000. Inequality in social capital. Contemporary Sociology, 29(6): 785-795.

Lin, N., Ensel, W. M., \& Vaughn, J. C. 1981. Social resources and strength of ties: Structural factors in occupational status attainment. American Sociological Review, 46: 393-405.

Lin, N., Vaughn, J. C., \& Ensel, W. M. 1981. Social resources and occupational status attainment. Social forces, 59(4): 1163-1181.

Liu, W. 2001. Expanding our understanding of multiculturalism: Developing a social class worldview model. In D. B. Pope-Davis \& H. L. K. Coleman (Ed.), The intersection of race, class, and gender in multicultural counseling: 127-170. Thousand Oakes, CA: Sage.

Livingstone, L. P., Nelson, D. L., \& Barr, S. H. 1997. Person-environment fit and creativity: An examination of supply-value and demand-ability versions of fit. Journal of Management, 23(2): 119-146.

Lopez-Kidwell, V., Grosser, T., Dineen, B., \& Borgatti, S. 2012. What matters when: A multistage model and empirical examination of job search effort. Academy of Management Journal, 56(6): 1655-1678.

Lubrano, A. 2004. Limbo: Blue-collar roots, white-collar dreams. Hoboken, NJ: John Wiley \& Sons.

Ludwig, J., Duncan, G. J., Gennetian, L. A., Katz, L. F., Kessler, R. C., Kling, J. R., \& Sanbonmatsu, L. 2012. Neighborhood effects on the long-term well-being of low-income adults. Science, 337(6101): 1505-1510.

Macan, T. 2009. The employment interview: A review of current studies and directions for future research. Human Resource Management Review, 19(3): 203-218.

MacKenzie, S. B. 2003. The dangers of poor construct conceptualization. Journal of the Academy of Marketing Science, 31(3): 323-326.

Magee, J. C., \& Galinsky, A. D. 2008. Social hierarchy: The self-reinforcing nature of power and 
status. Academy of Management Annals, 2(1): 351-398.

Mann, M. 1973. Consciousness and action among the western working class. London: Macmillan.

Markus, H. R., \& Conner, A. 2013. Clash! 8 cultural conflicts that make us who we are. New York, NY: Hudson Street Press.

Markus, H. R., \& Fiske, S. T. 2012. Introduction: A wide-angle lens on the psychology of social class. In S.T. Fiske \& H.R. Markus (Ed.), Facing social class: How societal rank influences interactions: 1-11. New York: Russell Sage Foundation.

Markus, H. R., \& Kitayama, S. 2003. Models of agency: Sociocultural diversity in the construction of action. Paper presented at Nebraska symposium on motivation.

Marsden, P. V. 1994. The hiring process recruitment methods. American Behavioral Scientist, 37(7): 979-991.

Marx, K. 1981. Capital, vol. III. In Marx; Engels collected works. New York, NY: International Publishers, 1967.

Marx, K. 1968. Theories of surplus value. Moscow: Progress Publishers.

Marx, K., \& Engels, F. 1848. The communist manifesto. London, England: Penguin Group.

Marx, K. 1845. Theses on feuerbach. In Marx and Engels (Ed.), Collected works, vol. 5. London: Lawrence and Wishart, 1976.

Maryland.gov. 2011. Maryland's top ten most popular baby names in 2011 by race, ethnicity, and sex. Retrieved on June 29, 2014 from https://data.maryland.gov/Health-and-HumanServices/Maryland-s-Top-Ten-Most-Popular-Baby-Names-in-2011/cx3k-8nq5.

Mason, W., \& Suri, S. (2012). Conducting behavioral research on Amazon's mechanical turk. Behavior Research Methods, 44(1): 1-23.

Maynard, M. T., Gilson, L. L., \& Mathieu, J. E. 2012. Empowerment—fad or fab? A multilevel review of the past two decades of research. Journal of Management, 38(4): 1231-1281.

McCarthy, J. M., Van Iddekinge, C. H., \& Campion, M. A. 2010. Are highly structured job interviews resistant to demographic similarity effects? Personnel Psychology, 63(2): 325-359.

McFarland, L. A., Ryan, A. M., Sacco, J. M., \& Kriska, S. D. 2004. Examination of structured interview ratings across time: The effects of applicant race, rater race, and panel composition. Journal of Management, 30(4): 435-452.

McKay, P. F., \& Avery, D. R. 2006. What has race got to do with it? unraveling the role of racioethnicity in job seekers' reactions to site visits. Personnel Psychology, 59(2): 395- 
429.

McLeod, C., O'Donohoe, S., \& Townley, B. 2009. The elephant in the room? class and creative careers in British advertising agencies. Human Relations, 62(7): 1011-1039.

Merriam, S. B. 2009. Qualitative research: A guide to design and implementation. San Francisco, CA: Jossey-Bass.

Miller, P. J., \& Sperry, D. E. 2012. Déjà vu: The continuing misrecognition of low-income children's verbal abilities. In S.T. Fiske \& H.R. Markus (Ed.), Facing social class: How societal rank influences interaction: 109-130. New York, NY: Russell Sage Foundation.

Milliken, F. J., \& Martins, L. L. 1996. Searching for common threads: Understanding the multiple effects of diversity in organizational groups. The Academy of Management Review, 21: 402-433.

Morehart, K. K. 2001. How to create an employee referral program that really works. HR Focus, 78(1): 3-5.

Morgeson, F. P., Campion, M. A., Dipboye, R. L., Hollenbeck, J. R., Murphy, K., \& Schmitt, N. 2007. Reconsidering the use of personality tests in personnel selection contexts.

Personnel Psychology, 60(3): 683-729.

Morgeson, F. P., Delaney-Klinger, K., \& Hemingway, M. A. 2005. The importance of job autonomy, cognitive ability, and job-related skill for predicting role breadth and job performance. Journal of Applied Psychology, 90(2): 399.

Morley, M. J. 2007. Person-organization fit. Journal of Managerial Psychology, 22(2): 109117.

Moss, P., \& Tilly, C. 2001. Stories employers tell: Race, skill, and hiring in America. New York, NY: Russell Sage Foundation.

Moss-Racusin, C. A., Dovidio, J. F., Brescoll, V. L., Graham, M. J., \& Handelsman, J. 2012. Science faculty's subtle gender biases favor male students. Proceedings of the National Academy of Sciences of the United States of America, 109(41): 16474-16479.

Muchinsky, P. M., \& Monahan, C. J. 1987. What is person-environment congruence? supplementary versus complementary models of fit. Journal of Vocational Behavior, 31(3): 268-277.

Nahrgang, J. D., Morgeson, F. P., \& Hofmann, D. A. 2011. Safety at work: A meta-analytic investigation of the link between job demands, job resources, burnout, engagement, and safety outcomes. Journal of Applied Psychology, 96(1): 71-94.

Nash, J. C. 2008. Re-thinking intersectionality. Feminist review, 89(1): 1-15.

New York City Department of Health and Mental Hygiene. 2011. Health Department 
Announces New York City's Favorite Baby Names from 2010. Retrieved on June 29, 2014 from http://www.nyc.gov/html/doh/html/pr2011/pr034-11.shtml.

New York City Department of Health and Mental Hygiene. 2010. Health Department Announces New York City's Favorite Baby Names from 2009. Retrieved on June 29, 2014 from http://www.nyc.gov/html/doh/html/pr2010/pr049-10.shtml.

Nguyen, N. T., Allen, C. L., \& Lynn Godkin, R. 2006. Recruiters' assessment and use of social capital in résumé Screening1. Journal of Applied Social Psychology, 36(8): 1813-1832.

Nielsen, M. L., \& Kuhn, K. M. 2009. Late payments and leery applicants: Credit checks as a selection test. Employee Responsibilities and Rights Journal, 21(2): 115-130.

Oakes, J. M., \& Rossi, P. H. 2003. The measurement of SES in health research: Current practice and steps toward a new approach. Social Science \& Medicine, 56(4): 769-784.

Obukhova, E., \& Lan, G. 2013. Do job seekers benefit from contacts? A direct test with contemporaneous searches. Management Science, 59(10): 2204-2216.

Oliver, M. L., \& Shapiro, T. M. 2006. Black wealth, white wealth: A new perspective on racial inequality. Boca Raton, FL: CRC Press.

O'Reilly, C. A., Chatman, J., \& Caldwell, D. F. 1991. People and organizational culture: A profile comparison approach to assessing person-organization fit. Academy of Management Journal, 34(3): 487-516.

Pablo, A. L. 1994. Determinants of acquisition integration level: A decision-making perspective. Academy of Management Journal, 37(4): 803-836.

Pager, D., Western, B., \& Sugie, N. 2009. Sequencing disadvantage: Barriers to employment facing young black and white men with criminal records. The Annals of the American Academy of Political and Social Science, 623(1): 195-213.

Parsons, C. K., \& Liden, R. C. 1984. Interviewer perceptions of applicant qualifications: A multivariate field study of demographic characteristics and nonverbal cues. Journal of Applied Psychology, 69(4): 557.

Perry, E. L., Davis-Blake, A., \& Kulik, C. T. 1994. Explaining gender-based selection decisions: A synthesis of contextual and cognitive approaches. Academy of Management Review, 19(4): 786-820.

Phillips, K. W., \& Loyd, D. 2006. When surface and deep-level diversity collide: The effects on dissenting group members. Organizational Behavior And Human Decision Processes, 99(2): 143-160.

Piff, P. K., Kraus, M. W., Côté, S., Cheng, B. H., \& Keltner, D. 2010. Having less, giving more: The influence of social class on prosocial behavior. Journal of Personality and Social Psychology, 99(5): 771-784. 
Piff, P. K., Stancato, D. M., Martinez, A. G., Kraus, M. W., \& Keltner, D. 2012. Class, chaos, and the construction of community. Journal of Personality and Social Psychology, 103(6): 949-962.

Pingitore, R., Dugoni, B. L., Tindale, R. S., \& Spring, B. 1994. Bias against overweight job applicants in a simulated employment interview. Journal of Applied Psychology, 79(6): 909-917.

Ployhart, R. E. 2006. Staffing in the 21st century: New challenges and strategic opportunities. Journal of Management, 32(6): 868-897.

Ployhart, R. E., Nyberg, A. J., Reilly, G., \& Maltarich, M. A. 2014. Human capital is dead; long live human capital resources! Journal of Management, 40(2): 371-398.

Podolny, J. M. 2001. Networks as the pipes and prisms of the Market1. American Journal of Sociology, 107(1): 33-60.

Polinko, N. K., \& Popovich, P. M. 2001. Evil thoughts but angelic actions: Responses to overweight job applicants. Journal of Applied Social Psychology, 31(5): 905-924.

Porter, S. R. 2004. Raising response rates: What works? New Directions for Institutional Research, 2004(121): 5-21.

Porter, S. R., Whitcomb, M. E., \& Weitzer, W. H. 2004. Multiple surveys of students and survey fatigue. New Directions for Institutional Research, 2004(121): 63-73.

Powell, G. N. 2011. Women \& men in management. Thousand Oaks, CA: Sage Publications, Inc.

Pugh, S. D., Groth, M., \& Hennig-Thurau, T. 2011. Willing and able to fake emotions: A closer examination of the link between emotional dissonance and employee well-being. Journal of Applied Psychology, 96(2): 377.

Raudenbush, S. W., \& Bryk, A. S. 2002. Hierarchical linear models: Applications and data analysis methods. Thousand Oaks, CA: Sage Publications.

Reay, D. 2004. Gendering Bourdieu's concepts of capitals? emotional capital, women and social class. The Sociological Review, 52(s2): 57-74.

Rampell, C. 2013. Data reveal a rise in college degrees among Americans. Retrieved on January 7, 2015 from http://www.nytimes.com/2013/06/13/education/a-sharp-rise-inamericans-with-college-degrees.html?pagewanted=all.

Resnick, S., \& Wolff, R. 2003. The diversity of class analyses: A critique of Erik Olin Wright and beyond. Critical Sociology, 29(1): 7-27.

Ricklefs, R. E. 1979. Adaptation, constraint, and compromise in avian postnatal development. Biological Reviews, 54(3): 269-290. 
Ridgeway, C. L., \& Fisk, S. R. 2012. Class rules, status dynamics, and "gateway" interactions. In S. T. Fiske \& H. R. Markus (Ed.), Facing social class: How societal rank influences interaction: 131-151. New York: Russell Sage Foundation.

Rivera, L. A. 2012. Hiring as cultural matching the case of elite professional service firms. American Sociological Review, 77(6): 999-1022.

Rivera, L. A. 2011. Ivies, extracurriculars, and exclusion: Elite employers' use of educational credentials. Research in Social Stratification and Mobility, 29(1): 71-90.

Roberson, Q. 2006. Disentangling the meanings of diversity and inclusion in organizations. Group \& Organization Management, 31: 212-235.

Ross, C. E., \& Jang, S. J. 2000. Neighborhood disorder, fear, and mistrust: The buffering role of social ties with neighbors. American Journal of Community Psychology, 28(4): 401420.

Rotundo, M., \& Sackett, P. R. 2002. The relative importance of task, citizenship, and counterproductive performance to global ratings of job performance: A policy-capturing approach. Journal of Applied Psychology, 87(1): 66-80.

Ruiz-Palomino, P., Martínez-Cañas, R., \& Fontrodona, J. 2013. Ethical culture and employee outcomes: The mediating role of person-organization fit. Journal of Business Ethics, 116(1): 173-188.

Ryan, A. M., Horvath, M., \& Kriska, S. D. 2005. The role of recruiting source informativeness and organizational perceptions in decisions to apply. International Journal of Selection and Assessment, 13(4): 235-249.

Rynes, S., \& Gerhart, B. 1990. Interviewer assessments of applicant "fit": An exploratory investigation. Personnel Psychology, 43(1): 13-35.

Rynes, S. L. 1989. Recruitment research and applicant attraction: What have we learned? CAHRS Working Paper Series: 1-40.

Sacco, J. M., Scheu, C. R., Ryan, A. M., \& Schmitt, N. 2003. An investigation of race and sex similarity effects in interviews: A multilevel approach to relational demography. Journal of Applied Psychology, 88(5): 852-865.

Sallume, X., \& Notestein, F. W. 1932. Trends in the size of families completed prior to 1910 in various social classes. American Journal of Sociology: 398-408.

Schmitt, D. P., Realo, A., Voracek, M., \& Allik, J. 2008. Why can't a man be more like a woman? Sex differences in big five personality traits across 55 cultures. Journal of Personality and Social Psychology, 94(1): 168-182.

Schneider, B. 1987. The people make the place. Personnel Psychology, 40(3): 437-453. 
Schuman, I., Lotito, M. J. \& Chilco, S. 2015. New year, new laws, compliance challenges U.S. employers face in 2015. Retrieved on November 24, 2015 from http://www.shrm.org/legalissues/stateandlocalresources/pages/new-laws-2015.aspx

Scott, J. 2005. Life at the top in America isn't just better, it's longer. Retrieved on February 3, 2014 from http://query.nytimes.com/gst/fullpage.html?res=980DE3DC1F30F935A25756C0A9639C $\underline{8 \mathrm{~B} 63}$.

Scott, J., \& Leonhardt, D. 2005. Shadowy lines that still divide. Retrieved on February 3, 2014 from http://www.nytimes.com/2005/05/15/national/class/OVERVIEWFINAL.html?pagewanted=all\&_r=0.

Scully, M., \& Blake-Beard, S. 2006. Locating class in organizational diversity work. In A.M. Konrad, P. Prasad, \& J.K. Pringle (Ed.) Handbook of workplace diversity: 431-453. London: Sage Publications.

Seidel, M. L., Polzer, J. T., \& Stewart, K. J. 2000. Friends in high places: The effects of social networks on discrimination in salary negotiations. Administrative Science Quarterly, 45(1): $1-24$.

Sekiguchi, T., \& Huber, V. L. 2011. The use of person-organization fit and person-job fit information in making selection decisions. Organizational Behavior and Human Decision Processes, 116(2): 203-216.

Seong, J. Y., Kristof-Brown, A. L., Park, W., Hong, D., \& Shin, Y. 2012. Person-group fit diversity antecedents, proximal outcomes, and performance at the group level. Journal of Management, DOI: 10.1177/0149206312453738

Serfass, D. G., \& Sherman, R. A. 2013. Personality and perceptions of situations from the thematic apperception test. Journal of Research in Personality, 47(6): 708-718.

Shapiro, T. M. 2004. The hidden cost of being African American. New York, NY: Oxford University Press.

Shinnar, R. S., Young, C. A., \& Meana, M. 2004. The motivations for and outcomes of employee referrals. Journal of Business and Psychology, 19(2): 271-283.

Skeggs, B. 2010. Class, culture, and morality: Legacies and logics in the space for identification. In The SAGE handbook of identities: 339-359. Thousand Oaks, CA: SAGE Publications Ltd.

Smith, J. P. 1998. Socioeconomic status and health. American Economic Review, 88(2): 192196.

Snibbe, A. C., \& Markus, H. R. 2005. You can't always get what you want: Educational attainment, agency, and choice. Journal of Personality and Social Psychology, 88(4): 703-720. 
Snipp, C. M. 1985. Occupational mobility and social class: Insights from men's career mobility. American Sociological Review 50(4): 475-493.

Society for Human Resource Management. 2014a. Hiring practices checklist. Retrieved on September 16, 2014 from http://www.shrm.org/templatestools/samples/hrforms/pages/hiringpracticeschecklist.aspx

Society for Human Resource Management. 2014b. Job fair is the opportunity for the employer to sell themselves to you. Unpublished internal document.

Society for Human Resource Management. 2014c. SHRM survey findings, resumes, cover letters, and interviews. Retrieved on June 11, 2014 from http://www.slideshare.net/slideshow/embed_code/33920136.

Society for Human Resource Management. 2005. SHRM weekly online survey. Presented by SHRM Research, July 19, 2005.

Society for Human Resource Management. 2001. Employee referral programs. Retrieved on July 28, 2014 from http://www.shrm.org/Research/SurveyFindings/Documents/Employee\%20Referral\%20Pr ograms.pdf.

Spence, M. 1973. Job market signaling. The quarterly journal of Economics, 87(3): 355-374.

Spybrook, J., Bloom, H., Congdon, R., Hill, C., Martinez, A., Raudenbush, S., \& TO, A. 2011. Optimal design plus empirical evidence: Documentation for the "Optimal design" software (version 3.0). Retrieved on November 5, 2014 from http://www.wtgrantfoundation.org/resources/consultation-service-and-optimal-design.

Stephens, N. M., Fryberg, S. A., \& Markus, H. R. 2012. It's your choice: How the middle-class model of independence disadvantages working-class Americans. In S.T. Fiske \& H.R. Markus (Ed.), Facing social class: How societal rank influences interaction: 87-106. New York: Russell Sage Foundation.

Stephens, N. M., Fryberg, S. A., \& Markus, H. R. 2011. When choice does not equal freedom: A sociocultural analysis of agency in working-class American contexts. Social Psychological and Personality Science, 2(1): 33-41.

Stephens, N. M., Markus, H. R., \& Townsend, S. S. 2007. Choice as an act of meaning: The case of social class. Journal of Personality and Social Psychology, 93(5): 814-830.

Stone, C., Trisi, D., Sherman, A., \& DeBot, B. 2014. A guide to statistics on historical trends in income inequality. Retrieved on January 7, 2015 from http://www.cbpp.org/cms/?fa=view\&id=3629.

Stumpf, S. A., \& London, M. 1981. Capturing rater policies in evaluating candidates for promotion. Academy of Management Journal, 24(4): 752-766. 
Taber, M. E., \& Hendricks, W. 2003. The effect of workplace gender and race demographic composition on hiring through employee referrals. Human Resource Development Quarterly, 14(3): 303-319.

Tajfel, H. 1972. Social categorization. In Serge Moscovici (Ed.), Introduction a la psychologie sociale, vol. 1: 272-302. Paris: Larousse.

Taylor, M. S., \& Bergmann, T. J. 1987. Organizational recruitment activities and applicants' reactions at different stages of the recruitment process. Personnel Psychology, 40(2): 261-285.

Tepper, B. J., Moss, S. E., \& Duffy, M. K. 2011. Predictors of abusive supervision: Supervisor perceptions of deep-level dissimilarity, relationship conflict, and subordinate performance. Academy of Management Journal, 54(2): 279-294.

The Ladders. 2012. You have 6 seconds to make an impression: How recruiters see your resume. Retrieved on October 29, 2015 from http://info.theladders.com/insidetheladders/you-only-get-6-seconds-of-fame-make-it-count.

Thomas, K. M., \& Wise, P. G. 1999. Organizational attractiveness and individual differences: Are diverse applicants attracted by different factors? Journal of Business and Psychology, 13(3): 375-390.

Timberlake, S. 2005. Social capital and gender in the workplace. Journal of Management Development, 24(1): 34-44.

Tirado, L. 2014. Hand to mouth: Living in bootstrap America. New York, NY: The Berkeley Publishing Group.

Tsai, W., Chi, N., Huang, T., \& Hsu, A. 2011. The effects of applicant résumé contents on recruiters' hiring recommendations: The mediating roles of recruiter fit perceptions. Applied Psychology: An International Review, 60(2): 231-254.

Tsui, A. S., \& O'Reilly, C. A. 1989. Beyond simple demographic effects: The importance of relational demography in superior-subordinate dyads. Academy of Management Journal, 32(2): 402-423.

Tucker, J. S., Kennedy, D., Ryan, G., Wenzel, S. L., Golinelli, D., Zazzali, J., \& McCarty, C. 2009. Homeless women's personal networks: Implications for understanding risk behavior. Human Organization, 68(2): 129-140.

Turner, J. C. 1985. Social categorization and the self-concept: A social cognitive theory of group. Advances in Group Processes, 2: 77-121.

Turner, J. C. 1987. Rediscovering the social group: A self-categorization theory. Oxford: Blackwell.

Turnley, W. H., \& Bolino, M. C. 2001. Achieving desired images while avoiding undesired 
images: Exploring the role of self-monitoring in impression management. Journal of Applied Psychology, 86(2): 351.

Tyler, T. R., Rasinski, K. A., \& Spodick, N. 1985. Influence of voice on satisfaction with leaders: Exploring the meaning of process control. Journal of Personality and Social Psychology, 48(1): 72-81.

U.S. Census Bureau. 2014. State and county quick facts. Retrieved on January 27, 2015, from http://quickfacts.census.gov/qfd/states/00000.html.

U.S. Census Bureau. 2012. North American industry classification system. Retrieved on December 12, 2014 from http://www.census.gov/cgi-bin/sssd/naics/naicsrch?chart=2012.

U.S. Equal Employment Opportunity Commission. 2015. 2015 EEO-1 survey. Retrieved on November 24, 2015 from http://www.eeoc.gov/employers/eeol survey/.

U.S. Equal Employment Opportunity Commission. 2014. Discrimination by type. Retrieved on November 4, 2015 from http://www.eeoc.gov/laws/types/index.cfm.

Ullman, J. C. 1966. Employee referrals: Prime tool for recruiting workers. Personnel, 43(3): 3035 .

Vandenberg, R. J., \& Lance, C. E. 1992. Examining the causal order of job satisfaction and organizational commitment. Journal of Management, 18(1): 153-167.

Verquer, M. L., Beehr, T. A., \& Wagner, S. H. 2003. A meta-analysis of relations between person-organization fit and work attitudes. Journal of Vocational Behavior, 63(3): 473489.

Vivian Chen, C., Lee, H., \& Yvonne Yeh, Y. 2008. The antecedent and consequence of personorganization fit: Ingratiation, similarity, hiring recommendations and job offer. International Journal of Selection and Assessment, 16(3): 210-219.

Wade, K. J., \& Kinicki, A. J. 1997. Subjective applicant qualifications and interpersonal attraction as mediators within a process model of interview selection decisions. Journal of Vocational Behavior, 50(1): 23-40.

Wallace, M., \& Junisbai, A. 2003. Finding class consciousness in the new economy. Research in Social Stratification and Mobility, 20: 385-421.

Wallace, M., Wright, B.R.E., \& Hyde, A. 2014. Religious affiliation and hiring discrimination in the American south: A field experiment. Social currents, 1(2): 189-207.

Watkins, L. M., \& Johnston, L. 2000. Screening job applicants: The impact of physical attractiveness and application quality. International Journal of Selection and Assessment, 8(2): 76-84.

Weber, M. 1946. Class status and party In H. H. Gerth and C. W. Mills (Ed.), Essays in 
sociology: 180-195. New York: Oxford University Press.

Weber, M. 1930. The protestant ethic and the spirit of capitalism. London: Allen and Unwin.

Webster, J., \& Trevino, L. K. 1995. Rational and social theories as complementary explanations of communication media choices: Two policy-capturing studies. Academy of Management Journal, 38(6): 1544-1572.

Werbel, J. D., \& Johnson, D. J. 2001. The use of person-group fit for employment selection: A missing link in person-environment fit. Human resource management, 40(3): 227-240.

Westphal, J. D., \& Stern, I. 2007. Flattery will get you everywhere (especially if you are a male Caucasian): How ingratiation, boardroom behavior, and demographic minority status affect additional board appointments at US companies. Academy of Management Journal, 50(2): 267-288.

Williams, J. C. 2012. The class culture gap. In S.T. Fiske \& H.R. Markus (Ed.), Facing social class: How societal rank influences interaction: 39-57. New York: Russell Sage Foundation.

Williams, J. C. 2010. Reshaping the work-family debate: Why men and class matter. Cambridge, MA: Harvard University Press.

Word, D. L., Coleman, C. D., Nunziata, R., \& Kominski, R. 2008. Demographic aspects of surnames from census 2000. Unpublished manuscript, Retrieved from http://citeseer.x.ist.psu.edu/viewdoc/download.

Wright, E. O., \& Wright, E. L. (1985). Classes. London: Verso.

Wright, E. O. 1984. A general framework for the analysis of class structure. Politics \& Society, 13: 383 .

Wright, E. O. 1980. Varieties of Marxist conceptions of class structure. Politics \& Society, 9(3): 323-370.

Wright, E. O. 1976. Class boundaries in advanced capitalist societies. New Left Review, 98: 341.

Wyatt, I. D., \& Hecker, D. E. 2006. Occupational changes during the 20th century. Retrieved on January 27, 2015, from http://www.bls.gov/opub/mlr/2006/03/art3full.pdf.

York, K. M. 1989. Defining sexual harassment in workplaces: A policy-capturing approach. Academy of Management Journal, 32(4): 830-850.

Zuberi, T. 2001. Thicker than blood: How racial statistics lie. Minnesota: University of Minnesota Press.

Zweig, M. 2004. What's class got to do with it?: American society in the twenty-first century. 
Ithaca, NY: Cornell University Press.

Zweig, M. 2000. The working class majority: America's best kept secret. Ithaca, NY: Cornell University Press. 
Table 1. Various Measures of Social Class

\begin{tabular}{|c|c|c|}
\hline Citation & Topic Area & How Social Class was Measured \\
\hline $\begin{array}{l}\text { Audretsch, Bönte, } \\
\& \text { Tamvada (2013) }\end{array}$ & $\begin{array}{l}\text { Entrepreneurship } \\
\text { and career choice }\end{array}$ & Caste system in India (Backward vs. forward) \\
\hline $\begin{array}{l}\text { Christie \& Barling } \\
\text { (2009) }\end{array}$ & Work stressors & SES - income, occupational prestige, and education \\
\hline $\begin{array}{l}\text { Cortina \& Wasti } \\
\text { (2005) }\end{array}$ & Sexual harassment & $\begin{array}{l}\text { Working-class - job type (factory workers, unskilled } \\
\text { labor positions, low job complexity) vs. professional } \\
\text { (highest educational attainment). Social power - } \\
\text { educational level attained and marital status }\end{array}$ \\
\hline $\begin{array}{l}\text { Currie \& Stabile } \\
(2002)\end{array}$ & Child health & SES, mother's educational level, total household income \\
\hline $\begin{array}{l}\text { Johnson, Messe \& } \\
\text { Crano (1984) }\end{array}$ & Job Performance & $\begin{array}{l}\text { U.S. Department of Labor income guidelines for } \\
\text { poverty }\end{array}$ \\
\hline $\begin{array}{l}\text { Judge \& Hurst } \\
\text { (2007) }\end{array}$ & Work attitudes & $\begin{array}{l}\text { Family SES - parents' education, parents' occupational } \\
\text { prestige, family poverty status; Individual - educational } \\
\text { level, high school GPA, SAT scores, hours works } \\
\text { (during a certain time span), spouse's income, annual } \\
\text { income (during same time hours worked); Authors } \\
\text { created an educational attainment and family advantages } \\
\text { composite variable based on family SES variables }\end{array}$ \\
\hline Keister (2004) & $\begin{array}{l}\text { Family structure, } \\
\text { race, and wealth }\end{array}$ & $\begin{array}{l}\text { Family background and adult wealth (whether or not } \\
\text { individuals owned a comprehensive list of assets and } \\
\text { debt and the value of each if applicable }\end{array}$ \\
\hline $\begin{array}{l}\text { Lautsch \& Scully } \\
\text { (2007) }\end{array}$ & Work Life Balance & Non-exempt employees (qualify for overtime) \\
\hline $\begin{array}{l}\text { Ludwig, Duncan, } \\
\text { Gennetian, Katz, } \\
\text { Kessler, Kling, \& } \\
\text { Sanbonmatsu } \\
\text { (2013) }\end{array}$ & Economic mobility & $\begin{array}{l}\text { Economic mobility - departed member's location, } \\
\text { schooling attainment, primary occupation, marital } \\
\text { status, and landholdings; Origin-household - household } \\
\text { income and owned landholdings, number of adult males } \\
\text { (over 20), average age of adult males, total number of } \\
\text { co-resident males }\end{array}$ \\
\hline $\begin{array}{l}\text { Piff, Stancato, } \\
\text { Martinez, Kraus, \& } \\
\text { Keltner (2012) }\end{array}$ & $\begin{array}{l}\text { Perceptions of } \\
\text { Chaos }\end{array}$ & $\begin{array}{l}\text { Household income, Annual family income, MacArthur } \\
\text { Scale of Subjective Socioeconomic Status (SES; Adler } \\
\text { et al., 2000; Piff et al., 2010), childhood and current } \\
\text { social class by rating their agreement with five } \\
\text { statements on a 7-point scale (e.g., Griskevicius, Delton, } \\
\text { et al., 2011). }\end{array}$ \\
\hline $\begin{array}{l}\text { Stephens, Markus, } \\
\text { \& Townsend } \\
\text { (2007) }\end{array}$ & Choice & $\begin{array}{l}\text { At least one parent with a 4-year college degree were } \\
\text { considered middle class and those who did not were } \\
\text { considered working class }\end{array}$ \\
\hline
\end{tabular}


Table 2. Total Combination of Applicants

\begin{tabular}{|c|c|c|c|c|c|}
\hline Race & Gender & Name & $\begin{array}{l}\text { Economic } \\
\text { capital }\end{array}$ & $\begin{array}{l}\text { Social } \\
\text { capital }\end{array}$ & $\begin{array}{l}\text { Cultural } \\
\text { capital }\end{array}$ \\
\hline Black & Male & Elijah Jefferson & Upper class & Upper class & Upper class \\
\hline Black & Male & Caleb Mack & Upper class & Upper class & Lower class \\
\hline Black & Male & Christian Hampton & Upper class & Lower class & Upper class \\
\hline Black & Male & Isaiah Booker & Lower class & Upper class & Upper class \\
\hline Black & Male & Jaiden Banks & Lower class & Lower class & Upper class \\
\hline Black & Male & Mason Jackson & Lower class & Upper class & Lower class \\
\hline Black & Male & Justin Harris & Upper class & Lower class & Lower class \\
\hline Black & Male & Jeremy Hinton & Lower class & Lower class & Lower class \\
\hline Black & Female & Aaliyah Ware & Upper class & Upper class & Upper class \\
\hline Black & Female & Makayla Gaines & Upper class & Upper class & Lower class \\
\hline Black & Female & Nevaeh Rivers & Upper class & Lower class & Upper class \\
\hline Black & Female & London Mays & Lower class & Upper class & Upper class \\
\hline Black & Female & Destiny Joseph & Lower class & Lower class & Upper class \\
\hline Black & Female & Gabrielle McNeil & Lower class & Upper class & Lower class \\
\hline Black & Female & Jada Branch & Upper class & Lower class & Lower class \\
\hline Black & Female & Kayla Williams & Lower class & Lower class & Lower class \\
\hline White & Male & David Yoder & Upper class & Upper class & Upper class \\
\hline White & Male & Jack Krueger & Upper class & Upper class & Lower class \\
\hline White & Male & Jackson Koch & Upper class & Lower class & Upper class \\
\hline White & Male & Jacob Erickson & Lower class & Upper class & Upper class \\
\hline White & Male & Matthew Christiansen & Lower class & Lower class & Upper class \\
\hline White & Male & Michael Kramer & Lower class & Upper class & Lower class \\
\hline White & Male & Moshe Shea & Upper class & Lower class & Lower class \\
\hline White & Male & Ryan Nielsen & Lower class & Lower class & Lower class \\
\hline White & Female & Emily Klein & Upper class & Upper class & Upper class \\
\hline White & Female & Ava Russo & Upper class & Upper class & Lower class \\
\hline White & Female & Rachel Weiss & Upper class & Lower class & Upper class \\
\hline White & Female & Sarah Jacobson & Lower class & Upper class & Upper class \\
\hline White & Female & Leah Petersen & Lower class & Lower class & Upper class \\
\hline White & Female & Isabel Larsen & Lower class & Upper class & Lower class \\
\hline White & Female & Julia Gallagher & Upper class & Lower class & Lower class \\
\hline White & Female & Olivia McGrath & Lower class & Lower class & Lower class \\
\hline
\end{tabular}

Note:

${ }^{1}$ This distribution of applicants will be available in each stage (acquiring, screening, interviewing)

${ }^{2}$ Consistency is highlighted by the upper or lower class distinctions for each form of capital 
Table 3. Amazon Mechanical Turk (MTurk) Screening Process

\begin{tabular}{|c|c|c|}
\hline $\begin{array}{c}\text { MTurk Worker } \\
\text { Common } \\
\text { Questions }\end{array}$ & Amazon Response & $\begin{array}{l}\text { What this means } \\
\text { for my study }\end{array}$ \\
\hline $\begin{array}{l}\text { How do I create } \\
\text { a Worker } \\
\text { account on } \\
\text { Mechanical } \\
\text { Turk? }\end{array}$ & $\begin{array}{l}\text { Select the "sign-in" link in the upper right corner of the } \\
\text { Worker website. You will be asked to provide your name, } \\
\text { email address, and password. In addition, you will be } \\
\text { asked to agree to the Mechanical Turk Participation } \\
\text { Agreement and provide your country of residence. Our } \\
\text { customer care team will review your account. The review } \\
\text { process can take up to } 48 \text { hours. We will send you an } \\
\text { email when the review of your account is complete. }\end{array}$ & $\begin{array}{l}\text { All MTurk } \\
\text { participants } \\
\text { must first be } \\
\text { approved by } \\
\text { Amazon. }\end{array}$ \\
\hline $\begin{array}{l}\text { My work was } \\
\text { rejected, what } \\
\text { can I do? }\end{array}$ & $\begin{array}{l}\text { A Requester may reject your work if they believe the } \\
\text { answer is wrong, the HIT was not completed correctly, or } \\
\text { that the instructions were not followed. If you believe that } \\
\text { your work was rejected in error, you may decide to } \\
\text { contact the Requester directly. }\end{array}$ & $\begin{array}{l}\text { I have the } \\
\text { ability to reject } \\
\text { work that is } \\
\text { completed } \\
\text { incorrectly or } \\
\text { haphazardly. }\end{array}$ \\
\hline $\begin{array}{l}\text { Why is the } \\
\text { number of HITs I } \\
\text { can do each day } \\
\text { limited? }\end{array}$ & $\begin{array}{l}\text { Amazon Mechanical Turk limits the number of HITs } \\
\text { Workers can do on a daily basis based on a number of } \\
\text { factors including your past performance and account } \\
\text { status. To make sure you can do as many HITs as you } \\
\text { want, continue to do good work for all Requesters. }\end{array}$ & $\begin{array}{l}\text { Provides } \\
\text { confidence that } \\
\text { work will be } \\
\text { completed } \\
\text { sufficiently. }\end{array}$ \\
\hline $\begin{array}{l}\text { What is a } \\
\text { Mechanical Turk } \\
\text { Master? }\end{array}$ & $\begin{array}{l}\text { Masters are elite groups of Workers who have } \\
\text { demonstrated accuracy on specific types of HITs on the } \\
\text { Mechanical Turk marketplace. Workers achieve a Masters } \\
\text { distinction by consistently completing HITs of a certain } \\
\text { type with a high degree of accuracy across a variety of } \\
\text { Requesters. Masters must continue to pass our statistical } \\
\text { monitoring to remain Mechanical Turk Masters. } \\
\text { Masters receive special perks including: } \\
\text { - Exclusive access to work that requires a Master } \\
\text { Qualification } \\
\text { - Access to a private forum available only to Masters } \\
\text { Please note that Workers cannot apply for this status - it is } \\
\text { a performance based distinction. The best thing a Worker } \\
\text { can do to become a Master is to submit Assignments with } \\
\text { accurate results across a wide variety of Requesters on the } \\
\text { Mechanical Turk marketplace. }\end{array}$ & $\begin{array}{l}\text { When } \\
\text { developing my } \\
\text { survey, I can } \\
\text { request this } \\
\text { designation. If } \\
\text { selected only } \\
\text { participants who } \\
\text { have earned this } \\
\text { elite status can } \\
\text { complete my } \\
\text { survey. }\end{array}$ \\
\hline
\end{tabular}

Note: Questions and responses taken directly from the Amazon Mechanical Turk website Frequently Asked Questions page https://www.mturk.com/mturk/help?helpPage=worker\#how to_register_worker 
Table 4. Organizational Cultural Profile Values

\begin{tabular}{|c|c|c|c|c|}
\hline Adaptability & Decisiveness & Stability & Being innovative & $\begin{array}{c}\text { Quick to take } \\
\text { advantage of } \\
\text { opportunities }\end{array}$ \\
\hline Being reflective & $\begin{array}{c}\text { Taking } \\
\text { identification } \\
\text { responsibility }\end{array}$ & Risk taking & $\begin{array}{c}\text { Opportunities for } \\
\text { professional } \\
\text { growth }\end{array}$ & Autonomy \\
\hline $\begin{array}{c}\text { Being rule } \\
\text { oriented }\end{array}$ & Being analytical & $\begin{array}{c}\text { Paying attention } \\
\text { to detail }\end{array}$ & $\begin{array}{c}\text { Confronting } \\
\text { conflict directly }\end{array}$ & $\begin{array}{c}\text { Being team } \\
\text { oriented }\end{array}$ \\
\hline $\begin{array}{c}\text { Sharing } \\
\text { information } \\
\text { freely }\end{array}$ & $\begin{array}{c}\text { Being people } \\
\text { oriented }\end{array}$ & Fairness & $\begin{array}{c}\text { Not being } \\
\text { constrained by } \\
\text { many rules }\end{array}$ & Tolerance \\
\hline $\begin{array}{c}\text { Informality } \\
\text { Bempetitive }\end{array}$ & Being highly & $\begin{array}{c}\text { Achievement } \\
\text { orientation }\end{array}$ & $\begin{array}{c}\text { A clear guiding } \\
\text { philosophy }\end{array}$ \\
\hline $\begin{array}{c}\text { Being results } \\
\text { oriented }\end{array}$ & $\begin{array}{c}\text { High } \\
\text { performance }\end{array}$ & Being aggressive & $\begin{array}{c}\text { High pay for } \\
\text { good } \\
\text { performance }\end{array}$ & $\begin{array}{c}\text { Security of } \\
\text { employment }\end{array}$ \\
\hline $\begin{array}{c}\text { Praise for good } \\
\text { performance }\end{array}$ & $\begin{array}{c}\text { Being supportive } \\
\text { Working long } \\
\text { hours }\end{array}$ & $\begin{array}{c}\text { Having a good } \\
\text { reputation }\end{array}$ & An emphasis on \\
quality & $\begin{array}{c}\text { Being distinctive } \\
\text { friends at work }\end{array}$ & $\begin{array}{c}\text { Being socially } \\
\text { responsible }\end{array}$ \\
\hline the job \\
\hline
\end{tabular}

Note: Reduced list of Organizational Culture Profile, adapted by Cable \& Judge (1997) 
Table 5. Demographic overview - All stages

\begin{tabular}{|c|c|c|c|c|c|c|c|c|c|c|}
\hline & & \multicolumn{3}{|c|}{ Acquiring } & \multicolumn{3}{|c|}{ Screening } & \multicolumn{3}{|c|}{ Interviewing } \\
\hline & & $\begin{array}{c}\text { M-Turk } \\
(\mathrm{N}=\mathbf{5 3})\end{array}$ & $\begin{array}{c}\text { Prof } \\
(\mathrm{N}=25)\end{array}$ & $\begin{array}{c}\text { Total } \\
(\mathbf{N}=78)\end{array}$ & $\begin{array}{c}\text { M-Turk } \\
(\mathrm{N}=74)\end{array}$ & $\begin{array}{c}\text { Prof } \\
(\mathrm{N}=\mathbf{3 4})\end{array}$ & $\begin{array}{c}\text { Total } \\
(\mathbf{N}=\mathbf{1 0 8})\end{array}$ & $\begin{array}{l}\text { M-Turk } \\
(\mathrm{N}=127)\end{array}$ & $\begin{array}{c}\text { Prof } \\
(\mathrm{N}=73)\end{array}$ & $\begin{array}{c}\text { Total } \\
(\mathbf{N}=\mathbf{2 0 0})\end{array}$ \\
\hline 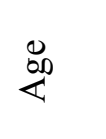 & & $\begin{array}{c}M=33.96 \\
(\mathrm{SD}=9.28)\end{array}$ & $\begin{array}{c}\mathrm{M}=44.04 \\
(\mathrm{SD}=13.78)\end{array}$ & $\begin{array}{c}\mathrm{M}=37.19 \\
(\mathrm{SD}=11.82)\end{array}$ & $\begin{array}{c}M=36.93 \\
(\mathrm{SD}=9.19)\end{array}$ & $\begin{array}{c}M=45.72 \\
(\mathrm{SD}=9.78)\end{array}$ & $\begin{array}{c}M=39.58 \\
(\mathrm{SD}=10.17)\end{array}$ & $\begin{array}{c}M=37.56 \\
(\mathrm{SD}=10.92)\end{array}$ & $\begin{array}{c}M=42.59 \\
(\mathrm{SD}=13.54)\end{array}$ & $\begin{array}{c}\mathrm{M}=39.35 \\
(\mathrm{SD}=12.12 \\
)\end{array}$ \\
\hline 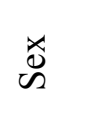 & & $\begin{array}{c}\mathrm{M}=58.5 \% \\
\mathrm{~F}=41.5 \%\end{array}$ & $\begin{array}{c}\mathrm{M}=44.0 \% \\
\mathrm{~F}=56.0 \%\end{array}$ & $\begin{array}{c}\mathrm{M}=53.8 \% \\
\mathrm{~F}=46.2 \%\end{array}$ & $\begin{array}{l}\mathrm{M}=54.1 \% \\
\mathrm{~F}=45.9 \%\end{array}$ & $\begin{array}{l}M=36.4 \% \\
F=63.6 \%\end{array}$ & $\begin{array}{c}M=48.6 \% \\
F=51.4 \%\end{array}$ & $\begin{array}{c}\mathrm{M}=63.0 \% \\
\mathrm{~F}=37.0 \%\end{array}$ & $\begin{array}{c}M=35.6 \% \\
F=64.4 \%\end{array}$ & $\begin{array}{l}\mathrm{M}=53.0 \% \\
\mathrm{~F}=47.0 \%\end{array}$ \\
\hline \multirow{5}{*}{ 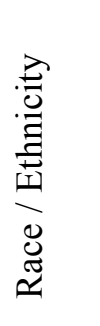 } & Asian & $7.5 \%$ & $4.2 \%$ & $6.5 \%$ & $9.5 \%$ & $0 \%$ & $6.5 \%$ & $6.3 \%$ & $0 \%$ & $4.0 \%$ \\
\hline & Black & $5.7 \%$ & $4.2 \%$ & $5.2 \%$ & $6.8 \%$ & $32.4 \%$ & $14.8 \%$ & $10.2 \%$ & $50.0 \%$ & $24.6 \%$ \\
\hline & Latino & $11.3 \%$ & $0 \%$ & $7.8 \%$ & $8.1 \%$ & $2.9 \%$ & $6.5 \%$ & $5.5 \%$ & $6.9 \%$ & $6.0 \%$ \\
\hline & Nat Am & $0 \%$ & $4.2 \%$ & $1.3 \%$ & $0 \%$ & $5.9 \%$ & $1.9 \%$ & $0 \%$ & $0 \%$ & $0 \%$ \\
\hline & White & $75.5 \%$ & $87.5 \%$ & $79.2 \%$ & $75.7 \%$ & $58.8 \%$ & $70.4 \%$ & $78.0 \%$ & $34.7 \%$ & $62.3 \%$ \\
\hline \multirow{8}{*}{ 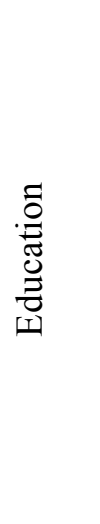 } & Some HS & $0 \%$ & $0 \%$ & $0 \%$ & $0 \%$ & $0 \%$ & $0 \%$ & $0.8 \%$ & $0 \%$ & $0.5 \%$ \\
\hline & HS Grad & $7.5 \%$ & $0 \%$ & $5.1 \%$ & $5.4 \%$ & $3.0 \%$ & $4.7 \%$ & $3.9 \%$ & $8.2 \%$ & $5.5 \%$ \\
\hline & Some college & $24.5 \%$ & $15.4 \%$ & $21.5 \%$ & $16.2 \%$ & $0 \%$ & $11.2 \%$ & $22.0 \%$ & $0 \%$ & $14.0 \%$ \\
\hline & Trade & $0 \%$ & $0 \%$ & $0 \%$ & $1.4 \%$ & $0 \%$ & $0.9 \%$ & $4.7 \%$ & $0 \%$ & $3.0 \%$ \\
\hline & Associates & $13.2 \%$ & $3.8 \%$ & $10.1 \%$ & $16.2 \%$ & $0 \%$ & $11.2 \%$ & $14.2 \%$ & $6.8 \%$ & $11.5 \%$ \\
\hline & Bachelors & $41.5 \%$ & $38.5 \%$ & $40.5 \%$ & $44.6 \%$ & $48.5 \%$ & $45.8 \%$ & $44.9 \%$ & $38.4 \%$ & $42.5 \%$ \\
\hline & Masters & $13.2 \%$ & $38.5 \%$ & $21.5 \%$ & $14.9 \%$ & $36.4 \%$ & $21.5 \%$ & $8.7 \%$ & $42.5 \%$ & $21.0 \%$ \\
\hline & Doctorate & $0 \%$ & $3.8 \%$ & $1.3 \%$ & $1.4 \%$ & $12.1 \%$ & $4.7 \%$ & $0.8 \%$ & $4.1 \%$ & $2.0 \%$ \\
\hline \multirow{2}{*}{ 异 } & Under $\$ 25 \mathrm{k}$ & $7.5 \%$ & $0 \%$ & $5.1 \%$ & $8.1 \%$ & $0 \%$ & $5.6 \%$ & $17.3 \%$ & $2.7 \%$ & $12.0 \%$ \\
\hline & $\$ 25-\$ 50$ & $35.8 \%$ & $0 \%$ & $24.4 \%$ & $32.4 \%$ & $3.0 \%$ & $23.4 \%$ & $28.3 \%$ & $2.7 \%$ & $19.0 \%$ \\
\hline
\end{tabular}




\begin{tabular}{|c|c|c|c|c|c|c|c|c|c|c|}
\hline & $\$ 50-\$ 75$ & $24.5 \%$ & $8.0 \%$ & $19.2 \%$ & $28.4 \%$ & $6.1 \%$ & $21.5 \%$ & $22.0 \%$ & $13.7 \%$ & $19.0 \%$ \\
\hline & $\$ 75-\$ 100$ & $17 \%$ & $12.0 \%$ & $15.4 \%$ & $18.9 \%$ & $18.2 \%$ & $18.7 \%$ & $14.2 \%$ & $19.2 \%$ & $16.0 \%$ \\
\hline & $\$ 100-\$ 125$ & $3.8 \%$ & $16.0 \%$ & $7.7 \%$ & $4.1 \%$ & $12.1 \%$ & $6.5 \%$ & $10.2 \%$ & $17.8 \%$ & $13.0 \%$ \\
\hline & Above $\$ 125$ & $11.3 \%$ & $40.0 \%$ & $20.5 \%$ & $5.4 \%$ & $60.6 \%$ & $22.4 \%$ & $6.3 \%$ & $39.7 \%$ & $18.5 \%$ \\
\hline & No response & $0 \%$ & $24.0 \%$ & $7.7 \%$ & $2.7 \%$ & $0 \%$ & $1.9 \%$ & $1.6 \%$ & $4.1 \%$ & $2.5 \%$ \\
\hline \multirow{11}{*}{ 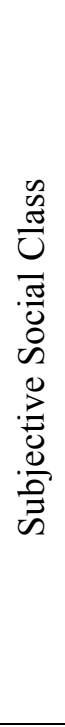 } & 0 & $0 \%$ & $0 \%$ & $0 \%$ & $0 \%$ & $0 \%$ & $0 \%$ & $3.1 \%$ & $0 \%$ & $2.0 \%$ \\
\hline & 1 & $0 \%$ & $0 \%$ & $0 \%$ & $0 \%$ & $0 \%$ & $0 \%$ & $4.7 \%$ & $0 \%$ & $3.1 \%$ \\
\hline & 2 & $13.2 \%$ & $0 \%$ & $3.8 \%$ & $1.4 \%$ & $0 \%$ & $0.9 \%$ & $5.5 \%$ & $0 \%$ & $3.6 \%$ \\
\hline & 3 & $26.4 \%$ & $0 \%$ & $10.3 \%$ & $9.5 \%$ & $6.3 \%$ & $8.5 \%$ & $15.0 \%$ & $1.4 \%$ & $10.2 \%$ \\
\hline & 4 & $43.4 \%$ & $0 \%$ & $15.4 \%$ & $16.2 \%$ & $6.3 \%$ & $13.2 \%$ & $15.0 \%$ & $4.3 \%$ & $11.2 \%$ \\
\hline & 5 & $1.9 \%$ & $4.0 \%$ & $11.5 \%$ & $17.6 \%$ & $6.3 \%$ & $14.2 \%$ & $18.1 \%$ & $14.5 \%$ & $16.8 \%$ \\
\hline & 6 & $5.7 \%$ & $20.0 \%$ & $23.1 \%$ & $23.0 \%$ & $9.4 \%$ & $18.9 \%$ & $18.1 \%$ & $18.8 \%$ & $18.4 \%$ \\
\hline & 7 & $1.9 \%$ & $32.0 \%$ & $16.7 \%$ & $16.2 \%$ & $37.5 \%$ & $22.6 \%$ & $15.7 \%$ & $27.5 \%$ & $19.9 \%$ \\
\hline & 8 & $7.5 \%$ & $24.0 \%$ & $12.8 \%$ & $14.9 \%$ & $18.8 \%$ & $16.0 \%$ & $15.7 \%$ & $27.5 \%$ & $12.2 \%$ \\
\hline & 9 & $0 \%$ & $20.0 \%$ & $6.4 \%$ & $1.4 \%$ & $12.5 \%$ & $4.7 \%$ & $0.8 \%$ & $4.3 \%$ & $2.0 \%$ \\
\hline & 10 & $0 \%$ & $0 \%$ & $0 \%$ & $0 \%$ & $3.1 \%$ & $0.9 \%$ & $0 \%$ & $1.4 \%$ & $0.5 \%$ \\
\hline \multirow{7}{*}{$\begin{array}{l}\stackrel{0}{\Xi} \\
\stackrel{\Xi}{E} \\
0 \\
0\end{array}$} & Assistant & $13.2 \%$ & $0 \%$ & $9.0 \%$ & $9.5 \%$ & $3.1 \%$ & $7.5 \%$ & $11.0 \%$ & $1.4 \%$ & $7.5 \%$ \\
\hline & Analyst & $26.4 \%$ & $4.0 \%$ & $19.2 \%$ & $28.4 \%$ & $9.4 \%$ & $22.6 \%$ & $23.6 \%$ & $12.5 \%$ & $19.6 \%$ \\
\hline & Manager & $43.4 \%$ & $80.0 \%$ & $55.1 \%$ & $44.6 \%$ & $43.8 \%$ & $44.3 \%$ & $40.9 \%$ & $40.3 \%$ & $40.7 \%$ \\
\hline & Vice President & $1.9 \%$ & $4.0 \%$ & $2.6 \%$ & $1.4 \%$ & $12.5 \%$ & $4.7 \%$ & $0.8 \%$ & $11.1 \%$ & $4.5 \%$ \\
\hline & Chief Officer & $0 \%$ & $0 \%$ & $0 \%$ & $0 \%$ & $3.1 \%$ & $0.9 \%$ & $1.6 \%$ & $1.4 \%$ & $1.4 \%$ \\
\hline & Self-employed & $5.7 \%$ & $0 \%$ & $3.8 \%$ & $1.4 \%$ & $3.1 \%$ & $1.9 \%$ & $4.7 \%$ & $8.3 \%$ & $6.0 \%$ \\
\hline & Student & $1.9 \%$ & $0 \%$ & $1.3 \%$ & $1.4 \%$ & $3.1 \%$ & $1.9 \%$ & $0 \%$ & $5.6 \%$ & $2.0 \%$ \\
\hline
\end{tabular}




\begin{tabular}{|c|c|c|c|c|c|c|c|c|c|c|}
\hline & Other & $7.5 \%$ & $12.0 \%$ & $9.0 \%$ & $13.5 \%$ & $21.9 \%$ & $16.0 \%$ & $17.3 \%$ & $19.4 \%$ & $18.1 \%$ \\
\hline \multirow{20}{*}{$\begin{array}{l}\stackrel{Z}{E} \\
\stackrel{0}{E} \\
\stackrel{\Xi}{E}\end{array}$} & Admin support & $3.8 \%$ & $0 \%$ & $2.6 \%$ & $4.1 \%$ & $0 \%$ & $2.8 \%$ & $13.6 \%$ & $10.4 \%$ & $11.7 \%$ \\
\hline & Agriculture & $0 \%$ & $0 \%$ & $0 \%$ & $0 \%$ & $0 \%$ & $0 \%$ & $1.2 \%$ & $3.5 \%$ & $2.6 \%$ \\
\hline & Arts & $5.7 \%$ & $4.0 \%$ & $5.1 \%$ & $4.1 \%$ & $6.3 \%$ & $4.7 \%$ & $4.9 \%$ & $8.7 \%$ & $7.1 \%$ \\
\hline & Construction & $1.9 \%$ & $0 \%$ & $1.3 \%$ & $4.1 \%$ & $0 \%$ & $2.8 \%$ & $6.2 \%$ & $2.6 \%$ & $4.1 \%$ \\
\hline & Education & $5.7 \%$ & $16.0 \%$ & $9.0 \%$ & $9.5 \%$ & $6.3 \%$ & $8.5 \%$ & $7.4 \%$ & $9.6 \%$ & $8.7 \%$ \\
\hline & Finance & $1.9 \%$ & $28.0 \%$ & $10.3 \%$ & $5.4 \%$ & $9.4 \%$ & $6.6 \%$ & $2.5 \%$ & $9.6 \%$ & $6.6 \%$ \\
\hline & Food service & $3.8 \%$ & $8.0 \%$ & $5.1 \%$ & $4.1 \%$ & $0 \%$ & $2.8 \%$ & $4.9 \%$ & $2.6 \%$ & $3.6 \%$ \\
\hline & Healthcare & $9.4 \%$ & $0 \%$ & $6.4 \%$ & $12.2 \%$ & $12.5 \%$ & $12.3 \%$ & $7.4 \%$ & $11.3 \%$ & $9.7 \%$ \\
\hline & Information & $3.8 \%$ & $0 \%$ & $2.6 \%$ & $9.5 \%$ & $9.4 \%$ & $9.4 \%$ & $4.9 \%$ & $7.8 \%$ & $6.6 \%$ \\
\hline & Management & $3.8 \%$ & $0 \%$ & $2.6 \%$ & $2.7 \%$ & $3.1 \%$ & $2.8 \%$ & $3.7 \%$ & $2.6 \%$ & $3.1 \%$ \\
\hline & Manufacturing & $3.8 \%$ & $0 \%$ & $2.6 \%$ & $8.1 \%$ & $18.8 \%$ & $11.3 \%$ & $2.5 \%$ & $5.2 \%$ & $4.1 \%$ \\
\hline & Mining & $0 \%$ & $0 \%$ & $0 \%$ & $0 \%$ & $0 \%$ & $0 \%$ & $2.5 \%$ & $0 \%$ & $1.0 \%$ \\
\hline & Other services & $5.7 \%$ & $8.0 \%$ & $6.4 \%$ & $4.1 \%$ & $0 \%$ & $2.8 \%$ & $7.4 \%$ & $0.9 \%$ & $3.6 \%$ \\
\hline & Professional & $9.4 \%$ & $4.0 \%$ & $7.7 \%$ & $10.8 \%$ & $18.8 \%$ & $13.2 \%$ & $7.4 \%$ & $6.1 \%$ & $6.6 \%$ \\
\hline & Public admin & $7.5 \%$ & $4.0 \%$ & $6.4 \%$ & $5.4 \%$ & $0 \%$ & $3.8 \%$ & $1.2 \%$ & $2.6 \%$ & $2.0 \%$ \\
\hline & Real estate & $1.9 \%$ & $0 \%$ & $1.3 \%$ & $2.7 \%$ & $0 \%$ & $1.9 \%$ & $0 \%$ & $3.5 \%$ & $2.0 \%$ \\
\hline & Transportation & $5.7 \%$ & $8.0 \%$ & $6.4 \%$ & $4.1 \%$ & $3.1 \%$ & $3.8 \%$ & $3.7 \%$ & $0.9 \%$ & $2.0 \%$ \\
\hline & Utilities & $3.8 \%$ & $4.0 \%$ & $3.8 \%$ & $0 \%$ & $0 \%$ & $0 \%$ & $2.5 \%$ & $0.9 \%$ & $1.5 \%$ \\
\hline & Wholesale & $18.9 \%$ & $4.0 \%$ & $4.1 \%$ & $5.4 \%$ & $3.1 \%$ & $4.7 \%$ & $6.2 \%$ & $7.0 \%$ & $6.6 \%$ \\
\hline & Other & $3.8 \%$ & $12.0 \%$ & $6.4 \%$ & $4.1 \%$ & $9.4 \%$ & $5.7 \%$ & $9.9 \%$ & $4.3 \%$ & $6.6 \%$ \\
\hline 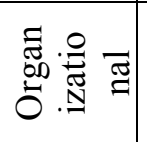 & Top 5 & $\begin{array}{c}\text { Emphasis on } \\
\text { quality }= \\
63.3 \%\end{array}$ & $\begin{array}{c}\text { Results } \\
\text { oriented }= \\
68.2 \%\end{array}$ & $\begin{array}{c}\text { Results } \\
\text { oriented = } \\
63 \%\end{array}$ & $\begin{array}{c}\text { Emphasis on } \\
\text { quality }= \\
55.1 \%\end{array}$ & $\begin{array}{l}\text { Emphasis } \\
\text { on quality } \\
=56.7 \%\end{array}$ & $\begin{array}{l}\text { Emphasis } \\
\text { on quality } \\
=55.6 \%\end{array}$ & $\begin{array}{c}\text { Emphasis on } \\
\text { quality }= \\
56.9 \%\end{array}$ & $\begin{array}{l}\text { Emphasis } \\
\text { on quality } \\
=59.2 \%\end{array}$ & $\begin{array}{l}\text { Emphasis } \\
\text { on quality } \\
=58.3 \%\end{array}$ \\
\hline
\end{tabular}




\begin{tabular}{|c|c|c|c|c|c|c|c|c|c|}
\hline & $\begin{array}{c}\text { Results } \\
\text { oriented }= \\
60.8 \%\end{array}$ & $\begin{array}{l}\text { Good } \\
\text { reputation - } \\
58.3 \%\end{array}$ & $\begin{array}{c}\text { Emphasis on } \\
\text { quality }= \\
59.5 \%\end{array}$ & $\begin{array}{c}\text { Attention to } \\
\text { detail = } \\
46.5 \%\end{array}$ & $\begin{array}{c}\text { Results } \\
\text { oriented }= \\
51.7 \%\end{array}$ & $\begin{array}{c}\text { Team } \\
\text { oriented }= \\
46.5 \%\end{array}$ & $\begin{array}{c}\text { Attention to } \\
\text { detail = } \\
46.5 \%\end{array}$ & $\begin{array}{l}\text { Adaptabilit } \\
\mathrm{y}=52.8 \%\end{array}$ & $\begin{array}{l}\text { Adaptabilit } \\
\mathrm{y}=53.9 \%\end{array}$ \\
\hline & $\begin{array}{c}\text { Achieve } \\
\text { orientation }= \\
50.0 \%\end{array}$ & $\begin{array}{c}\text { People } \\
\text { oriented }= \\
58.3 \%\end{array}$ & $\begin{array}{c}\text { People } \\
\text { oriented }= \\
52.7 \%\end{array}$ & $\begin{array}{c}\text { Achieve } \\
\text { orientation }= \\
46.2 \%\end{array}$ & $\begin{array}{l}\text { Good } \\
\text { reputation } \\
=51.6 \%\end{array}$ & $\begin{array}{c}\text { Results } \\
\text { oriented }= \\
46.0 \%\end{array}$ & $\begin{array}{c}\text { Achieve } \\
\text { orientation }= \\
55.6 \%\end{array}$ & $\begin{array}{c}\text { Results } \\
\text { oriented }= \\
51.9 \%\end{array}$ & $\begin{array}{l}\text { Achieve } \\
\text { orientation } \\
=52.7 \%\end{array}$ \\
\hline & $\begin{array}{c}\text { People } \\
\text { oriented }= \\
50.0 \%\end{array}$ & $\begin{array}{c}\text { High perf } \\
\text { expect }= \\
53.8 \%\end{array}$ & $\begin{array}{c}\text { Achieve } \\
\text { orientation }= \\
47.4 \%\end{array}$ & $\begin{array}{c}\text { Team } \\
\text { oriented }= \\
46.5 \%\end{array}$ & $\begin{array}{l}\text { High perf } \\
\text { expect }= \\
50.0 \%\end{array}$ & $\begin{array}{l}\text { Adaptabilit } \\
\mathrm{y}=43.3 \%\end{array}$ & $\begin{array}{l}\text { Adaptability } \\
\quad=55.6 \%\end{array}$ & $\begin{array}{c}\text { Achieve } \\
\text { orientation } \\
=50.8 \%\end{array}$ & $\begin{array}{c}\text { Results } \\
\text { oriented }= \\
51.1 \%\end{array}$ \\
\hline & $\begin{array}{c}\text { Analytical = } \\
45.1 \% / \\
\text { Highly } \\
\text { organized = } \\
45.1 \%\end{array}$ & $\begin{array}{c}\text { Emphasis on } \\
\text { quality }= \\
52.0 \%\end{array}$ & $\begin{array}{l}\text { High perf } \\
\text { expectations } \\
=44.2 \%\end{array}$ & $\begin{array}{l}\text { Adaptability } \\
\quad=45.7 \%\end{array}$ & $\begin{array}{c}\text { Team } \\
\text { oriented }= \\
46.4 \%\end{array}$ & $\begin{array}{l}\text { Achieve } \\
\text { orientation } \\
=42.9 \%\end{array}$ & $\begin{array}{c}\text { Results } \\
\text { oriented }= \\
50.0 \%\end{array}$ & $\begin{array}{c}\text { People } \\
\text { oriented }= \\
44.7 \%\end{array}$ & $\begin{array}{c}\text { People } \\
\text { oriented }= \\
44.9 \%\end{array}$ \\
\hline Bottom 5 & $\begin{array}{l}\text { Risk taking } \\
=35.8 \%\end{array}$ & $\begin{array}{c}\text { Being } \\
\text { aggressive }= \\
37.5 \%\end{array}$ & $\begin{array}{l}\text { Risk taking } \\
=34.2 \%\end{array}$ & $\begin{array}{l}\text { Risk taking } \\
=38.4 \%\end{array}$ & $\begin{array}{l}\text { Being } \\
\text { aggressive } \\
=46.2 \%\end{array}$ & $\begin{array}{l}\text { Risk taking } \\
=34.3 \%\end{array}$ & $\begin{array}{l}\text { Risk taking } \\
=30.2 \%\end{array}$ & $\begin{array}{l}\text { Risk taking } \\
=32.3 \%\end{array}$ & $\begin{array}{l}\text { Risk taking } \\
=31.4 \%\end{array}$ \\
\hline & $\begin{array}{l}\text { High pay for } \\
\text { perf }= \\
28.8 \%\end{array}$ & $\begin{array}{l}\text { Risk taking } \\
=30.8 \%\end{array}$ & $\begin{array}{c}\text { Not } \\
\text { constrained } \\
\text { by many } \\
\text { rules }= \\
27.6 \%\end{array}$ & $\begin{array}{c}\text { Working } \\
\text { long hours }= \\
28.4 \%\end{array}$ & $\begin{array}{c}\text { High pay } \\
\text { for perf }= \\
44.8 \%\end{array}$ & $\begin{array}{c}\text { Being } \\
\text { aggressive } \\
=30.9 \%\end{array}$ & $\begin{array}{c}\text { Working } \\
\text { long hours }= \\
27.2 \%\end{array}$ & $\begin{array}{c}\text { Not } \\
\text { constrained } \\
\text { by many } \\
\text { rules }= \\
28.9 \%\end{array}$ & $\begin{array}{c}\text { High pay } \\
\text { for perf }= \\
27.4 \%\end{array}$ \\
\hline & $\begin{array}{c}\text { Not } \\
\text { constrained } \\
\text { by many rules } \\
=28.3 \%\end{array}$ & $\begin{array}{c}\text { Not } \\
\text { constrained } \\
\text { by many rules } \\
=26.1 \%\end{array}$ & $\begin{array}{l}\text { High pay for } \\
\text { perf }=26.3 \%\end{array}$ & $\begin{array}{c}\text { Being } \\
\text { aggressive }= \\
25.4 \%\end{array}$ & $\begin{array}{l}\text { Risk taking } \\
=25.0 \%\end{array}$ & $\begin{array}{c}\text { High pay } \\
\text { for perf }= \\
27.0 \%\end{array}$ & $\begin{array}{c}\text { High pay for } \\
\text { perf }= \\
26.8 \%\end{array}$ & $\begin{array}{c}\text { High pay } \\
\text { for perf = } \\
27.7 \%\end{array}$ & $\begin{array}{l}\text { Working } \\
\text { long hours } \\
=27.0 \%\end{array}$ \\
\hline & $\begin{array}{c}\text { Identificatio } \\
\mathrm{n} \text { respon }= \\
22.0 \%\end{array}$ & $\begin{array}{c}\text { High pay for } \\
\text { perf }= \\
20.8 \%\end{array}$ & $\begin{array}{c}\text { Being } \\
\text { aggressive }= \\
26.8 \%\end{array}$ & $\begin{array}{c}\text { Not } \\
\text { constrained } \\
\text { by many rules } \\
=23.6 \%\end{array}$ & $\begin{array}{c}\text { Being } \\
\text { distinctive } \\
=24.0 \%\end{array}$ & $\begin{array}{l}\text { Working } \\
\text { long hours } \\
=25.0 \%\end{array}$ & $\begin{array}{c}\text { Not } \\
\text { constrained } \\
\text { by many rules } \\
=23.1 \%\end{array}$ & $\begin{array}{l}\text { Being } \\
\text { aggressive } \\
=26.8 \%\end{array}$ & $\begin{array}{c}\text { Not } \\
\text { constrained } \\
\text { by many } \\
\text { rules }= \\
26.6 \%\end{array}$ \\
\hline & $\begin{array}{c}\text { Being } \\
\text { aggressive }= \\
21.3 \%\end{array}$ & $\begin{array}{l}\text { Informality } \\
=17.4 \%\end{array}$ & $\begin{array}{c}\text { Identificatio } \\
\mathrm{n} \text { respon }= \\
19.7 \%\end{array}$ & $\begin{array}{c}\text { Sharing info } \\
\text { freely }= \\
20.8 \%\end{array}$ & $\begin{array}{c}\text { Confront } \\
\text { conflict } \\
\text { directly = } \\
23.3 \%\end{array}$ & $\begin{array}{c}\text { Confront } \\
\text { conflict } \\
\text { directly = } \\
20.4 \%\end{array}$ & $\begin{array}{l}\text { Informality } \\
\quad=21 \%\end{array}$ & $\begin{array}{l}\text { Working } \\
\text { long hours } \\
=26.8\end{array}$ & $\begin{array}{l}\text { Being } \\
\text { aggressive } \\
=25.2 \%\end{array}$ \\
\hline
\end{tabular}

*Due to same percentages for some items, top six cultural profile items were shown for the M-Turk sample type. 
Table 6. Counterbalancing - All Stages

\begin{tabular}{|c|c|c|c|}
\hline Applicant number & $\begin{array}{l}\text { Acquiring - \# of } \\
\text { ratings }\end{array}$ & $\begin{array}{l}\text { Screening - \# of } \\
\text { ratings }\end{array}$ & $\begin{array}{c}\text { Interviewing - \# of } \\
\text { ratings }\end{array}$ \\
\hline 1 & 45 & 40 & 25 \\
\hline 2 & 45 & 37 & 25 \\
\hline 3 & 46 & 38 & 26 \\
\hline 4 & 46 & 34 & 34 \\
\hline 5 & 48 & 34 & 20 \\
\hline 6 & 48 & 34 & 20 \\
\hline 7 & 47 & 42 & 27 \\
\hline 8 & 48 & 40 & 22 \\
\hline 9 & 50 & 40 & 36 \\
\hline 10 & 43 & 34 & 30 \\
\hline 11 & 50 & 40 & 27 \\
\hline 12 & 48 & 36 & 25 \\
\hline 13 & 43 & 40 & 24 \\
\hline 14 & 46 & 39 & 29 \\
\hline 15 & 46 & 40 & 28 \\
\hline 16 & 48 & 37 & 21 \\
\hline 17 & 48 & 37 & 26 \\
\hline 18 & 52 & 38 & 23 \\
\hline 19 & 47 & 36 & 28 \\
\hline 20 & 51 & 37 & 31 \\
\hline 21 & 46 & 42 & 27 \\
\hline 22 & 45 & 39 & 29 \\
\hline 23 & 47 & 39 & 23 \\
\hline 24 & 49 & 39 & 23 \\
\hline 25 & 47 & 34 & 30 \\
\hline 26 & 52 & 38 & 20 \\
\hline 27 & 46 & 40 & 25 \\
\hline 28 & 48 & 41 & 27 \\
\hline 29 & 50 & 39 & 26 \\
\hline 30 & 52 & 39 & 27 \\
\hline 31 & 44 & 40 & 35 \\
\hline 32 & 46 & 37 & 23 \\
\hline
\end{tabular}


Table 7. Percentage of variance for each hiring process stage

$$
\text { DV - PO Perceptions }
$$

\begin{tabular}{|c|c|c|c|c|c|c|}
\hline & Level-1 N & $\begin{array}{c}\text { Level-1 } \\
\text { variance }\end{array}$ & Level-2 N & Level-2 & Level-3 N & Level-3 \\
variance & & & variance \\
\hline Acquiring & 1241 & $38 \%$ & 79 & $58 \%$ & 32 & $4 \%$ \\
\hline Screening & 1037 & $66 \%$ & 105 & $29 \%$ & 32 & $4 \%$ \\
\hline Interviewing & 852 & $72 \%$ & 220 & $23 \%$ & 32 & $5 \%$ \\
\hline
\end{tabular}


Table 8. Means, SD, Correlations - Acquiring stage

\begin{tabular}{|c|c|c|c|c|c|c|c|c|c|c|c|c|c|c|}
\hline & Mean & $\mathrm{SD}$ & 1 & 2 & 3 & 4 & 5 & 6 & 7 & 8 & 9 & 10 & 11 & 12 \\
\hline \multicolumn{15}{|l|}{ Level-1 $(N=1517)$} \\
\hline PO fit perceptions & 3.07 & 0.77 & $(.93)$ & & & & & & & & & & & \\
\hline Continue in hiring process & 3.37 & .97 & $.760^{* *}$ & & & & & & & & & & & \\
\hline \multicolumn{15}{|l|}{ Level-2 Applicant $(N=1517)$} \\
\hline Applicant economic capital & 0.50 & 0.50 & $.118^{* *}$ & $.093^{* *}$ & & & & & & & & & & \\
\hline Applicant social capital & 0.50 & 0.50 & $.111^{* *}$ & $.166^{* *}$ & .002 & & & & & & & & & \\
\hline Applicant race & 0.49 & 0.50 & -.004 & -.012 & .001 & -.061 & .006 & & & & & & & \\
\hline Applicant sex & 0.50 & 0.50 & .010 & -.018 & .001 & .007 & .006 & .001 & & & & & & \\
\hline \multicolumn{15}{|l|}{ Level-2 Hiring Manager $(N=1253)$} \\
\hline Hiring manager subjective social class (ruler) & 5.66 & 1.95 & -.043 & $.000^{*}$ & .052 & -.003 & .001 & -.012 & .000 & & & & & \\
\hline Hiring managers' subjective social class (scale) & 3.12 & 0.79 & $.082^{* *}$ & $.080^{* *}$ & .041 & -.008 & .009 & .000 & -.014 & $.525^{* *}$ & $(.78)$ & & & \\
\hline Hiring managers' social capital value & 4.00 & 0.54 & $-.085^{* *}$ & -.031 & -.008 & -.025 & .000 & -.012 & -.027 & .034 & .052 & $(.77)$ & & \\
\hline Hiring managers' race & 0.27 & 0.26 & -.031 & .049 & .031 & $-.073^{*}$ & -.012 & -.026 & -.006 & .050 & -.041 & $.129^{*}$ & & \\
\hline Hiring managers' sex & 0.48 & 0.49 & $.062^{*}$ & $.065^{*}$ & -.029 & .007 & .030 & .008 & -.011 & -.026 & $-.120^{* *}$ & $-.304^{* *}$ & $-.078^{* *}$ & - \\
\hline
\end{tabular}

**. Correlation is significant at the 0.01 level (2-tailed).
$*$. Correlation is significant at the 0.05 level (2-tailed). 
Table 9. Means, SD, Correlations - Screening stage

\begin{tabular}{|c|c|c|c|c|c|c|c|c|c|c|c|c|c|}
\hline & Mean & SD & 1 & 2 & 3 & 4 & 5 & 6 & 7 & 8 & 9 & 10 & 11 \\
\hline \multicolumn{14}{|l|}{ Level-1 $(N=1220)$} \\
\hline PO fit perceptions & 3.35 & 0.71 & $(.93)$ & & & & & & & & & & \\
\hline Continue in hiring process & 3.33 & 0.88 & $.805^{* *}$ & & & & & & & & & & \\
\hline \multicolumn{14}{|l|}{ Level-2 Applicant $(N=1220)$} \\
\hline Applicant economic capital & 0.50 & 0.50 & $-.153^{* *}$ & $-.246^{* *}$ & & & & & & & & & \\
\hline Applicant social capital & 0.49 & 0.50 & -.031 & -.017 & -.006 & & & & & & & & \\
\hline Applicant cultural capital & 0.50 & 0.50 & $.122^{* *}$ & $.112^{* *}$ & -.002 & .005 & & & & & & & \\
\hline Applicant race & 0.50 & 0.50 & .021 & .021 & .023 & -.007 & .002 & & & & & & \\
\hline Applicant sex & 0.50 & 0.50 & .021 & .021 & -.008 & .002 & .013 & .005 & & & & & \\
\hline \multicolumn{14}{|l|}{ Level-2 Hiring Manager $(N=2368)$} \\
\hline Hiring manager subjective social class (ruler) & 5.96 & 1.84 & $-.062^{*}$ & -.028 & .028 & -.017 & .026 & -.002 & -.020 & & & & \\
\hline Hiring manager subjective social class (scale) & 3.15 & 0.73 & $.118^{* *}$ & .041 & .023 & .005 & .037 & -.002 & .038 & $.451^{* *}$ & $(.67)$ & & \\
\hline Hiring manager race & 0.29 & 0.46 & $.073^{*}$ & .044 & .034 & -.017 & .039 & .006 & -.012 & $.073^{*}$ & $.149^{* *}$ & & \\
\hline Hiring manager sex & 0.51 & 0.50 & -.010 & -.030 & -.020 & .000 & .033 & -.024 & -.024 & $-.096^{* *}$ & $-.110^{* *}$ & .051 & - \\
\hline
\end{tabular}

**. Correlation is significant at the 0.01 level (2-tailed).

*. Correlation is significant at the 0.05 level (2-tailed). 
Table 10. Means, SD, Correlations - Interviewing stage

\begin{tabular}{|c|c|c|c|c|c|c|c|c|c|c|c|c|c|c|}
\hline & Mean & SD & 1 & 2 & 3 & 4 & 5 & 6 & 7 & 8 & 9 & 10 & 11 & 12 \\
\hline \multicolumn{15}{|l|}{ Level-1 $(N=852)$} \\
\hline PO fit perceptions & 3.48 & 0.90 & $(.90)$ & & & & & & & & & & & \\
\hline Continue in hiring process & 3.54 & 1.15 & $.858^{* *}$ & & & & & & & & & & & \\
\hline Hiring recommendations $(\mathrm{N}=106)$ & 3.35 & 1.00 & $.891^{* *}$ & $.865^{* *}$ & $(.95)$ & & & & & & & & & \\
\hline \multicolumn{15}{|l|}{ Level-2 Applicant $(N=852)$} \\
\hline Applicant economic capital & 0.49 & 0.50 & $-.732^{* *}$ & $-.606^{* *}$ & $-.753^{* *}$ & & & & & & & & & \\
\hline Applicant social capital & 0.51 & 0.50 & .050 & .059 & .040 & -.049 & & & & & & & & \\
\hline Applicant cultural capital & 0.51 & 0.50 & $.072^{*}$ & $.094^{* *}$ & .060 & -.033 & .030 & & & & & & & \\
\hline Applicant race & 0.50 & 0.50 & $0.78^{*}$ & $.088^{*}$ & .136 & -.047 & .021 & -.028 & & & & & & \\
\hline Applicant sex & 0.50 & 0.50 & $.113^{* *}$ & $.094^{* *}$ & .080 & -.061 & -.007 & -.009 & -.005 & & & & & \\
\hline \multicolumn{15}{|l|}{ Level -2 Hiring Manager $(N=852)$} \\
\hline $\begin{array}{l}\text { Hiring manager subjective social class } \\
\text { (ruler) }\end{array}$ & 3.73 & 3.11 & $.095^{* *}$ & .030 & .015 & -.014 & .056 & .031 & -.005 & -.007 & & & & \\
\hline $\begin{array}{l}\text { Hiring manager subjective social class } \\
\text { (scale) }\end{array}$ & 2.06 & 1.68 & $.094^{* *}$ & .057 & -.047 & -.025 & .044 & .017 & -.004 & -.006 & $.788^{* *}$ & $(.75)$ & & \\
\hline Hiring manager race $(\mathrm{N}=584)$ & 0.35 & 0.48 & .034 & .024 & -.076 & -.068 & -.073 & -.042 & -.003 & .000 & .071 & .070 & & \\
\hline Hiring manager sex $(N=584)$ & 0.53 & 0.50 & .006 & .052 & -.123 & .046 & -.026 & -.025 & .000 & .010 & .041 & $-.084^{*}$ & .055 & - \\
\hline
\end{tabular}

**. Correlation is significant at the 0.01 level (2-tailed)

*. Correlation is significant at the 0.05 level (2-tailed). 


\begin{tabular}{|c|c|c|c|}
\hline \multicolumn{4}{|c|}{ Table 11a. Results of Three-Level Analysis - Acquiring Stage } \\
\hline \multirow{2}{*}{ Level and variable } & \multicolumn{3}{|c|}{ Perceptions of applicant P-O Fit } \\
\hline & 1 & 2 & 3 \\
\hline \multicolumn{4}{|l|}{ Level $1(N=1241)$} \\
\hline Intercept & $3.54(.55)^{* *}$ & $3.30(.55)^{* *}$ & $3.29(.55)^{* *}$ \\
\hline \multicolumn{4}{|l|}{ Level 2 - Applicant $(N=32)$} \\
\hline 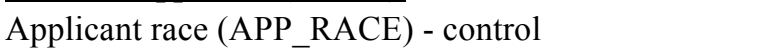 & $-.02(.06)$ & $-.02(.03)$ & $-.02(.03)$ \\
\hline Applicant sex (APP_SEX) - control & $.02(.06)$ & $.02(.03)$ & $.02(.03)$ \\
\hline Applicant average social class (AVGCAP) & & $.49(.05)^{* *}$ & \\
\hline Applicant economic capital (EC) & & & $.16(.03)^{* *}$ \\
\hline Applicant social capital (SC) & & & $.22(.03)^{* *}$ \\
\hline Applicant cultural capital (CC) & & & $.11(.03)^{* *}$ \\
\hline \multicolumn{4}{|l|}{ Applicant class code (ULCODE) } \\
\hline \multicolumn{4}{|l|}{ Applicant social class conflict (CONFLICT) } \\
\hline \multicolumn{4}{|l|}{ Level 2 - Hiring Manager $(N=79)$} \\
\hline Hiring manager race (control) & $-.01(.10)$ & $-.01(.10)$ & $-.01(.10)$ \\
\hline Hiring manager sex (control) & $.05(.14)$ & $.05(.14)$ & $.05(.14)$ \\
\hline Hiring manager value of social capital (control) & $-.11(.13)$ & $-.11(.13)$ & $-.11(.13)$ \\
\hline \multicolumn{4}{|l|}{ Hiring manager social class (SCLASS) } \\
\hline \multicolumn{4}{|l|}{$\underline{\text { Interactions }}$} \\
\hline \multicolumn{4}{|l|}{ 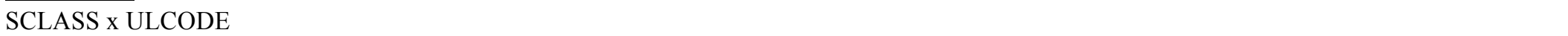 } \\
\hline \multicolumn{4}{|l|}{ ULCODE x CONFLICT (INT) } \\
\hline \multicolumn{4}{|l|}{ EC x CONFLICT (ECINT) } \\
\hline \multicolumn{4}{|l|}{ SC x CONFLICT (SCINT) } \\
\hline \multicolumn{4}{|l|}{ CC x CONFLICT (CCINT) } \\
\hline$\sim \mathrm{R}^{2}$ & 0.18 & 0.21 & 0.21 \\
\hline Deviance & 2029.970 & 1989.448 & 1982.116 \\
\hline $\mathrm{df}_{\text {intercept }}$ & 1130 & 1130 & 1130 \\
\hline
\end{tabular}




\begin{tabular}{|c|c|c|c|c|}
\hline \multicolumn{5}{|c|}{ Table 11b. Results of Three-Level Analysis - Acquiring Stage } \\
\hline \multirow{2}{*}{ Level and variable } & \multicolumn{4}{|c|}{$\begin{array}{l}\text { Perceptions of applicant P-O Fit } \\
\end{array}$} \\
\hline & $4 a$ & $4 \mathbf{b}$ & $5 \mathbf{a}$ & 5b \\
\hline \multicolumn{5}{|l|}{ Level $1(N=1241)$} \\
\hline $\begin{array}{l}\text { Intercept } \\
\end{array}$ & $2.91(.61)^{* *}$ & $3.24(.63)^{* *}$ & $3.16(.56)^{* *}$ & $2.33(.59)^{* *}$ \\
\hline \multicolumn{5}{|l|}{ Level 2 - Applicant $(N=32)$} \\
\hline 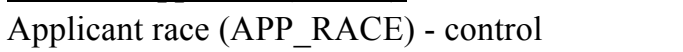 & $-.02(.04)$ & $-.02(.04)$ & $-.02(.04)$ & $-.02(.03)$ \\
\hline Applicant sex (APP_SEX) - control & $.01(.04)$ & $.02(.04)$ & $.01(.04)$ & $.02(.03)$ \\
\hline \multicolumn{5}{|l|}{ Applicant average social class (AVGCAP) } \\
\hline \multicolumn{5}{|l|}{ Applicant economic capital (EC) } \\
\hline \multicolumn{5}{|l|}{ Applicant social capital (SC) } \\
\hline \multicolumn{5}{|l|}{ Applicant cultural capital (CC) } \\
\hline Applicant class code (ULCODE) & $.25(04)^{* *}$ & $.02(.12)$ & $.25(04)^{* *}$ & $.81(.13)^{* *}$ \\
\hline Applicant social class conflict (CONFLICT) & & & $.003(.05)$ & $.49(.11)^{* *}$ \\
\hline \multicolumn{5}{|l|}{ Level 2 - Hiring Manager $(N=79)$} \\
\hline $\begin{array}{l}\text { Hiring manager race (control) } \\
\text { (c) }\end{array}$ & $-.005(.10)$ & $-.005(.10)$ & $-.01(.10)$ & $-.01(.10)$ \\
\hline Hiring manager sex (control) & $.07(.14)$ & $.07(.14)$ & $.05(.14)$ & $.05(.14)$ \\
\hline Hiring manager value of social capital (control) & $-.11(.13)$ & $-.11(.13)$ & $-.11(.13)$ & $-.11(.13)$ \\
\hline Hiring manager social class (SCLASS) & $.08(.09)$ & $-.02(.10)$ & & \\
\hline \multicolumn{5}{|l|}{ Interactions } \\
\hline SCLASS x ULCODE & & $.07(.04)^{*}$ & & \\
\hline ULCODE x CONFLICT (INT) & & & & $-.32(.07)^{* *}$ \\
\hline \multicolumn{5}{|l|}{ EC x CONFLICT (ECINT) } \\
\hline \multicolumn{5}{|l|}{ SC x CONFLICT (SCINT) } \\
\hline \multicolumn{5}{|l|}{ CC x CONFLICT (CCINT) } \\
\hline$\sim \mathrm{R}^{2}$ & 0.21 & 0.21 & 0.20 & 0.21 \\
\hline Deviance & 2003.915 & 1990.004 & 2004.882 & 1989.44 \\
\hline $\mathrm{df}_{\text {intercept }}$ & 1130 & 1130 & 1130 & 1130 \\
\hline
\end{tabular}

Note. Values in parentheses are standard errors; entries are unstandardized coeffiecients. ${ }^{*} \mathrm{p}<.05$, two-tailed. ${ }^{* *} \mathrm{p}<.01$, two-tailed. 


\begin{tabular}{|c|c|c|c|}
\hline \multicolumn{4}{|c|}{ Table 11c. Results of Three-Level Analysis - Acquiring Stage } \\
\hline \multirow{2}{*}{ Level and variable } & \multicolumn{3}{|c|}{ Perceptions of applicant P-O Fit } \\
\hline & $5 \mathbf{c}$ & $5 \mathbf{d}$ & $5 e$ \\
\hline \multicolumn{4}{|l|}{ Level $1(N=1241)$} \\
\hline$\overline{\text { Intercept }}$ & $3.07(.56)^{* *}$ & $3.11(.56)^{* *}$ & $3.04(.56)^{* *}$ \\
\hline \multicolumn{4}{|l|}{ Level 2 - Applicant $(N=32)$} \\
\hline$\overline{\text { Applicant race (APP_RACE) - control }}$ & $-.02(.04)$ & $-.02(.03)$ & $-.02(.04)$ \\
\hline Applicant sex (APP_SEX) - control & $.02(.04)$ & $.02(.03)$ & $.02(.04)$ \\
\hline \multicolumn{4}{|l|}{ Applicant average social class (AVGCAP) } \\
\hline Applicant economic capital (EC) & $.93(.16)^{* *}$ & & \\
\hline Applicant social capital (SC) & & $.84(.14)^{* *}$ & \\
\hline Applicant cultural capital (CC) & & & $-.51(.10)^{* *}$ \\
\hline \multicolumn{4}{|l|}{ Applicant class code (ULCODE) } \\
\hline Applicant social class conflict (CONFLICT) & $.22(.06)^{*}$ & $.18(.06)^{*}$ & $.26(.07)^{* *}$ \\
\hline \multicolumn{4}{|l|}{ Level 2 - Hiring Manager $(N=79)$} \\
\hline Hiring manager race (RACE) - control & $-.01(.10)$ & $-.01(.10)$ & $-.01(.10)$ \\
\hline Hiring manager sex (SEX) - control & $.05(.14)$ & $.05(.14)$ & $.05(.14)$ \\
\hline Hiring manager value of social capital (control) & $-.11(.13)$ & $-.11(.13)$ & $-.11(.13)$ \\
\hline \multicolumn{4}{|l|}{ Hiring manager social class (SCLASS) } \\
\hline \multicolumn{4}{|l|}{$\underline{\text { Interactions }}$} \\
\hline \multicolumn{4}{|l|}{ SCLASS x ULCODE } \\
\hline \multicolumn{4}{|l|}{ ULCODE x CONFLICT (INT) } \\
\hline EC x CONFLICT (ECINT) & $-.44(.09)^{* *}$ & & \\
\hline SC x CONFLICT (SCINT) & & $-.35(.08)^{* *}$ & \\
\hline CC x CONFLICT (CCINT) & & & $-.51(.09)^{* *}$ \\
\hline$\sim \mathrm{R}^{2}$ & 0.20 & 0.20 & 0.20 \\
\hline Deviance & 2004.415 & 1995.963 & 2005.493 \\
\hline $\mathrm{df}_{\text {intercept }}$ & 1130 & 1130 & 1130 \\
\hline
\end{tabular}




\begin{tabular}{|c|c|c|c|}
\hline \multicolumn{4}{|c|}{ Table 12a. Results of Three-Level Analysis - Screening Stage } \\
\hline \multirow{2}{*}{ Level and variable } & \multicolumn{3}{|c|}{ Perceptions of applicant P-O Fit } \\
\hline & 6 & 7 & 8 \\
\hline \multicolumn{4}{|l|}{ Level $1(N=1037)$} \\
\hline Intercept & $3.33(.08)^{* *}$ & $3.38(.10)^{* *}$ & $3.38(.08)^{* *}$ \\
\hline \multicolumn{4}{|l|}{ Level 2 - Applicant $(N=32)$} \\
\hline$\overline{\text { Applicant race (APP_RACE) - control }}$ & $.03(.07)$ & $.03(.06)$ & $.03(.04)$ \\
\hline Applicant sex (APP_SEX) - control & $-.001(.07)$ & $-.002(.06)$ & $-.002(.04)$ \\
\hline Applicant average social class (AVGCAP) & & $-.10(.11)$ & \\
\hline Applicant economic capital (EC) & & & $-.26(.04) * *$ \\
\hline Applicant social capital (SC) & & & $-.01(.04)$ \\
\hline Applicant cultural capital (CC) & & & $.17(.04)^{* *}$ \\
\hline \multicolumn{4}{|l|}{ Applicant class code (ULCODE) } \\
\hline \multicolumn{4}{|l|}{ Applicant social class conflict (CONFLICT) } \\
\hline \multicolumn{4}{|l|}{ Level 2 - Hiring Manager $(N=105)$} \\
\hline Hiring manager race (RACE) - control & $.12(.09)$ & $.12(.09)$ & $.11(.09)$ \\
\hline Hiring manager sex (SEX) - control & $-.02(.08)$ & $-.02(.08)$ & $-.02(.08)$ \\
\hline \multicolumn{4}{|l|}{ Hiring manager social class (SCLASS) } \\
\hline \multicolumn{4}{|l|}{ Interactions } \\
\hline \multicolumn{4}{|l|}{ 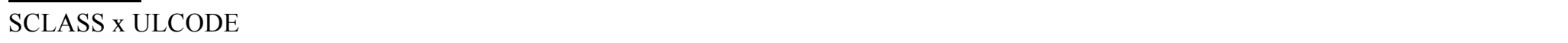 } \\
\hline \multicolumn{4}{|l|}{ ULCODE x CONFLICT (INT) } \\
\hline \multicolumn{4}{|l|}{ EC x CONFLICT (ECINT) } \\
\hline \multicolumn{4}{|l|}{ SC x CONFLICT (SCINT) } \\
\hline \multicolumn{4}{|l|}{ CC x CONFLICT (CCINT) } \\
\hline$\sim \mathrm{R}^{2}$ & 0.31 & 0.32 & 0.35 \\
\hline Deviance & 2028.142 & 2027.394 & 1986.888 \\
\hline $\mathrm{df}_{\text {intercept }}$ & 900 & 900 & 900 \\
\hline
\end{tabular}




\begin{tabular}{|c|c|c|c|c|}
\hline \multicolumn{5}{|c|}{ Table 12b. Results of Three-Level Analysis - Screening Stage } \\
\hline \multirow{2}{*}{ Level and variable } & \multicolumn{4}{|c|}{$\begin{array}{l}\text { Perceptions of applicant P-O Fit } \\
\end{array}$} \\
\hline & $9 \mathrm{a}$ & $9 \mathbf{b}$ & 10a & $10 \mathrm{~b}$ \\
\hline \multicolumn{5}{|l|}{ Level $1(N=1037)$} \\
\hline 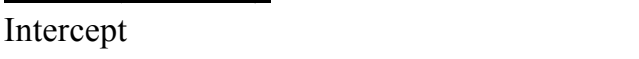 & $3.08(.24)^{* *}$ & $3.16(.35)^{* *}$ & $3.27(.18)^{* *}$ & $3.45(.42)^{* *}$ \\
\hline \multicolumn{5}{|l|}{ Level 2 - Applicant $(N=32)$} \\
\hline 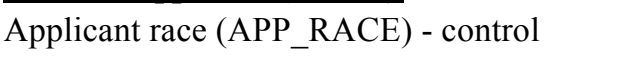 & $.03(.06)$ & $.03(.06)$ & $.03(.06)$ & $.03(.06$ \\
\hline Applicant sex (APP_SEX) - control & $-.003(.06)$ & $-.002(.06)$ & $-.002(.06)$ & $-.002(.06)$ \\
\hline \multicolumn{5}{|l|}{ Applicant average social class (AVGCAP) } \\
\hline Applicant economic capital (EC) & $.12(.17)$ & & & \\
\hline \multicolumn{5}{|l|}{ Applicant social capital (SC) } \\
\hline \multicolumn{5}{|l|}{ Applicant cultural capital (CC) } \\
\hline Applicant class code (ULCODE) & & $-.10(.19)$ & $-.05(.06)$ & $-.16(.26)$ \\
\hline Applicant social class conflict (CONFLICT) & $.19(.07)^{*}$ & & $.08(.07)$ & $-.02(.23)$ \\
\hline \multicolumn{5}{|l|}{ Level 2 - Hiring Manager $(N=105)$} \\
\hline Hiring manager race (RACE) - control & $.12(.09)$ & $.10(.09)$ & $.12(.09)$ & $.12(.09)$ \\
\hline Hiring manager sex (SEX) - control & $-.02(.08)$ & $-.01(.08)$ & $-.02(.08)$ & $-.02(.08)$ \\
\hline Hiring manager social class (SCLASS) & & $.08(.10)$ & & \\
\hline \multicolumn{5}{|l|}{$\underline{\text { Interactions }}$} \\
\hline 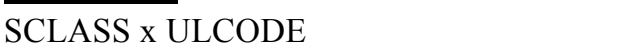 & & $.02(.06)$ & & \\
\hline ULCODE x CONFLICT (INT) & & & & $-.02(.23)$ \\
\hline EC x CONFLICT (ECINT) & $-.22(.09)^{*}$ & & & \\
\hline \multicolumn{5}{|l|}{ SC x CONFLICT (SCINT) } \\
\hline \multicolumn{5}{|l|}{ CC x CONFLICT (CCINT) } \\
\hline$\sim \mathrm{R}^{2}$ & 0.34 & 0.32 & 0.32 & 0.32 \\
\hline Deviance & 1998.826 & 2024.835 & 2026.539 & 2026.33 \\
\hline $\mathrm{df}_{\text {intercept }}$ & 900 & 899 & 900 & 900 \\
\hline
\end{tabular}

Note. Values in parentheses are standard errors; entries are unstandardized coeffiecients. ${ }^{*} \mathrm{p}<.05$, two-tailed. ${ }^{* *} \mathrm{p}<.01$, two-tailed. 


\begin{tabular}{|c|c|c|c|}
\hline \multicolumn{4}{|c|}{ Table 12c. Results of Three-Level Analysis - Screening Stage } \\
\hline \multirow{2}{*}{ Level and variable } & \multicolumn{3}{|c|}{ Perceptions of applicant P-O Fit } \\
\hline & $10 \mathrm{c}$ & 10d & $10 \mathrm{e}$ \\
\hline \multicolumn{4}{|l|}{ Level $1(N=1037)$} \\
\hline$\overline{\text { Intercept }}$ & $3.13(.14)^{* *}$ & $3.30(.20)^{* *}$ & $3.43(.16)^{* *}$ \\
\hline \multicolumn{4}{|l|}{ Level 2 - Applicant $(N=32)$} \\
\hline 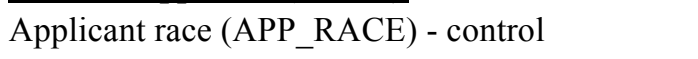 & $.03(.04)$ & $.03(.06)$ & $.03(.05)$ \\
\hline Applicant sex (APP_SEX) - control & $-.004(.04)$ & $-.002(.06)$ & $-.002(.05)$ \\
\hline \multicolumn{4}{|l|}{ Applicant average social class (AVGCAP) } \\
\hline Applicant economic capital (EC) & $.12(.17)$ & & \\
\hline Applicant social capital (SC) & & $-.21(.26)$ & \\
\hline Applicant cultural capital (CC) & & & $-.46(.20)^{*}$ \\
\hline \multicolumn{4}{|l|}{ Applicant class code (ULCODE) } \\
\hline Applicant social class conflict (CONFLICT) & $.19(.07)^{*}$ & $.02(.10)$ & $-.11(.08)$ \\
\hline \multicolumn{4}{|l|}{ Level 2 - Hiring Manager $(N=105)$} \\
\hline Hiring manager race (RACE) - control & $.12(.09)$ & $.12(.09)$ & $.11(.09)$ \\
\hline Hiring manager sex (SEX) - control & $-.02(.08)$ & $-.02(.08)$ & $-.02(.08)$ \\
\hline \multicolumn{4}{|l|}{ Hiring manager social class (SCLASS) } \\
\hline \multicolumn{4}{|l|}{$\underline{\text { Interactions }}$} \\
\hline \multicolumn{4}{|l|}{ SCLASS x ULCODE } \\
\hline \multicolumn{4}{|l|}{ ULCODE x CONFLICT (INT) } \\
\hline EC x CONFLICT (ECINT) & $-.22(.09)^{*}$ & & \\
\hline SC x CONFLICT (SCINT) & & $.11(.15)$ & \\
\hline CC x CONFLICT (CCINT) & & & $.36(.11)^{*}$ \\
\hline$\sim \mathrm{R}^{2}$ & 0.34 & 0.32 & 0.34 \\
\hline Deviance & 1998.826 & 2026.465 & 2009.132 \\
\hline$d f_{\text {intercept }}$ & 900 & 900 & 900 \\
\hline
\end{tabular}

Note. Values in parentheses are standard errors; entries are unstandardized coeffiecients. ${ }^{*} \mathrm{p}<.05$, two-tailed. ${ }^{* *} \mathrm{p}<.01$, two-tailed. 


\begin{tabular}{|c|c|c|c|c|}
\hline \multicolumn{5}{|c|}{ Table 13a. Results of Three-Level Analysis - Interviewing Stage } \\
\hline \multirow{2}{*}{ Level and variable } & \multicolumn{4}{|c|}{ Perceptions of applicant P-O Fit } \\
\hline & $11 \mathrm{a}^{\&}$ & $11 b^{\&}$ & 12 & 13 \\
\hline \multicolumn{5}{|l|}{ Level $1(N=852)$} \\
\hline$\overline{\text { Intercept }}$ & $3.27(.10)^{* *}$ & $3.31(.07)^{* *}$ & $3.30(.10)^{* *}$ & $3.30(.09)^{* *}$ \\
\hline \multicolumn{5}{|l|}{ Level 2 - Applicant $(N=32)$} \\
\hline 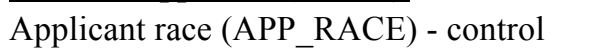 & $.15(.08)$ & $.14(.08)$ & $.14(.08)$ & $.14(.07)^{*}$ \\
\hline Applicant sex (APP_SEX) - control & $.22(.08)^{*}$ & $.21(.08)^{*}$ & $.21(.08)^{*}$ & $.22(.07)^{*}$ \\
\hline Applicant average social class (AVGCAP) & & & $.01(.15)$ & \\
\hline Applicant economic capital (EC) & & & & $-.20(.07)^{*}$ \\
\hline Applicant social capital (SC) & & & & $.07(.07)$ \\
\hline Applicant cultural capital (CC) & & & & $.13(.07)$ \\
\hline \multicolumn{5}{|l|}{ Applicant class code (ULCODE) } \\
\hline \multicolumn{5}{|l|}{ Applicant social class conflict (CONFLICT) } \\
\hline \multicolumn{5}{|l|}{ Level 2 - Hiring Manager $(N=220)$} \\
\hline Hiring manager race (control) & $.15(.09)$ & - & - & - \\
\hline Hiring manager sex (control) & $-.06(.08)$ & - & - & - \\
\hline \multicolumn{5}{|l|}{ Hiring manager social class (SCLASS) } \\
\hline \multicolumn{5}{|l|}{$\underline{\text { Interactions }}$} \\
\hline \multicolumn{5}{|l|}{ 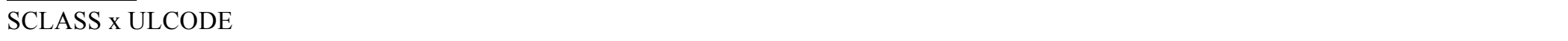 } \\
\hline \multicolumn{5}{|l|}{ ULCODE x CONFLICT (INT) } \\
\hline \multicolumn{5}{|l|}{ EC x CONFLICT (ECINT) } \\
\hline \multicolumn{5}{|l|}{ SC x CONFLICT (SCINT) } \\
\hline \multicolumn{5}{|l|}{ CC x CONFLICT (CCINT) } \\
\hline$\sim \mathrm{R}^{2}$ & 0.06 & 0.05 & 0.05 & 0.07 \\
\hline Deviance & 1948.28 & 2163.17 & 2163.16 & 2152.13 \\
\hline $\mathrm{df}_{\text {intercept }}$ & 539 & 600 & 600 & 600 \\
\hline
\end{tabular}




\begin{tabular}{|c|c|c|c|c|}
\hline \multicolumn{5}{|c|}{ Table 13b. Results of Three-Level Analysis - Interviewing Stage } \\
\hline \multirow{2}{*}{ Level and variable } & \multicolumn{4}{|c|}{ Perceptions of applicant P-O Fit } \\
\hline & $14 a$ & $14 \mathrm{~b}$ & $15 \mathbf{a}$ & $15 \mathrm{~b}$ \\
\hline \multicolumn{5}{|l|}{ Level $1(N=1241)$} \\
\hline$\overline{\text { Intercept }}$ & $3.12(.23)^{* *}$ & $2.47(.48)^{* *}$ & $3.06(.21)^{* *}$ & $3.46(.53)^{* *}$ \\
\hline \multicolumn{5}{|l|}{ Level 2 - Applicant $(N=32)$} \\
\hline 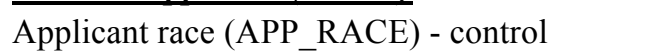 & $.15(.08)$ & $.15(.08)$ & $.14(.08)$ & $.14(.08)$ \\
\hline Applicant sex (APP_SEX) - control & $.22(.08)^{*}$ & $.22(.08)^{*}$ & $.21(.08)^{*}$ & $.21(.08)^{*}$ \\
\hline \multicolumn{5}{|l|}{ Applicant average social class (AVGCAP) } \\
\hline \multicolumn{5}{|l|}{ Applicant economic capital (EC) } \\
\hline \multicolumn{5}{|l|}{ Applicant social capital (SC) } \\
\hline \multicolumn{5}{|l|}{ Applicant cultural capital (CC) } \\
\hline Applicant class code (ULCODE) & $.03(.09)$ & $.46(.25)$ & $.04(.08)$ & $-.22(.33)$ \\
\hline Applicant social class conflict (CONFLICT) & & & $.10(.09)$ & $-.12(.29)$ \\
\hline \multicolumn{5}{|l|}{ Level 2 - Hiring Manager $(N=79)$} \\
\hline Hiring manager race (control) & $.15(.09)$ & $.14(.09)$ & - & - \\
\hline Hiring manager sex (control) & $-.06(.08)$ & $-.06(.08)$ & - & - \\
\hline Hiring manager social class (SCLASS) & $.03(.05)$ & $.25(.13)$ & & \\
\hline \multicolumn{5}{|l|}{ Interactions } \\
\hline SCLASS x ULCODE & & $-.14(.08)$ & & \\
\hline ULCODE x CONFLICT (INT) & & & & $.15(.18)$ \\
\hline \multicolumn{5}{|l|}{ EC x CONFLICT (ECINT) } \\
\hline \multicolumn{5}{|l|}{ SC x CONFLICT (SCINT) } \\
\hline \multicolumn{5}{|l|}{ CC x CONFLICT (CCINT) } \\
\hline$\sim \mathrm{R}^{2}$ & 0.12 & 0.12 & 0.05 & 0.06 \\
\hline Deviance & 1947.73 & 1944.42 & 2161.71 & 2161.04 \\
\hline $\mathrm{df}_{\text {intercept }}$ & 539 & 538 & 600 & 600 \\
\hline
\end{tabular}


Table 13c. Results of Three-Level Analysis - Interviewing Stage

\begin{tabular}{|c|c|c|c|}
\hline \multicolumn{4}{|c|}{ Table 13c. Results of Three-Level Analysis - Interviewing Stage } \\
\hline \multirow{2}{*}{ Level and variable } & \multicolumn{3}{|c|}{ Perceptions of applicant P-O Fit } \\
\hline & $15 \mathrm{c}$ & 15d & $15 \mathrm{e}$ \\
\hline \multicolumn{4}{|l|}{ Level $1(N=1241)$} \\
\hline Intercept & $3.07(.22)^{* *}$ & $3.26(.24)^{* *}$ & $3.29(.23)^{* *}$ \\
\hline \multicolumn{4}{|l|}{ Level 2 - Applicant $(N=32)$} \\
\hline Applicant race (APP_RACE) - control & $.14(.07)^{*}$ & $.14(.07)$ & $.14(.07)$ \\
\hline Applicant sex (APP_SEX) - control & $.21(.07)^{*}$ & $.21(.07)^{*}$ & $.21(.07)^{*}$ \\
\hline \multicolumn{4}{|l|}{ Applicant average social class (AVGCAP) } \\
\hline Applicant economic capital (EC) & $.11(.30)$ & & \\
\hline Applicant social capital (SC) & & $-.26(.32)$ & \\
\hline Applicant cultural capital (CC) & & & $-.33(.31)$ \\
\hline \multicolumn{4}{|l|}{ Applicant class code (ULCODE) } \\
\hline Applicant social class conflict (CONFLICT) & $.19(.12)$ & $.003(.13)$ & $-.03(.12)$ \\
\hline \multicolumn{4}{|l|}{ Level 2 - Hiring Manager $(N=79)$} \\
\hline Hiring manager race (RACE) - control & - & - & - \\
\hline Hiring manager sex (SEX) - control & - & - & - \\
\hline \multicolumn{4}{|l|}{ Hiring manager social class (SCLASS) } \\
\hline \multicolumn{4}{|l|}{$\underline{\text { Interactions }}$} \\
\hline \multicolumn{4}{|l|}{ SCLASS x ULCODE } \\
\hline \multicolumn{4}{|l|}{ ULCODE x CONFLICT (INT) } \\
\hline EC x CONFLICT (ECINT) & $-.18(.16)$ & & \\
\hline SC x CONFLICT (SCINT) & & $.19(.18)$ & \\
\hline CC x CONFLICT (CCINT) & & & $.27(.17)$ \\
\hline$\sim \mathrm{R}^{2}$ & 0.06 & 0.06 & 0.06 \\
\hline Deviance & 2154.21 & 2159.96 & 2156.76 \\
\hline $\mathrm{df}_{\text {intercept }}$ & 600 & 600 & 600 \\
\hline
\end{tabular}

Note. Values in parentheses are standard errors; entries are unstandardized coeffiecients. ${ }^{*} \mathrm{p}<.05$, two-tailed. ${ }^{* *} \mathrm{p}<.01$, two-tailed. 
Table 14. Hypothesis Summary

\begin{tabular}{|c|c|c|c|c|}
\hline & & Acquiring & Screening & Interviewing \\
\hline \multirow{16}{*}{ 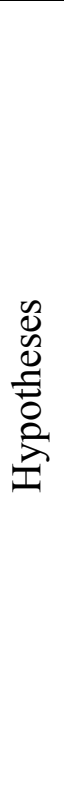 } & 1 & Supported & Not supported & Not supported \\
\hline & $2 \mathrm{a}$ & Supported & - & \\
\hline & $2 b$ & Supported & - & \\
\hline & $2 \mathrm{c}$ & Supported & - & \\
\hline & $2 \mathrm{~d}$ & Supported & - & \\
\hline & $2 \mathrm{e}$ & Supported & - & \\
\hline & $3 a$ & - & Not supported & \\
\hline & $3 b$ & - & Not supported & \\
\hline & $3 \mathrm{c}$ & - & Supported & \\
\hline & $4 a$ & - & - & Not supported \\
\hline & $4 b$ & - & - & Not supported \\
\hline & $4 c$ & - & - & Not supported \\
\hline & $4 d$ & - & - & Not supported \\
\hline & $4 \mathrm{e}$ & - & - & Not supported \\
\hline & 5 & Supported & Not supported & Not supported \\
\hline & 6 & Supported & Not supported & Not supported \\
\hline
\end{tabular}


Table 15. Hypothesis Summary - Detailed

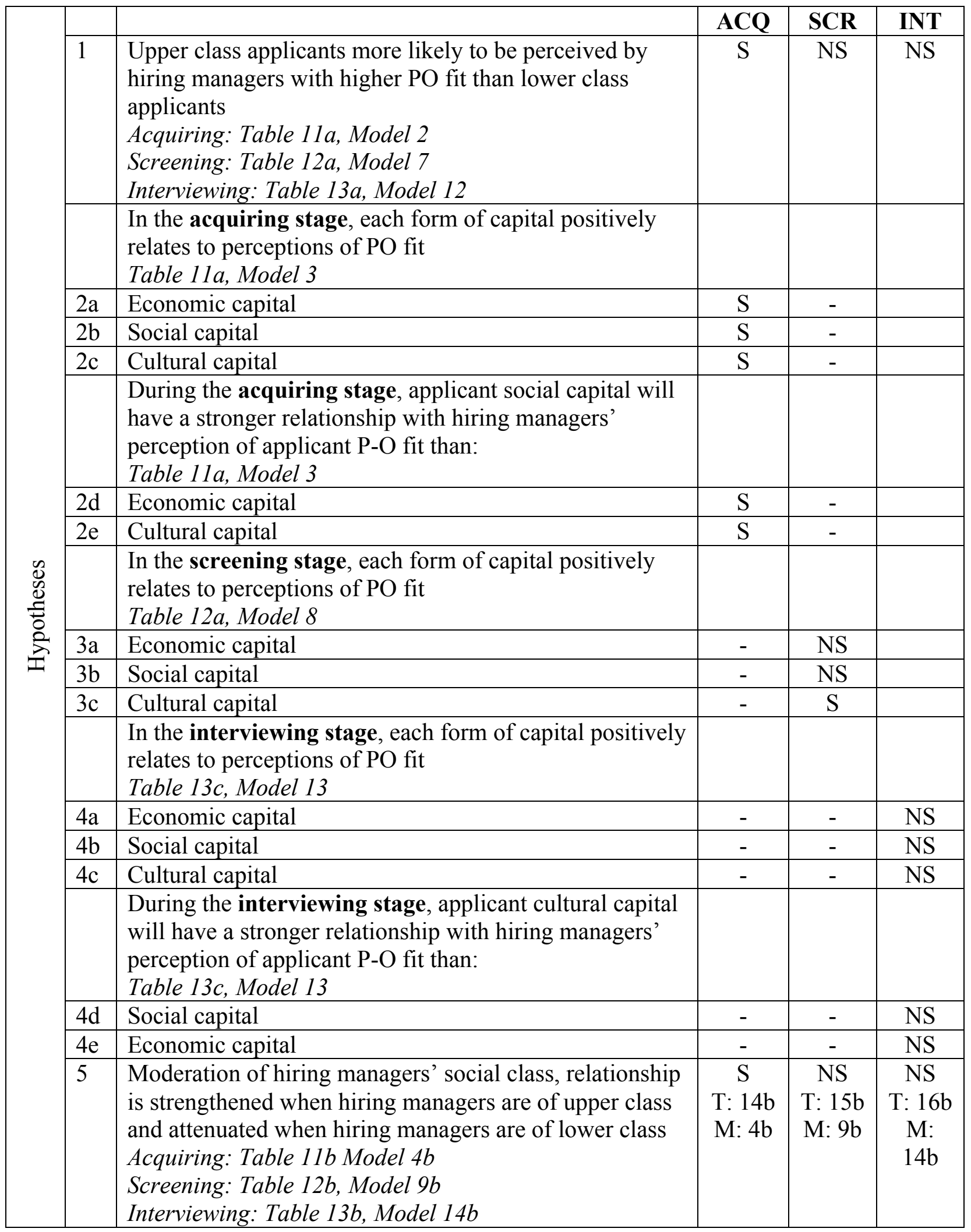




\begin{tabular}{|l|l|l|c|c|c|}
\hline 6 & $\begin{array}{l}\text { Moderation of hiring managers' perceptions of forms of } \\
\text { capital, such that the relationship is weakened when } \\
\text { applicants' forms of capital conflict }\end{array}$ & S & NS $14 \mathrm{~b}$ & T: $15 \mathrm{~b}$ \\
Acquiring: Table $11 \mathrm{~b}$, Model $5 b$ & $\mathrm{M}: 5 \mathrm{~b}$ & $\mathrm{M}: 16 \mathrm{~b}$ \\
Screening: Table $12 \mathrm{~b}$, Model $10 \mathrm{~b}$ & $\mathrm{M}:$ \\
Interviewing: Table 13b, Model $15 \mathrm{~b}$ & & $10 \mathrm{~b}$ & $15 \mathrm{~b}$ \\
\hline
\end{tabular}

$\mathrm{ACQ}=$ Acquiring stage

$\mathrm{SCR}=$ Screening stage

$\mathrm{INT}=$ Interviewing stage 
Table 16. Manager's Summary

\begin{tabular}{|l|l|l|}
\hline Acquiring & Screening & Interviewing \\
\hline $\begin{array}{l}\text { Applicants who are } \\
\text { perceived to be upper class } \\
\text { will be perceived to fit better } \\
\text { with the organization }\end{array}$ & $\begin{array}{l}\text { No apparent preference for } \\
\text { upper or lower class } \\
\text { applicants }\end{array}$ & $\begin{array}{l}\text { No apparent prefence } \\
\text { for upper or lower class } \\
\text { applicants }\end{array}$ \\
\hline $\begin{array}{l}\text { Hiring managers can detect } \\
\text { and use all forms of capital } \\
\text { (e.g., economic, social, } \\
\text { cultural) to drive perceptions } \\
\text { of fit, with social capital } \\
\text { driving the fit perceptions the } \\
\text { most }\end{array}$ & $\begin{array}{l}\text { Hiring managers can detect } \\
\text { cultural capital and can use } \\
\text { those to impact their } \\
\text { perceptions of fit }\end{array}$ & $\begin{array}{l}\text { Hiring managers are } \\
\text { unable to clearly detect } \\
\text { and differentiate the forms } \\
\text { of capital during this stage }\end{array}$ \\
\hline $\begin{array}{l}\text { Hiring managers' social class } \\
\text { impacts their evaluation of } \\
\text { applicants of varying social } \\
\text { class to fit within an } \\
\text { organization }\end{array}$ & $\begin{array}{l}\text { Hiring managers' social class } \\
\text { does not impact their } \\
\text { evaluation of applicants of } \\
\text { varying social class and their } \\
\text { fit within an organization }\end{array}$ & $\begin{array}{l}\text { Hiring managers' social } \\
\text { class does not impact their } \\
\text { evaluation of applicants of } \\
\text { varying social class and } \\
\text { their fit within an } \\
\text { organization }\end{array}$ \\
\hline $\begin{array}{l}\text { Applicants with social class } \\
\text { that is difficult to detect will } \\
\text { shift hiring managers' } \\
\text { perceptions of applicant fit }\end{array}$ & $\begin{array}{l}\text { Applicants with social class } \\
\text { that is difficult to detect will } \\
\text { not shift hiring managers' } \\
\text { perceptions of applicant fit }\end{array}$ & $\begin{array}{l}\text { Applicants with social } \\
\text { class that is difficult to } \\
\text { detect will not shift hiring } \\
\text { managers' perceptions of } \\
\text { applicant fit }\end{array}$ \\
\hline
\end{tabular}


Figure 1. Model Depicting the Impact of Applicant Social Class and Hiring Managers' Perception of P-O Fit

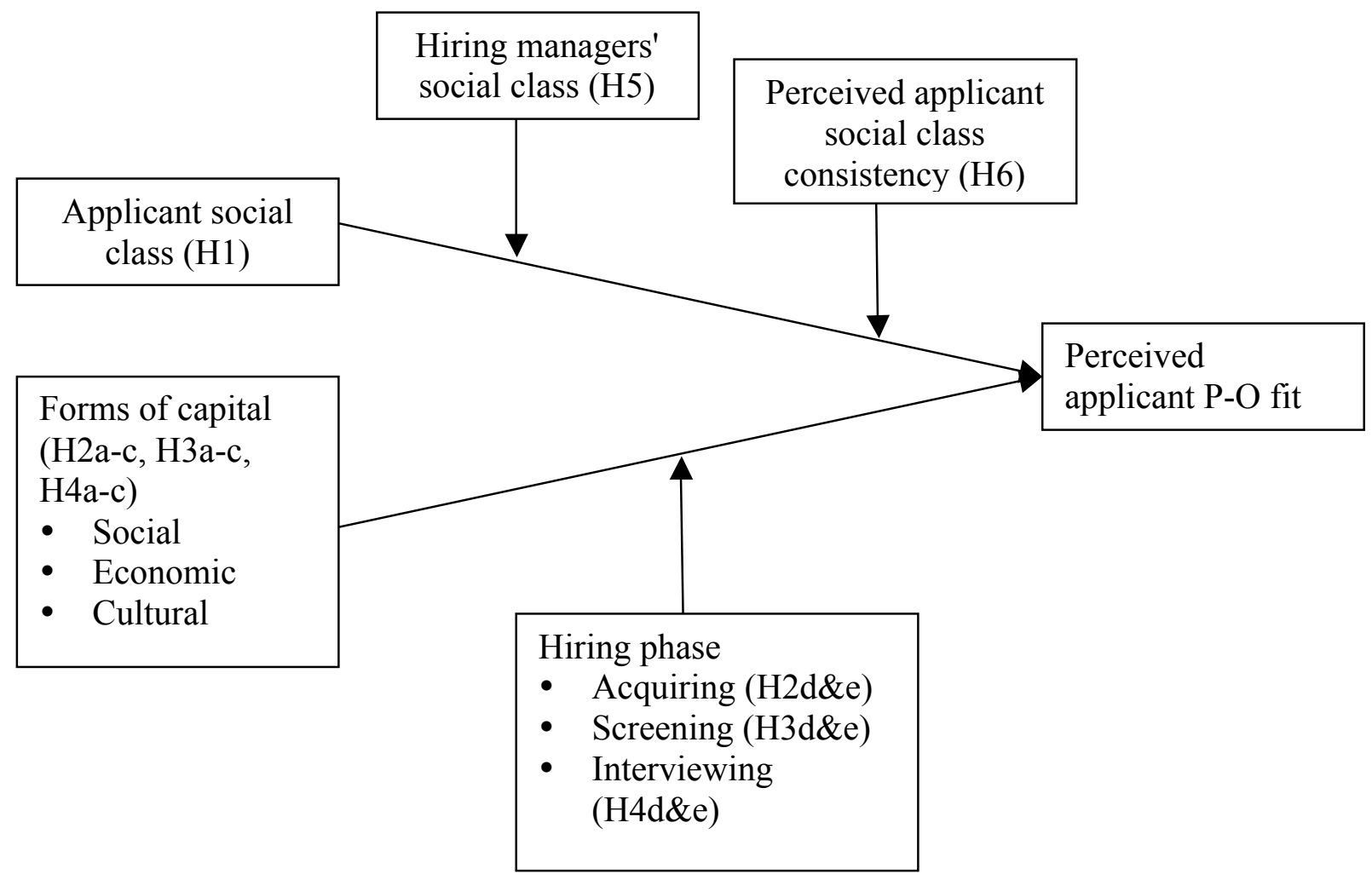


Figure 2. Forms of Capital in Current Literature

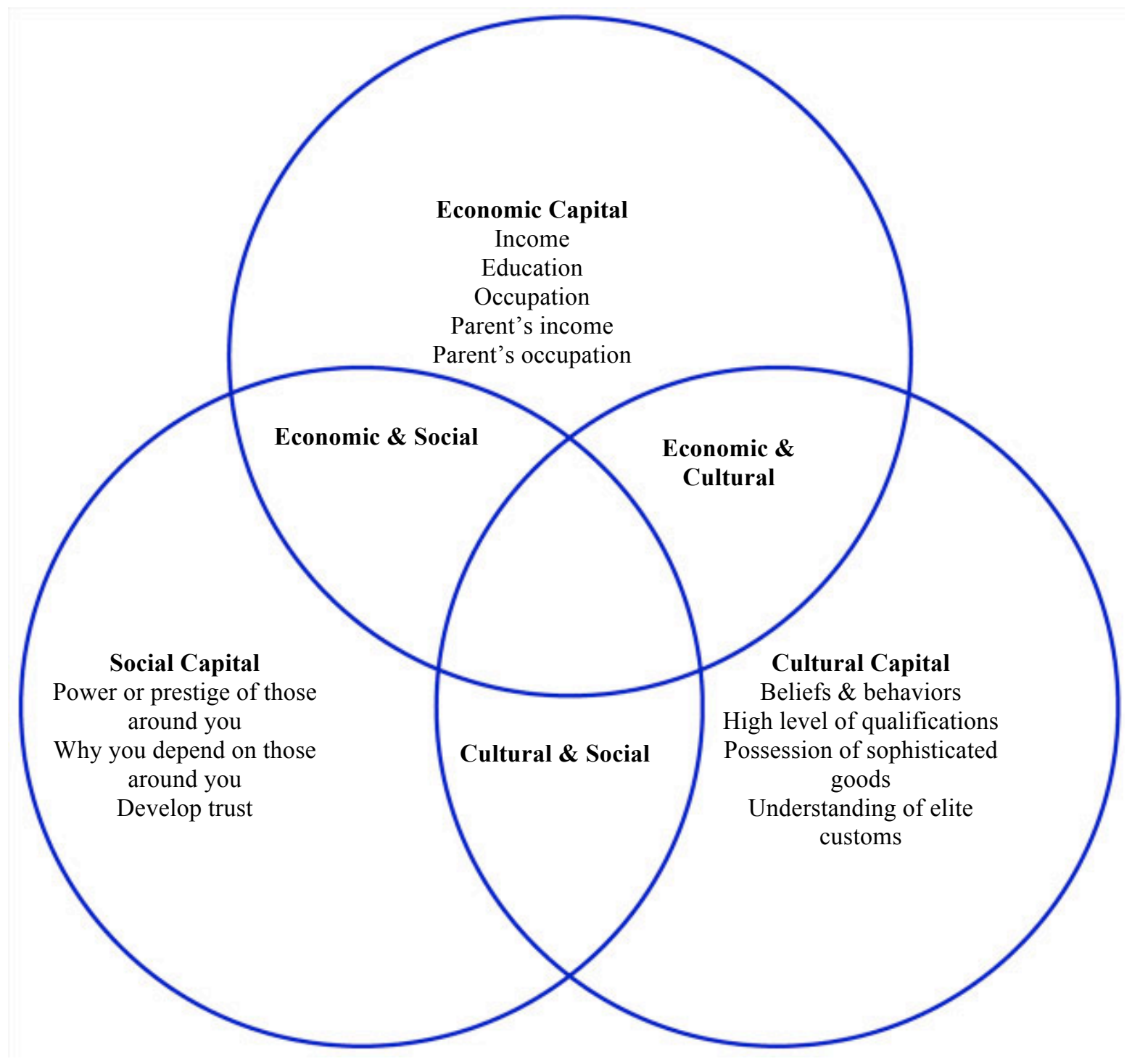


Figure 3. Forms of Capital based on Construct Clarity Study

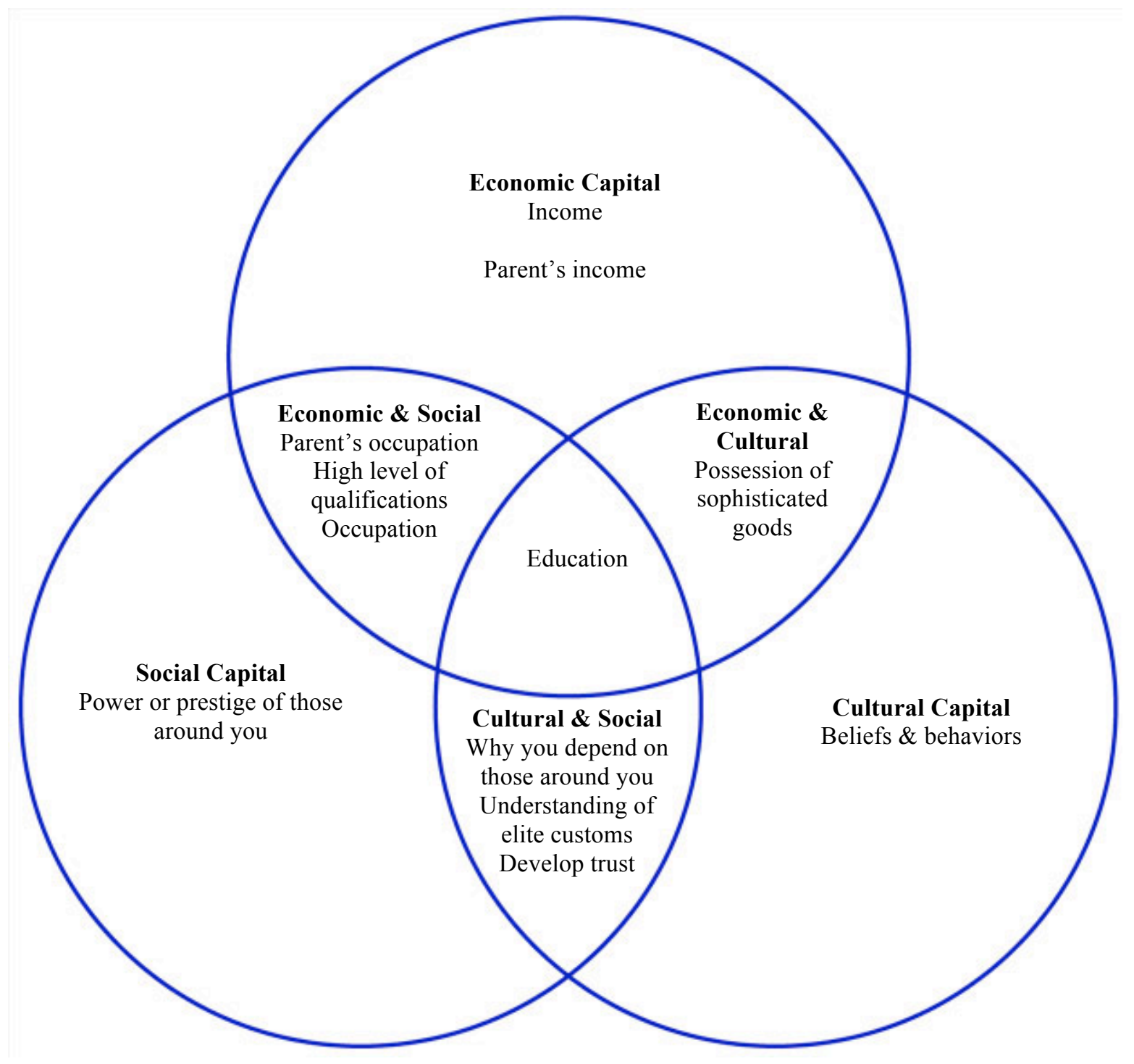


Figure 4. Power Analysis from Optimal Design - Stage One: Referral Email

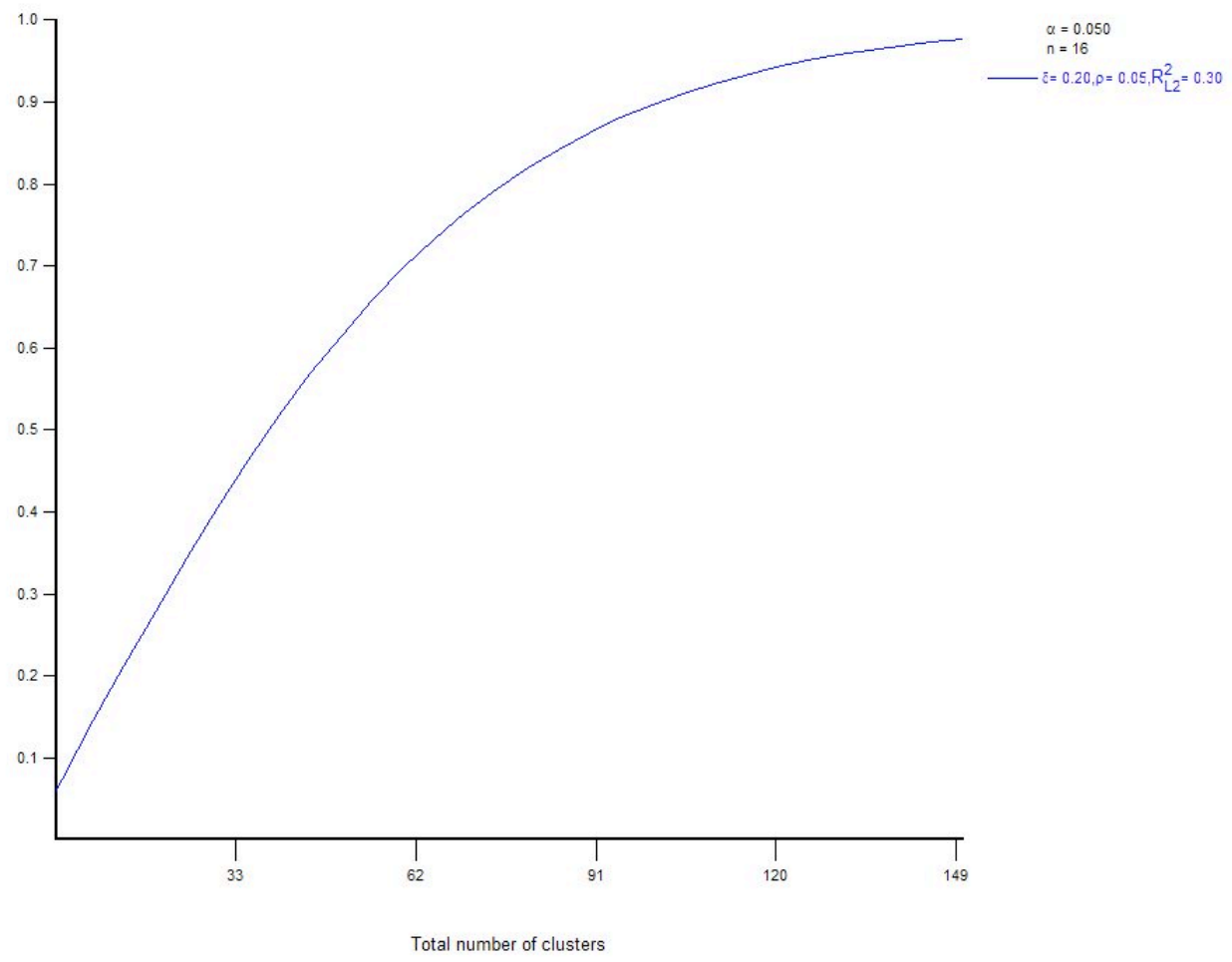


Figure 5. Power Analysis from Optimal Design - Stage Two: Applicant Resume

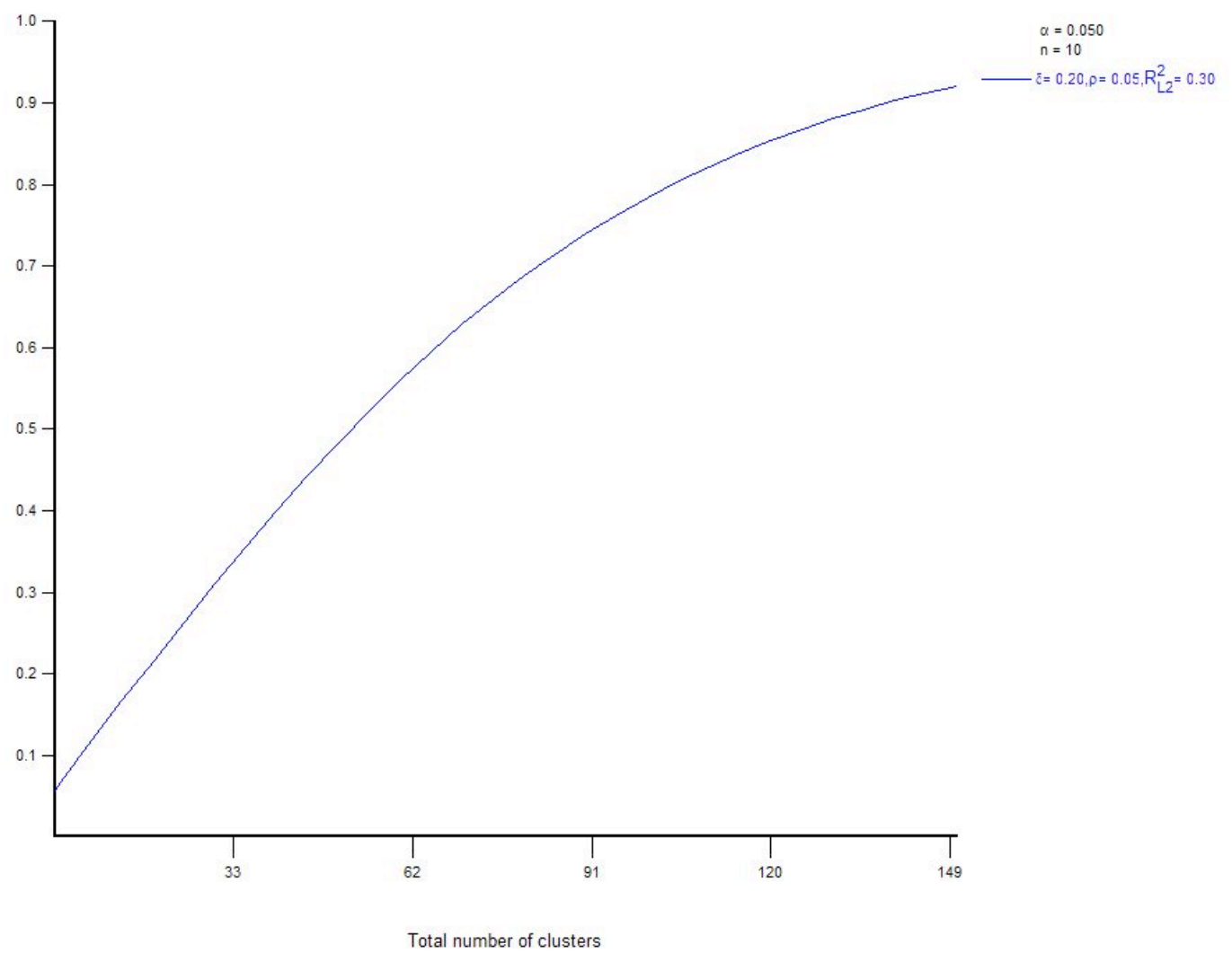


Figure 6. Power Analysis from Optimal Design - Stage Three: Applicant Interview

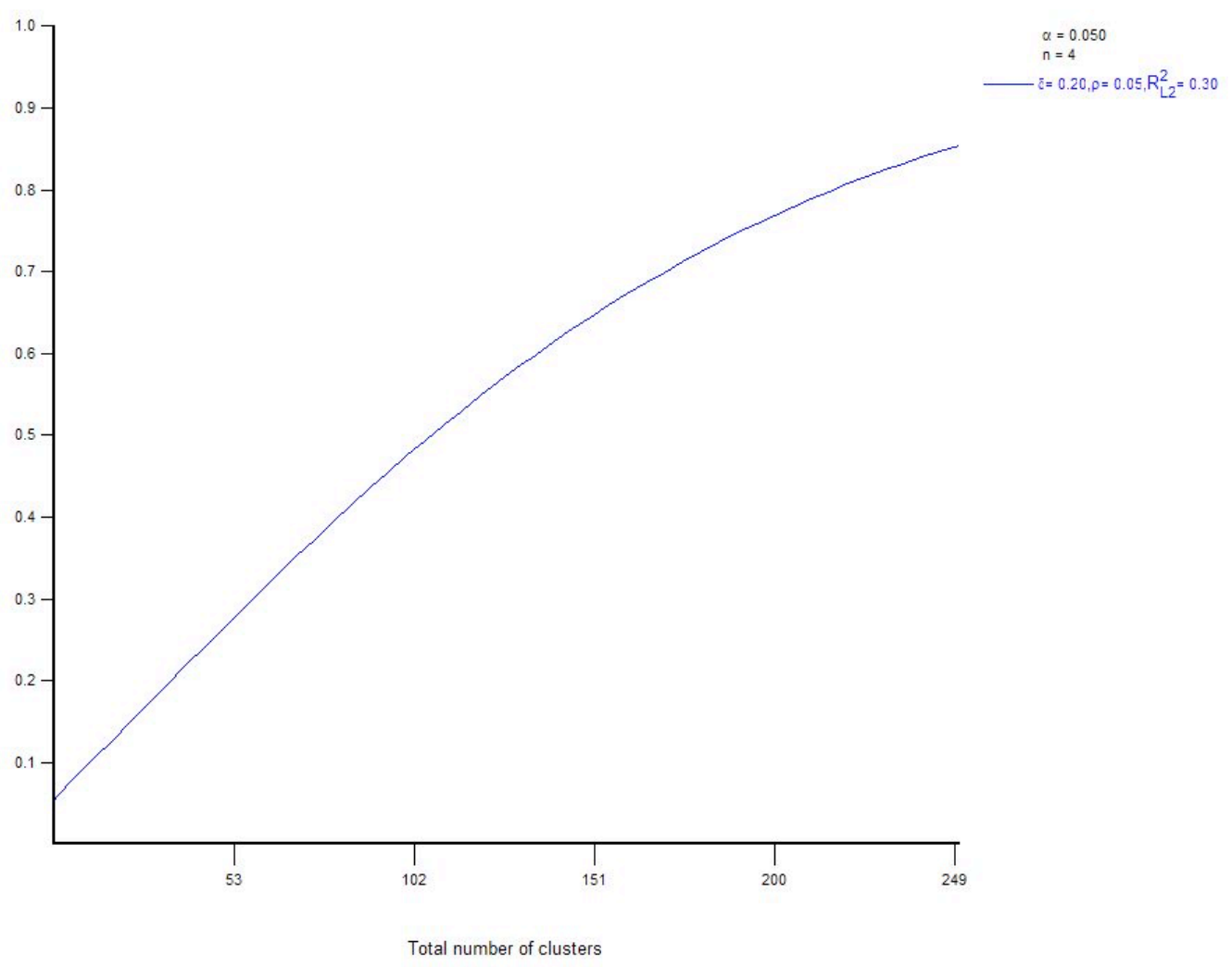


Figure 7. Hypothesis 5 - Acquiring Stage

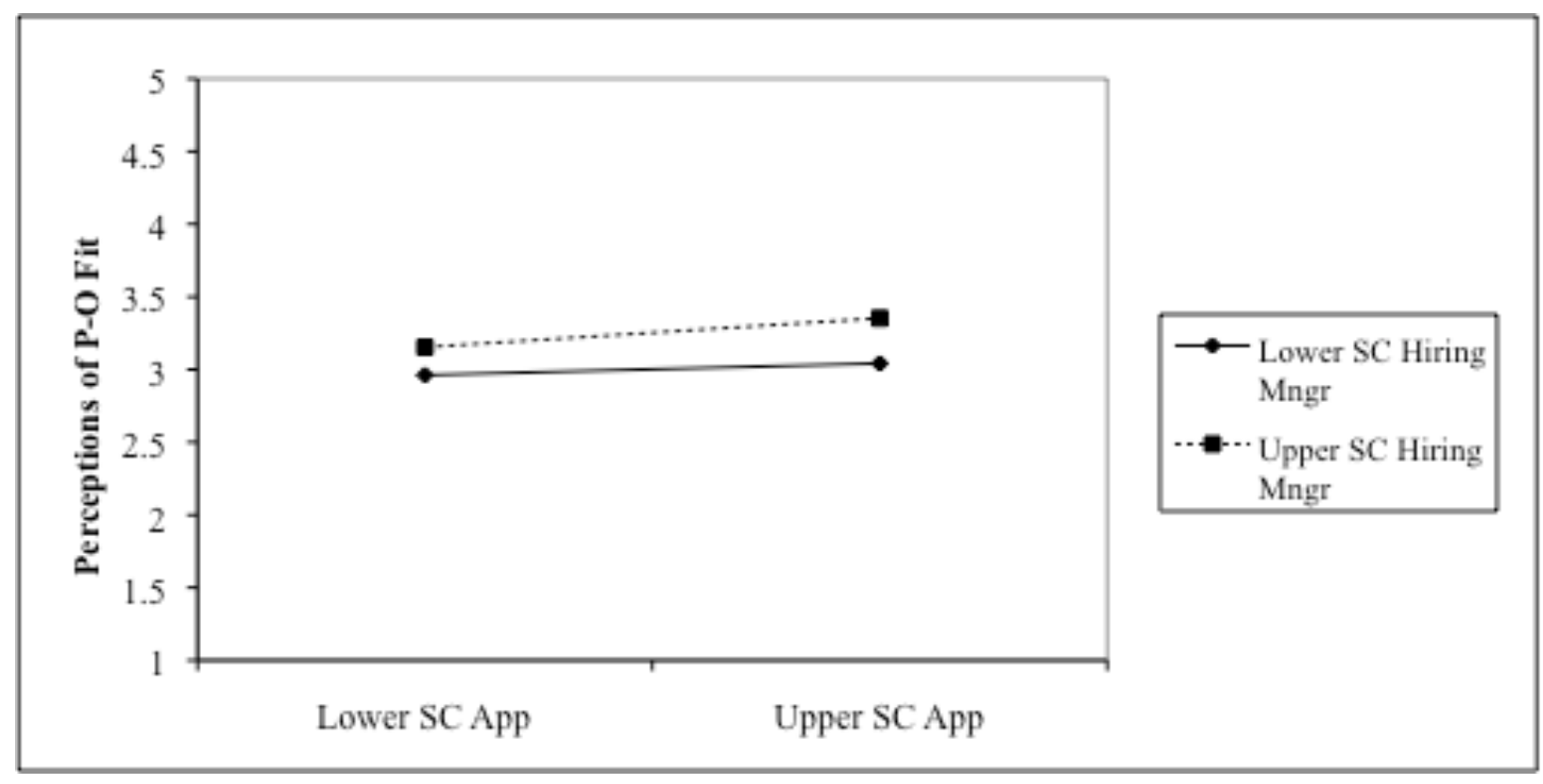


Figure 8. Hypothesis 6 - Acquiring Stage

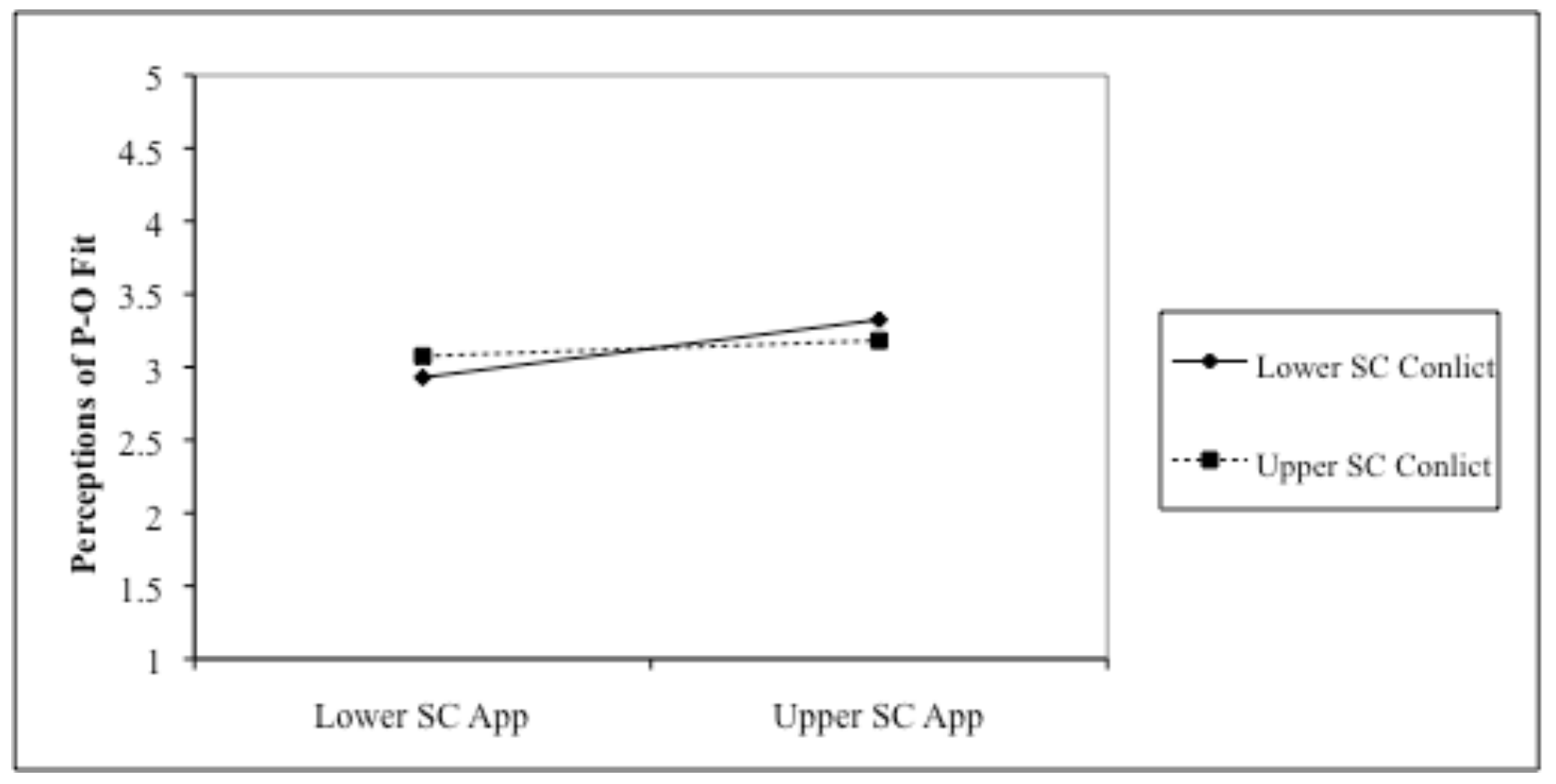


Figure 9. Hypothesis 5 - Screening Stage

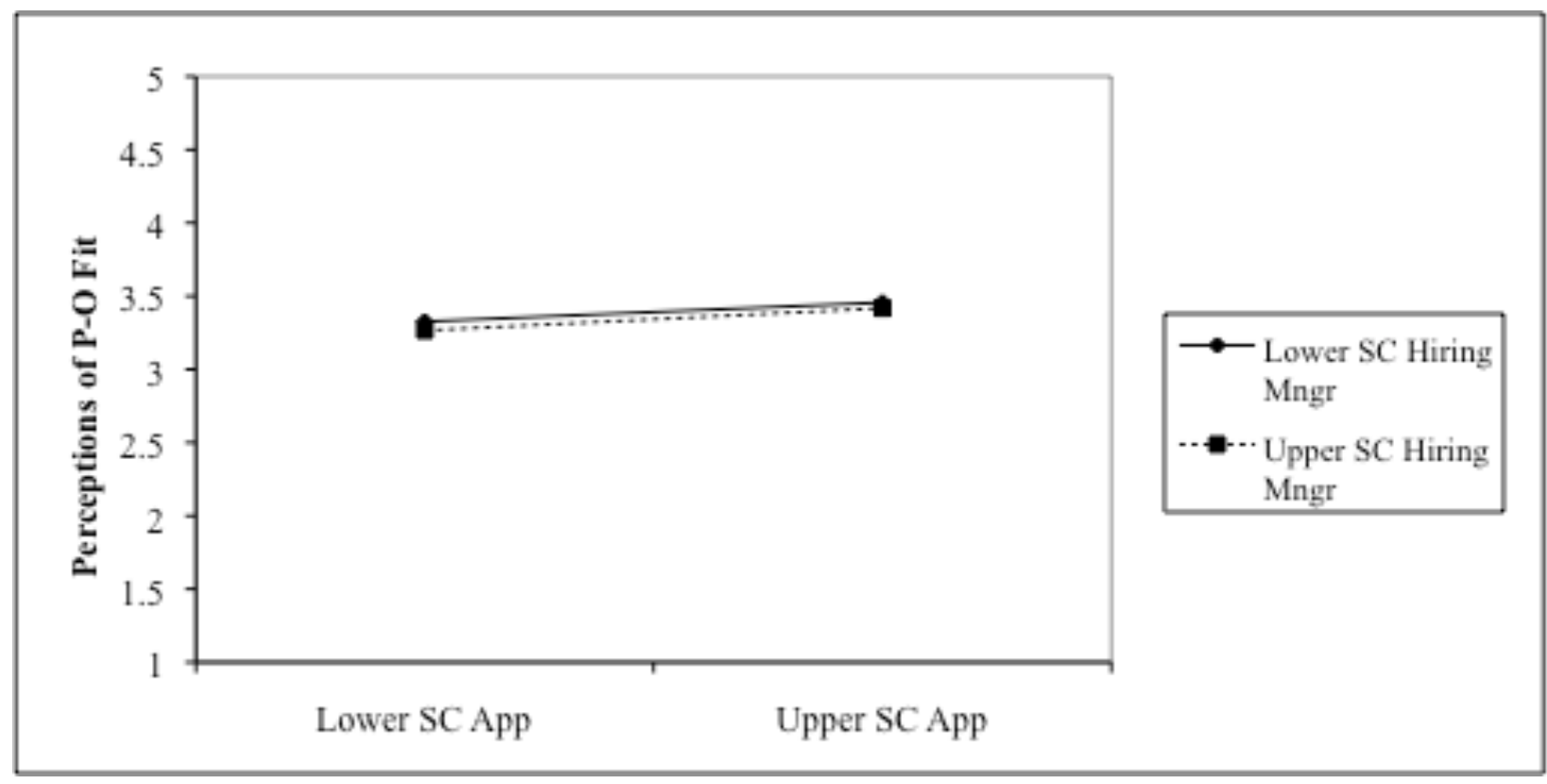


Figure 10. Hypothesis 6 - Screening Stage

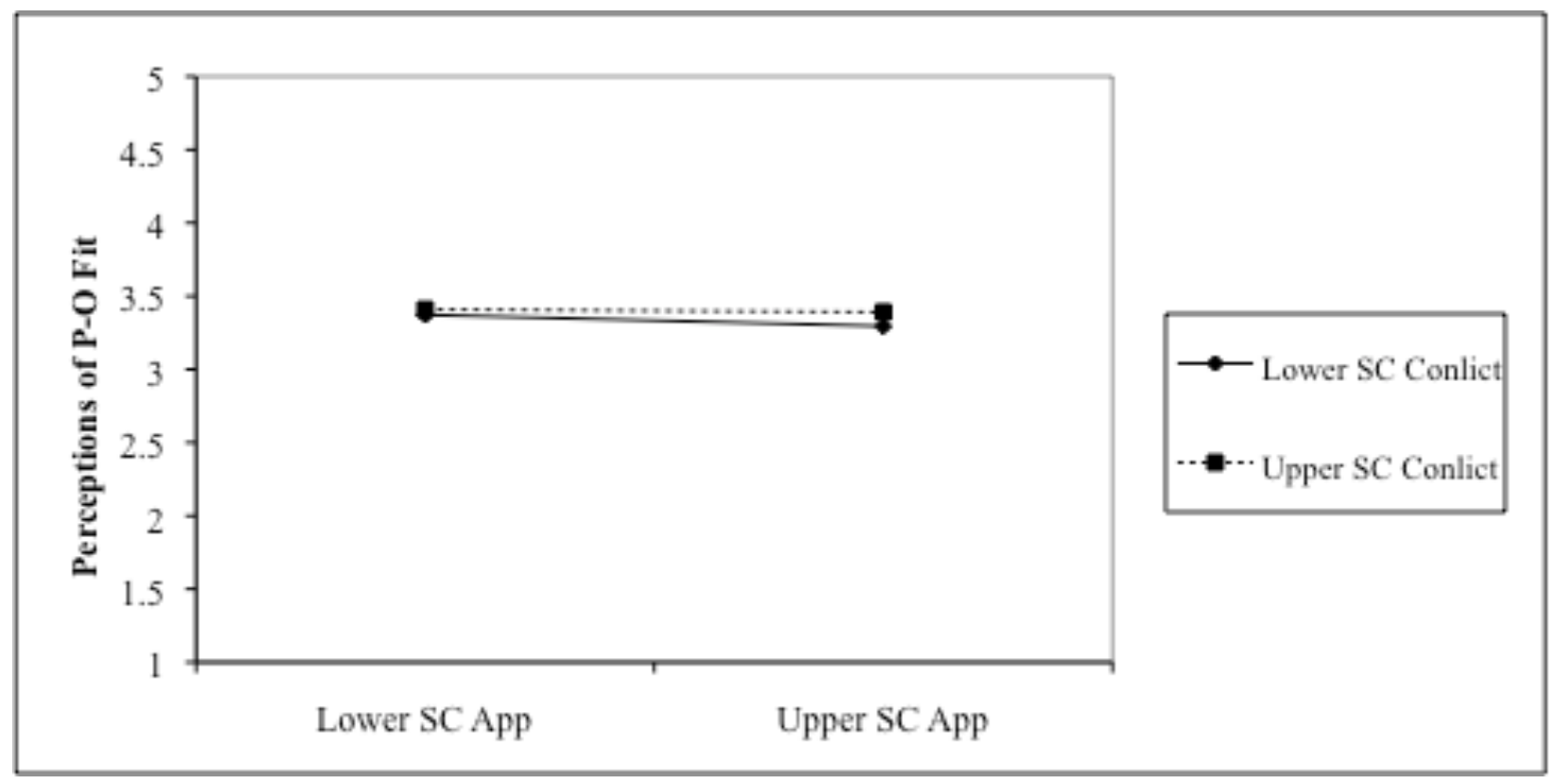


Figure 11. Hypothesis 5 - Interviewing Stage

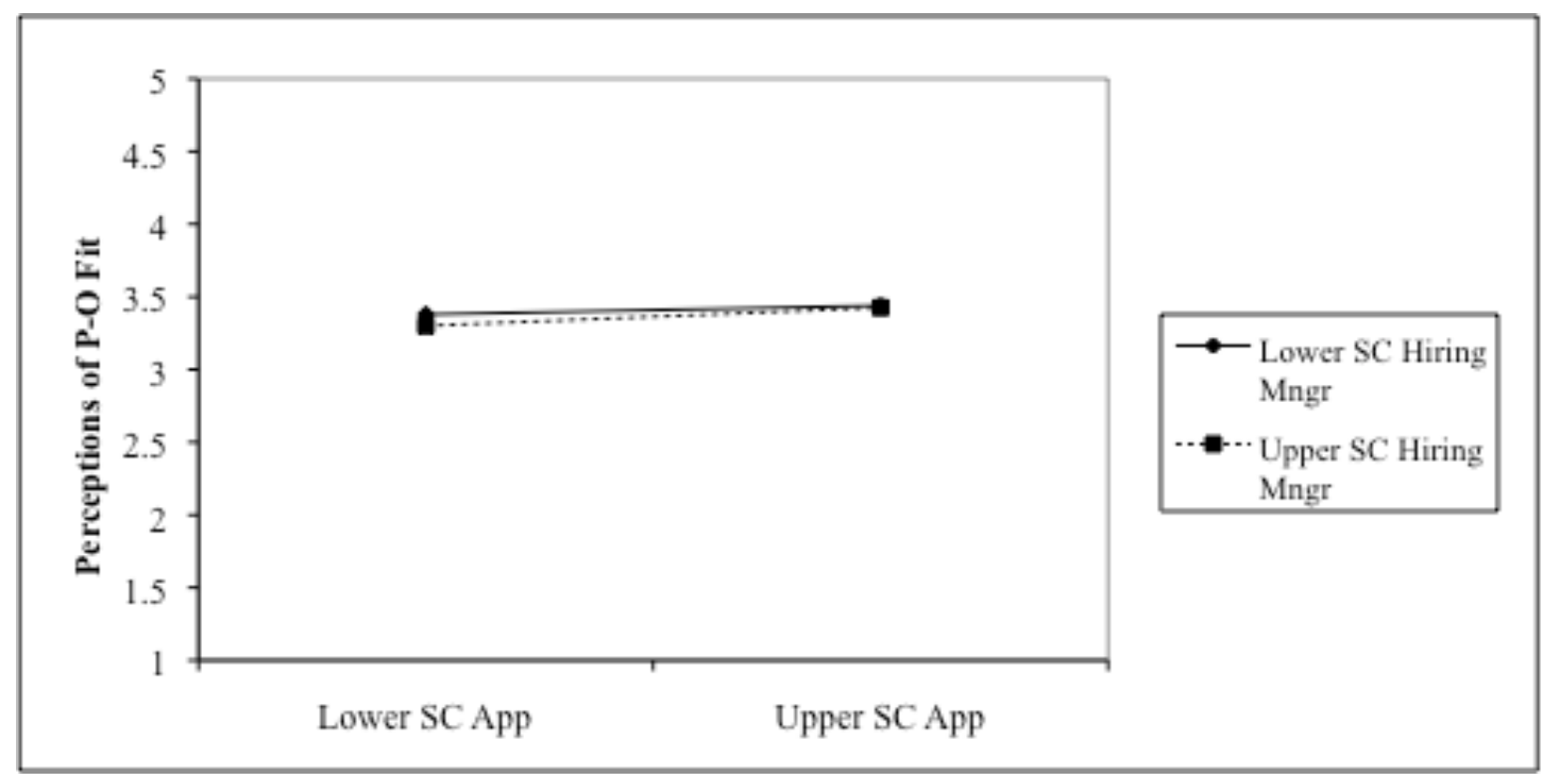


Figure 12. Hypothesis 6 - Interviewing Stage

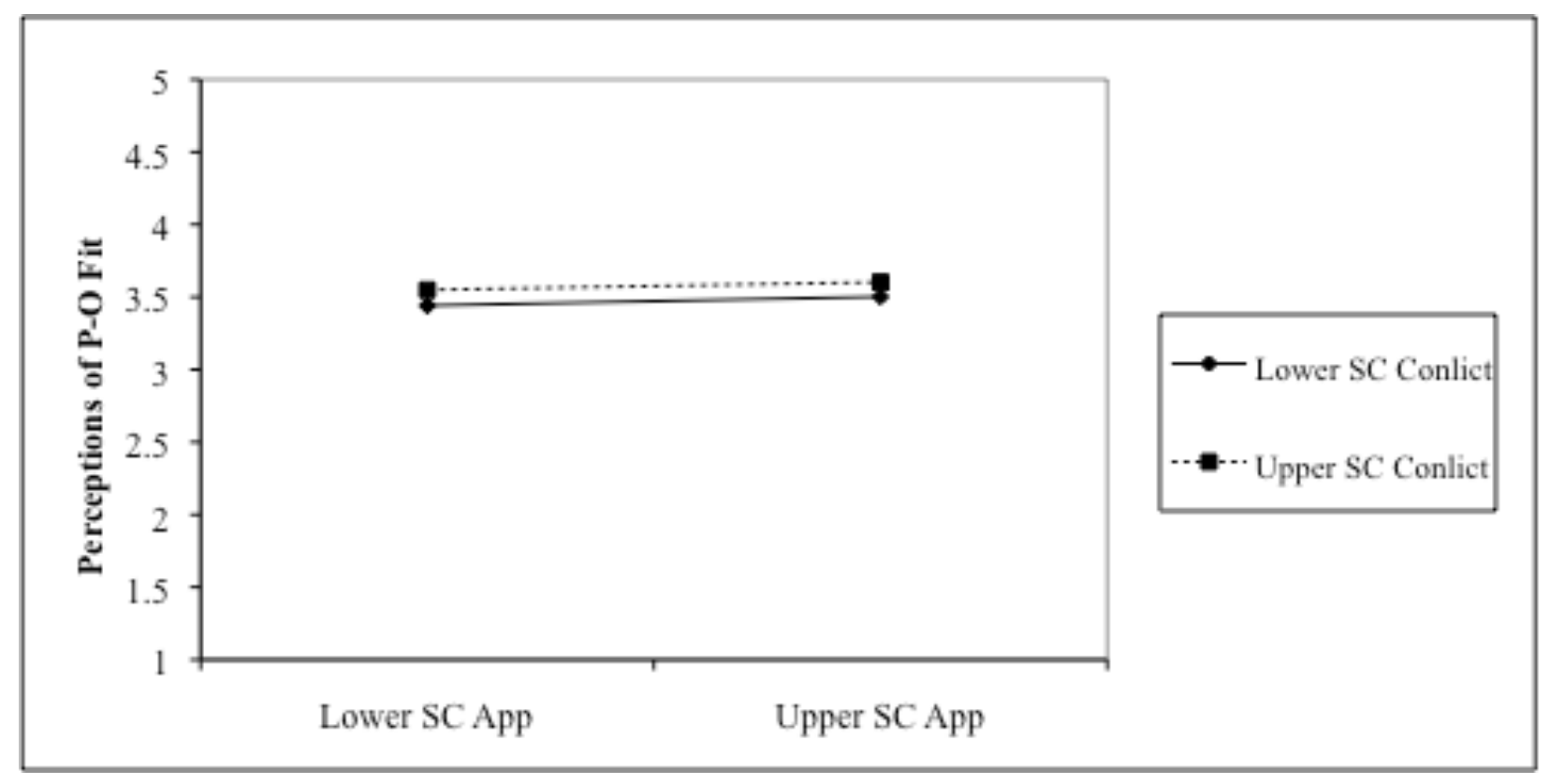




\section{Example 1. Sample Referral Email}

From: Christopher Washington

Sent: Tuesday, January 27, 2015

Subject: Budgeting Analyst Referral

Hi,

Hope all is well. My name is Christopher Washington and I am a Director in the Finance department. I wanted to recommend a colleague Elijah Jefferson, whom I met through a book club, for the Budgeting Analyst position.

Elijah is currently earning an above average salary from another company, so we will have to make a competitive offer. I have attached the resume, and would be happy to speak with you should you have any questions.

Take care,

Christopher 


\section{Example 2. Sample Applicant Resume}

\section{ELIJAH JEFFERSON}

\section{EXPERIENCE}

\section{Elite Financial}

Budgeting Intern
New York, NY

Summer 2014

- Prepared end of quarter financial statements for department heads

- Conducted actual to budget/forecast variance analysis

- Reviewed management reports with Vice President and recommended operational changes

\section{Amazing Bank}

Budgeting Account Specialist
White Plains, NY

September 2013 - May 2014

- Oversaw the capital and expense spending for 88 retail locations

- Audited and authorized subject fee and Form G payments

- Monitor departmental expenditures to ensure proper allocation of budgeted funds on a monthly basis

Financiers, Inc.

Finance Specialist

- Managed daily cash payment processing

- Monitored gross pay and operating expenditures lines

- Responded to inquiries from individuals and departments regarding overpayments

\section{HOBBIES \& ACTIVITIES}

Book club

\section{SALARY REQUIREMENTS}

Salary requirements - $\$ 80,000$

Elite Financial - \$30/hour

Amazing Bank - \$25/hour

Financiers, Inc. - \$25/hour

RECOMMENDATIONS

Christopher Washington, Director of Finance, Elite Financial 


\section{Example 3. Sample Applicant Interview Script}

The below interview questions were adapted from the Society of Human Resource Management (SHRM)

http://www.shrm.org/TemplatesTools/Samples/InterviewQuestions/Pages/OpeningandClosingQu estions.aspx

The response portions that highlight class differences are underlined in red text. The form of capital (economic, social, or cultural) is listed in parenthesis next to the interview question number.

Interview Question \#1 (Economic capital):

Welcome! So did you have any trouble finding us?

\begin{tabular}{|l|l|}
\hline Upper Class Response & Lower Class Response \\
\hline $\begin{array}{l}\text { I just bought a new car so I typed your address } \\
\text { into my GPS. I found your office with no } \\
\text { problem. }\end{array}$ & It was a few transfers on the bus and train, but \\
\hline
\end{tabular}

Interview Question \#2 (Social capital):

I see you were referred to this job opening, who referred you to this position?

\begin{tabular}{|l|l|}
\hline Upper Class Response & Lower Class Response \\
\hline $\begin{array}{l}\text { My mother is a Vice President of Finance, and } \\
\text { she recommended that I consider a position } \\
\text { with your company. }\end{array}$ & $\begin{array}{l}\text { My mother is an Administrative Assistant in } \\
\text { the Finance Department, and she recommended } \\
\text { that I consider a position with your company. }\end{array}$ \\
\hline
\end{tabular}

Interview Question \#3 (Cultural capital):

What would you say if asked to talk about your thoughts of success to a group of colleagues?

\begin{tabular}{|l|l|}
\hline Upper Class Response & Lower Class Response \\
\hline $\begin{array}{l}\text { I think anyone can be successful if they work } \\
\text { hard. }\end{array}$ & $\begin{array}{l}\text { I think anyone can be successful if given } \\
\text { access to opportunities. }\end{array}$ \\
\hline
\end{tabular}




\section{Example 4. Overview of Directions for Each Stage}

\section{Stage one: Referral Emails}

\section{Introduction to Referral Email stage}

Your company recently decided to hire a Budget Analyst. As soon as the announcement was made, you were flooded with referral emails. You decide to go through some of your emails, as you think some of these referrals may result in a great candidate.

\section{Directions for Referral Email stage}

Please review each email as presented below. After reviewing each referral email, please respond to the questions that follow.

\section{Stage two: Applicant Resumes}

Introduction to Applicant Resume stage

Your company recently decided to hire a Budget Analyst. According to the Bureau of Labor

Statistics, the median salary for Budget Analysts is $\$ 69,000 /$ year.

This position requires a Bachelor's degree, so your company has decided to recruit from a local university. Your HR Assistant has already screened the resumes, and all applicants meet the minimum educational requirement of Bachelor's degree. Now you just need to evaluate the remainder of the resume.

\section{Directions for Applicant Resume stage}

Please review each resume as presented below. After reviewing each resume, please respond to the questions that follow.

\section{Stage three: Applicant interviews}

Introduction to Applicant interview stage

Your company recently decided to hire a Budget Analyst. You have narrowed the applicant pool down to four applicants. Unfortunately, you were out of town when the applicants came to interview, but because your input is valuable, you are asked to review all four interviews and provide your feedback.

All four of the applicants are from a local university, and have received advice from their university's career center. To allow you to evenly compare each applicant, your staff has sent you each interview highlighting the same interview questions.

\section{Directions for Applicant interview stage}

Please review each applicant interview video as presented below. After reviewing each interview, please respond to the questions that follow. 


\section{APPENDIX A: CONSTRUCT CLARITY STUDY}

I conducted a pilot construct clarity study with three different sample types to confirm that (1) social class items were perceived to align with middle and working class (or upper or lower class) individuals, (2) broader categories of social class align with the three forms of social class, (3) social class status terms were ranked in the order described in the literature (sample three only). The results of this study proved to be useful as I designed my dissertation study.

\section{Sample}

Sample one. The first sample was comprised primarily of academic participants (e.g., graduate students, professors). A small initial convenience sample from a large northeastern university as well as graduate student members from the PhD Project were contacted to complete the survey. Those individuals then forwarded the email to additional individuals, relying on snowball sampling. The academic sample resulted in 46 participants who started the survey and 33 participants who actually completed the survey, for a $72 \%$ response rate.

The majority of the sample indicated their industry as academia and their job title as $\mathrm{PhD}$ student or Professor. There were 21 females and 12 males. The majority (64\%) of the sample was between the ages of 25 to $34,12 \%$ were under 25 years of age, $18 \%$ were between the ages of $35-44$, and $6 \%$ were between the ages of $45-54$. This sample was quite racially and ethnically diverse with Asian or Pacific Islander (18\%), Black, African American, or West Indian (30\%), Hispanic or Latino (15\%), and White or Caucasian (33\%), and one individual who preferred not to respond (3\%). The sample was also highly educated with $27 \%$ obtaining a Bachelor's Degree, $55 \%$ with a Master's, and $15 \%$ with a Doctoral Degree. As only one individual (3\%) indicated completion of some college credit, but no degree, $97 \%$ of this sample earned a Bachelor's Degree or above. The income ranged widely, with $18 \%$ under $\$ 25,000,24 \%$ between $\$ 25,001$ - 
$\$ 50,000,15 \%$ between $\$ 50,001-\$ 75,000,15 \%$ between $75,001-\$ 100,000,3 \%$ between $\$ 100,001$ $\$ 125,000,21 \%$ above $\$ 125,000$, and 3\% who opted not to respond.

Sample two. The second sample was comprised of Human Resources (HR) professionals, hiring managers, and/or those involved in the hiring process. Similar to the first sample, a small initial convenience sample from the mid-Atlantic was contacted to complete the survey. Those individuals then forwarded the email to additional individuals who met the study's criteria. For the professional sample this resulted in 33 participants who started the survey and 30 participants who actually completed the survey, for a $91 \%$ response rate.

Sample participants were comprised of 20 females and 10 males. The age range of the sample was 25 to 34 (37\%), 35-44 (30\%), 45-54 (11\%), 55-64 (20\%) and 65-74 (3\%). There were no participants below the age of 25 above 74 . The racial and ethnic diversity was mostly comprised of Black, African American, or West Indian (43\%), White or Caucasian (43\%), Other (11\%), and four percent (4\%) who preferred not to respond. Regarding the highest level of education, ten percent (10\%) of participants completed some college credit with no degree, $43 \%$ have a Bachelor's Degree, and 47\% have a Masters or Professional Degree. Half of the sample (50\%) indicated an income above $\$ 125,000$, with $47 \%$ under $\$ 125,000$ and $3 \%$ who preferred not to respond. The titles of participants ranged widely from Recruiter, Director, to Vice President. Some of the representative industries were healthcare, education, recruiting, financial services, information technology, manufacturing, and consulting.

Sample three. The third sample was from Amazon Mechanical Turk (MTurk). Amazon MTurk is an online resource that allows individuals to register and receive compensation for available opportunities, such as completion of surveys (Amazon Mechanical Turk, 2014). Master responders were selected, as these have been designated as an elite group of survey responders 
because of their accuracy in completing prior surveys. Additional criteria requested that participants be eligible to work in the United States and 18 years of age or older. To recruit MTurk survey responders, a brief survey description and survey link was posted on the Amazon MTurk website, offering one dollar (\$1) for compensation. There were 39 participants who started the survey and 33 participants who actually completed the survey, for a $85 \%$ response rate.

Sample participants were comprised of 15 females and 18 males. The age range of the sample was, Under 25 (6\%), 25 to 34 (39\%), 35-44 (24\%), 45-54 (18\%), 55-64 (9\%) and 65-74 (3\%). There were no participants above the age of 74 . The racial and ethnic diversity was mostly comprised of Asian / Pacific Islander (15\%), Hispanic / Latino (9\%), and White or Caucasian $(43 \%)$. The educational levels were quite varied, with at least one respondent in each category. For the categories of some high school, no diploma (3\%), high school graduate or equivalent (9\%), some college credit with no degree (21\%), Trade or Vocational School (3\%), Associate's Degree (12\%), Bachelor's Degree (39\%), Masters or Professional Degree (9\%), and Doctorate Degree (3\%). Unlike the prior samples, all participants indicated their income was $\$ 100,000$ or below. For the categories of under $\$ 25,000(21 \%), \$ 25,001-\$ 50,000(45 \%), \$ 50,001-\$ 75,000$ (24\%), and $\$ 75,001-\$ 100,000(9 \%)$. The titles of participants ranged widely from Data Entry Clerk, Contractor, and Manager. Some of the representative industries were healthcare financial, consumer goods, insurance, retail, and manufacturing.

Sample comparison. Overall, the number of participants per sample type was similar resulting in a total of 96 participants. However, some differences between the samples did exist. Social class literature often relies on education (i.e., Bachelor's degree) to distinguish between upper and lower class individuals. Using this as a distinction, the academic and professional 
samples would be representative of upper class and the MTurk sample would resemble the most diverse sample on the basis of social class status. Despite these social class status differences, the significant differences were generally related to the strength of the perception rather than a difference in perception between upper and lower class status.

\section{Survey development}

Based upon the results for the academic and professional samples, I made structural changes to the survey before administering it to MTurk participants. Therefore, I have separated this section into "pilot survey version one" and "pilot survey version two".

Pilot survey version one. The survey requested that participants categorize different indicators of each form of social class (e.g., economic capital, social capital, cultural capital) as "much more representative of middle class," "somewhat representative of middle class," "equally representative of both middle and working class," "somewhat representative of working class," and "much more representative of working class." At the top of each applicable survey page, participants were presented with the definitions of middle class and working class and asked to refer to these definitions when categorizing the items. Second, participants were asked to categorize different factors into the three forms of capital (economic, social, and cultural). At the top of the survey page, participants were presented with the definitions of economic capital, social capital, and cultural capital, and asked to refer to these definitions when categorizing items. Throughout the survey, a comment box was provided at the bottom of the survey page to capture any feedback or items that may have been confusing and impacted the analysis. Lastly, demographic and background information was collected from all participants.

Pilot survey version two. Based on the results of the prior two surveys I made some changes, which resulted in a survey version two. First, while the use of Amazon MTurk is 
believed to provide more diverse samples and its use in management research has increased in recent years (e.g., Bendersky \& Shah, 2013; Chua, 2013), because it is still new I included a social desirability scale. Second, while many participants seemed confident assessing what items constituted middle class, they appeared less confident regarding assessing the items that constituted working class. To account for this, I changed the terms in the survey to "upper class" and "lower class," which is also consistent with social class literature. Due to this change I also incorporated a new section that requested participants to rank order the social class status categorizations (e.g., elite, upper, lower, under class). Lastly, the prior surveys allowed participants to respond with options labeled "None of the above" or "Equally representative of upper class and lower class." While this may have provided more comfort for participants, to force a determination I eliminated these options. However, to still account for differentiation between the items I incorporated a slider that ranged from upper to lower class as opposed to multiple-choice selections for each item.

Similar to survey version one, survey participants were asked to categorize different indicators of each form of social class (e.g., economic capital, social capital, cultural capital) using a sliding scale with a range of 0 to 10 , with 0 representative of "Lower class" and 10 representative of "Upper class". At the top of each applicable survey page, participants were presented with the definitions of upper class and lower class and asked to refer to these definitions when categorizing the items. Second, participants were asked to categorize different factors into the three forms of capital (economic, social, and cultural). At the top of the survey page, participants were presented with the definitions of economic capital, social capital, and cultural capital, and asked to refer to these definitions when categorizing items. Third, participants were asked to rank order the social class status categorizations. Lastly, demographic 
and background information was collected from all participants. In addition to the previously requested items, version two also asked participants to identify their social class standing using a sliding scale.

\section{Measures}

Social class indicators. Indicators for each form of capital were selected based on the social class literature. Items were representative of both upper (middle) class and lower (working) class. Twenty items were used for economic capital, and sample items included: "One or more parents earned a Bachelor's degree or higher," "Growing up parent(s) could afford to buy him/her what s/he wanted," "Occupation requires adherence to a particular schedule." Fifteen items were used for social capital, and sample items included: " Social network contains people of low power or prestige," "Network is comprised of people who have power or influence in their job role," "Purpose of network is to provide emotional support," "Relies on network for

job assistance." Seventeen items were used for cultural capital, and sample items included:

"Belief that individual success is reflective of your available opportunities," "Owns a large number of books (over 50)," "Hobbies include sailing," "Prefer clothes that are comfortable and durable." Items in each section were displayed in random order.

Forms of social class. Similar to the first portion of the survey, indicators for each of the three forms of capital were selected based on the social class literature. Twelve items were used and required participants to categorize as economic capital, social capital, and cultural capital. Definitions for each form of capital were provided at the top of the survey page. Sample items for categorization included: "Education," "Power or prestige of those around you," and "Understanding of elite customs." All items were displayed to participants in random order. 
Social class categorization ranking. As stated, version two of the survey asked participants to rank order the social class categorizations from highest, (1) representative of the social class status with the highest income, most access to resources, etc. to lowest, (4) as the social class status with the lowest income, least access to resources, etc. Participants were provided with the social class categorizations of "Elite class," "Middle class," "Working class," and "Under class," which were displayed in random order.

Social desirability. Using an abbreviated version of the Maslow-Crowne social desirability scale (Reynolds, 1982), I relied on the 11-item Form A scale. Sample items included: "I sometimes feel resentful when I don't get my way," "No matter who I'm talking to I'm always a good listener," and "There have been occasions when I took advantage of someone."

\section{Analysis}

To assess the upper (middle) and lower (working) class indicator portion of the survey I relied on confirmatory factor analysis (CFA) and scale reliability. Each form of capital was analyzed first using the items that were predicted to load on each form of capital and then based upon the items that actually did load, as noted from the CFA. I conducted an ANOVA to assess whether any items had significant effects related to demographic characteristics. As some of the demographic characteristics did have significant relationships, I then conducted post-hoc analysis using S-N-K and Tukey analysis. I also relied on the same analysis to detect any between sample differences. To assess the forms of social class portion of the survey I relied on frequencies to determine the item that was most related to each form of capital. As I combined the professional and academic samples to gain more power, I conducted ANOVA analysis to determine if any significant differences existed between the two groups. 
For the social class categorization ranking I relied on mean values to determine highest and lowest associations. Lastly, for the social desirability of participants I created an overall scale score for each participant and used a regression analysis to determine if social desirability significantly related to any of the forms of social capital.

\section{Results}

Despite the differences in the three samples, all items except for two resulted in factor loadings of .40 or above, as shown in Tables 17-19. Additionally, with few exceptions, item loadings aligned between samples, noting that there may not have been a preference in terms (e.g., upper and middle; lower and working). Within the MTurk sample there were three items with dual loadings (economic and social capital) on upper (middle) and lower (working) class and one dual loading (cultural capital) for the academic sample. While these dual loadings existed, they were rated as lower (working) class items by the remaining samples. Below provides additional detail about discrepancies in item loading.

For the economic capital items "Earned a Bachelor's degree" loaded as .737 for upper (middle) class for the MTurk sample, but the academic and professional samples rated this item as lower (working) class. "Occupation provides autonomy instead of a set schedule" was found to be an upper (middle) class item by the academic and MTurk sample, but the professional sample associated this with lower (working) class. Lastly, the item "Graduated from Private University" was rated as lower (working) class by the academic sample, but not by the other two samples.

The social capital items also resulted in some discrepancy between samples. For the item "Believe that individuals should be trusted" the professional sample was the only sample to regard this as an upper (middle) class item, which is consistent with the social class literature. 
Another item with discrepant perspectives was "Relies on network to assist with personal matters," which was noted as a lower (working) class item by the academic and MTurk samples, but not the professional sample.

The cultural capital items also resulted in two item discrepancies, with the MTurk sample selecting the social class categorization aligned with social class literature. For "Owns a small amount of artwork or wall decor ( 1 or 2 pieces)" and "Communicates in a storytelling or narrative format" the MTurk sample rated this as consistent with a lower (lower) class individual.

For the forms of capital, the samples did not fully align with prior social class literature. The only items to align with economic capital were "Income" and "Parent's Income". "Power or prestige of those around you" was the only item to align with social capital, and "Beliefs \& behaviors" was the only item to align with cultural capital. Therefore, all other items were representative of two or more forms of capital.

Lastly, participants ranked the class statuses in the following order: elite, middle, working, and under class, which was consistent with the order used in social class literature. The ability of participants to accurately rank order these terms confirmed that middle class is considered to be one of the upper classes and working class is considered to be one of the lower classes.

\section{Discussion}

Now that I have identified relevant factors of each form of capital and the associated social class items, I can use these items to develop the dissertation stimulus materials such as the referral email, applicant resume, and applicant interview script. Additionally, because of this 
pilot study focused on construct development the stimulus materials do not need to undergo further pilot testing prior to inclusion in my dissertation surveys. 
Table 17. Economic Capital Items by Sample Type

\begin{tabular}{|c|c|c|c|c|c|c|}
\hline \multirow[t]{2}{*}{ Item } & \multicolumn{2}{|c|}{$\underline{\text { Academic }}$} & \multicolumn{2}{|c|}{ Professional } & \multicolumn{2}{|c|}{$\underline{\text { MTurk }}$} \\
\hline & WC & $\mathrm{MC}$ & WC & $\mathrm{MC}$ & Lower & Upper \\
\hline Earned a Bachelor's Degree & .780 & & .542 & & & .737 \\
\hline Earned a Master's or Professional Degree & & .678 & & .804 & & .591 \\
\hline Annual income above the national average & & .556 & & .537 & & \\
\hline Annual income below the national average & & & & & .808 & \\
\hline $\begin{array}{l}\text { Annual income similar to the national } \\
\text { average }\end{array}$ & & & & & .406 & \\
\hline $\begin{array}{l}\text { One or more parents earned a Bachelor's } \\
\text { Degree or higher }\end{array}$ & & .545 & & .552 & & .726 \\
\hline $\begin{array}{l}\text { Growing up parent(s) could always afford } \\
\text { to buy him/her what s/he wanted }\end{array}$ & & .652 & & .826 & & \\
\hline $\begin{array}{l}\text { May have to worry about money in the } \\
\text { future }\end{array}$ & & & & & .678 & \\
\hline $\begin{array}{l}\text { One or more parents did not complete } \\
\text { college }\end{array}$ & & & & & .501 & \\
\hline $\begin{array}{l}\text { Occupation provides autonomy instead of a } \\
\text { set schedule }\end{array}$ & & .629 & .422 & & & .445 \\
\hline $\begin{array}{l}\text { Occupation requires adherence to a } \\
\text { particular schedule }\end{array}$ & & & & & .519 & \\
\hline Earned an Associate's Degree & .590 & & .535 & & .520 & \\
\hline Attended a Trade or Vocational School & & & .578 & & & \\
\hline $\begin{array}{l}\text { Graduated from Ivy League University (ex. } \\
\text { Yale University) }\end{array}$ & & .597 & & .712 & & .493 \\
\hline $\begin{array}{l}\text { Graduated from Public University (ex. } \\
\text { University of Connecticut) }\end{array}$ & .711 & & .597 & & .516 & .417 \\
\hline $\begin{array}{l}\text { Graduated from Private Career-Focused } \\
\text { College (ex. DeVry College) }\end{array}$ & .669 & & .555 & & & \\
\hline $\begin{array}{l}\text { Graduated from Private University (ex. } \\
\text { Vassar College) }\end{array}$ & .671 & & & .596 & & .465 \\
\hline Lived in a relatively wealthy neighborhood & & .508 & & .559 & & .453 \\
\hline Does not worry much about paying bills & & & & .600 & & .706 \\
\hline $\begin{array}{l}\text { Has enough money to buy the things s/he } \\
\text { wants }\end{array}$ & & .724 & & .689 & & \\
\hline
\end{tabular}


Table 18. Social Capital Items by Sample Type

\begin{tabular}{|c|c|c|c|c|c|c|}
\hline \multirow[t]{2}{*}{ Item } & \multicolumn{2}{|c|}{$\underline{\text { Academic }}$} & \multicolumn{2}{|c|}{ Professional } & \multicolumn{2}{|c|}{$\underline{\text { MTurk }}$} \\
\hline & WC & $\mathrm{MC}$ & WC & $\mathrm{MC}$ & Lower & Upper \\
\hline $\begin{array}{l}\text { Social network contains people of low } \\
\text { power or prestige }\end{array}$ & & & .437 & & .488 & \\
\hline $\begin{array}{l}\text { Network provides access to resources or } \\
\text { opportunities }\end{array}$ & & .750 & & .711 & & .663 \\
\hline $\begin{array}{l}\text { Network is comprised of people who } \\
\text { provide emotional support }\end{array}$ & .521 & & .853 & & .784 & \\
\hline Believe that individuals should be trusted & .773 & & & .558 & .801 & \\
\hline $\begin{array}{l}\text { Network is comprised of people who have } \\
\text { power or influence in their job role }\end{array}$ & & .746 & & .618 & & .480 \\
\hline $\begin{array}{l}\text { Network is comprised of people who } \\
\text { provide tangible job related support (ex. } \\
\text { providing job assistance, reviewing } \\
\text { resumes) }\end{array}$ & & .614 & & .661 & & .590 \\
\hline $\begin{array}{l}\text { Network is comprised of people who can } \\
\text { provide assistance with personal matters }\end{array}$ & .836 & & .795. & & .505 & .545 \\
\hline $\begin{array}{l}\text { Purpose of a network is to provide social } \\
\text { and emotional support }\end{array}$ & .738 & & .586 & & .420 & .591 \\
\hline $\begin{array}{l}\text { Purpose of a network is to provide access } \\
\text { to opportunities }\end{array}$ & & .723 & & .667 & & .713 \\
\hline $\begin{array}{l}\text { Believe that individuals should not be } \\
\text { trusted }\end{array}$ & & & & & & \\
\hline $\begin{array}{l}\text { Believe that a personal connection is } \\
\text { necessary before someone can ask for } \\
\text { help }\end{array}$ & & .406 & & .436 & & \\
\hline $\begin{array}{l}\text { Relies on network to assist with personal } \\
\text { matters }\end{array}$ & .670 & & & .422 & .599 & \\
\hline Relies on network for job assistance & & .713 & & .770 & & .663 \\
\hline $\begin{array}{l}\text { Has limited options to turn to for job } \\
\text { assistance }\end{array}$ & & & & & & \\
\hline $\begin{array}{l}\text { Believe it is important to remain in } \\
\text { contact with individuals if you want their } \\
\text { help }\end{array}$ & & .694 & & .777 & & \\
\hline
\end{tabular}


Table 19. Cultural Capital Items by Sample Type

\begin{tabular}{|c|c|c|c|c|c|c|}
\hline \multirow[t]{2}{*}{ Item } & \multicolumn{2}{|c|}{$\underline{\text { Academic }}$} & \multicolumn{2}{|c|}{ Professional } & \multicolumn{2}{|c|}{$\underline{\text { MTurk }}$} \\
\hline & WC & MC & WC & $\mathrm{MC}$ & Lower & Upper \\
\hline $\begin{array}{l}\text { Belief that individuals can succeed if they } \\
\text { work hard }\end{array}$ & & .634 & & & & .634 \\
\hline $\begin{array}{l}\text { Belief that individual success is reflective } \\
\text { of your available opportunities }\end{array}$ & & & .623 & & .792 & \\
\hline Owns a large number of books (over 50) & & .758 & & .657 & & \\
\hline $\begin{array}{l}\text { Attends musical or theatrical } \\
\text { performances }\end{array}$ & & .783 & & .720 & & \\
\hline $\begin{array}{l}\text { Owns a small amount of artwork or wall } \\
\text { decor ( } 1 \text { or } 2 \text { pieces })\end{array}$ & & .476 & & .515 & .636 & \\
\hline $\begin{array}{l}\text { Belief that inheritance is important to the } \\
\text { increasing or decreasing economic } \\
\text { disparity of individuals }\end{array}$ & & & & & & .509 \\
\hline $\begin{array}{l}\text { Belief that prejudice and discrimination } \\
\text { are important to the increasing or } \\
\text { decreasing economic disparity of } \\
\text { individuals }\end{array}$ & & & .783 & & & \\
\hline Attended an Ivy League University & & .649 & & .475 & & .597 \\
\hline Scored below average on the SAT exam & & & .693 & & & \\
\hline $\begin{array}{l}\text { Belief that individual success is based on } \\
\text { ability and talent }\end{array}$ & & .531 & & & & .780 \\
\hline Hobbies include sailing & & .620 & & .743 & & .627 \\
\hline Hobbies include playing basketball & .539 & & & & & \\
\hline Hobbies include drawing & .452 & .457 & & & .508 & \\
\hline $\begin{array}{l}\text { Relies on complex language to } \\
\text { communicate }\end{array}$ & & .628 & & .611 & & .491 \\
\hline $\begin{array}{l}\text { Communicates in a storytelling or } \\
\text { narrative format }\end{array}$ & .786 & & & & & .684 \\
\hline Prefer well made, well tailored clothes & & .795 & & .632 & & \\
\hline $\begin{array}{l}\text { Prefer clothes that are comfortable and } \\
\text { durable }\end{array}$ & & & & & .671 & \\
\hline
\end{tabular}




\section{APPENDIX B: RESUME SOCIAL CLASS PILOT STUDY}

To confirm that HR professionals and hiring managers could actually detect social class from applicant materials such as a resume, I conducted a pilot study prior to developing my dissertation study. This pilot study was conducted prior to the construct clarity study. The results of this study proved to be useful as I finalized my dissertation design.

\section{Sample \& Procedure}

I conducted my pilot study using the attendee list from the Society of Human Resource Management (SHRM) 2014 Tri-State Conference, which was targeted to HR professionals in the northeast (i.e. Connecticut, Massachusetts, and Rhode Island). Participants were invited to participate in this study via email, and the surveys were administered online using Qualtrics. A total of 310 participants were emailed and participants were able to forward the surveys to others for completion. To qualify for survey participation, participants had to respond affirmatively that they have or previously have screened applicant resumes for available positions. The final survey resulted in 29 usable surveys for a total response rate of $9 \%{ }^{3}$

While the sample was focused on HR professionals, the titles of the participants ranged from HR Assistant to Chief Human Resources Officer. Some of the representative industries were healthcare, insurance, utilities, software development, non-profit, marketing, manufacturing, engineering consulting, and education. There were seven males (24\%) and 22 females (76\%). The racial and ethnic diversity was 4\% Asian or Pacific Islander, $4 \%$ Black or African American or West Indian, 4\% Hispanic or Latino, 79\% White or Caucasian, and 11\% who preferred not to respond. Twenty-nine percent (29\%) of the sample was between ages $45-54$ and 55-64 respectively, and 25\% between ages $34-44$. A wide distribution of educational

\footnotetext{
${ }^{3}$ Fifty-four (54) individuals began the survey, with one respondent failing to qualify, resulting in 53 possible responses. Although 33 participants responded to the first question, 29 participants completed all required sections of the survey relating to social class.
} 
experience was indicated, with $47 \%$ having a Masters, Professional, or Doctoral degree, $39 \%$ with a Bachelor's degree, and 15\% having less than a Bachelor's degree (i.e. Associates, some college, but no degree, and some high school, but no diploma).

\section{Survey Development}

The survey requested that participants review two pseudo resumes to assess the social class of the job applicants. Afterwards, participants were asked to review each resume section separately (i.e., Background, Education, Experience, Organizations \& Awards) and describe how important each section was to their assessment of social class. Third, participants were asked to categorize the resumes by social class categories. Lastly, demographic information was collected from all participants.

Resume development. Two resumes were developed, one representative of an upper (middle) class job applicant and the other of a lower (working) class job applicant, depicted in Examples 4 and 5. Due to the multidimensional nature of social class and its ability to influence various factors, it is difficult to parse out social class from other constructs. Therefore, resume development relied on highlighting differences that have been found between upper and lower class individuals. Although comparable, because social class is related to economic, social, cultural capital, differences in the content existed within each section of the resume. To minimize extraneous effects, each resume was formatted in the same manner and contained the same four content areas: background, education, experience, and organizations and awards.

For the background section, the residential address of each applicant was altered to highlight economic capital differences. In the education section, the Bachelor's degree and GPA were consistent, however, the name of the institution and related information within the education section differed. These changes were representative of economic and cultural capital 
dimensions of social class. For experience, all position titles were the same, but the names of the companies were altered. As individuals often find jobs due to their social capital networks, these alterations were representative of the social capital dimension. Additionally, while the responsibilities were comparable they were written differently to account for language and verbal differences, which is associated with the cultural capital dimension of social class. Lastly, the organizations and awards section both featured leadership experiences and awards. However, the types of organizations and awards differed to account for differences in values, which aligns with cultural capital.

\section{Measures}

Social class. To assess the social class of the pseudo job applicants, I adapted the subjective social class measure developed by Adler, Epel, Castellazzo, and Ickovics (2000). This measure requires the use of a ladder with ten positions, which allows the participants to select where individuals fall relative to others. For purposes of this study, I relied on the following description:

"below is a ruler with 10 positions. Think of the ruler as representing where people stand in our society. The right side of the ruler (represented by a 10) are the people who are the best off, those who have the most money, most education, and best jobs, and at the left side of the ruler (represented by a 0 ) are the people who are the worst off, those who have the least money, least education, and worst jobs or no job. After reviewing Resume $A$ and Resume $B$ above, please move the slider in the place that best represents where you think these candidates would fall on the ruler."

Participants were presented with this statement after reviewing both resumes in full and then provided with an opportunity to explain what about the resume influenced their decision of social standing.

Resume Section Importance. To assess how important each resume section was to the determination of social class, each resume section was shown separately. Participants were then 
asked to rate how important a particular section of the resume was to their ultimate decision of social class. Participants were also given an opportunity to explain what portion of each section most influenced their ratings and why.

Resume social class categorization. To assess the validity of the construct, participants were asked to categorize each resume. Participants were presented with the categories of: lower middle class, middle class, upper middle class, and working class. These were presented in alphabetical order.

\section{Results}

Overall, the results of this pilot study were very promising. On the question of social standing, participants rated the middle class resume higher $(\mathrm{M}=6.91 ; \mathrm{SD}=1.40)$ than the working class resume $(\mathrm{M}=5.61 ; \mathrm{SD}=1.46)$. Therefore, participants confirmed that the middle class applicant resume corresponded to higher perceptions of social standing as compared to the working class applicant resume. When considering the importance of each resume section on the perception of social standing, experience, education, organizations and awards, followed by background information were rated as most to least important. However, no one section had an overwhelming effect on the perception of social class, meaning that showing participants the complete resume had a more pronounced effect than revealing each part individually.

Regarding the categorization of the resumes, a general consensus was found between participants. The majority of participants selected the term "middle class" for the working class applicant's resume and "upper middle class" for the middle class applicant's resume, which was the expected result. Although the term "working class" was provided, it was minimally selected. The term "working class" is widely used within the social class literature (e.g., Markus \& Fiske, 2012; Zweig, 2004, 2011), however, it is rarely used in general communication or through the 
media. Additionally, for some, the term "working class" may be representative of a stigma (Skeggs, 2004). As such, a high selection of the term "working class" was not expected from survey participants.

Beyond the survey responses, many of the participants shared their connections between resume content and social class in their comments. Although some participants noted how similar the resumes were, others discussed how the middle class applicant showed a "higher skill set" or "better understanding and application of concepts." One participant stated that "...one had a family/cultural advantage-it appears", highlighting the relevance of the cultural capital dimension in each resume. Some participants referenced how the residential neighborhood could be an indication of money, highlighting the relevance of the economic capital dimension. One participant commented, "to attend [university] you must have funds to pay for college or get a scholarship which is easier for someone more wealthy..." This view not only highlights the economic capital dimension of social class, but also is consistent with a working class perspective. One participant commented that one candidate seemed more "socially/community focused" while the other was more "work/monetary driven", which also supports the distinctions between middle and working class individuals in the literature. It is clear that resume content may easily lend itself to assumptions about a job applicant.

Upon further review of the comments, it appeared that some participants were focused on their hiring decisions - although this question was not posed. Some participants referenced the importance of the address when considering applicant commutes. One candidate even prefaced his/her comment as, "when hiring for a position..." even though that was not the question. Although these comments may be attributable to HR professionals' natural inclination to review 
resumes for purposes of hiring, they may also be indicative that these implicit social class assumptions may be easily translated into hiring decisions.

To conclude, social class can be detected in applicant resumes and biases related to social class standing may be unconsciously considered in hiring decisions. 


\title{
Example 4. Working class sample resume
}

\author{
1200 Baychester Ave, Apt. 4H \\ Bronx, NY 10499 \\ Phone: (718) 555-5555 \\ Cell: (646) 888-8888 \\ DaveJJ2014@hotmail.com
}

\section{EDUCATION}

Lehman College

Bronx, NY

Bachelor of Science in Marketing

May 2014

Cumulative GPA: 3.8/4.0

- Relevant courses - Marketing Research, Marketing in Non-Profits

- Urban Leaders Summer Program (Summer 2012)

\section{EXPERIENCE}

\section{Urban Housing Association $\quad$ New York, NY \\ Marketing Intern Summer 2013}

- Developed marketing strategies to increase the number of clients of served by the nonprofit agency

- Conducted market research to identify possible collaborating partners in non-profit and for-profit industries

- Developed and presented social media marketing strategies to increase annual fundraising dollars generated

- Assisted in creation of marketing materials for new local urban housing initiatives

\section{Neighborhoods Unite Bronx, NY}

Marketing Specialist

Sept 2012- May 2013

- Created new promotional material to increase student sign-up for after school programming

- Developed and managed a "street team" to distribute promotional material to neighborhood schools

- Assisted in promotion of adult language learning classes

- Presented available programming to community outreach associations and governmental entities

\section{Buy in Bulk Warehousing}

Bronx, NY

Warehouse Specialist

Sept 2011- May 2012

- Developed promotional flyers to distribute to local community

- Managed inventory and placed orders with vendors by the palette

- Assisted with customer service in retail section of store

\section{ORGANIZATIONS \& AWARDS}

President, Omega Lambda Chapter of Alpha Phi Alpha Fraternity, Inc., May 2013-Present Community Service Chair, National Urban League Young Professionals, Jan 2013-Present Scholarship Award, Our Two Hearts Church, May 2012 


\title{
Example 5. Middle class sample resume
}

\author{
1200 West $86^{\text {th }}$ Street, Apt. $32 \mathrm{H}$ \\ New York, NY 10054 \\ Home: (212) 555-5555 \\ Cell: (917) 888-8888 \\ David.Johnson@gmail.com
}

\section{EDUCATION}

Penn State University, University Park

Bachelor of Science in Marketing

State College

Cumulative GPA: 3.8/4.0

May 2014

- Dean's List: Fall \& Spring 2012 and 2013

- Marketing Students Association Study Abroad Program - Paris, France (Summer 2012)

\section{EXPERIENCE}

\section{Consumer Packing, Inc. $\quad$ New York, NY \\ Summer 2013}

Marketing Intern

- Developed global marketing strategies to improve brand recognition, resulted in $10 \%$ increase in sales

- Conducted market research, identified product segments for expansion, and developed nine-month business plan to target new mothers

- Developed and presented social media marketing strategies based on market research data targeted to penetrate consumer purchasing for individuals aged 18-34

- Assisted in creation of new marketing distribution protocols for three product lines

\section{Amazing Bank}

Marketing Account Specialist
State College, PA

September 2012- May 2013

- Collaborated with marketing consultants to develop new promotional material to increase college student banking, resulted in a $23 \%$ increase in student account openings

- Assisted in promotion of small business customer servicing, payroll and wire transfer processing, and account management

- Led monthly marketing and promotional meetings and presented ROI reports

- Conducted monthly customer banking reviews and research to develop new marketing recommendations

Retailers, Inc.

State College, PA

Warehouse Specialist $\quad$ September 2011- May 2012

- Developed promotional materials to increase customer purchases, resulting in over $\$ 10,000$ in sales in a three month period

- Processed domestic and international customer orders through Salesforce.com database

- Created daily manifest for shipping pickups using ShipperX program.

\section{ORGANIZATIONS \& AWARDS}

President, Marketing Students Association, September 2013-Present

Publicity Chair, American Marketing Association, 2011-Present

Recipient of the Penn State Leadership Circle Award, May 2013 


\section{APPENDIX C. DEVELOPMENT OF STIMULUS MATERIALS}

This dissertation required the development of stimulus materials representative of what hiring managers would expect to evaluate during each stage of the hiring process. Thus, a referral email, resume, and video interview were developed. Below I have outlined how each stimulus material was developed.

\section{Development of referral emails and resumes}

Referral emails and resumes were developed similarly and were based on actual samples found during a Google search. Information such as company names were developed using a company name generator (e.g., Spodify), which is available online and creates randomized names. Thirty-two company names were created and randomly rotated on applicant resumes. Additional considerations related to the selection of applicant names and the position.

Previous research has shown that applicants with more stereotypical Black sounding names (e.g., Aisha, Keisha) generally receive a lower call back rate when compared to stereotypical White sounding names (e.g., Emily, Anne) (Bertrand \& Mullainathan, 2003). While these differences may highlight long-standing stereotypes about race that impact the selection process (King et al., 2006), stereotypical Black sounding names may elicit even more pervasive negative reactions and stereotypes (Huffington Post, 2013). As such, the use of stereotypical Black sounding names may exacerbate racial differences and stereotypes. Considering this, I relied on governmental data reported by the U.S. Census Bureau and state governmental agencies to select applicant names and highlight racial differences.

According to the U.S. Census (Word, Coleman, Nunziata, \& Kominski, 2000), last names have different levels of occurrence depending on race. For instance, while the last name Barajas is ranked $989^{\text {th }}$ in popularity, it is the most popular last name for Latinos and is ranked first. 
Therefore, to ensure individuals associate a name with a particular race, it was important to select names that occur most often for a particular race. For Blacks the top 10 most common last names were: Washington, Jefferson, Booker, Banks, Jackson, Mosley, Dorsey, Gaines, Rivers, and Joseph. For Whites the top 10 most common last names were: Yoder, Krueger, Mueller, Koch, Schwartz, Schmitt, Novak, Schneider, Schroeder, and Haas. As parents typically select first names, I relied on listings of the most popular boys' baby names from two states in the MidAtlantic that report the most popular baby names by race (e.g., New York for 2009 and 2010, New York City Department of Health and Mental Hygiene, 2011; 2010; Maryland for 2011, Maryland.gov, 2013). Tables 20-22 list the most popular names for New York and Maryland for the respective years. Sixty-four names were created using a randomized combination of first and last names. Thirty-two of the names were used for applicant names and 32 were designated as referral names. Each demographic grouping (e.g., White female) had 16 designated.

In addition to race, sex also influences the selection process, most notably as related to the position. Some positions have been perceived as more suitable for one gender as opposed to the other (Moss-Racusin et al., 2012). Thus, it was imperative to select a gender-neutral position. However, assumptions of why one position may be perceived as gender-neutral may be complex. For instance, positions of varying cognitive demand (e.g., marketing internship, mail-sorting internships) have been perceived as equally suitable for men and women (Hosoda, Stone, \& Stone-Romero, 2003), but leadership positions are usually perceived as more acceptable for men (Eagly \& Karau, 2002). Therefore, I relied on actual employment statistics provided by the U.S. Bureau of Labor Statistics (2014a) that indicated how many women held particular occupational titles. Additional considerations were to select a realistic position based on applicant age, education, and prior work experience within the study. Using these factors, I selected the 
position of Budget Analyst, where women constituted 49.3\% of all Budget Analyst positions at yearend 2013. This was the most gender-neutral position out of all business related entry-level positions. Applicant materials were developed in accordance with the position of Budget Analyst using samples found online (e.g., accountingresumes.net).

\section{Development of video interviews}

Development of the video interviews required the selection of actors and development of an interview script.

Actor recruitment. Recruitment of actors was done using a casting call email (see Example 6) sent to undergraduate theater students at a mid-Atlantic university in the United States and postings on Craigslist. The casting call requested individuals with a theater background, aged 18-25, who were Black or White, male or female, to respond to the call by submitting a headshot, where they were suggested to dress in business attire. A total of 18 photos were received with five photos from Black males, four photos from Black females, four photos from White males, and five photos from White females.

Actor selection. Previous research has shown various factors such as attractiveness (e.g., Dipboye, Arvey, \& Terpstra, 1977; Watkins \& Johnston, 2000) or weight (e.g., Pingitore, Dugoni, Tindale, \& Spring, 1994; Polinko \& Popovich, 2001) can influence the perception of employability. Additionally, the mixed race and sex of the applicants as well as the varying appearance of the headshots, as the headshots were likely taken for different purposes, added

further complication to the selection process. Considering these factors, it was imperative to pilot the submitted photos for rater consistency. Therefore, after receipt of headshots, I relied on three small samples (e.g., current and former professionals, undergraduate business students, and graduate students) to engage in a q-sort to assess comparability between applicants. 
The q-sort method requires that "characteristics are sorted into a fixed distribution" (Serfass \& Sherman, 2013, p. 853). Thus, it is more difficult to assess than a likert scale. Following Block $(1961,1978)$, each sample was presented with pictures of all student actors and asked to sort them into four piles of comparability. Samples were told that each pile had to contain one student actor of each demographic category (i.e., Black male, Black female, White male, and White female). Despite the differences in age, race, and professional status of the samples, the sorting was quite similar. The same four student actors, or a combination of two females and two males, were often grouped together as comparable. Therefore, these four student actors were contacted about participating as applicants to depict varying levels of social class during an employment interview.

Actor instructions. As applicant dress has been shown to influence interviewer perceptions (Forsythe, Drake, \& Cox, 1985), it was important to standardize applicant appearance for consistency. Therefore, each actor was instructed to wear a suit. Men were also instructed to wear a solid colored tie. Additionally, applicants were asked to have conservative hairstyles and to wear minimal makeup and jewelry. The hiring manager was an actual professional who was also asked to dress professionally.

The hiring manager asked each applicant a series of questions, and actors were asked to assume the role of an upper or lower class applicant and were provided with some key words to insert into their response. For the remainder of their response they were asked to ad-lib, to ensure that each interview was not exactly the same. For instance, the hiring manager was directed to begin the interview by asking, "So how did you arrive here today? Did you have any trouble finding us?" Actors responding as an upper class applicant were instructed to include keywords such as "I just bought a new car so I typed your address into my GPS" whereas when responding 
as a lower class applicant they were instructed to include keywords such as "It was a few transfers on the bus and train."

Video setting and recording. Interview recordings occurred on a university campus conference room (see Example 7) to simulate a realistic interview setting. The videos were filmed and edited by a professional video production company. Edited videos were no longer than five minutes, and each video was uploaded and embedded into the survey to be viewable by survey participants. 
Table 20. Most Popular Boys and Girls' Names in New York in 2009

\begin{tabular}{|c|c|c|}
\hline & Black & White \\
\hline Boy & Jayden & Michael \\
\hline Boy & Joshua & David \\
\hline Boy & Elijah & Daniel \\
\hline Boy & Justin & Joseph \\
\hline Boy & Michael & Jacob \\
\hline Boy & Jeremiah & Moshe \\
\hline Boy & Ethan & Jack \\
\hline Boy & Christian & Benjamin \\
\hline Boy & Daniel & Samuel \\
\hline Boy & Josiah & James / Matthew \\
\hline Girl & Madison & Olivia \\
\hline Girl & Kayla & Sarah \\
\hline Girl & Nevaeh & Rachel \\
\hline Girl & Jada & Leah \\
\hline Girl & Malia & Esther \\
\hline Girl & Makayla & Emma / Sophia \\
\hline Girl & Aaliyah & Chana / Chaya / Isabella \\
\hline Girl & London & Ava \\
\hline Girl & Arianna / Brianna & Julia \\
\hline Girl & Destiny & Emily \\
\hline
\end{tabular}


Table 21. Most Popular Boys and Girls' Names in New York in 2010

\begin{tabular}{|l|c|c|}
\hline & Black & White \\
\hline Boy & Jayden & Joseph \\
\hline Boy & Joshua & David \\
\hline Boy & Elijah & Jacob \\
\hline Boy & Jeremiah & Michael \\
\hline Boy & Ethan & Daniel \\
\hline Boy & Aiden & Moshe \\
\hline Boy & Justin & Benjamin \\
\hline Boy & Michael & Matthew \\
\hline Boy & Christian & Alexander \\
\hline Boy & Tyler & Jack / Samuel \\
\hline Girl & Madison & Esther \\
\hline Girl & Kayla & Olivia \\
\hline Girl & Nevaeh & Leah \\
\hline Girl & London & Sophia \\
\hline Girl & Makayla & Emma \\
\hline Girl & Jada & Rachel \\
\hline Girl & Taylor & Isabella \\
\hline Girl & Chloe & Sarah \\
\hline Girl & Brianna & Chana \\
\hline Girl & Gabrielle & Ava / Chaya \\
\hline
\end{tabular}


Table 22. Most Popular Boys and Girls' Names in Maryland in 2011

\begin{tabular}{|l|c|c|}
\hline & Black & White \\
\hline Boy & Jaiden & Lucas \\
\hline Boy & Aiden & Mason \\
\hline Boy & Christopher & Jackson \\
\hline Boy & Cameron & Jacob \\
\hline Boy & Elijah & John \\
\hline Boy & Jeremy & Aiden \\
\hline Boy & Michael & Alexander \\
\hline Boy & Isaiah & Liam \\
\hline Boy & Mason & William \\
\hline Boy & Caleb & Ryan \\
\hline Girl & Chloe & Sophia \\
\hline Girl & London & Isabel \\
\hline Girl & Layla & Abigail \\
\hline Girl & Madison & Olivia \\
\hline Girl & Kennedy & Ava \\
\hline Girl & Aaliyah & Riley \\
\hline Girl & McKenzie & Madison \\
\hline Girl & Zoe(y) & Emily \\
\hline Girl & Payton & McKenzie \\
\hline Girl & Taylor & Chloe \\
\hline
\end{tabular}




\section{Example 6. Actor Recruitment Email}

October 12, 2014

Dear Theatre Majors,

I am a PhD student in Organizational Behavior at the University of Connecticut, and I am researching the employability of job applicants based on appearance.

I am looking for theater majors, or individuals with experience in acting, to submit headshots for inclusion in a survey to be viewed by hiring professionals. As this is a study about employability, headshots or photos that appear more professional (e.g., business attire) are preferred.

Individuals who are selected as most employable may be contacted to participate in a short industrial-style film for compensation.

\section{SEEKING:}

2 African American women (18-25)

2 African American men (18 - 25)

2 White women $(18-25)$

2 White men $(18-25)$

All pictures should be emailed to Nicole.Jones@business.uconn.edu in a .jpg or .jpeg format. Should you have any questions please feel free to contact me at the above email address.

Sincerely,

Nicole C. Jones Young

Doctoral Candidate, Management 


\section{Example 7. Video setting}

Below is the picture of the interview setting where the recordings occurred.

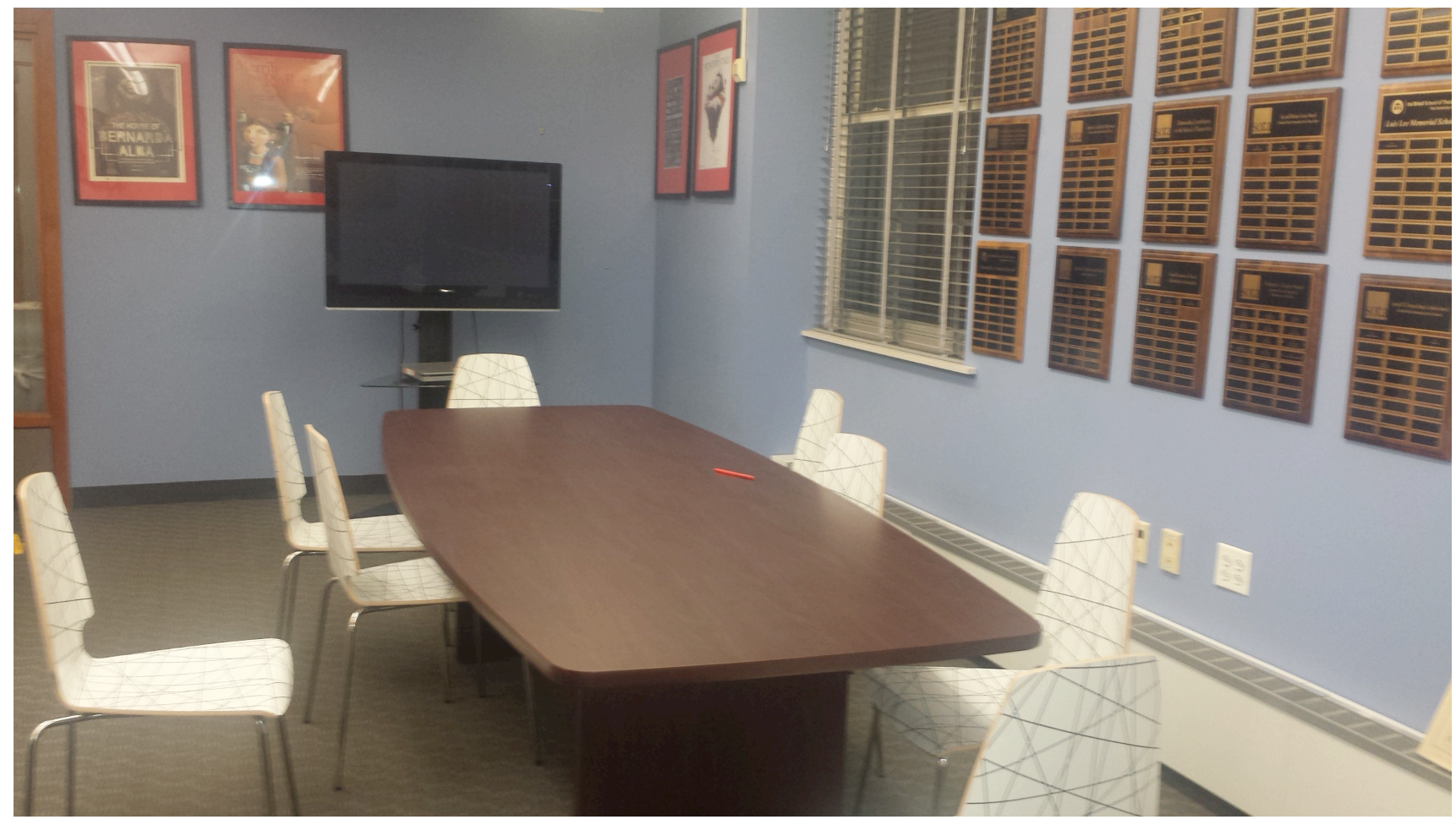

